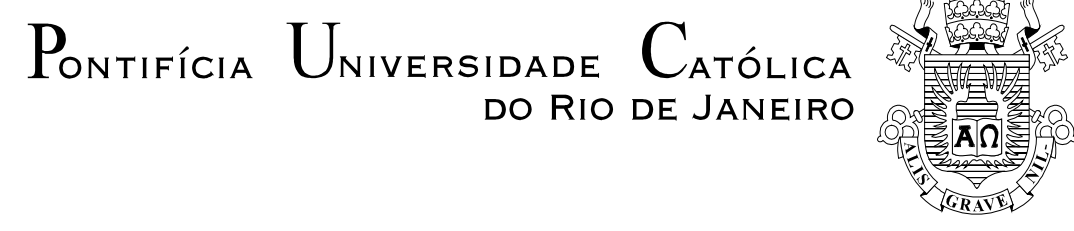

Dinart Duarte Braga

\title{
Estratégias de Controle Inteligente para Mitigação de Golfadas Severas em Sistemas de Produção de Petróleo
}

Dissertação de Mestrado

Dissertação apresentada como requisito parcial para obtenção do grau de Mestre pelo Programa de Pós-Graduação em Engenharia Elétrica da PUC-Rio.

Orientador:

Prof. Ricardo Tanscheit

Co-orientadora: Profa. Marley Maria Bernardes Rebuzzi Vellasco 


\title{
Pontifícia Universidade Católica $_{\text {anta }}$ DO RIO DE JANEIRO

Dinart Duarte Braga

\section{Estratégias de Controle Inteligente para Mitigação de Golfadas Severas em Sistemas de Produção de Petróleo}

Dissertação apresentada como requisito parcial para obtenção do grau de Mestre pelo Programa de Pós-Graduação em Engenharia Elétrica da PUC-Rio. Aprovada pela Comissão Examinadora abaixo assinada.

\author{
Prof. Ricardo Tanscheit \\ Orientador \\ Departamento de Engenharia Elétrica - PUC-Rio \\ Profa. Marley Maria Bernardes Rebuzzi Vellasco \\ Co-orientadora \\ Departamento de Engenharia Elétrica - PUC-Rio \\ Prof. Eduardo Costa da Silva \\ Departamento de Engenharia Elétrica - PUC-Rio
}

Prof. José Franco Machado do Amaral

UERJ

Prof. Márcio da Silveira Carvalho

Coordenador Setorial do Centro

Técnico Científico - PUC-Rio

Rio de Janeiro, 29 de agosto de 2017 
Todos os direitos reservados. É proibida a reprodução total ou parcial do trabalho sem autorização do autor, do orientador e da universidade.

\section{Dinart Duarte Braga}

Graduou-se em Engenharia Elétrica pela Universidade Federal de Campina Grande (UFCG) em 2011 e desde então exerce o cargo de Engenheiro de Equipamentos na Petrobras, atuando nas áreas de automação e controle das plataformas de produção do campo de Marlim, na Bacia de Campos.

Ficha Catalográfica

\section{Braga, Dinart Duarte}

Estratégias de controle inteligente para mitigação de golfadas severas em sistemas de produção de petróleo / Dinart Duarte Braga; orientador: Ricardo Tanscheit, coorientadora: Marley Maria Bernardes Rebuzzi Vellasco.2017.

148f. : il. color. ; $30 \mathrm{~cm}$

Dissertação (mestrado) - Pontifícia Universidade Católica do Rio de Janeiro, Departamento de Engenharia Elétrica, 2017.

Inclui bibliografia.

1. Engenharia elétrica - Teses. 2. Controle inteligente. 3. Mitigação de golfadas severas. 4. Controle fuzzy. 5. Algoritmo genético. 6. Produção de petróleo. I. Tanscheit, Ricardo. II. Vellasco, Marley Maria Bernardes Rebuzzi. III. Pontifícia Universidade Católica do Rio de Janeiro. Departamento de Engenharia Elétrica. IV. Título. 


\section{Agradecimentos}

À minha amada esposa Gabriella, pelo seu incentivo contínuo durante a escrita deste texto e também pela sua compreensão dos momentos que precisaram ser renunciados, para que este trabalho fosse desenvolvido.

À minha mãe Elita, por me encorajar a continuar buscando meu desenvolvimento acadêmico, mesmo após o início da minha atuação profissional.

Aos meus orientadores Ricardo e Marley, pelo ótimo direcionamento no desenvolvimento deste trabalho, sempre com muito conhecimento, vontade, tranquilidade, bom humor e empatia.

Aos meus colegas de trabalho Gabriel, Sergei, Austeclides e Nilmar, por assumirem minhas responsabilidades profissionais como se fossem suas, sempre que eu precisava me ausentar em virtude do mestrado.

Aos colegas da gerência de Elevação e Escoamento, Diogo e Fulton, pelas detalhadas explicações relativas à escoamentos multifásicos em sistemas de produção de petróleo e à formação de golfadas nestes sistemas.

À Petrobras, PUC e CAPES, por confiarem na minha capacidade, me apoiando ao longo do mestrado. 


\section{Resumo}

Braga, Dinart Duarte; Tanscheit, Ricardo; Vellasco, Marley Maria Bernardes Rebuzzi. Estratégias de Controle Inteligente para Mitigação de Golfadas Severas em Sistemas de Produção de Petróleo. Rio de Janeiro, 2017. 148p. Dissertação de Mestrado - Departamento de Engenharia Elétrica, Pontifícia Universidade Católica do Rio de Janeiro.

Um dos maiores desafios da produção de petróleo offshore é garantir um escoamento regular do reservatório até a unidade de processamento da produção. Entre os fenômenos que podem dificultar esta tarefa está o estabelecimento de um escoamento em golfadas no riser de produção, caracterizado por oscilações periódicas e de grande amplitude nas vazões do sistema, que diminuem a eficiência da planta de separação, sujeitam equipamentos a esforços cíclicos e causam graves descontroles de processo. Por esta razão, foram desenvolvidas nas últimas décadas diversas soluções que visam a evitar a formação das golfadas, ou ao menos, atenuar suas consequências. Entre as soluções mais promissoras estão os controladores que evitam a formação das golfadas através da manipulação ativa da válvula choke e os controladores que amortecem as golfadas nos vasos separadores da planta de processo. Neste trabalho, estas estratégias de controle são revisitadas sob a óptica do controle inteligente, possibilitando a obtenção de resultados fora do alcance dos controladores lineares. Além de um modelo computacional que descreve um sistema de produção do poço ao vaso separador, também foram desenvolvidos neste trabalho dois controladores inteligentes. O primeiro deles é um controlador antigolfada de arquitetura híbrida Fuzzy-PID, que é capaz de suprimir as golfadas mesmo em sistemas desprovidos de medições submarinas e com válvula choke lenta. O segundo é um controlador amortecedor de golfadas fuzzy, otimizado por um algoritmo genético, com alta capacidade de atenuação das golfadas e capaz de manter o nível dentro de uma faixa considerada segura. Ambos os controladores são testados em diversos cenários e têm seus resultados comparados aos obtidos por controladores lineares.

\section{Palavras-chave}

Controle Inteligente; Mitigação de Golfadas Severas; Controle Fuzzy; Algoritmo Genético; Produção de Petróleo. 


\section{Abstract}

Braga, Dinart Duarte; Tanscheit, Ricardo (Advisor); Vellasco, Marley Maria Bernardes Rebuzzi (Co-advisor). Intelligent Control Strategies for Severe Slug Mitigation in Oil Production Plants. Rio de Janeiro, 2017. 148p. Dissertação de Mestrado - Departamento de Engenharia Elétrica, Pontifícia Universidade Católica do Rio de Janeiro.

One of the major challenges of offshore oil production is to ensure a regular flow from the reservoir to the production processing unit. Among the phenomena that may hamper this task is the establishment of slug flow in the production riser, characterized by periodic oscillations of large amplitude in the system flow rates, which reduce the efficiency of the separation plant, subject equipment to cyclical fatigue and cause serious process instabilities. For this reason, several solutions that aim at avoiding the formation of slugs or, at least, mitigating their consequences have been developed in the last decades. Among the most promising solutions are controllers that prevent the formation of slugs by actively manipulating the choke valve and controllers that dampen the slugs in the vessels of the separation plant. In this work, these control strategies are revisited from perspective of intelligent control, allowing the obtainment of results beyond the reach of linear controllers. In addition to a computational model that comprises a production system from the well to the separation vessel, two intelligent controllers were developed in this work. One of them is a hybrid Fuzzy-PID anti-slug controller that is capable of suppressing slugs even in systems without submarine measurements available and with slow choke valve. The other one is a fuzzy slug damping controller, optimized by a genetic algorithm, with high slug attenuation capacity and able to maintain the level within a specified range. Both controllers are tested in several scenarios and have their results compared to those obtained by linear controllers.

\section{Keywords}

Intelligent Control; Severe Slug Mitigation; Fuzzy Control; Genetic Algorithm; Oil Production. 


\section{Sumário}

1 . Introdução 15

1.1. Motivações 15

1.2. Objetivos 18

$\begin{array}{ll}\text { 1.3. Contribuições } & 18\end{array}$

1.4. Organização da Dissertação 19

2. Fundamentos 21

2.1. Descrição de um Sistema de Produção de Petróleo Offshore 21

2.2. Escoamento Multifásico em Sistemas de Produção 23

2.3. Golfadas Severas em Risers 26

2.3.1. Processo de Formação das Golfadas Severas 27

2.3.2. Efeitos Nocivos das Golfadas 28

2.3.3. Técnicas de Minimização de Golfadas 29

2.4. Modelagem de um Sistema de Produção Offshore 43

2.4.1. Modelo Simplificado de Riser (SRM) 44

3. Desenvolvimento do Modelo de Processo 56

3.1. Desenvolvimento do Modelo do Poço Produtor 57

3.2. Desenvolvimento do Modelo do Vaso Separador 61

3.2.1. Modelagem do Nível do Separador 61

3.2.2. Modelagem da Pressão do Separador 65

3.2.3. Acoplamento do Modelo do Separador 67

3.3. Melhorias na Estabilidade Numérica do Modelo 67

3.4. Ensaios do Modelo 69

3.4.1. Ensaio 1: Controle Estrito do Separador 70

3.4.2. Ensaio 2: Controle Permissivo do Separador 75

3.4.3. Ensaio 3: Malha Fechada 78

3.4.4. Considerações Gerais 80 
4. Desenvolvimento dos Controladores 81

4.1. Controlador Supressor de Golfadas 81

4.1.1. Estimador de Severidade das Golfadas 83

4.1.2. Sistema de Inferência Fuzzy 85

4.1.3. Algoritmo PID 92

4.2. Controlador Amortecedor de Golfadas 93

4.2.1. Estrutura do Controlador 94

4.2.2. Sistema de Inferência Fuzzy 95

4.2.3. Sintonia por Algoritmo Genético 100

4.2.4. Resultado da Otimização 107

4.2.5. Otimização de Controlador PI de Referência 110

5. Análise dos Resultados 111

5.1. Controlador Supressor de Golfadas 111

5.1.1. Supressão de Golfada 112

5.1.2. Limite da Velocidade de Atuação da Choke 116

5.1.3. Estabilização de um Ponto de Operação Instável 119

5.1.4. Ganhos de Produção 120

5.1.5. Rejeição à Perturbações 122

5.1.6. Operação com Setpoint Instável 127

5.2. Controlador Amortecedor de Golfadas 131

5.2.1. Amortecimento de Golfadas 131

5.2.2. Múltiplos Estágios de Amortecimento 134

5.2.3. Entradas Compostas 135

6. Conclusões e Trabalhos Futuros 139

6.1. Conclusões 139

6.2. Trabalhos Futuros 142

7. Referências bibliográficas 145 


\section{Lista de Figuras}

Figura 1 - Ilustração da parcela submarina de um sistema de produção offshore [12].

Figura 2 - Diagrama de um sistema de produção offshore simplificado.

Figura 3 - Regimes de escoamento em tubulações horizontais. [15]

Figura 4 - Ilustração de golfadas de terreno em uma flowline apoiada em um terreno acidentado.

Figura 5 - llustração da formação de uma golfada em um riser.

Figura 6 - Representação do processo cíclico de formação de golfadas em risers.

Figura 7 - Representação do dispositivo atenuador de golfadas, apresentado na patente de Makogan e Brook [20].

Figura 8 - Representação de um sistema flowline-riser com injeção de gás na base do riser.

Figura 9 - Representação de um sistema flowline-riser com reinjeção de gás.

Figura 10 - Representação da banda de controle em um vaso separador.

Figura 11 - Representação simplificada do controlador proposto por Nunes.

Figura 12 - Representação simplificada do controlador proposto por Campos.

Figura 13 - Diagrama de bifurcação de Hopf para um sistema flowline-riser (Adapatado de [4]).

Figura 14 - Representação da localização espacial dos principais parâmetros e variáveis do SRM.

Figura 15 - Diagrama de bifurcação de $P 1$, obtidos por meio de três modelos: OLGA (referência), Simplified Riser Model (SRM) e Two-Fluid. (Adapatado de [4]).

Figura 16 - Diagrama simplificado de um sistema de produção offshore. 
Figura 17 - Ajuste do modelo proposto aos dados obtidos através do simulador MARLIM.

Figura 18 - Representação de um vaso cilindrico horizontal parcialmente preenchido.

Figura 19 - Estimátivas das áreas das seções horizontais em vasos cilíndricos horizontais obtidas por meio de diferentes modelos.

Figura 20 - Diagramas de bifurcação das pressões da flowline e do riser (Ensaio 1).

Figura 21 - Pressões da flowline e do riser para abertura de $30 \%$ e $80 \%$ (Ensaio 1).

Figura 22 - Resposta das pressões da flowline e do riser a um degrau de produção (Ensaio 1).

Figura 23 - Diagrama de bifurcação e média da produção de líquido. (Ensaio 1).

Figura 24 - Vazões de líquido e gás para aberturas da choke de $20 \%$ e $100 \%$.(Ensaio 1).

Figura 25 - Diagramas de bifurcação das variáveis de estado do vaso separador (Ensaio 2).

Figura 26 - Diagramas de bifurcação das vazões na entrada e na saída do separador. (Ensaio 2).

Figura 27 - Diagramas de bifurcação das pressões da flowline e do riser (Ensaio 2).

Figura 28 - Pressões do riser e do vaso separador durante ocorrência de golfadas no sistema com a choke totalmente aberta (Ensaio 2).

Figura 29 - Comparação entre as produções médias obtidas nos ensaios 2 e 3 .

Figura 30 - Arquitetura do controlador supressor de golfadas.

Figura 31 - Resultado do ensaio de verificação do algoritmo de autocorrelação para estimação de frequência.

Figura 32 - Diagrama do sistema de inferência fuzzy utilizado no controlador supressor de golfadas.

Figura 33 - Funções de pertinência da variável linguística "Erro". 
Figura 34 - Funções de pertinência da variável linguística "Frequência de Oscilação".

Figura 35 - Funções de pertinência da variável linguística "Ação Restritiva".

Figura 36 - Funções de pertinência da variável linguística "Ganho Integral".

Figura 37 - Superfície de resposta do SIF para a variável de saída "Açao Restritiva".

Figura 38 - Superfície de resposta do SIF para a variável de saída "Ganho Integral".

Figura 39 - Diagrama do controlador amortecedor de golfadas, com ênfase no sistema de inferência fuzzy.

Figura 40 - Funções de pertinência da variável linguística "Erro".

Figura 41 - Funções de pertinência da variável linguística "Diferença do Erro".

Figura 42 - Funções de pertinência da variável linguística "Variação de Abertura da Válvula".

Figura 43 - Vazão de entrada de líquido utilizada na simulação para obtenção de aptidão.

Figura 44 - Função custo utilizada na determinação da capacidade de regulação.

Figura 45 - Vazão de entrada e de referência utilizados na determinação da capacidade de amortecimento.

105

Figura 46 - Evolução das aptidões média e máxima durante o processo de otimização.

Figura 47 - Funções de pertinência das variáveis lingúisticas do controlador fuzzy otimizado.

Figura 48 - Superfície de resposta do SIF para a variável de saída "Variação de Abertura da Válvula".

Figura 49 - Respostas das variáveis mais relevantes do ensaio de capacidade de supressão com abertura inicial da choke de $40 \%$.

Figura 50 - Respostas das variáveis mais relevantes do ensaio de capacidade supressão com abertura inicial da choke de $100 \%$ 
Figura 51 - Respostas da vazão e abertura de válvula no ensaio com o controlador PID baseado na pressão no topo do riser e abertura prévia de $40 \%$.

Figura 52 - Influência da limitação da taxa de entrada à sinais de controladores rápidos.

Figura 53 - Vazão e abertura de válvula para os ensaios em que a atuação é instantânea (à esquerda) e lenta (à direita). Curvas laranjas são do FPID-P 2 e azuis do PI-P1.

Figura 54 - Respostas da vazão e abertura de válvula no ensaio de estabilização de ponto estável.

Figura 55 - Comparação da produção média obtida pelo controlador fuzzy, controlador de referência e planta em malha aberta.

Figura 56 - Respostas da vazão e abertura de válvula no ensaio de produção ruidosa.

Figura 57 - Respostas da vazão e abertura de válvula no ensaio de resposta à degraus de produção.

Figura 58 - Respostas da vazão e abertura de válvula no ensaio de resposta à degraus de produção com válvula choke realista.

Figura 59 - Respostas da vazão e abertura de válvula no ensaio de resposta de mudanças de condições operacionais realizado com o controlador $\mathrm{PI}-\mathrm{P}_{1}$.

Figura 60 - Respostas da vazão e abertura de válvula no ensaio de resposta de mudanças de condições operacionais realizado com o controlador FPID-P2.

Figura 61 - Diagramas de bifurcação dos níveis (acima) e das vazões de líquido (abaixo).

Figura 62 - Razão entre as amplitudes das golfadas na vazão de entrada e na vazão de saída.

Figura 63 - Nível do vaso (esquerda) e vazão de líquido na saída do vaso (direita) nos ensaios em que válvula choke encontravase $30 \%$ aberta.

Figura 64 - Diagramas de bifurcação das vazões de líquido no ensaio de amortecimento multi-estágio.

Figura 65 - Níveis dos vasos (esquerda) e vazões de líquido nas saídas dos vasos (direita) no ensaio de amortecimento multiestágio em que válvula choke encontrava-se $30 \%$ aberta. 
Figura 66 - Vazão de entrada no primeiro ensaio de entradas compostas.

Figura 67 - Nível e vazão de saída do vaso separador no ensaio em que a entrada é composta por uma combinação de golfadas de difeerntes severidades.

Figura 68 - Nível e vazão de saída do vaso separador no ensaio em que a entrada, ruidosa, é sujeita um pequeno degrau de produção.

Figura 69 - Nível e vazão de saída do vaso separador no ensaio em que uma entrada ruidosa é sujeita a um grande degrau de produção. 


\section{Lista de Tabelas}

Tabela 1 - Descrição dos principais parâmetros e variáveis do SRM.

Tabela 2 - Parâmetros do sistema utilizados no OLGA®.

Tabela 3 - Dados do ponto de operação crítico.

Tabela 4 - Parâmetros de simulação de poço no software MARLIM.

Tabela 5 - Condições de contorno da simulação de poço no software MARLIM.

Tabela 6 - Vazões obtidas através da simulação do poço no software MARLIM.

Tabela 7 - Parâmetros do modelo de poço utilizado no trabalho.

Tabela 8 - Parâmetros do modelo de separador de produção.

Tabela 9 - Frequências de oscilação do sistema para diferentes aberturas de válvula. (Ensaio 1)

Tabela 10 - Frequências de oscilação do sistema para diferentes aberturas de válvula.

Tabela 11 - Heurística utilizada na síntese das quinze regras a partir dos parâmetros $R n$.

Tabela 12 - Caracterização do cromossomo de um indivíduo.

100

Tabela 13 - Cromossomo do melhor indíviduo.

108

Tabela 14 - Tempo necessário para supressão das golfadas (FPID-P 2 e PI-P1).

Tabela 15 - Tempo necessário para supressão das golfadas (Fuzzy e PID-P2).

Tabela 16 - Tempo necessário para supressão das golfadas para diferentes velocidades de atuação da válvula choke (Fuzzy e $\left.\mathrm{Pl}-\mathrm{P}_{1}\right)$ 


\section{1. Introdução}

\section{1. \\ Motivações}

Desde o início da exploração comercial do petróleo pela indústria moderna, em meados do século XIX, sua demanda tem aumentado continuamente em virtude do mesmo ser a matéria prima de produtos essenciais para a vida moderna, como combustíveis e petroquímicos.

Além disso, organizações como a Agência Internacional de Energia (AIE) e a Organização dos Países Exportadores de Petróleo (OPEP) preveem um crescimento da ordem de $20 \%$ da demanda até 2040, mesmo em um cenário em que os países cumpram os compromissos climáticos assumidos no Acordo de Paris de 2015, que impõe menor emissão de gases de efeito estufa [1, 2].

Atender a esta demanda crescente tem se tornado um desafio cada vez maior, já que os reservatórios dos quais o petróleo pode ser facilmente extraído têm se tornado cada vez mais raros, uma vez que sua exploração foi priorizada no passado devido aos menores custos envolvidos. O petróleo proveniente destes campos, muitas vezes chamado de "óleo fácil", representava $75 \%$ da produção em 1990, mas até 2040 deve representar apenas $25 \%$ da produção mundial [1].

O restante da produção é extraído de reservatórios cuja exploração é mais complexa, por estarem localizados em regiões de difícil logística, como em águas profundas e ultraprofundas, ou por possuírem petróleo de baixa ou baixíssima viscosidade, o que dificulta enormemente o processo de extração.

Esta escalada da complexidade de exploração das novas descobertas tem justificado um interesse cada vez maior em se aumentar o fator de recuperação de óleo dos campos já em produção. No entanto, isto implica a necessidade de se realizarem ajustes nos sistemas de produção com o objetivo de torná-los capazes de operar de maneira econômica até mesmo em reservatórios maduros, caracterizados por uma pressão interna reduzida e pela consequente dificuldade no escoamento da produção [3]. 
No Brasil, o campo gigante de Marlim, já em estado maduro e operado pela Petrobras, deverá passar por um processo de ajuste dos sistemas de produção com o objetivo de estender sua vida útil econômica, viabilizando um fator de recuperação de óleo superior ao alcançável com sistemas atuais. O projeto foi batizado de "Revitalização de Marlim" e contempla a instalação de duas novas plataformas de produção, em substituição às nove plataformas em operação, além de grande rearranjo dos sistemas submarinos.

Entre os ajustes a serem feitos está a interligação de um grande número de poços a uma única plataforma de produção, muitas vezes resultando em redes de tubulações submarinas de comprimentos significativos e com diferentes condições de pressão e temperatura [3]. O grande desafio deste novo arranjo é garantir o escoamento da mistura multifásica de óleo, gás e água produzida nos poços através destes longos trechos de tubulações horizontais e verticais até plataformas de produção. Este desafio é ainda maior em campos maduros, cuja baixa pressão do reservatório dificulta um escoamento de características favoráveis [4].

Entre os fenômenos que podem prejudicar o escoamento estão problemas de natureza físico-química, como deposição de cera, formação de hidratos e corrosão da linha, e também problemas de natureza física, como o estabelecimento de um fenômeno de escoamento conhecido como golfada severa, caracterizado por oscilações periódicas e de grande amplitude nas vazões de líquido e gás, que diminuem a eficiência do processo de separação da plataforma de produção e que podem causar danos à estrutura do reservatório, às tubulações e aos equipamentos da plataforma [3]. Por esta razão, projetistas procuram garantir um escoamento contínuo da produção dos poços, mas, com a depleção natural dos reservatórios, não é incomum o estabelecimento de um regime de escoamento com golfadas severas. Quando isto ocorre, são procuradas alternativas para se reestabelecer a estabilidade do escoamento, como reprojeto e substituição de parte das instalações submarinas, injeção de gás na base da tubulação ascendente que liga a plataforma à tubulação apoiada no leito do mar (riser), fechamento parcial da válvula de entrada da produção (choking estático) e controle ativo da válvula de entrada da produção (choking dinâmico) [3].

As duas primeiras soluções propostas acima envolvem substituição ou adição de novas instalações submarinas e, portanto, são raramente utilizadas em virtude do alto custo envolvido. Na maioria dos casos, a estabilização da vazão dos 
poços é obtida pela atuação na válvula de entrada da produção (válvula choke), mais comumente de forma estática do que por meio de controle ativo.

A atuação estática, que consiste em manter a válvula choke com uma abertura parcial fixa, é uma solução bastante utilizada por ser efetiva na estabilização da vazão, sem necessidade de instalação de equipamento adicional. Em contrapartida, esta solução causa aumento da pressão na cabeça do poço, implicando em diminuição da produção de petróleo e consequentes perdas financeiras.

O controle ativo da abertura da válvula choke permite a mesma estabilização na vazão de produção com uma menor pressão na cabeça do poço quando comparada àquela obtida com a técnica de choking estático e, portanto, proporciona uma maior produção [4-6]. No entanto, a maioria dos casos bem-sucedidos de aplicação do controle ativo exige a medição de alguma pressão submarina, como a pressão na cabeça do poço [7] ou na base do riser [4, 6, 8], que costumam ser grandezas de difícil aquisição por exigirem a instalação de instrumentos no leito marinho e uma custosa manutenção submarina, que só pode ser executada por embarcações especializadas. Por esta razão, é comum que estas medições não estejam disponíveis, seja por ausência do instrumento ou por falha devido à falta de manutenção [9].

A literatura indica que a grande maioria dos resultados obtidos através do controle ativo das variáveis de topo, como a pressão a montante da válvula choke, não foram tão favoráveis quanto os obtidos através do controle de variáveis de fundo [3]. Inclusive, análises de controlabilidade indicam que estas variáveis não são boas para o controle de estabilidade dos sistemas de produção devido à localização dos zeros da função de transferência correspondente no lado direito do plano complexo [4].

Quando a utilização de métodos que evitam a formação das golfadas não é possível ou ineficaz, podem-se adotar estratégias de controle na planta de processo da plataforma que atenuam parcialmente o efeito nocivo das golfadas severas sobre a eficiência dos processos de separação e sobre a durabilidade dos equipamentos. Estas estratégias consistem essencialmente em tirar proveito da capacitância volumétrica dos vasos de processo no intuito de amortecer as vazões de saída dos vasos separadores de produção [10, 11]. 
Considerando a relevância das estratégias de controle referidas acima e o fato dos controladores convencionais serem, em sua maioria, implementados a partir de algoritmos lineares clássicos, como o PID, vislumbra-se que abordagens com algoritmos não-lineares sejam capazes de atingir resultados até então não alcançados, seja por melhoria de desempenho, aumento de interpretabilidade dos algoritmos ou até mesmo facilitação de instalação em ambiente industrial.

Dado o exposto, propõe-se neste trabalho o desenvolvimento de controladores supressores e atenuadores de golfadas por meio da aplicação de técnicas de inteligência computacional, como lógica fuzzy e computação evolucionária.

\section{2.}

\section{Objetivos}

O principal objetivo deste trabalho é o desenvolvimento de controladores inteligentes para supressão e atenuação de golfadas severas, capazes de obter resultados superiores aos alcançados com técnicas clássicas de controle linear. Além disso, pretende-se que esses controladores tenham baixa complexidade, facilitando sua utilização em aplicações industriais.

O objetivo secundário deste trabalho é o desenvolvimento de um modelo computacional amplo, capaz de simular o comportamento de um sistema de produção de petróleo que inclua poço, tubulação no leito marinho (flowline), tubulação ascendente (riser), válvula choke, vaso separador e as válvulas de controle deste vaso. Este modelo será utilizado no desenvolvimento e na avaliação dos resultados obtidos com os controladores propostos neste trabalho.

\section{3.}

\section{Contribuições}

As principais contribuições deste trabalho são:

- Extensão do Modelo Simplificado de Riser de Storkaas (SRM) [4], através do acoplamento de um modelo de poço produtor, permitindo auferir ganhos de produção em decorrência das estratégias de controle, e de um modelo de vaso separador de produção cilindro horizontal, viabilizando o desenvolvimento e validação de controladores atenuadores de 
golfada. Além disso, são propostas pequenas modificações às equações do SRM, de modo a proporcionar maior estabilidade numérica ao modelo.

- Desenvolvimento de um controlador Fuzzy-PID com o objetivo de suprimir as golfadas severas em risers de produção por meio da atuação na válvula choke. Este controlador é dependente apenas da facilmente obtida medição de pressão no topo do riser e é capaz de estabilizar um sistema de produção em aberturas de válvula superiores às alcançadas com o uso da técnica de choking estático, proporcionando ganhos de produção significativos.

- Desenvolvimento de um controlador fuzzy, otimizado por algoritmos genéticos, capaz de manter o nível do vaso separador dentro de uma faixa especificada e, ao mesmo tempo, atenuar significativamente a variação da vazão de saída do vaso, reduzindo os efeitos negativos das golfadas severas na planta de processo.

\section{4. \\ Organização da Dissertação}

Esta dissertação é dividida em seis capítulos, descritos a seguir.

No Capítulo 2 é feita uma revisão bibliográfica dos temas mais relevantes ao trabalho em questão, com uma descrição dos sistemas de produção offshore, do mecanismo de formação de golfadas em risers, das técnicas de supressão mais utilizadas e do Modelo Simplificado de Riser (SRM), que descreve matematicamente um sistema flowline-riser, sendo capaz de prever a formação de golfadas severas.

No Capítulo 3 são apresentadas as etapas do desenvolvimento do modelo de processo utilizado neste trabalho, incluindo as modificações nas equações do SRM que aumentam sua estabilidade numérica e também os acoplamentos dos modelos de poço linear e de vaso separador bifásico cilíndrico horizontal, derivado para este trabalho. Por fim, são realizados ensaios do modelo obtido.

No Capítulo 4 são apresentadas as etapas de desenvolvimento dos dois controladores concebidos neste trabalho, desde sua motivação conceitual até sua definição formal e parametrização. No caso do controlador atenuador de golfadas, que é otimizado através de um algoritmo genético, são mostrados também os 
detalhes relevantes do algoritmo, com foco especial na função de avaliação utilizada.

No Capítulo 5 são apresentados os resultados oriundos de ensaios realizados com a aplicação de ambos controladores ao modelo de processo desenvolvido. Os resultados são analisados individualmente e também comparados com os obtidos por controladores classicamente utilizados em tais problemas de controle.

No Capítulo 6 são apresentadas as conclusões do trabalho, comentando-se sobre os resultados obtidos de maneira mais ampla, à luz do contexto discutido nesta introdução. Além disso, são apresentadas algumas ideias que podem ser utilizadas para desenvolvimento de trabalhos futuros. 


\section{2. \\ Fundamentos}

\section{1. \\ Descrição de um Sistema de Produção de Petróleo Offshore}

Para que o petróleo e o gás sejam extraídos de um reservatório submarino, escoados até uma unidade de produção e passem pelo processo de separação necessário para sua exportação, um complexo sistema de produção precisa ser instalado, com componentes submarinos e de superfície.

Os principais componentes submarinos desse sistema são os poços produtores, grandes trechos de tubulação apoiados no leito do mar, chamados de flowlines, e tubulações ascendentes que ligam as flowlines à plataforma, chamadas de risers. Estes componentes principais podem ser observados na Figura 1.

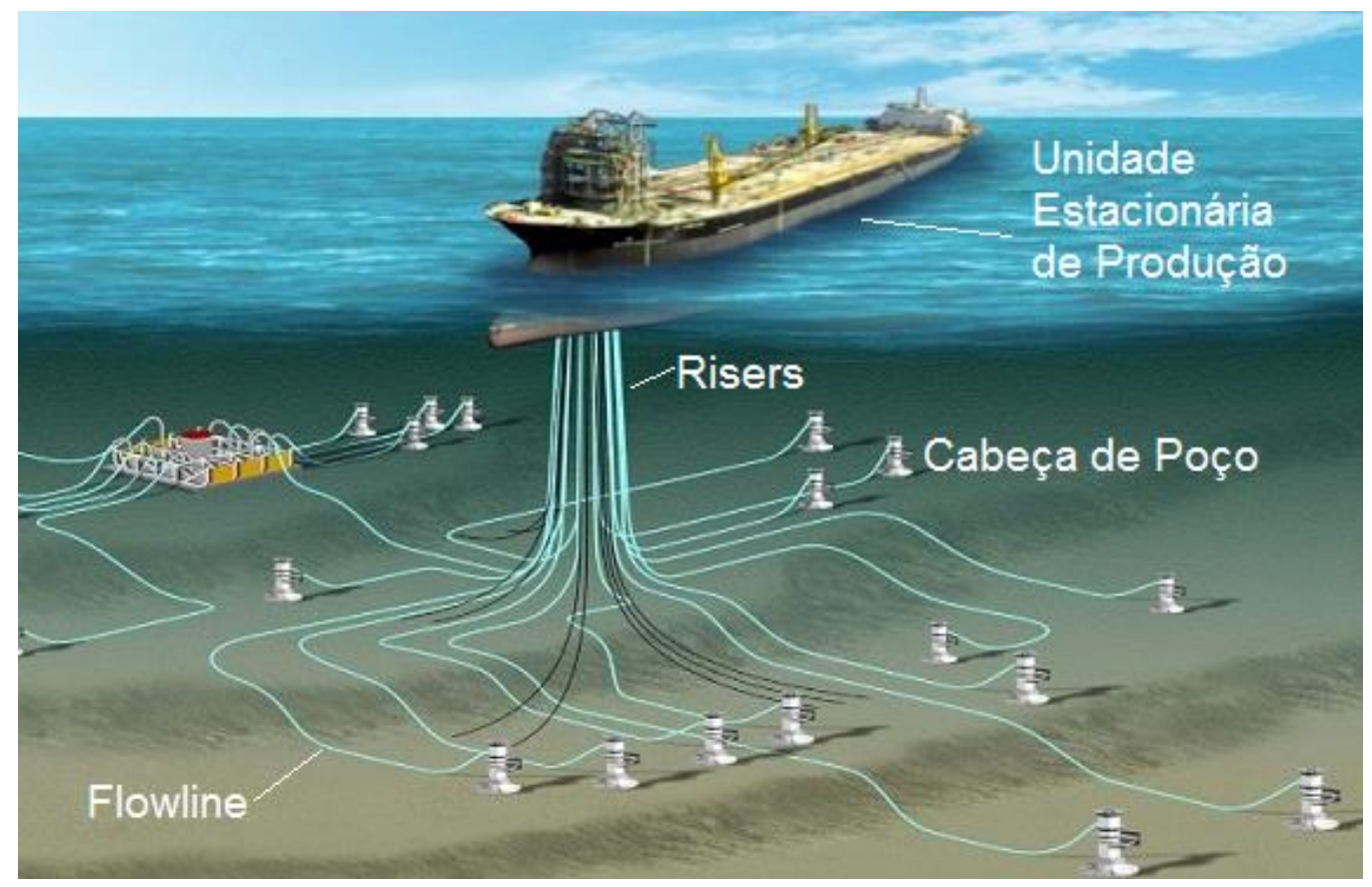

Figura 1 - Ilustração da parcela submarina de um sistema de produção offshore [12].

Já na superfície, existe uma grande diversidade de equipamentos com os mais diversos objetivos, que podem ser resumidos em: separar a água, o óleo e o gás provenientes do poço, tratar a água produzida para posterior descarte, exportar 
o óleo e o gás produzidos, captar e injetar água no reservatório e garantir a habitabilidade da plataforma para sua tripulação. Para os fins deste trabalho, faz-se necessário considerar somente os equipamentos relativos à separação e exportação da produção: os vasos separadores, as bombas de exportação de óleo e os compressores de exportação de gás.

$\mathrm{Na}$ Figura 2, é mostrado o diagrama de um sistema de produção offshore simplificado, utilizado como base no desenvolvimento deste trabalho. Nele, um único poço é ligado, através de uma flowline, à um riser que transporta a produção até uma válvula choke, posicionada na entrada da plataforma. Na superfície, o fluido produzido é levado a um vaso separador bifásico, com saídas de líquido e gás, cujas vazões são controladas por válvulas de controle que direcionam estes fluídos para bombas e compressores de exportação.

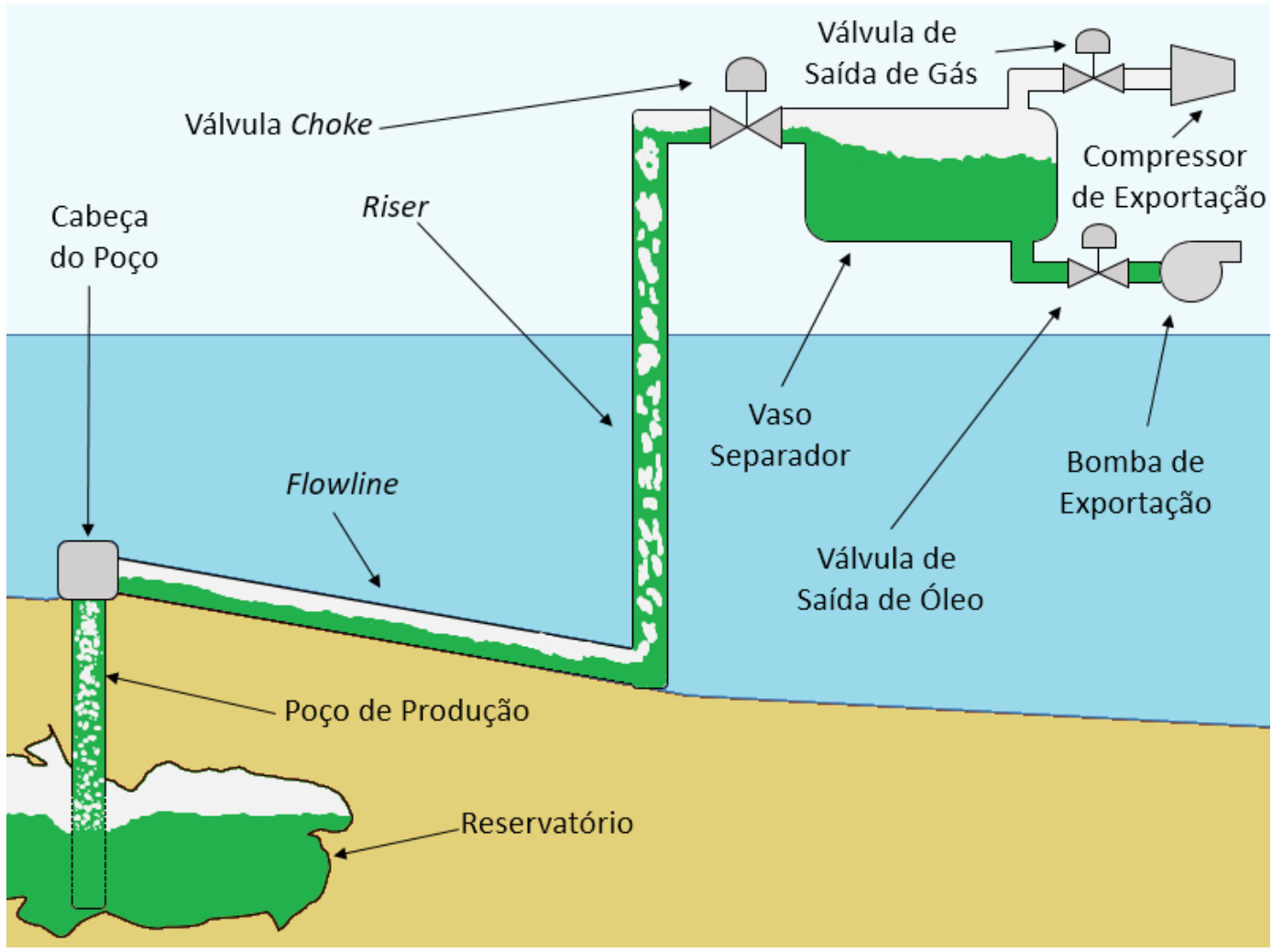

Figura 2 - Diagrama de um sistema de produção offshore simplificado.

As principais simplificações do sistema mostrado na Figura 2 são a presença de apenas um poço e um sistema de separação primária composto por um único separador, que é capaz apenas de separar o gás do líquido (mistura água-óleo). Em geral, plataformas possuem dezenas de poços interligados aos seus sistemas de separação, que por sua vez são compostos por separadores trifásicos e bifásicos, 
vasos tratadores eletrostáticos, hidrociclones e diversos outros equipamentos que garantem uma separação adequada dos fluídos produzidos [10]. No entanto, este modelo simplificado descreve o processo de produção de petróleo com detalhes suficientes para elaboração de um modelo matemático que permita o projeto dos controladores anti-golfada propostos neste trabalho.

\section{2. Escoamento Multifásico em Sistemas de Produção}

Um escoamento é classificado como multifásico quando a mistura escoada é formada por duas ou mais fases, que são transportadas simultaneamente através de um mesmo invólucro fechado, como uma tubulação [13]. Em um sistema de produção de petróleo offshore, a mistura extraída do reservatório é composta por água, petróleo e gás, que são escoados através de uma tubulação fechada até a unidade de produção. Portanto, trata-se de um escoamento multifásico formado por três fases.

Um dos maiores desafios apresentados por escoamentos multifásicos decorre do fato de que podem assumir diferentes configurações, em função da vazão de cada fase e da geometria da tubulação. Por exemplo, um escoamento com fases gasosa e líquida em uma tubulação horizontal, com a vazão de gás baixa e de líquido alta, costuma apresentar pequenas bolhas de gás dispersas ao longo do líquido, que não coalescem devido à ação do líquido que em altas velocidades garante a turbulência necessária para realizar a mistura contínua dos fluídos. Por outro lado, ao se diminuir gradualmente a velocidade do líquido, essas bolhas tendem a coalescer, formando bolhas cada vez maiores (plugs). Abaixo de uma certa velocidade da fase líquida, todas as bolhas coalescem e o escoamento torna-se estratificado, com uma fase líquida na parcela inferior da tubulação e uma fase gasosa na parcela superior.

Para baixas vazões de líquido em relação ao gás, o líquido se apresenta como gotículas dispersas ao longo do gás, com adesão da fase líquida nas paredes da tubulação, de forma bastante semelhante à disposição das gotas de água no parabrisa de um automóvel em alta velocidade. Este regime de escoamento é costumeiramente chamado de escoamento anular. 
De maneira geral, a literatura de escoamento multifásico não apresenta uma classificação definitiva para as várias formas de escoamento, uma vez que esta classificação é realizada de maneira subjetiva pela observação dos padrões de escoamento em laboratório. Uma classificação bastante aceita na comunidade de engenharia para escoamentos bifásicos é a de Chisholm [14], cujos regimes em tubulações horizontais são exibidos na Figura 3. Por sua vez, destaca-se que o escoamento bifásico em tubulações verticais diferencia-se principalmente pela ausência dos regimes estratificado e em ondas.
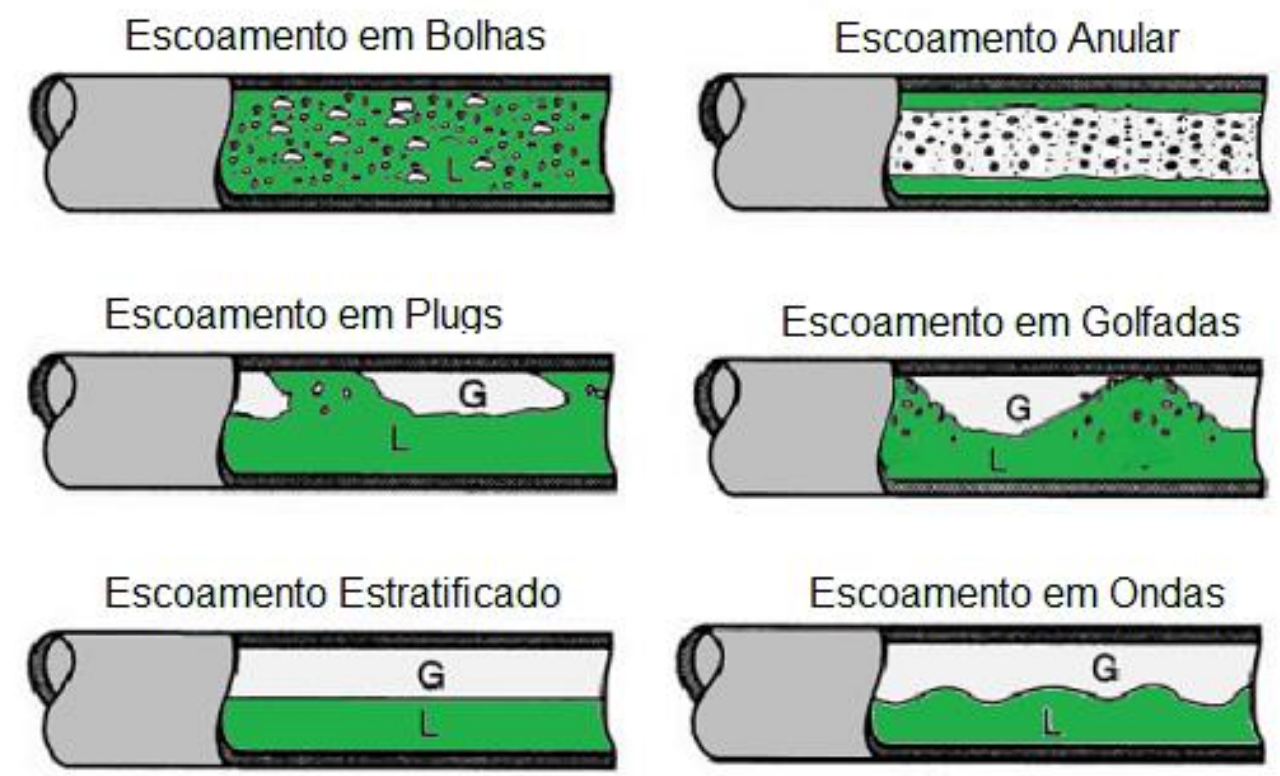

Figura 3 - Regimes de escoamento em tubulações horizontais. [15]

Conforme discutido anteriormente, o regime de escoamento bifásico estratificado costuma se estabelecer em tubulações horizontais com vazões de gás e líquido baixas. Com o aumento da velocidade do gás, ondas começam a se formar na interface entre as duas fases, caracterizando o escoamento em ondas. Caso estas atinjam amplitude suficiente para ocupar toda uma seção transversal da tubulação, o gás é momentaneamente bloqueado, levando à formação de plugs ou, em casos mais acentuados, golfadas.

Estas golfadas são chamadas de golfadas hidrodinâmicas e diferem das golfadas severas discutidas na introdução deste trabalho. Na verdade, sistemas de produção de petróleo offshore estão sujeitos a, pelo menos, quatro tipos distintos de golfadas [4]: 


\section{a) Golfadas Hidrodinâmicas}

Características do regime de escoamento em golfadas, as golfadas hidrodinâmicas ocorrem em tubulações horizontais quando as ondas de líquido interrompem a passagem de gás pela tubulação, conforme pode ser observado na Figura 3. Possuem dimensão relativamente pequena, sendo as de menor impacto nos sistemas de produção de superfície.

\section{b) Golfadas de Terreno}

As golfadas de terreno possuem um mecanismo de formação semelhante ao das hidrodinâmicas, com a diferença de que o preenchimento da tubulação por líquido é induzido por acidentes geográficos no leito marinho em que a tubulação está apoiada. Estas golfadas possuem comprimento bastante variável, a depender das características do acidente geográfico. Na Figura 4, é possível observar o mecanismo típico da formação deste tipo de golfada em uma tubulação irregular.

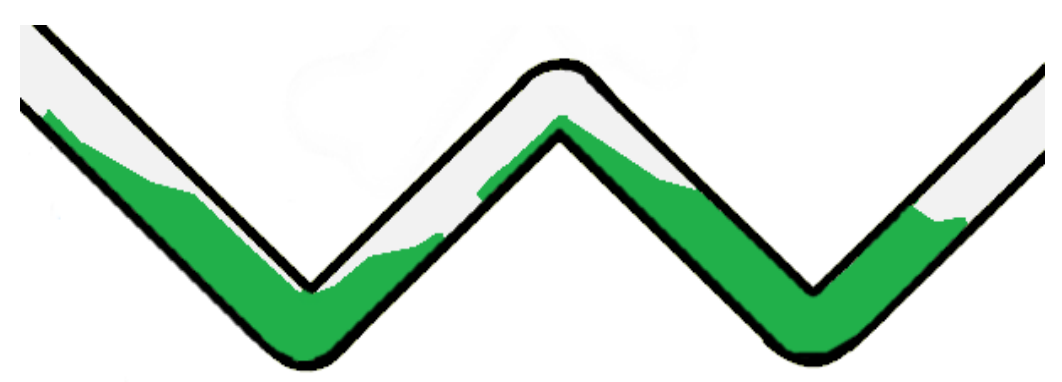

Figura 4 - Ilustração de golfadas de terreno em uma flowline apoiada em um terreno acidentado.

\section{c) Golfadas Transientes}

As golfadas transientes são geradas a partir de certas operações realizadas no sistema de produção, como aumento de produção, despressurização da linha e passagem de PIGs (Pipeline Inspection Gauge). A dimensão destas golfadas varia com a operação executada, mas as mesmas podem ser tão longas quanto às golfadas severas de risers. No entanto, o dano causado pelas golfadas transientes aos sistemas de produção é limitado, visto que não são fenômenos periódicos e sua ocorrência é antecipada pelos operadores do sistema ao realizarem a operação, permitindo a tomada de medidas mitigadoras em antecipação. 


\section{d) Golfadas em Risers}

Golfadas em risers ocorrem em sistemas flowline-riser quando o líquido obstrui a passagem de gás da flowline para o riser, causando o acúmulo de gás ao longo da flowline e de líquido no riser, como pode ser observado na Figura 5. As golfadas geradas por este mecanismo, que será mais bem explanado adiante, podem ter quilômetros de comprimento, sendo extremamente prejudicais aos sistemas de produção.

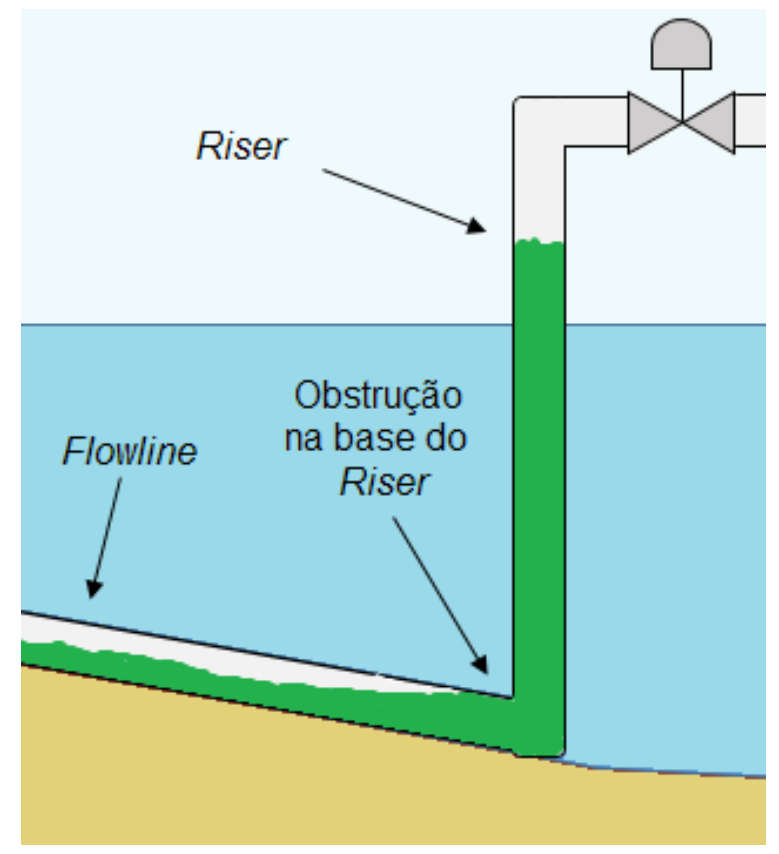

Figura 5 - Ilustração da formação de uma golfada em um riser.

No contexto da indústria de óleo e gás, estas golfadas também são conhecidas como golfadas severas e sua eliminação ou atenuação configuram os objetivos principais dos controladores desenvolvidos neste trabalho.

\section{3.}

\section{Golfadas Severas em Risers}

Devido a relevância das golfadas severas para este trabalho, nesta seção é realizado um detalhamento do seu processo de formação e são discutidas as consequências deste fenômeno para os sistemas de produção de petróleo e as técnicas mais utilizadas para sua eliminação ou atenuação. 


\subsection{1.}

\section{Processo de Formação das Golfadas Severas}

O processo cíclico de geração de golfadas severas pode ser melhor explicado quando dividido em quatro etapas $[4,3,16]$, mostradas na Figura 6.

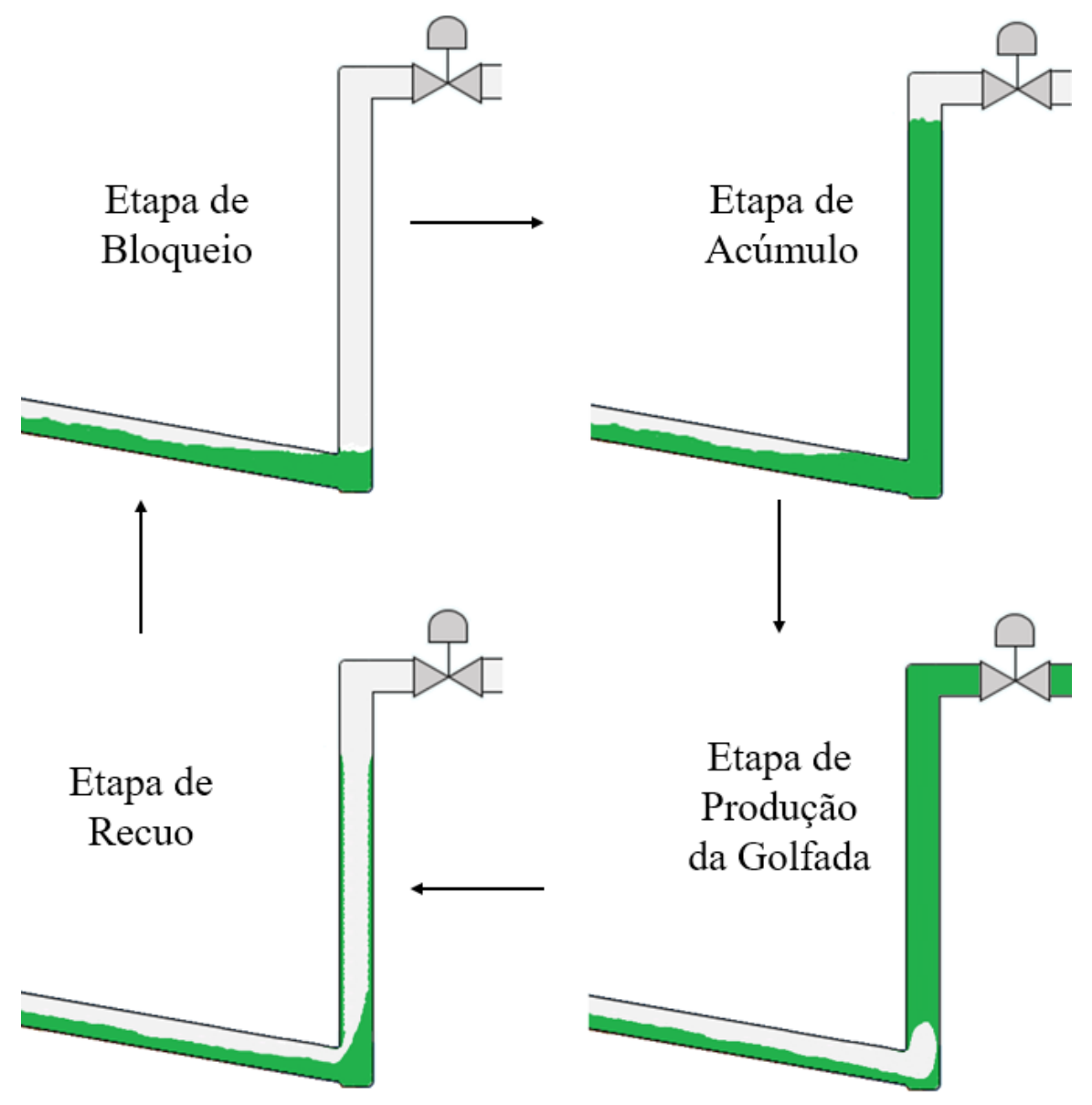

Figura 6 - Representação do processo cíclico de formação de golfadas em risers.

A etapa de bloqueio inicia-se quando, devido à ação gravitacional, o líquido se acumula na base do riser e bloqueia a passagem de gás da flowline para o riser. Esta condição só ocorre quando tanto a vazão de líquido quanto a vazão de gás são suficientemente baixas ao ponto de criar as condições necessárias para o estabelecimento de um regime de escoamento que possibilite a ocorrência deste bloqueio, como o escoamento estratificado. É por esta razão que sistemas de produção com escoamentos estáveis passam a apresentar golfadas severas à medida que os reservatório amadurecem e, consequentemente, diminuem a vazão produzida. 
Com a base do riser bloqueada por líquido, inicia-se a etapa de acúmulo, caracterizada pela pressurização da flowline pelo gás bloqueado e pelo preenchimento gradual do riser com líquido, repercutindo em aumento da pressão na base do riser devido à pressão hidrostática da coluna. Estas duas pressões continuam crescendo enquanto a pressão na base do riser for maior que a pressão da flowline. Como a pressão hidrostática da coluna de líquido é limitada pelo comprimento finito do riser, eventualmente a pressão da flowline irá superar a pressão na base do riser.

No instante da ocorrência desta superação, inicia-se a etapa de produção da golfada, em que o gás adquire pressão suficiente para impulsionar o líquido acumulado para fora do riser; além disso o gás começa a penetrar axialmente no volume de líquido. Conforme o líquido é expelido do riser, a pressão da flowline diminui, causando expansão do gás e consequente aumento nas velocidades de escoamento, caracterizando uma realimentação positiva que explica, em grande parte, a severidade deste tipo de golfada.

Após a saída da maior parte do gás e do líquido do riser, o gás deixa de se expandir causando uma diminuição na sua velocidade, que em certo ponto se torna insuficiente para impulsionar o líquido para cima, dando início à etapa de recuo. Nesta etapa, o líquido presente no riser, majoritariamente na região anular, inicia um fluxo reverso, em direção à base do riser, devido à ação gravitacional. Eventualmente, o acúmulo deste líquido na base do riser volta a bloquear a passagem do gás, dando início a um novo ciclo de golfada.

\subsection{2.}

\section{Efeitos Nocivos das Golfadas}

A grande variação das vazões e das pressões causadas pelas golfadas severas são um grande problema em sistemas de produção, pois prejudicam a eficiência do processo de separação, sujeitam equipamentos como bombas, compressores e válvulas a esforços cíclicos e causam descontroles de processo que podem levar a paradas de emergência e acidentes [3, 4, 17].

A diminuição da eficiência do processo de separação pode fazer com que água descartada para o mar tenha uma concentração de óleo superior ao limite estabelecido pela agência ambiental, gerando custosas multas à empresa operadora 
do campo. Uma separação deficiente também repercute em cargas de óleo com conteúdo de água em excesso, que muitas vezes não podem ser entregues ao comprador em virtude de exigências contratuais de qualidade do produto, implicando em necessidade de reprocessamento. Como ambas as situações são indesejáveis, plantas com baixa eficiência de separação têm sua vazão processada diminuída, causando significativos prejuízos financeiros devido à diminuição da produção.

Caso as grandes variações nas vazões de entrada se propaguem através da planta de separação, equipamentos que ficam sujeitos a estas variações, como válvulas de controle, bombas de exportação e compressores de gás, tendem a ter confiabilidade e vida útil reduzidas [18]. Isto repercute em aumento dos custos de manutenção da planta de processo e também dos custos associados às perdas de produção em virtude de falhas nestes equipamentos.

Finalmente, as golfadas também podem repercutir em descontroles de processo, com diminuição ou aumento repentino do nível dos vasos separadores, causando paradas de emergência [4], e, em casos mais graves, derramamento de óleo no mar ou admissão de óleo no compressor de gás, condição extremamente danosa para o equipamento.

\subsection{3. \\ Técnicas de Minimização de Golfadas}

Ante o exposto na seção anterior, torna-se evidente o potencial danoso das golfadas severas aos sistemas de produção de petróleo offshore e, em última análise, à lucratividade do negócio. Por esta razão, foram desenvolvidas diversas técnicas no intuito de prevenir a formação de golfadas ou, ao menos, atenuar seus efeitos nocivos às plantas de produção.

Estas técnicas diferem amplamente em diversos aspectos, como quanto ao princípio de funcionamento, à exigência de mudança nas instalações, ao local da intervenção (submarina ou superfície) e ao custo de implementação. Essas características determinam a viabilidade de aplicação das soluções.

A seguir, é feita uma breve revisão das principais técnicas de minimização de golfadas. Uma descrição mais detalhada pode ser encontrada em Ogazi [3]. 


\subsubsection{1. Redução do Diâmetro Interno da Flowline}

Uma das possíveis formas de se interferir no mecanismo de formação da golfada visando a sua eliminação é a diminuição do diâmetro interno da flowline. Esta alteração faz com que a velocidade de escoamento dos fluídos aumente, evitando o estabelecimento de um regime de escoamento na flowline propício para formação de golfadas severas, como o escoamento estratificado.

Em um estudo conduzido no campo gigante de Upper Zakum nos Emirados Árabes Unidos, Fargharly reportou que a otimização do diâmetro interno da flowline é capaz de aliviar a ocorrência de golfadas severas, embora não seja capaz de eliminá-las por completo [19]. O maior problema desta solução é que a substituição de uma flowline é uma atividade com um custo muito elevado, ao ponto de se tornar inviável. Além disso, o diâmetro ideal da tubulação depende das características do reservatório, que se alteram ao longo de sua exploração, o que torna a solução pouco eficaz.

\subsubsection{2.}

\section{Mudança na Geometria da Flowline}

Outra forma de se interferir no mecanismo de formação de golfadas é por meio de mudanças na geometria da flowline, como proposto por Makogan e Brook da British Petroleum [20], que patentearam um dispositivo que pode ser descrito como uma tubulação em formato de "U" invertido instalado imediatamente antes do riser, conforme pode ser observado na Figura 7.

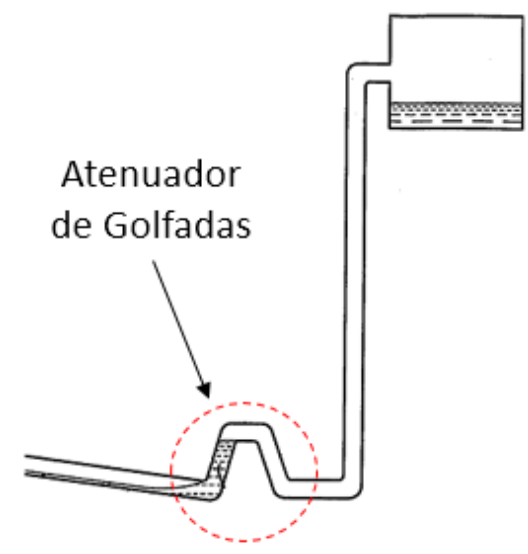

Figura 7 - Representação do dispositivo atenuador de golfadas, apresentado na patente de Makogan e Brook [20]. 
Os criadores do dispositivo alegam que seu invento diminui o comprimento das golfadas e aumenta a sua frequência, fazendo com o que regime de golfada severa se degenere em um regime de escoamento em plug, que poderia ser facilmente atenuado pela dinâmica lenta dos vasos da planta de separação primária. No entanto, até o momento não existem resultados divulgados que suportem essas alegações, até mesmo em ambientes simulados, o que levanta dúvidas sobre a eficácia da técnica.

\subsubsection{3.}

\section{Separação Submarina}

As golfadas em riser ocorrem devido à necessidade de elevação da mistura multifásica óleo-gás até a plataforma. Logo, estas golfadas podem ser evitadas ao se realizar a separação da mistura no leito do mar, por meio de um sistema de separação submarino.

Os fluídos resultantes podem ser então elevados em risers distintos para a unidade de superfície ou até mesmo exportados diretamente através de gasodutos e oleodutos submarinos. Como nos risers distintos o escoamento é monofásico, elimina-se a possibilidade de formação de golfadas. Naturalmente, torna-se necessária a instalação de um sistema de bombeamento submarino para garantir o escoamento do óleo através do riser ou oleoduto.

$\mathrm{Na}$ realidade atual, tal sistema é bastante custoso devido à necessidade de instalação e manutenção de uma planta de separação primária adicional no leito do mar. No entanto, essas plantas são um primeiro passo no sentido de desenvolver sistemas de produção totalmente submarinos, eliminando a necessidade de uma instalação de superfície.

Por esta razão, existem diversas plantas piloto de separação submarina no mundo, como o SSAO (Sistema de Separação Submarina Água-Óleo) instalado no campo de Marlim e operado pela Petrobras.

\subsubsection{4.}

\section{Injeção de Gás na Base do Riser}

Golfadas severas também podem ser evitadas ao se facilitar a elevação do líquido com a injeção de gás comprimido na base do riser, evitando assim o 
acúmulo de líquido que bloqueia a passagem de gás. Para esta finalidade, deve-se comprimir parte do gás produzido e injetá-lo na base do riser através de uma tubulação que vai da instalação de superfície até o leito marinho, conforme pode ser observado na Figura 8.

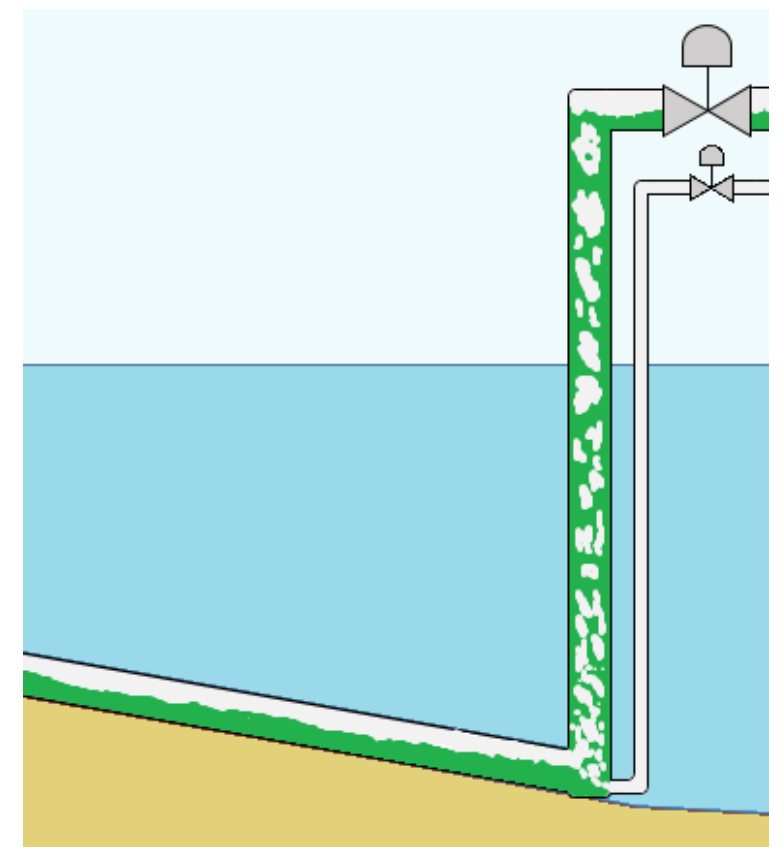

Figura 8 - Representação de um sistema flowline-riser com injeção de gás na base do riser.

A literatura apresenta diversos casos de sucesso da aplicação desta técnica, tanto em ambientes experimentais [21], quanto em aplicações industriais [22]. Entretanto, não são raros os relatos de que a introdução da injeção de gás na base do riser degradou as condições de escoamento do sistema, até mesmo desencadeando a formação de golfadas hidrodinâmicas em sistemas que apresentavam regime de escoamento estável [23].

Um fator que explica esses resultados contraditórios é que o sucesso da técnica é bastante dependente da aplicação de uma vazão de gás adequada para cada cenário de escoamento, o que frequentemente não é uma tarefa fácil [3]. Além disso, diversos estudos concluíram que a vazão necessária para estabilizar um sistema com golfadas severas é extremamente alta [21, 24], ao ponto do custo de compressão associado tornar-se proibitivo e, portanto, inviabilizar a técnica para aplicações industriais [25]. 


\subsubsection{5.}

\section{Reinjeção de Gás}

O princípio que fundamenta a reinjeção de gás é semelhante ao da injeção na base do riser, mas, ao invés de se utilizar gás comprimido na unidade de superfície, utiliza-se o próprio gás disponível na flowline para auxiliar a elevação do líquido, conforme representado na Figura 9.

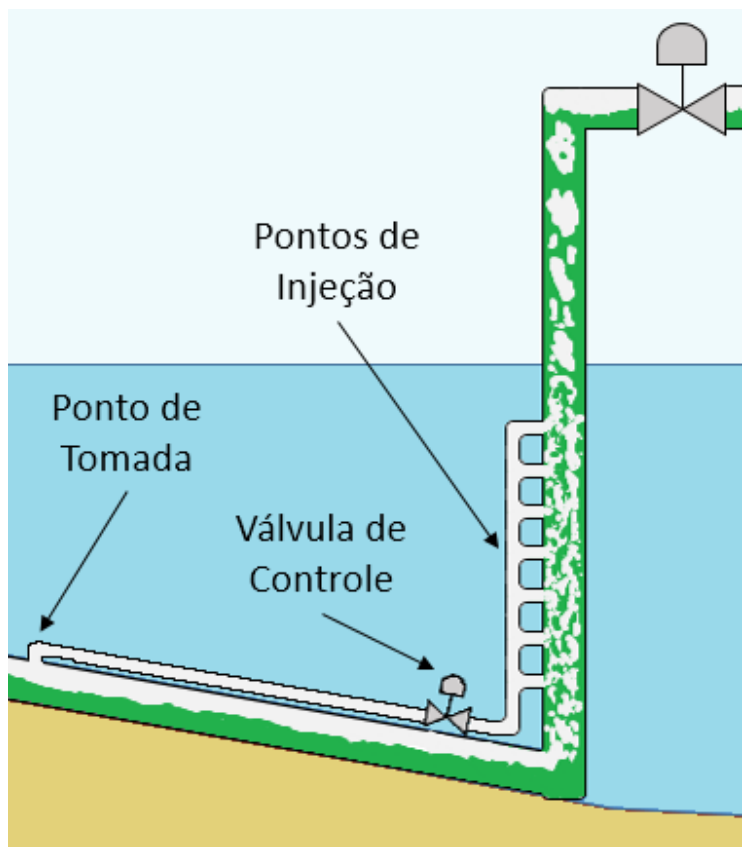

Figura 9 - Representação de um sistema flowline-riser com reinjeção de gás.

Este método visa a formação de um sistema auto regulável, tendo como maior vantagem o fato de não necessitar de uma fonte de gás adicional [3]. Porém, esta mesma vantagem pode se tornar um problema caso a vazão de gás não seja suficiente para estabilizar o escoamento.

Entre as desvantagens deste método estão a necessidade de se desenvolver uma boa estratégia de controle para a válvula e os grandes custos associados com as extensas modificações da instalação submarina.

\subsubsection{6.}

Homogeneização dos Fluídos Produzidos

Como as golfadas severas ocorrem exclusivamente em escoamentos multifásicos, é possível evitá-las por meio da homogeneização dos fluídos produzidos. Uma das formas de alcançar este objetivo é por meio da injeção de 
elementos químicos tensoativos na flowline [26], que reduzem a tensão superficial do líquido, fazendo com que os fluídos se misturem em uma espuma homogênea.

Além do custo financeiro associado à injeção contínua do elemento tensoativo e à necessidade de instalação submarina, esse método tem como grande desvantagem uma queda drástica na eficiência de separação da planta de superfície, com consequências potencialmente piores do que as advindas das golfadas.

\subsubsection{7.}

\section{Capturadores de Golfada}

Os capturadores de golfada são vasos instalados a jusante das válvulas choke e servem como amortecedores das golfadas de líquido provenientes do riser. Portanto, estes equipamentos não são capazes de impedir a formação da golfada, mas, ao atenuar as bruscas variações das golfadas, mitigam o seu impacto na planta de processo.

$\mathrm{Na}$ prática, os capturadores de golfada pouco diferem de um separador de produção e sua instalação pode ser caracterizada como a adição de um novo estágio de separação à planta, com o diferencial de serem vasos projetados com dimensões suficientes para amortecer as golfadas de líquido geradas pelo sistema ao qual estão conectados.

Em sistemas sujeitos às golfadas severas, em que estas podem ser tão longas ou até maiores que os próprios risers, às vezes com quilometros de comprimento, os vasos capturadores de golfada precisam possuir grandes dimensões para serem capazes de amortecer as golfadas adequadamente. Isto torna a instalação desses equipamentos em plataformas existentes praticamente inviável, uma vez que não costuma existir espaço livre em deck suficiente ou capacidade estrutural para instalação desta carga adicional.

Além disso, a instalação de um novo estágio de separação implica em mudanças drásticas na planta de processo, que dificilmente podem ser executadas fora de um estaleiro. 


\subsubsection{8.}

\section{Controle de Nível por Banda}

Nas últimas décadas, diversos pesquisadores atentaram para o fato de que não é necessário um vaso exclusivo, o capturador de golfadas, para se realizar o amortecimento das golfadas severas, uma vez que elas podem ser amortecidas nos próprios vasos que compõem os diferentes estágios do sistema de separação primária. Para tal, altera-se a estratégia de controle destes vasos, que normalmente tem como único objetivo manter o nível de líquido igual a um valor de referência constante. Isto porque esta exigência elimina a capacidade de amortecimento das perturbações da vazão de entrada, já que o nível só pode ser mantido constante caso a vazão de saída seja igual à vazão de entrada.

Uma alteração da estratégia de controle que concede capacidade de amortecimento aos vasos consiste em ter como objetivo a estabilização da vazão de saída, permitindo-se que o nível flutue dentro de uma faixa de valores aceitáveis, costumeiramente chamada de banda [11]. A ilustração de um vaso com sua banda definida é mostrada na Figura 10.

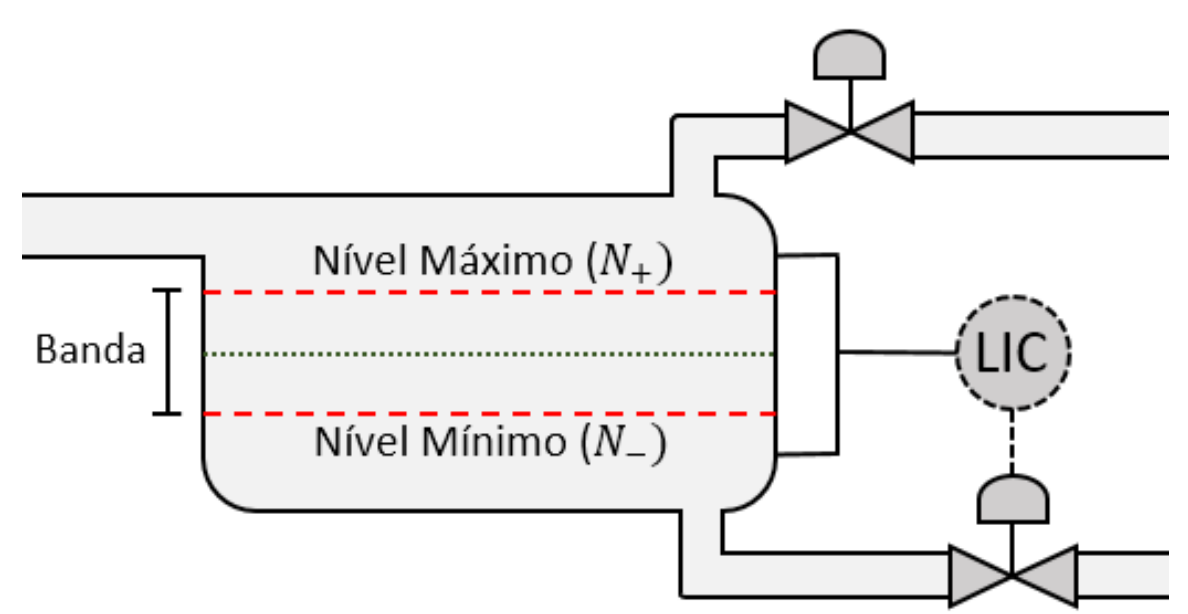

Figura 10 - Representação da banda de controle em um vaso separador.

Naturalmente, quanto maior for o volume da banda, maior será a capacidade de amortecimento das vazões processadas. No entanto, existem limites para a flutuação do nível, pois caso o nível desça demais, pode haver passagem de gás na saída de líquido, e caso o nível suba demais, pode haver arraste de líquido na saída de gás. Por esta razão, a definição da banda é feita tendo em vista uma relação de 
compromisso entre capacidade de amortecimento e risco para o processo, sendo uma importante etapa do projeto do controlador.

Outro aspecto interessante dessa estratégia de controle é que ela pode ser aplicada nos vasos dos diferentes estágios de separação da planta de processo, potencializando a capacidade de amortecimento, especialmente em sistemas com mais de dois estágios.

A aplicação de algoritmos de controle por bandas bem configurados à um sistema de separação primária equivale à instalação de um vaso capturador de golfadas cujo volume é igual à soma dos volumes das bandas dos vasos controlados. Como a aplicação destes controladores tem custo bastante reduzido, já que não se requer modificação física na planta de processo, esta técnica tem sido preferencialmente utilizada, ao invés da instalação de capturadores de golfada.

Os controladores baseados na estratégia de controle por banda são inerentemente não-lineares, pois possuem comportamentos distintos em função da posição do nível em relação à banda, apresentando ação lenta quando o nível está dentro da banda e rápida quando o nível a viola. A forma como esta não-linearidade é introduzida no controlador diferencia as várias técnicas, que serão discutidas brevemente a seguir.

No trabalho em que Nunes [11] define o conceito de controle por banda, é sugerida uma implementação baseada em dois controladores PI: um lento que atua dentro da banda e um rápido que assume o controle sempre que a banda é violada. Além disso, a saída do controlador PI lento passa por um estágio de pósprocessamento que calcula média móvel durante um período $T$, que deve ser superior ao período máximo das golfadas. Uma representação simplificada desta técnica é apresentada na Figura 11, onde podem ser observados os sete parâmetros de sintonia.

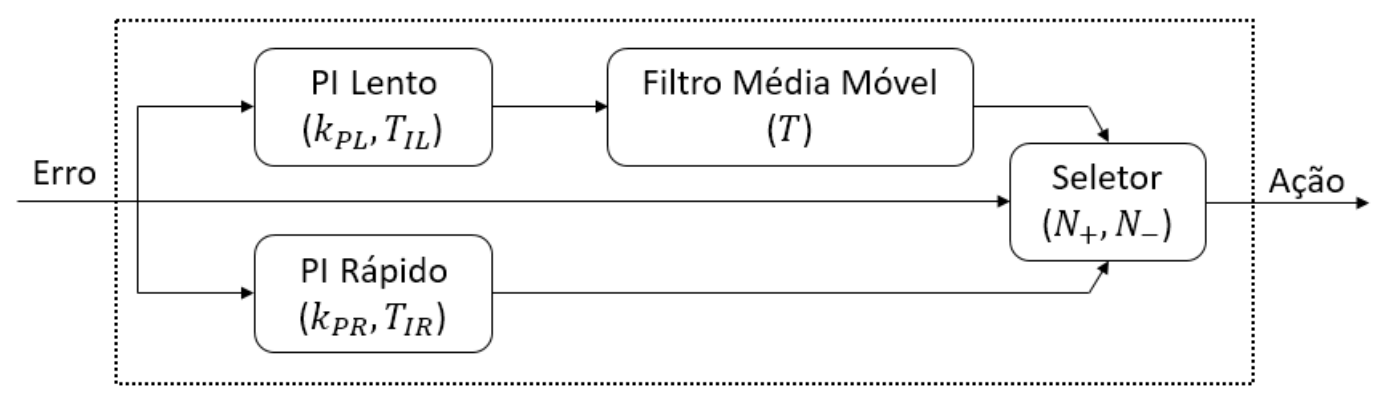

Figura 11 - Representação simplificada do controlador proposto por Nunes. 
Em Campos [27], é sugerida a utilização de um controlador PI cujos ganhos são escalonados por uma função não-linear do erro, como a exibida na Figura 12. Além dos valores de banda máxima e mínima, $N_{+}$e $N_{-}$, é necessário determinar o escalonamento máximo, $f_{a}$, a faixa de transição entre as ações rápida e lenta, $L$, e os dois ganhos base do controlador, $K_{p}$ e $T_{i}$, totalizando seis parâmetros de sintonia. Em algumas aplicações deste controlador, considera-se $L$ nulo, de modo que a técnica possa ser implementada através do chaveamento direto entre um controlador lento, dentro da banda, e um controlador rápido, fora da mesma.

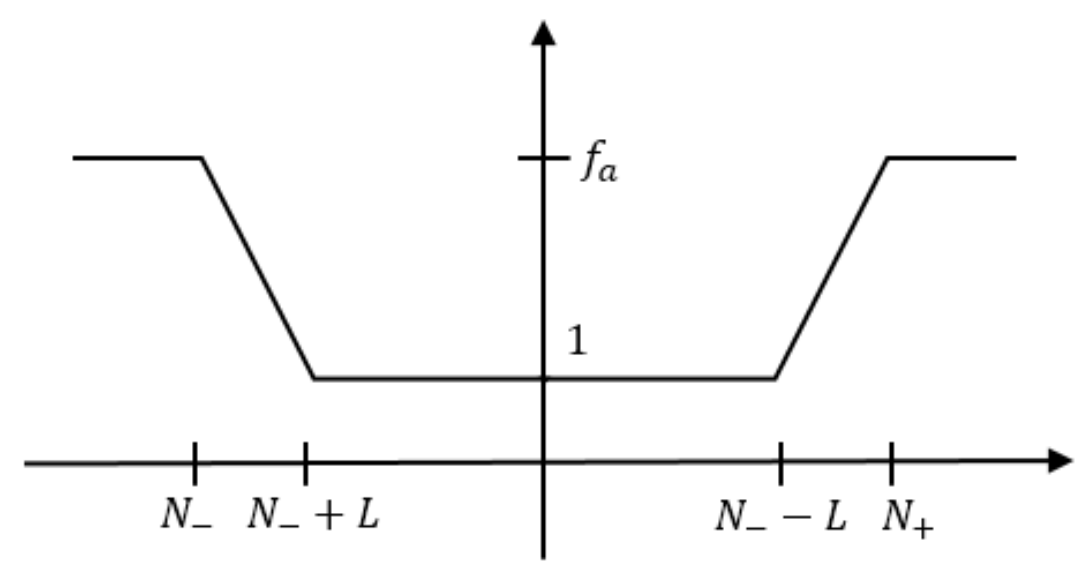

Figura 12 - Representação simplificada do controlador proposto por Campos.

Por sua vez, Sausen [28] propõe uma técnica de controle por banda similar à implementação de Nunes, com a substituição do controlador PI lento por um controlador PI cujos ganhos são determinados a partir de uma função afim, de certa forma hibridizando as ideias de Nunes e Campos.

Esses controladores têm em comum o fato de observarem apenas a variável de nível do vaso, o que torna o problema de controle significativamente mais difícil. Em situações onde medições das vazões de entrada e saída estão disponíveis, é possível utilizar a média móvel da vazão de entrada como valor de referência para um controlador da vazão de saída, simplificando significativamente este tipo de problema [29].

Outro aspecto comum de todas as técnicas apresentadas deve-se ao fato das mesmas implementarem suas não-linearidades por meio de modificações na estrutura dos controladores PID clássicos e não pela utilização de controladores inerentemente não lineares, como controladores fuzzy. 


\subsubsection{9. Choking Estático}

A técnica conhecida como choking estático, que consiste no fechamento parcial da válvula choke a jusante do riser, é o método mais largamente utilizado na indústria do petróleo para supressão da formação de golfadas em risers [3], tendo sido sugerida originalmente por Schmidt [30].

O princípio de funcionamento desta técnica é baseado em dois fenômenos que se intensificam a medida que a válvula choke é fechada. O primeiro é um aumento das pressões de operação, que causam a diminuição da compressibilidade do sistema, tornando-o mais estável. O segundo fenômeno é um aumento da queda de pressão por atrito ao longo da válvula choke sempre que houver aumento na vazão de saída do riser, causando um efeito estabilizante adicional.

Esta técnica é muito popular devido a sua simplicidade de aplicação, pois não exige a instalação de equipamentos adicionais às instalações submarinas ou de superfície e também não depende do desenvolvimento e sintonia de algoritmos de controle.

No entanto, a utilização desta técnica possui uma grande desvantagem, que é o aumento das pressões na cabeça do poço, fazendo com que as vazões de óleo e gás produzidos sejam reduzidas significativamente, implicando em perdas financeiras.

\subsubsection{0. Choking Dinâmico}

A técnica de choking dinâmico consiste na manipulação contínua da abertura da válvula choke por um controlador em malha fechada, que é realimentado por uma ou mais variáveis do sistema.

Os controladores que executam esta função são costumeiramente chamados de "Controladores Anti-Golfada" e possuem a interessante característica de estabilizar um regime de escoamento não-oscilatório nas mesmas condições de contorno em que ocorreriam golfadas caso não houvesse controle [4]. 
A ideia de estabilizar escoamento em condições de contorno instáveis pode ser melhor entendida ao se observar, na Figura 13, o diagrama de bifurcação de Hopf da pressão da flowline de um sistema de produção sujeito a golfadas.

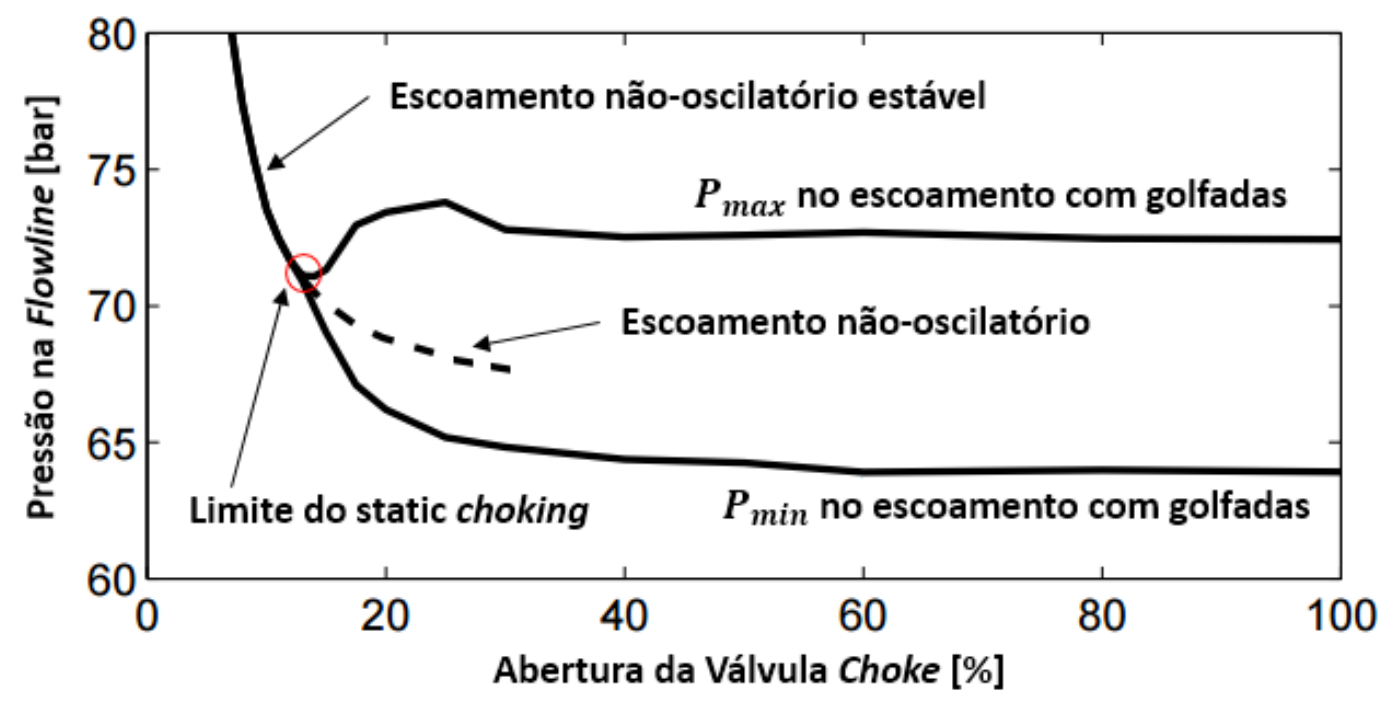

Figura 13 - Diagrama de bifurcação de Hopf para um sistema flowline-riser (Adapatado de [4]).

Neste diagrama, pode ser observado que, para aberturas da choke inferiores a um certo valor crítico - cerca de $13 \%$-, o escoamento é inerentemente nãooscilatório. Este valor crítico representa o limite da técnica de choking estático.

Ao se operar este sistema sem controle ativo e com aberturas da choke maiores do que este valor crítico, golfadas severas surgem no sistema e a pressão da flowline começa a oscilar entre um valor alto, $P_{\max }$, e um valor baixo, $P_{\min }$. Estas duas pressões para cada abertura de choke são mostradas nas linhas contínuas do diagrama. No entanto, ao se utilizar controle ativo na válvula choke, é possível obter uma solução de regime permanente não oscilatória em aberturas de válvula que gerariam instabilidades em malha aberta. Estes pontos de operação são representados pela linha pontilhada no diagrama de Hopf.

É interessante notar que, além de eliminar as golfadas do sistema, a utilização de controle ativo na choke estabiliza o escoamento com uma pressão na flowline significativamente inferior à pressão mínima obtida com o choking estático, conforme indicado na Figura 13. Esta redução de pressão tem como consequência direta uma maior vazão de óleo e gás produzidos, aumentando a lucratividade do negócio. 
Embora as vantagens do controle ativo da válvula choke tenham sido verificados experimentalmente por Schmidt [30] e Hedne [31] em 1979 e 1990, respectivamente, nenhuma aplicação industrial dos algoritmos desenvolvidos foi divulgada até um ressurgimento do interesse nestas técnicas nas últimas duas décadas.

Em 1996, Courbot [5] apresentou um sistema automático que era capaz de prevenir golfadas em um sistema de produção localizado no campo de Dunbar, localizado no mar do Norte. O sistema fechava gradualmente a choke sempre que a pressão na base do riser fosse inferior a uma determinada pressão mínima, correspondente à pressão de pico durante um ciclo de golfada, evitando assim a sua formação. Embora este sistema prevenisse a formação de golfadas, o mesmo apenas automatizava a antiga estratégia de choking estático sem de fato ser capaz de estabilizar o escoamento em condições de contorno inerentemente instáveis [4].

A primeira demonstração explícita de um controlador capaz de estabilizar um ponto de operação instável em aplicação industrial foi apresentada por Havre [7] em uma revista técnica da $\mathrm{ABB}$, no ano de 2000. Nesta publicação, foram apresentados os resultados obtidos com a aplicação do controlador patenteado SlugCon ${ }^{\circledR}$ no campo de Valhall, localizado no mar do norte norueguês. Este controlador utilizava a abertura da válvula choke como variável manipulada e uma média de medições de pressão próximas ao poço como variável controlada. Um resultado até então inédito apresentado neste trabalho foi o fato de que golfadas voltavam a se formar no sistema sempre que o controlador era desligado e a válvula choke era mantida na última posição definida pelo algoritmo, confirmado a capacidade do controlador de estabilizar um ponto de operação instável.

Dalsmo [32] também obteve resultados promissores no campo de Brage, em 2002, com o mesmo controlador utilizado por Havre. Em seu trabalho, ele relata problemas de confiabilidade na medição da pressão na cabeça do poço, que implicaram no desligamento do controle automático, levando à recorrência de golfadas severas no sistema. Este problema é recorrente em medições submarinas (de fundo), já que os instrumentos são de difícil manutenção e não raramente estão indisponíveis.

Storkaas [4] foi um dos primeiros a realizar uma análise formal de um sistema de produção offshore sujeito a golfadas, em 2005. Para isto, utilizou-se da teoria de controle para realizar análises de estabilidade e controlabilidade do sistema, 
considerando a abertura da válvula choke como variável manipulada e diferentes grandezas como variável controlada. Um de seus resultados mais interessantes foi a confirmação teórica de que a melhor variável para ser utilizada no controle antigolfada é a pressão da flowline, em virtude da função de transferência correspondente não conter zeros no lado direto do plano complexo, o que caracteriza um sistema de fase mínima, mais facilmente controlado. Drengsig [33] havia chegado a esta mesma conclusão de forma experimental, indicando a pressão da flowline como variável ótima para controle.

Na conclusão de sua tese, Storkaas comenta que, quando apenas medições de topo estão disponíveis, como a pressão do gás no riser, limitações fundamentais do processo (fase não-mínima e baixo ganho) impedem a utilização de controladores anti-golfada SISO. No entanto, é ressaltado que talvez existam outras medidas físicas ou combinações não-lineares das medidas disponíveis que não possuam essas limitações fundamentais, permitindo o desenvolvimento de controladores anti-golfada SISO apenas com medidas de topo.

Muito possivelmente em virtude da dificuldade de se utilizarem grandezas de topo como variável controlada em algoritmos de controle anti-golfada, não existem muitos relatos de aplicações industriais bem-sucedidas de controladores que utilizem esta abordagem.

Uma notável exceção é o controlador desenvolvido na Universidade de Cranfield, o Inferential Slug Control (ISC®), patenteado em 2010 [34] e testado em um campo produtor no mar do Norte em 2011 [35]. O ISC é um controlador MISO (Multiple Input Single Output) que possui um número ajustável de entradas de topo e que possui como única saída a posição da válvula choke. Seu algoritmo é baseado na aplicação da técnica de Análise de Componentes Principais (PCA) às entradas do controlador, com o objetivo de sintetizar uma variável fictícia formada por uma combinação linear das entradas do controlador, que possui variância máxima durante a ocorrência de golfadas. Esta variável é chamada de Primeiro Componente Principal (PCP).

Após a aplicação do PCA, define-se um valor de referência (setpoint) para um controlador cuja variável controlada é esta grandeza fictícia. A saída deste controlador é dada pela regra de controle apresentada a seguir: 


$$
z(t)=z_{0}+k\left(\boldsymbol{W}^{T} \boldsymbol{X}(t)-R\right)
$$

em que:

$z(t)$ é a saída do controlador, abertura da choke.

$z_{0}$ é um valor de abertura da choke em que não ocorrem golfadas severas, determinado experimentalmente.

$\boldsymbol{X}(t)$ é o vetor das entradas utilizadas no controlador.

$W$ é um vetor de pesos da combinação linear que forma o PCP.

$R$ é o valor de referência do controlador em termos do PCP.

$k$ é o ganho do controlador.

Observando a equação de controle do ISC, pode-se concluir que o mesmo implementa um controlador proporcional puro em termos do primeiro componente principal (PCP).

Uma funcionalidade interessante deste controlador é que periodicamente o controlador aumenta o valor de $z_{0}$ e avalia se o sistema passou a apresentar golfadas severas. Caso sim, retorna-se $z_{0}$ ao valor anterior. Caso não, é realizada uma nova análise de componentes principais, para atualização dos valores de $\boldsymbol{R}$ e $\boldsymbol{W}$.

Analisando o controlador, percebe-se que a capacidade de regulação e, portanto, de estabilização de um ponto de operação instável é garantida pelo controlador proporcional. Já o aumento periódico da abertura da válvula choke replica a ação dos operadores ao utilizarem a técnica de choking estático, com abertura gradual da válvula até o limite de estabilidade do escoamento.

Este controlador foi inicialmente testado tanto por meio de um modelo computacional quanto por meio de ensaios experimentais em um laboratório de escoamento multifásico. Nestes ensaios foram utilizadas dez variáveis de entrada, entre pressões, vazões, níveis e emissões de raios gama. Os resultados foram positivos, com estabilização do escoamento e aumento da vazão produzida [34].

Mais recentemente, o algoritmo de controle foi testado em um campo no mar do Norte [35]. Foram utilizadas doze variáveis da planta de processo nesta implementação e o controlador foi capaz de reduzir a amplitude das golfadas pela metade, mesmo tendo que lidar com diversas perturbações que ocorreram na planta ao longo das 42 horas de teste. Além disso, os autores atribuem um aumento observado na produção do poço ao controlador. 


\section{4. Modelagem de um Sistema de Produção Offshore}

Uma das maiores dificuldades encontradas no desenvolvimento de controladores para plantas industriais é que, na maior parte das vezes, as plantas não estão disponíveis para a experimentação característica do processo de desenvolvimento, já que descontroles de processo oriundos de testes malsucedidos podem causar perdas financeiras ou até mesmo acidentes de alto potencial danoso. Dessa forma, um modelo computacional da planta em estudo é uma ferramenta de grande utilidade no desenvolvimento de algoritmos de controle, pois permite a realização de análises de desempenho dos algoritmos em diversas situações operacionais através de simulações numéricas, facilitando a realização de ajustes finos e possibilitando a validação do algoritmo antes da implementação em ambiente de produção.

No caso particular dos sistemas de produção de petróleo sujeitos a golfadas, é importante que o modelo da planta incorpore a natureza não-linear do processo de formação das golfadas em risers e seja capaz de realizar uma boa previsão de como as diversas variáveis do sistema influenciam nas características da golfada, como amplitude e frequência.

Os modelos que são classicamente utilizados para descrever escoamentos multifásicos são o Two Fluid, baseado no balanço de massa e momento para cada uma das fases, e o Drift Flux, baseado no balanço de massa para cada uma das fases e um balanço de momento combinado para todas as fases [3]. No entanto, ambos os modelos são baseados em equações diferenciais que precisam ser discretizadas espacialmente para a obtenção de uma solução numérica. Este processo gera um sistema de equações ordinárias de altíssima ordem e de difícil interpretação, dificultando o projeto de controladores [3]. Por esta razão, pesquisadores como Storkaas [4] e Di Meglio [36] propuseram modelos fenomenológicos específicos para sistemas de produção de petróleo, capazes de descrever a dinâmica destes sistemas por meio de um número pequeno de equações diferenciais ordinárias, obtidas a partir da aplicação de equações de conservação de massa e de escoamento. Um dos modelos mais utilizados em estudos acadêmicos é o de Storkaas, o Simplified Riser Model (SRM) [3, 28], descrito detalhadamente a seguir. 


\subsection{1. \\ Modelo Simplificado de Riser (SRM)}

O SRM é um modelo fenomenológico que descreve a dinâmica de formação das golfadas em um sistema flowline-riser sujeito a um escoamento bifásico formado por uma fase gasosa e uma fase líquida. Uma descrição completa do modelo pode ser encontrada na tese de doutorado de Storkaas [4].

$\mathrm{Na}$ Figura 14 e Tabela 1 são apresentadas as localizações espaciais e descrições dos principais parâmetros e variáveis que são utilizados no desenvolvimento do SRM, apresentado nesta seção

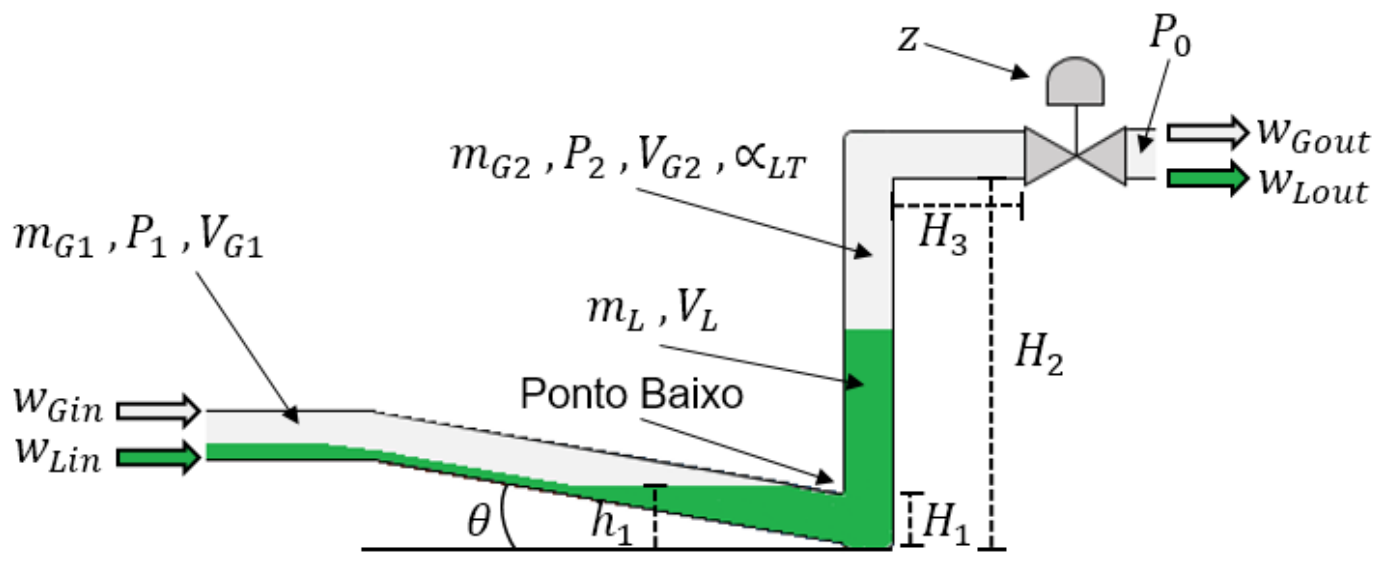

Figura 14 - Representação da localização espacial dos principais parâmetros e variáveis do SRM.

Tabela 1 - Descrição dos principais parâmetros e variáveis do SRM.

\begin{tabular}{c|c} 
Parâmetro & Descrição \\
\hline$w_{L i n}$ & Fluxo mássico de líquido na entrada da flowline \\
$w_{G i n}$ & Fluxo mássico de gás na entrada da flowline \\
$m_{G 1}$ & Massa do gás acumulado na flowline \\
$m_{G 2}$ & Massa do gás acumulado no riser \\
$m_{L}$ & Massa do líquido acumulado no sistema \\
$P_{1}$ & Pressão do gás na flowline \\
$P_{2}$ & Pressão do gás no riser \\
$V_{G 1}$ & Volume do gás na flowline \\
$V_{G 2}$ & Volume do gás no riser \\
$V_{L}$ & Volume do líquido no sistema \\
$\alpha_{L T}$ & Fração volumétrica de líquido na corrente de saída do riser \\
$Z$ & Abertura da válvula choke \\
$P_{0}$ & Pressão do vaso separador \\
$h_{1}$ & Diâmetro da tubulação \\
$H_{1}$ & Altura do riser \\
$H_{2}$ & Altura de líquido no ponto baixo da flowline \\
$\theta$ & Ângulo de inclinação da flowline
\end{tabular}




\subsubsection{1.}

\section{Premissas do Modelo}

O modelo é baseado nas seguintes premissas:

- A dinâmica do líquido na flowline é desprezada, isto é, admite-se que a velocidade do líquido é constante nessa seção.

- O volume de gás na flowline, $V_{G 1}$, é considerado constante, ocorrendo apenas variação de massa e pressão de gás.

- Somente um estado dinâmico de acúmulo de líquido, $m_{L}$, é considerado, contabilizando líquido no riser e no ponto baixo da flowline.

- São definidos dois estados dinâmicos para o acúmulo de gás: um na flowline, $m_{G 1}$, e outro no riser, $m_{G 2}$. Os volumes são conectados pelo escoamento de gás no ponto baixo da flowline.

- O gás tem comportamento ideal.

- Existe um balanço de pressão estacionário ao longo do riser.

- A vazão de saída através da choke é dada por uma equação de válvula simplificada.

- A temperatura do sistema é constante.

\subsubsection{2.}

\section{Equações de Estado do Modelo}

As três equações de estado do modelo são obtidas pela aplicação do princípio da conservação de massa às três variáveis de estado do sistema. São elas:

$$
\begin{gathered}
\dot{m}_{L}=w_{\text {Lin }}-w_{\text {Lout }} \\
\dot{m}_{G 1}=w_{G i n}-w_{G 1} \\
\dot{m}_{G 2}=w_{G 1}-w_{G o u t}
\end{gathered}
$$

em que:

$m_{L}$ é a massa de líquido acumulada no sistema. $[\mathrm{kg}]$

$w_{L i n}$ é a vazão mássica de entrada de líquido no sistema. $[\mathrm{kg} / \mathrm{s}]$ (Constante) 
$w_{\text {Lout }}$ é a vazão mássica de saída de líquido do sistema. $[\mathrm{kg} / \mathrm{s}]$

$m_{G 1}$ é a massa de gás acumulada na flowline. $[\mathrm{kg}]$

$w_{\text {Gin }}$ é a vazão mássica de entrada de gás no sistema. $[\mathrm{kg} / \mathrm{s}]$ (Constante)

$w_{G 1}$ é a vazão mássica de gás que flui da flowline para o riser. $[\mathrm{kg} / \mathrm{s}]$

$m_{G 2}$ é a massa de gás acumulada no riser. $[\mathrm{kg}]$

$w_{\text {Gout }}$ é a vazão mássica de saída de gás do sistema. $[\mathrm{kg} / \mathrm{s}]$

Embora as vazões de entrada sejam consideradas constantes, Storkaas comenta que o modelo também aceitaria vazões dependentes de pressão, representando melhor o comportamento de um poço.

\subsubsection{3.}

\section{Equações Internas do Modelo}

De posse das massas em cada região de acúmulo, são inicialmente calculadas as grandezas dadas pelas seguintes equações:

$$
\begin{gathered}
\mathrm{P}_{1}=\frac{m_{G 1} R T}{M_{g} V_{G 1}} \\
\rho_{G 1}=\frac{m_{G 1}}{V_{G 1}} \\
\mathrm{~V}_{\mathrm{L}}=m_{L} / \rho_{L}
\end{gathered}
$$

em que:

$P_{1}$ é a pressão do gás na flowline. $[\mathrm{Pa}]$

$R$ é a constante universal dos gases perfeitos. $[\mathrm{J} / \mathrm{K}$. mol $]$ (Constante)

$T$ é a temperatura do sistema. $[K]$ (Constante)

$M_{g}$ é massa molecular do gás. $[\mathrm{kg} / \mathrm{mol}]$. (Constante)

$V_{G 1}$ é o volume do gás na flowline. $\left[\mathrm{m}^{3}\right]$. (Constante)

$\rho_{G 1}$ é a densidade do gás na flowline. $\left[\mathrm{kg} / \mathrm{m}^{3}\right]$

$V_{L}$ é o volume de líquido total do sistema. $\left[\mathrm{m}^{3}\right]$

$\rho_{L}$ é a densidade do líquido. $\left[\mathrm{kg} / \mathrm{m}^{3}\right]$ (Constante)

Devido à premissa de balanço de pressão estacionário no riser, a seguinte relação hidrostática é válida: 


$$
\mathrm{P}_{1}-P_{2}=\bar{\rho} g H_{2}-\rho_{L} g h_{1}
$$

em que:

$P_{2}$ é a pressão do gás no riser. $[P a]$

$\bar{\rho}$ é a densidade média da mistura bifásica no riser. $\left[\mathrm{kg} / \mathrm{m}^{3}\right]$

$g$ é a aceleração gravitacional. $\left[\mathrm{m} / \mathrm{s}^{2}\right]$ (Constante)

$\mathrm{H}_{2}$ é a altura do riser. $[\mathrm{m}]$ (Constante)

$h_{1}$ é a altura de líquido no ponto baixo da flowline. [m]

Como a Equação (2.8) possui três variáveis ainda não determinadas $\left(P_{2}, \bar{\rho}, h_{1}\right)$, é necessário resolvê-la em conjunto com outras equações do modelo, dadas por:

$$
\begin{gathered}
P_{2}=\frac{m_{G 2} R T}{V_{G 2} M_{g}} \\
h_{1}=\frac{\left(V_{L}-V_{L R}\right)}{\frac{A_{1}}{\operatorname{sen}(\theta)}} \\
\bar{\rho}=\frac{\left(m_{G 2}+V_{L R} \rho_{L}\right)}{V_{T}} \\
V_{G 2}=V_{T}-V_{L R}
\end{gathered}
$$

em que:

$V_{G 2}$ é o volume do gás no riser. $\left[\mathrm{m}^{3}\right]$

$V_{L R}$ é o volume de líquido exclusivamente no riser. $\left[\mathrm{m}^{3}\right]$

$A_{1}$ é a área da seção transversal da flowline. $\left[\mathrm{m}^{2}\right]$ (Constante)

$\theta$ é o ângulo de inclinação da flowline. [ rad] (Constante)

$V_{T}$ é o volume total do riser. $\left[\mathrm{m}^{3}\right]$ (Constante)

A Equação (2.10) define a altura do líquido no ponto baixo da flowline por meio da razão entre o volume de líquido acumulado nesta tubulação e a área de sua secção horizontal. Sempre que essa altura, $h_{1}$, for maior do que o diâmetro da tubulação, $H_{1}$, o ponto baixo do riser está bloqueado, configurando a formação da golfada.

A Equação (2.11) é um cálculo direto de densidade média e a Equação (2.12) decorre do fato do riser estar totalmente preenchido por gás e líquido. 
Desenvolvendo-se o sistema formado pelas Equações (2.8) à (2.12), chega-se a uma equação de segundo grau em termos de $\bar{\rho}$, que, ao ser resolvida, possibilita a determinação das outras variáveis do sistema $\left(V_{L R}, h_{1}, V_{G 2}\right.$ e $\left.P_{2}\right)$ pela aplicação direta das Equações (2.11), (2.10), (2.12) e (2.9), respectivamente. Em seguida, essas variáveis são utilizadas para calcular a densidade do gás no riser, $\rho_{G 2}$, e a fração volumétrica de líquido no riser, $\alpha_{L}$, por meio das Equações (2.13) e (2.14), respectivamente.

$$
\begin{gathered}
\rho_{G 2}=\frac{m_{G 2}}{V_{G 2}} \\
\alpha_{L}=V_{L R} / V_{T}
\end{gathered}
$$

Uma vez concluída a determinação de todas as pressões, volumes, densidades e alturas, estas grandezas são utilizadas na modelagem do escoamento que ocorre no sistema.

\subsubsection{4.}

\section{Equações de Transporte do Modelo}

Como discutido anteriormente, sempre que o líquido estiver bloqueando o ponto baixo da flowline ( $h_{1}>H_{1}$, como representado na Figura 14), a vazão de gás da flowline para o riser é nula. Em outras palavras, não há transferência de massa entre $V_{G 1}$ e $V_{G 2}$.

Já quando o líquido não estiver bloqueando o ponto baixo $\left(h_{1}<H_{1}\right)$, o gás fluirá de $V_{G 1}$ para $V_{G 2}$ com uma taxa $w_{G 1}$. Storkaas sugeriu que esta vazão fosse modelada a partir de uma equação de válvula, visto que os dois parâmetros mais importantes que a definem são a diferença de pressão ao longo do ponto baixo e a área livre para escoamento, de forma semelhante a uma válvula. Foi proposta a utilização da razão $\left(H_{1}-h_{1}\right) / H_{1}$ como grau de abertura dessa válvula fictícia.

Agregando as duas situações descritas, pode-se equacionar a vazão de gás através do ponto baixo por meio da seguinte expressão:

$$
w_{G 1}=\left\{\begin{aligned}
K_{2} \hat{\mathrm{A}} \frac{H_{1}-h_{1}}{H_{1}} \sqrt{\rho_{G 1}\left(P_{1}-P_{2}-\rho_{L} g \alpha_{L} H_{2}\right)}, & h_{1}<H_{1} \\
0, & h_{1} \geq H_{1}
\end{aligned}\right.
$$


Na equação (2.15), $K_{2}$ é uma constante de sintonia do modelo e Â representa a seção transversal livre de líquido no ponto baixo, disponível para escoamento de gás. Como Â também é função também de $h_{1}$, essa "válvula" tem características de abertura quadrática.

Outro aspecto crucial do SRM é que ele dispensa a modelagem da distribuição espacial das fases do escoamento ao longo do riser, fazendo uso de uma abordagem mais simples ao definir uma equação de carregamento, que determina a fração de líquido na corrente de saída do riser, $\propto_{L T}$, que é limitada por dois extremos:

- $\propto_{L T}=\propto_{L T}^{*}$ : é o extremo inferior, que ocorre quando o líquido bloqueia o escoamento de gás para o riser $\left(w_{G 1}=0\right)$. Na maioria dos casos, $\propto_{L T}^{*}=0$, pois haverá apenas gás saindo do riser, como mostrado na Figura 14. No entanto, caso a parcela vertical do riser esteja totalmente inundada por líquido, $\propto_{L T}^{*}$ pode ser maior do que zero.

- $\propto_{L T}=\propto_{L}$ : é o extremo superior, que ocorre quando a velocidade do gás, $w_{G 1}$, é muito alta, situação na qual a fração de líquido na corrente de saída é considerada igual à fração volumétrica de líquido no riser.

Storkaas argumenta que a transição entre esses dois extremos deve ser suave, conforme a velocidade do gás, $w_{G 1}$, aumenta. Dessa forma, foram definidas as seguintes equações para modelar o carregamento no riser:

$$
\begin{gathered}
\propto_{L T}=\propto_{L T}^{*}+\frac{q^{n}}{1+q^{n}}\left(\propto_{L}-\propto_{L T}^{*}\right) \\
\propto_{L T}^{*}=\left\{\begin{array}{cc}
0, & V_{L R} \leq H_{2} A_{2} \\
\frac{V_{L R}-A_{2} H_{2}}{A_{2} L_{3}}, & V_{L R}>H_{2} A_{2}
\end{array}\right. \\
q=\frac{K_{3} \rho_{G 1}\left(\frac{w_{G 1}}{\rho_{G 1} \hat{\mathrm{A}}}\right)^{2}}{\rho_{L}-\rho_{G 1}}
\end{gathered}
$$

em que:

$n$ é um parâmetro de sintonia que determina a suavidade da transição. (Constante) $A_{2}$ é a área da seção transversal do riser. $\left[\mathrm{m}^{2}\right]$ (Constante) $L_{3}$ é o comprimento da seção horizontal do riser. $[m]$. (Constante) $K_{3}$ é um parâmetro de sintonia do modelo de carregamento. $\left[\mathrm{s}^{2} / \mathrm{m}^{2}\right]$ (Constante) 
Analisando as equações, percebe-se que, caso a vazão $w_{G 1}$ seja nula, $q$ também será nulo, fazendo com que a fração de líquido que sai do riser seja nula, a não ser que este esteja inundado $\left(V_{L R}>H_{2} A_{2}\right)$. Neste caso, a fração de líquido será proporcional ao nível do líquido na parte horizontal do riser.

Por outro lado, se a vazão $w_{G 1}$ for muito alta, pode-se observar que a Equação (2.16) degenera em $\propto_{L T}=\propto_{L}$, ou seja, a fração de líquido na corrente de saída torna-se igual à fração de líquido no riser, como esperado.

Com a fração volumétrica de líquido na corrente de saída definida, são calculadas as seguintes grandezas:

$$
\begin{gathered}
\rho_{T}=\propto_{L T} \rho_{L}+\left(1-\propto_{L T}\right) \rho_{G 2} \\
\propto_{L}^{m}=\frac{\propto_{L T} \rho_{L}}{\propto_{L T} \rho_{L}+\left(1-\propto_{L T}\right) \rho_{G 2}}
\end{gathered}
$$

em que:

$\rho_{T}$ é a densidade da corrente de saída do riser. $\left[\mathrm{kg} / \mathrm{m}^{3}\right]$

$\propto_{L}^{m}$ é a fração mássica de líquido na corrente de saída do riser. [-]

Por fim, são computadas a vazão mássica da corrente que deixa o riser por meio da Equação (2.21), que modela o comportamento da válvula choke, e as vazões mássicas de cada uma das fases, por meio das Equações (2.22) e (2.23).

$$
\begin{gathered}
w_{\text {out }}=z K_{1} \sqrt{\rho_{T}\left(P_{2}-P_{0}\right)} \\
w_{\text {Lout }}=\propto_{L}^{m} w_{\text {out }} \\
w_{\text {Gout }}=\left(1-\propto_{L}^{m}\right) w_{\text {out }}
\end{gathered}
$$

em que:

$w_{\text {out }}$ é a vazão mássica da corrente de saída. $\left[\mathrm{kg} / \mathrm{m}^{3}\right]$

$z$ é a abertura da válvula choke. [\%]

$K_{1}$ é a constante de vazão da válvula . $\left[\mathrm{m}^{-2}\right]$ (Constante)

$P_{0}$ é a pressão do vaso separador. $[P a]$ (Constante)

$w_{\text {Lout }}$ é a vazão mássica de líquido que deixa o riser. $\left[\mathrm{kg} / \mathrm{m}^{3}\right]$

$w_{\text {Gout }}$ é a vazão mássica de gás que deixa o riser. $\left[\mathrm{kg} / \mathrm{m}^{3}\right]$ 
Determinados $w_{\text {Lout }}$ e $w_{\text {Gout }}$, o sistema flowline-riser fica totalmente definido, pois todas as pressões, densidades e vazões se tornam conhecidas. Com essas variáveis, pode-se determinar as derivadas das três variáveis de estado, $\dot{m}_{L}, \dot{m}_{G 1} \mathrm{e}$ $\dot{m}_{G 2}$, permitindo a realização de uma integração numérica que computa o próximo estado do sistema, para o qual todo o processo descrito nesta seção é repetido.

\subsubsection{5.}

\section{Sintonia do Modelo}

O modelo de Storkaas possui cinco parâmetros que podem ser utilizados para sintonizar o modelo: $K_{3}$ e $n$ nas equações de carregamento (2.16) e (2.18), $K_{2}$ na equação da vazão de gás no ponto baixo (2.15), $K_{1}$ na equação da válvula choke (2.21) e $V_{G 1}$ na equação de pressão do gás na flowline (2.6).

A determinação destes parâmetros deve ser feita com base em um conjunto de dados de operação, que podem ser obtidos em um sistema industrial real, em um experimento laboratorial ou em um software de simulação de escoamento.

O método de sintonia proposto por Storkaas baseia-se no fato de que um sistema flowline-riser possui um par de autovalores complexos puros no ponto de bifurcação de Hopf, no qual ocorre a transição de escoamento estável para instável. Esse fato restringe o espaço de soluções para a solução estacionária no ponto de bifurcação, facilitando a determinação dos parâmetros de sintonia.

Para aplicação do método, o primeiro passo é identificar no conjunto de dados o ponto de bifurcação do sistema, utilizando-se duas medições, como $P_{1}$ e $P_{2}$, para fixar dois graus de liberdade na solução estacionária do sistema. Em seguida arbitrase um valor para $h_{1}$ entre 0 e $H_{1}$ e itera-se o valor de $n$ até que o sistema admita dois autovalores complexos puros. Por fim, determinam-se os valores de $K_{1}, K_{2}$ e $K_{3}$ da solução estacionária do sistema.

O processo de sintonia garante que a bifurcação do modelo simplificado ocorra para a mesma abertura de choke obtida no sistema em que foram coletados os dados de referência, mas não garante um comportamento similar fora deste ponto. Por esta razão, os resultados do modelo para outros pontos de operação devem ser comparados com os dados de referência e, caso haja desvio significativo, um novo processo de sintonia deve ser realizado com a arbitragem de novos valores para $h_{1}$ e, se necessário, $V_{G 1}$. 


\subsubsection{6.}

\section{Validação do Modelo}

Para verificação de validade, o modelo foi ajustado a partir dos resultados obtidos em dois ensaios distintos, o primeiro realizado em laboratório e o segundo realizado em um software de simulação de escoamento multifásico.

O ensaio de laboratório foi realizado pela Statoil no Laboratório de Fluxo Multifásico e Pesquisa em Petróleo (SINTEF), na Noruega. O arranjo deste experimento foi composto por uma tubulação de 200 metros de comprimento levemente inclinada, flowline, conectada a uma tubulação vertical, riser, de 15 metros de altura com uma válvula de controle em sua saída, modelando a choke.

Verificou-se que o modelo SRM ajustado aos dados experimentais foi capaz de descrever satisfatoriamente a dinâmica do sistema em malha aberta e fechada. Além disso, os ganhos ótimos do controlador desenvolvido com base no modelo foram praticamente os mesmos ganhos ótimos encontrados no trabalho experimental, confirmando a utilidade do modelo no desenvolvimento de controladores.

O modelo também foi ajustado aos resultados obtidos por meio de um ensaio realizado no software comercial OLGA ${ }^{\circledR}$, amplamente utilizado pela indústria de petróleo para análise de escoamento multifásico em sistemas de produção [37]. Os parâmetros que descrevem o sistema de produção simulado no OLGA estão listados na Tabela 2.

$\mathrm{Na}$ Tabela 3, são mostradas as principais medidas operacionais do sistema em seu ponto crítico, correspondente a uma abertura de 13\% da válvula choke. Nota-se que, devido ao princípio de conservação da massa, as vazões de saída são iguais às de entrada em toda solução estacionária estável.

Tabela 2 - Parâmetros do sistema utilizados no OLGA®.

\begin{tabular}{c|c|c} 
Parâmetro & Valor & Descrição \\
\hline$w_{\text {Lin }}$ & $8,64 \mathrm{~kg} / \mathrm{s}$ & Fluxo mássico de líquido na entrada da flowline \\
$w_{\text {Gin }}$ & $0,36 \mathrm{~kg} / \mathrm{s}$ & Fluxo mássico de gás na entrada da flowline \\
$r$ & $0,06 \mathrm{~m}$ & Raio da flowline e do riser \\
$H_{2}$ & $300 \mathrm{~m}$ & Altura do riser \\
$L_{1}$ & $4300 \mathrm{~m}$ & Comprimento horizontal da flowline \\
$L_{3}$ & $100 \mathrm{~m}$ & Comprimento da seção horizontal do riser \\
$P_{0}$ & $5 \mathrm{MPa}$ & Pressão a jusante da válvula choke \\
$\rho_{L}$ & $750 \mathrm{~kg} / \mathrm{m}^{3}$ & Densidade do líquido \\
$\theta$ & $0,274 \mathrm{rad}$ & Declividade da flowline
\end{tabular}


Tabela 3 - Dados do ponto de operação crítico.

\begin{tabular}{c|c|c} 
Variável & Valor & Descrição \\
\hline$z^{\text {crit }}$ & $13 \%$ & Abertura crítica do choke \\
$P_{1}^{\text {crit }}$ & $7,17 \mathrm{MPa}$ & Pressão do gás na flowline \\
$P_{2}^{\text {crit }}$ & $5,35 \mathrm{MPa}$ & Pressão do gás no riser \\
$w_{\text {Lout }}^{\text {crit }}$ & $8,64 \mathrm{~kg} / \mathrm{s}$ & Fluxo mássico de líquido na saída do riser \\
$w_{\text {Gout }}^{\text {rit }}$ & $0,36 \mathrm{~kg} / \mathrm{s}$ & Fluxo mássico de gás na saída do riser
\end{tabular}

Após a sintonia, o modelo SRM foi utilizado na simulação do sistema para diferentes aberturas da válvula choke, sem controle e com controle da pressão da flowline, $P_{1}$. Os resultados obtidos nestes ensaios foram utilizados para gerar o diagrama de bifurcação de $P_{1}$, mostrado na Figura 15 , em que o mesmo é comparado aos diagramas obtidos por meio do modelo de referência (OLGA) e por meio do modelo two-fluid.

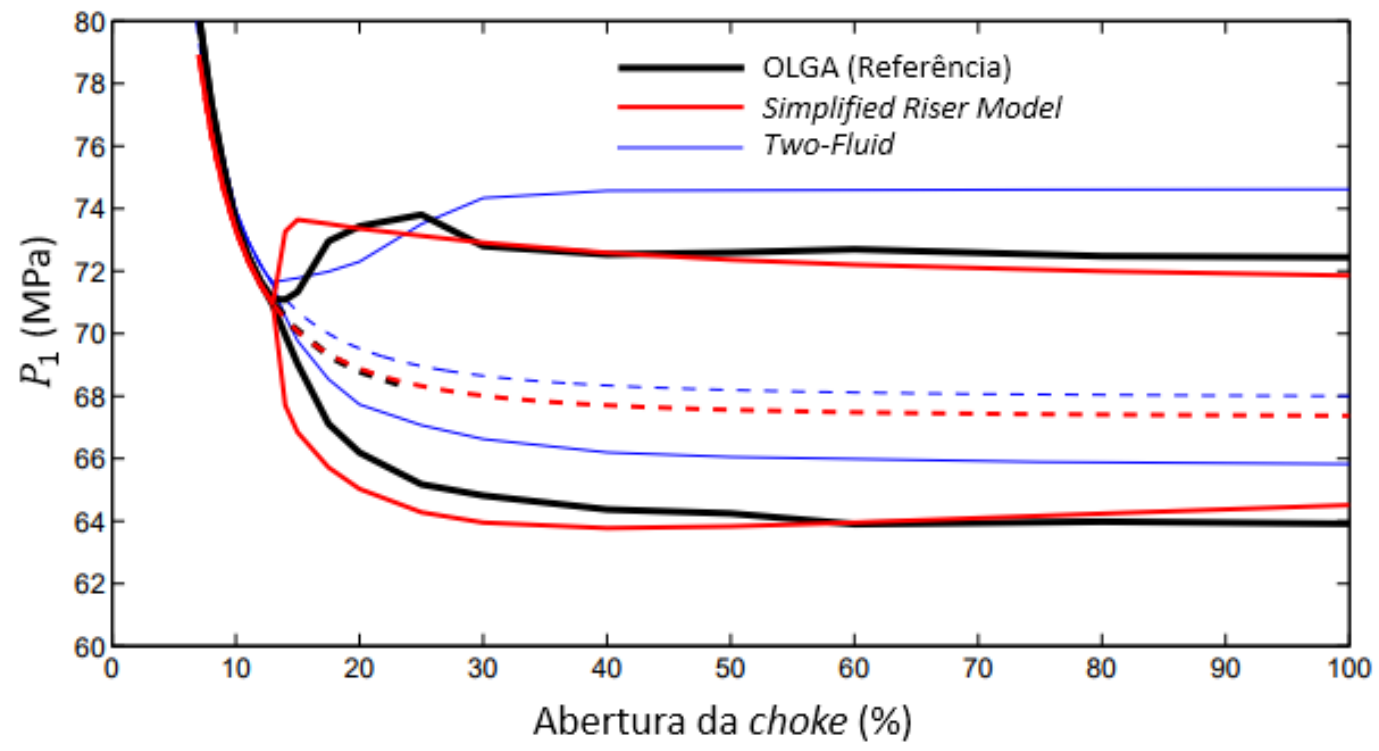

Figura 15 - Diagrama de bifurcação de $P_{1}$, obtidos por meio de três modelos: OLGA (referência), Simplified Riser Model (SRM) e Two-Fluid. (Adapatado de [4]).

Como pode ser observado no diagrama, o SRM ajustou-se bem aos dados de referência, confirmando a viabilidade de sua utilização no projeto de controladores. Por esta razão, ele tem sido amplamente empregado no desenvolvimento de controladores anti-golfada por diversos pesquisadores [3, 28, 38] e também será utilizado neste trabalho. 


\subsubsection{7. Modificações do SRM}

O SRM, apresentado na seção anterior, é comumente modificado por pesquisadores, que veem necessidade de acrescentar ou aprimorar algum aspecto do modelo original para utilização em seus estudos.

Sausen [28] propôs acoplar ao SRM um modelo de separador cilíndrico horizontal após a válvula choke, que recebe a mistura proveniente do riser e a separa em dois fluxos distintos, que são exportados através de válvulas de líquido e de gás. Esta alteração torna o SRM mais semelhante ao modelo simplificado apresentado na Figura 2.

Este acoplamento resultou na adição de mais dois estados ao modelo: o nível de líquido no separador e a pressão do separador, cujas equações são mostradas a seguir:

$$
\begin{gathered}
\dot{N}=\frac{\sqrt{r_{S}^{2}-\left(r_{s}-N\right)^{2}}}{2 H_{S} \rho_{L} N\left(3 r_{S}-2 N\right)}\left(w_{\text {Lout }}-w_{\text {LSout }}\right) \\
\dot{P}_{0}=\frac{\rho_{L} R T M_{G}^{-1}\left(w_{G o u t}-w_{G S o u t}\right)+P_{0}\left(w_{\text {Lout }}-w_{\text {LSout }}\right)}{\rho_{L}\left(V_{S}-V_{L S}\right)}
\end{gathered}
$$

em que:

$N$ é o nível de líquido no separador. $[m]$

$r_{s}$ é o raio da seção transversal do separador. [m] (Constante)

$H_{s}$ é o comprimento do separador. $[m]$ (Constante)

$w_{L S o u t}$ é a vazão de saída de líquido do separador. $[\mathrm{kg} / \mathrm{s}]$

$P_{0}$ é a pressão do gás no separador. $[P a]$

$w_{G S o u t}$ é a vazão de saída de gás do separador. $[\mathrm{kg} / \mathrm{s}]$

$V_{S}$ é o volume do vaso separador. $\left[\mathrm{m}^{3}\right]$ (Constante)

$V_{L S}$ é o volume de líquido no vaso separador. $\left[\mathrm{m}^{3}\right]$ (Constante)

Esta modificação foi necessária para viabilizar o desenvolvimento de um controlador que atenue as golfadas utilizando a capacitância do vaso separador, como discutido na seção 2.3.3.8. 
Por sua vez, Ogazi [3] propôs acoplar ao SRM modelos de um separador cilíndrico vertical e de um poço produtor, cuja vazão produzida aumenta linearmente com a diminuição da pressão da flowline.

A inclusão do separador vertical também acerretou na adição de dois estados ao modelo, os mesmos definidos por Sausen. No entanto, como o separador vertical possui seção transversal constante, a equação de estado do nível do separador é significativamente mais simples, dada por:

$$
\dot{N}=\frac{w_{\text {Lout }}-w_{\text {LSout }}}{\pi r_{S}^{2} \rho_{L}}
$$

A adição do poço linear ao modelo permitiu a verificação de ganhos de produção decorrentes da aplicação de diferentes estratégias de controle [39]. A equação utilizada por Ogazi para modelagem do poço linear é dada por:

$$
w_{\text {in }}=k\left(P_{\text {res }}-P_{1}\right)
$$

em que:

$w_{\text {in }}$ é a vazão total do poço. $[\mathrm{kg} / \mathrm{s}]$

$k$ é a constante de produtividade do poço. $[\mathrm{kg} / \mathrm{sPa}]$ (Constante)

$P_{\text {res }}$ é a pressão do reservatório. (Constante)

$P_{1}$ é a pressão na cabeça do poço. [MPa]

Além do acoplamento dos modelos de poços e separador, Ogazi também propôs modificações na equação de carregamento e uma modelagem dinâmica do volume ocupado pelo gás na flowline, $V_{G 1}$. Ogazi chamou modelo obtido após estas alterações de Improved Simplified Riser Model (ISRM). 


\section{3. \\ Desenvolvimento do Modelo de Processo}

Neste trabalho, o Simplified Riser Modelo (SRM), detalhado no capítulo anterior, é utilizado como base para o desenvolvimento de um modelo que contém todos os principais elementos de um sistema de produção offshore, representado na Figura 2, repetida abaixo sob nova numeração (Figura 16) por conveniência.

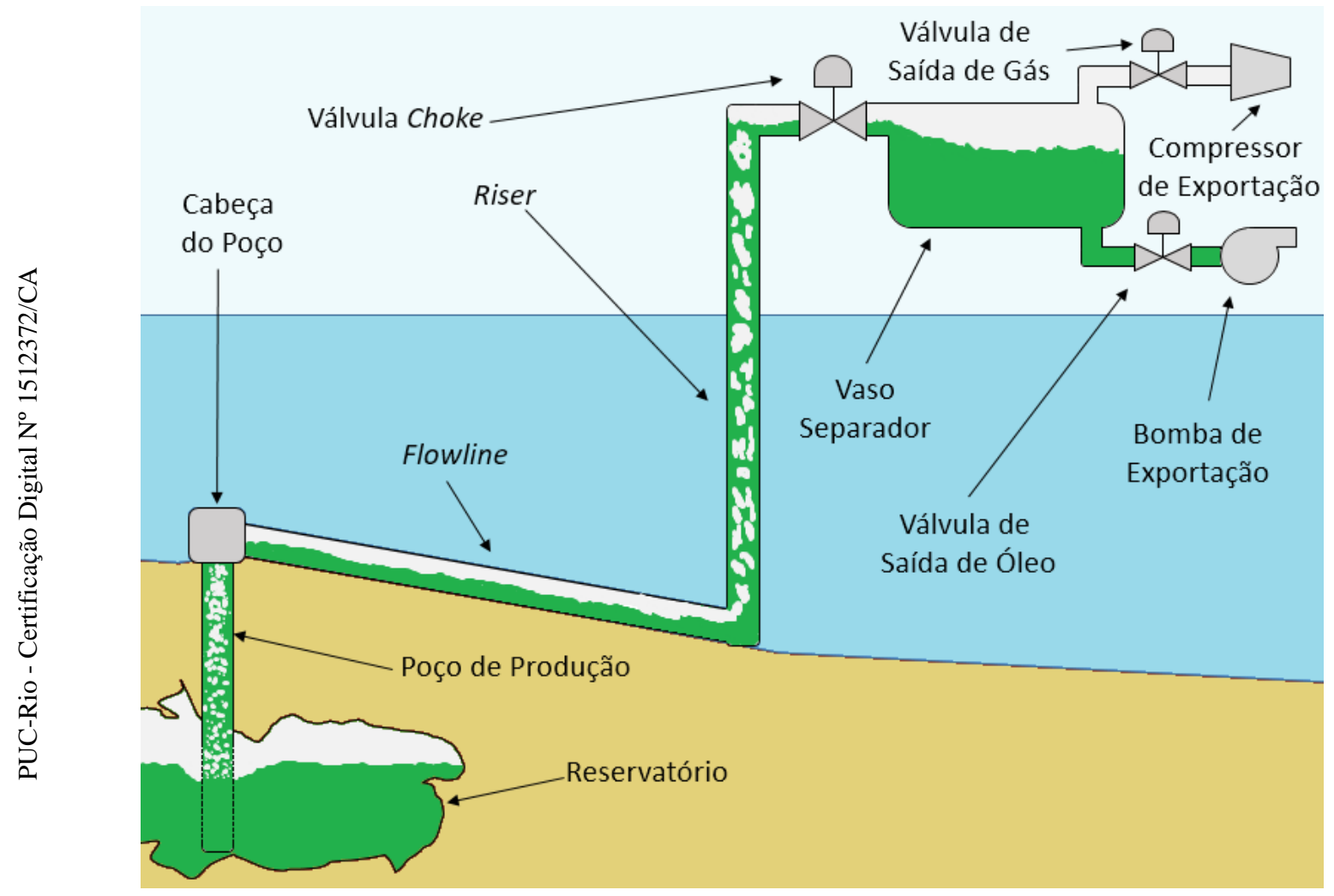

Figura 16 - Diagrama simplificado de um sistema de produção offshore.

Além das equações do SRM que modelam a dinâmica do conjunto flowlineriser-choke, o modelo desenvolvido neste trabalho engloba equações que descrevem o comportamento do poço produtor e a dinâmica do vaso separador horizontal, aumentando a capacidade de representação do modelo.

O processo de desenvolvimento dos modelos de poço e de separador são discutidos no início deste capítulo, enquanto as seções finais apresentam os resultados obtidos em diversos ensaios realizados a fim de se adquirir maior 
entendimento sobre o sistema, visando o desenvolvimento de estratégias de controle mitigadoras de golfada.

Com objetivo de possibilitar a comparação de resultados, adotou-se a mesma parametrização utilizada no segundo estudo de caso de Storkaas, apresentada na Tabela 2. Além disso, as condições de contorno constantes do SRM $\left(w_{L i n}, w_{\text {Gin }} \mathrm{e}\right.$ $P_{0}$ ), que se tornaram variáveis dinâmicas com a inclusão de modelos para o poço e para o separador, foram utilizadas como valores de referência na parametrização destes modelos, garantido que as pressões e vazões do sistema se situassem na mesma faixa de valores daquelas observadas no estudo de caso em questão.

\section{1. Desenvolvimento do Modelo do Poço Produtor}

Além de aumentar a semelhança entre o modelo matemático e os sistemas de produção reais, a inserção de um modelo de poço produtor ao SRM permite que sejam verificados ganhos ou perdas de produção em função da mudança de parâmetros operacionais ou da adoção de novas estratégias de controle. Desta forma, será possível verificar as alegações de diversos autores que indicam um aumento de produção decorrente da aplicação de controladores anti-golfada. Como estes ganhos de produção ocorrem em virtude da conhecida relação inversa entre pressão na cabeça do poço e vazão produzida, é de se esperar que controladores capazes de reduzir a pressão média na cabeça dos poços também sejam capazes de aumentar a vazão produzida.

O modelo de poço discutido na revisão bibliográfica, proposto por Ogazi e descrito pela Equação (2.27), apresenta o problema de que sua variável independente é a pressão no fundo do poço, $P_{w f}$, a qual não está disponível no SRM, que modela apenas a pressão na cabeça do poço, $P_{1}$. Além disso, a diferença de pressão entre $P_{1}$ e $P_{w f}$ é função da vazão de produção, que por sua vez é função de $P_{1}$, dificultando a aplicação direta do modelo ao SRM.

Com objetivo de determinar a relação entre a vazão total do poço, $w_{i n}$, e a pressão na cabeça poço, $P_{1}$, foi realizada uma simulação por meio do software MARLIM (Multiphase Flow and Artificial Lift Modelling), desenvolvido pela Petrobras para estudar o comportamento dos poços do campo de Marlim. 
Os parâmetros utilizados nesta simulação, mostrados na Tabela 4, foram determinados através de uma combinação de valores usuais para os poços do campo de Marlim e de parâmetros utilizados no estudo de caso de Storkaas, como a massa molecular do gás, densidade do óleo e fração de água e sedimentos (BSW).

Tabela 4 - Parâmetros de simulação de poço no software MARLIM.

\begin{tabular}{c|c} 
Parâmetro & Valor \\
Tipo de poço & Vertical \\
Comprimento do poço & $3000 \mathrm{~m}$ \\
Diâmetro interno da coluna de produção & $5 \%$ \\
Correlação de escoamento no poço & Duns \& Ross \\
Equação de produção do poço & Vogel \\
Densidade do óleo & $750 \mathrm{~kg} / \mathrm{m}^{3}$ \\
Densidade relativa do gás (em relação ao ar) & 0,652 \\
Fração de água e sedimentos (BSW) & $0 \%$
\end{tabular}

A equação de Vogel, referida na Tabela 4, relaciona a vazão do poço e a pressão no fundo do poço, sendo dada por:

$$
w_{T}=w_{i n}^{\operatorname{Max}}\left(1-0,2\left(\frac{P_{f}}{P_{e}}\right)-0,8\left(\frac{P_{f}}{P_{e}}\right)^{2}\right)
$$

em que:

$w_{T}$ é a vazão total do poço. $[\mathrm{kg} / \mathrm{s}]$

$w_{\text {in }}^{\text {Max }}$ é a vazão máxima teórica do poço, para uma $P_{f}$ nula. $[\mathrm{kg} / \mathrm{s}]$ (Constante)

$P_{e}$ é a pressão estática do reservatório. [bar] (Constante)

$P_{f}$ é a pressão dinâmica no fundo do poço. [bar]

Para definição das constantes da Equação (3.1), o software requer o estabelecimento de condições de contorno, com vazões e pressões do sistema para um determinado ponto de operação. Dessa foram, foram utilizadas as condições de contorno do segundo estudo de caso de Storkaas, apresentadas na Tabela 3 e um IPR (Índice de Produtividade do Poço) de $25 \mathrm{~m}^{3} . \mathrm{cm}^{2} /($ dia.kgf), típico dos poços de Marlim. Essas condições de contorno são resumidas na Tabela 5.

Tabela 5 - Condições de contorno da simulação de poço no software MARLIM.

\begin{tabular}{c|c} 
Parâmetro & Valor \\
\hline Vazão de óleo & $8,64 \mathrm{~kg} / \mathrm{s}$ \\
Vazão de gás & $0,36 \mathrm{~kg} / \mathrm{s}$ \\
IPR aparente & $25 \mathrm{~m}^{3} \cdot \mathrm{cm}^{2} /(\mathrm{dia} \cdot \mathrm{kgf})$ \\
Pressão na cabeça do poço & $71,7 \mathrm{bar}$
\end{tabular}


Com os parâmetros e as condições de contorno definidos, realizou-se a simulação do sistema para diferentes pressões na cabeça do poço, $P_{1}$. As vazões obtidas para cada uma destas pressões são mostradas na Tabela 6 , onde se pode notar que a condição de contorno do estudo de caso, marcada em cinza, foi respeitada.

Tabela 6 - Vazões obtidas através da simulação do poço no software MARLIM.

\begin{tabular}{c|c|c|c}
$\boldsymbol{P}_{\mathbf{1}}(\mathbf{b a r})$ & $\boldsymbol{w}_{\boldsymbol{L}}(\boldsymbol{k g} / \boldsymbol{s})$ & $\boldsymbol{w}_{\boldsymbol{G}}(\boldsymbol{k g} / \boldsymbol{s})$ & $\boldsymbol{w}_{\boldsymbol{T}}(\boldsymbol{k g} / \boldsymbol{s})$ \\
\hline 60,0 & 11,15 & 0,47 & 11,61 \\
65,0 & 10,21 & 0,43 & 10,63 \\
67,0 & 9,56 & 0,40 & 9,96 \\
69,0 & 9,24 & 0,39 & 9,63 \\
71,0 & 8,92 & 0,37 & 9,29 \\
71,7 & 8,64 & 0,36 & 9,00 \\
73,0 & 8,43 & 0,35 & 8,78 \\
75,0 & 8,11 & 0,34 & 8,44 \\
80,0 & 6,94 & 0,29 & 7,23
\end{tabular}

Ao se analisarem os dados da Tabela 6, é possível notar duas características importantes:

- A relação gás-óleo, $w_{L} / w_{g}$, é constante em todos os pontos do ensaio.

- Existe uma relação aproximadamente linear entre a pressão na cabeça do poço e as vazões do sistema.

Por este motivo, propõe-se as seguintes equações para modelar a vazão do poço a partir da pressão na sua cabeça:

$$
\begin{gathered}
w_{T}=k_{p}\left(P_{r a}-P_{1}\right) \\
w_{L}=f_{L} w_{T} \\
w_{G}=f_{G} w_{T}
\end{gathered}
$$

em que:

$w_{T}$ é a vazão total do poço. $[\mathrm{kg} / \mathrm{s}]$

$k_{p}$ é a constante de produtividade do poço. $[\mathrm{kg} /$ (s. bar $\left.)\right]$ (Constante)

$P_{r a}$ é a pressão estática aparente do reservatório. [bar] (Constante)

$f_{L}$ é a fração mássica de líquido no fluído produzido. (Constante)

$f_{G}$ é a fração mássica de gás no fluído produzido. (Constante)

$P_{1}$ é a pressão na cabeça do poço. [bar] 
Os parâmetros encontrados no ajuste destas curvas são mostrados na Tabela 7 e um gráfico com a representação do ajuste linear proposto é mostrado na Figura 17, em que pode ser observada a adequação da suposição de relação linear entre as variáveis, com $R^{2}$ de 0,9934 .

Tabela 7 - Parâmetros do modelo de poço utilizado no trabalho.

\begin{tabular}{c|c|c} 
Parâmetro & Valor & Descrição \\
\hline$P_{r a}$ & 112,4747 bar & Pressão estática aparente do reservatório \\
$k_{p}$ & $0,2207 \mathrm{~kg} /(\mathrm{s}$. bar $)$ & Constante de produtividade do poço \\
$f_{L}$ & 0,9598 & Fração de líquido no fluído produzido \\
$f_{G}$ & 0,0402 & Fração de gás no fluído produzido
\end{tabular}

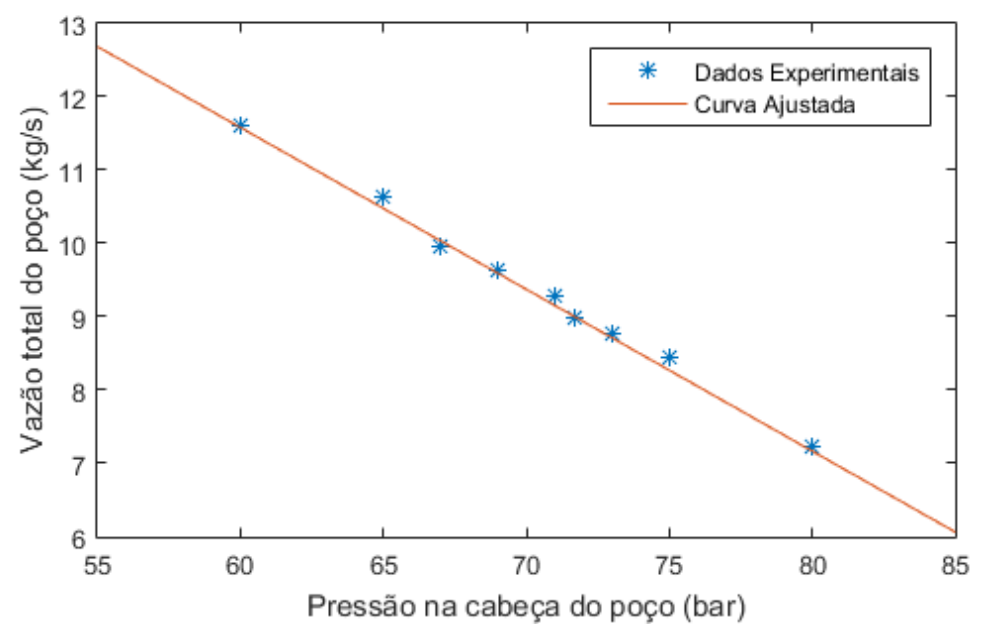

Figura 17 - Ajuste do modelo proposto aos dados obtidos através do simulador MARLIM.

Em uma primeira análise, a formalização matemática apresentada pode parecer idêntica à proposta por Ogazi [3], apresentada na Equação (2.27). No entanto, há uma diferença sutil, mas relevante: a equação de Ogazi é definida em termos da pressão de fundo do poço, $P_{w f}$, não modelada pelo SRM, enquanto o modelo proposto é definido em termos da pressão na flowline, $P_{1}$, disponível. Esta diferença fica clara ao se comparar a pressão estática do reservatório, $P_{e}$, obtida durante a simulação, com a pressão estática aparente, $P_{r a}$, obtida através do ajuste linear. Enquanto a primeira é da ordem de 290 bar, a segunda é de 112 bar. A diferença entre estas pressões corresponde à perda de carga devido à elevação do fluído ao longo dos 3000 metros de poço.

Definido o modelo, este pode ser acoplado ao SRM considerando $w_{L i n}=w_{L} \mathrm{e}$ $w_{\text {Gin }}=w_{G}$ por meio das Equações (3.2), (3.3) e (3.4). Esta abordagem elimina a necessidade de descrever a dinâmica de escoamento no poço. 


\section{2. \\ Desenvolvimento do Modelo do Vaso Separador}

No SRM, considera-se que a pressão do vaso separador, $P_{0}$, é constante e, portanto, não sofre perturbações provenientes das golfadas de líquido e gás que chegam a sua entrada. Essa suposição negligencia o efeito da capacitância finita do separador na dinâmica do sistema, afetando a capacidade da predição de golfadas [3]. Além disso, a ausência de modelo para o vaso separador impossibilita o desenvolvimento de controladores que amorteçam as golfadas através de estratégias que tiram proveito da capacitância dos vasos do sistema de separação, como os controladores por banda discutidos em detalhes no capítulo anterior. Por consequente, decidiu-se adicionar um modelo de separador bifásico ao SRM.

Uma vez que as duas principais variáveis do separador são o nível de líquido e a pressão interna do gás, estas duas grandezas foram escolhidas como as variáveis de estado do modelo.

\subsection{1. Modelagem do Nível do Separador}

A variação do nível de líquido em um vaso está relacionada à variação no volume de líquido de acordo com a seguinte equação:

$$
\dot{L}_{S}=\frac{\dot{V}_{L S}}{A_{S}}=\frac{\dot{m}_{L S}}{\rho_{L} A_{S}}
$$

em que:

$L_{S}$ é o nível de líquido no separador. $[m]$

$V_{L S}$ é o volume de líquido no separador. $\left[\mathrm{m}^{3}\right]$

$A_{S}$ é a área da seção horizontal do separador na altura $L_{S} \cdot\left[\mathrm{m}^{2}\right]$

$m_{L S}$ é a massa de líquido no separador. $[\mathrm{kg}]$

$\rho_{L}$ é a densidade do líquido. $\left[\mathrm{kg} / \mathrm{m}^{3}\right]$ (Constante)

Uma vez que a maioria dos vasos separadores instalados em unidades offshore possuem o formato de um cilindro na horizontal, utilizou-se esta geometria na modelagem realizada neste trabalho. Neste tipo de separador, a área da seção horizontal, $A_{S}$, é função do nível de líquido no vaso, $L_{S}$, o que torna o modelo um 
pouco mais complexo do que o de separadores de seção horizontal constante, como é o caso do vaso cilíndrico vertical modelado por Ogazi no ISRM.

A Figura 18 representa um vaso cilíndrico horizontal de comprimento $H_{S}$, raio da base $r_{S}$, nível de líquido $L_{S}$ e largura da superfície de líquido $C_{S}$. A análise das relações geométricas desta representação é suficiente para determinação de todas as relações relevantes do modelo.

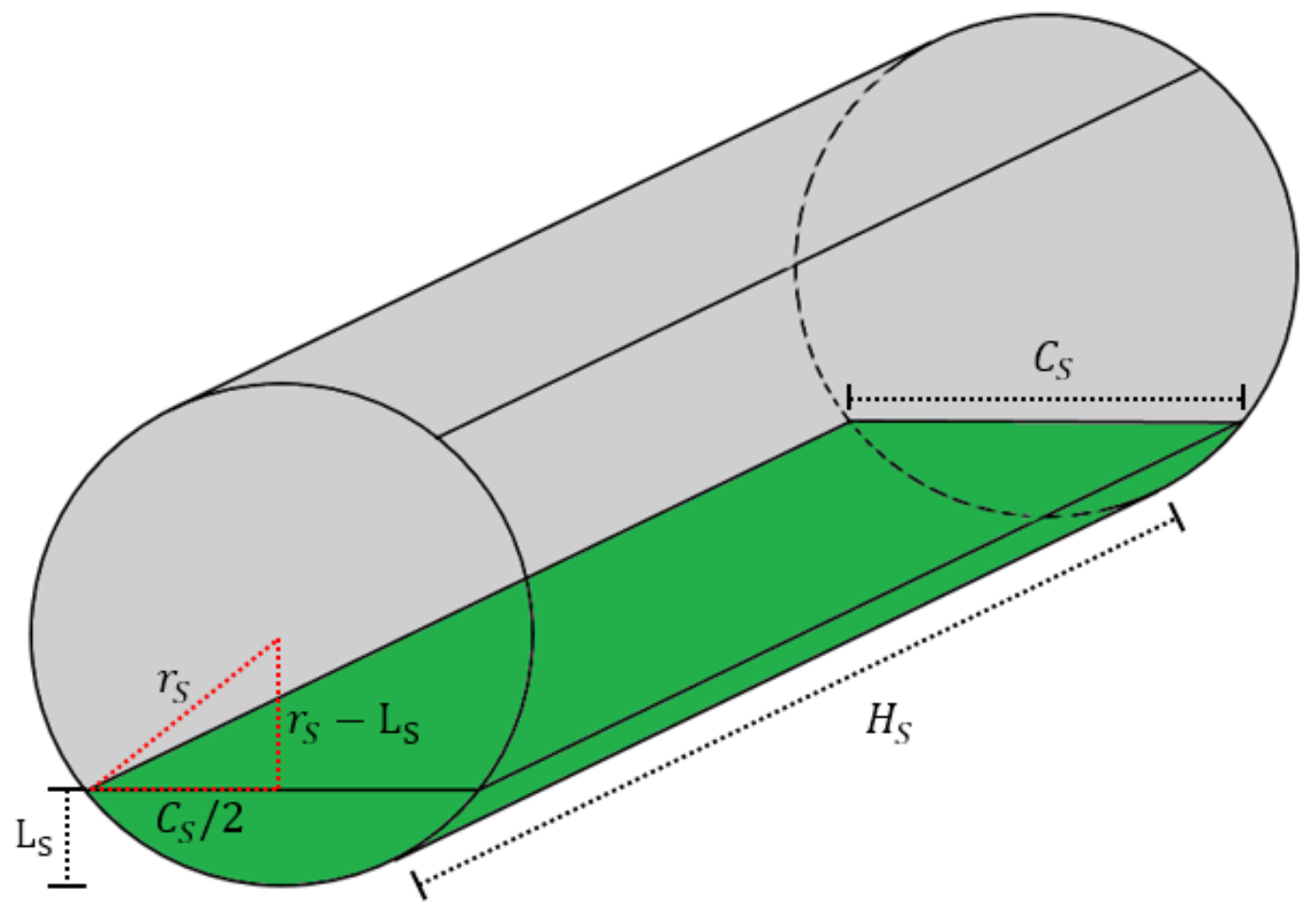

Figura 18 - Representação de um vaso cilindrico horizontal parcialmente preenchido.

Primeiramente, nota-se que a área da seção horizontal na altura $L_{S}$ é igual à da superfície livre de líquido, que por sua vez é igual à área do retângulo de lados $H_{S}$ e $C_{S}$.

Enquanto $H_{S}$ é um parâmetro geométrico conhecido do separador, $C_{S}$ é uma incógnita. Com objetivo de determinar seu valor em função de parâmetros conhecidos, utilizou-se a conhecida relação de Pitágoras no triângulo retângulo destacado em vermelho na Figura 18, resultando em:

$$
r_{S}^{2}=\left(r_{S}-L_{S}\right)^{2}+\left(\frac{C_{S}}{2}\right)^{2}
$$


Após uma rápida manipulação algébrica, esta equação resulta em:

$$
C_{S}=\sqrt{8 L_{S} r_{S}-4 L_{S}^{2}}
$$

Com $C_{S}$ definido a partir de termos conhecidos, a Equação (3.5) pode ser reescrita da seguinte forma:

$$
\dot{L}_{S}=\frac{\dot{m}_{L S}}{\rho_{L} H_{S} \sqrt{8 L_{S} r_{S}-4 L_{S}^{2}}}
$$

Por sua vez, a variação da massa de líquido no separador, $\dot{m}_{L S}$, é dada por:

$$
\dot{m}_{L S}=w_{L S i n}-w_{L S o u t}
$$

em que:

$w_{L S i n}$ é a vazão de entrada de líquido no separador. $[\mathrm{kg} / \mathrm{s}]$

$w_{L S o u t}$ é a vazão de saída de líquido no separador. $[\mathrm{kg} / \mathrm{s}]$

Ao substituir a Equação (3.9) na Equação (3.8), obtém-se:

$$
\dot{L}_{S}=\frac{w_{L S i n}-w_{L S o u t}}{\rho_{L} H_{S} \sqrt{8 L_{S} r_{S}-4 L_{S}^{2}}}
$$

A vazão $w_{L S i n}$ é uma condição de contorno que, quando acoplada ao SRM, é definida como a vazão de saída de riser. Já a vazão $w_{L S o u t}$ foi modelada por uma equação de válvula linear, similar à utilizada para modelagem da válvula choke. Esta equação é exibida a seguir:

$$
w_{L S o u t}=z_{L S} K_{4} \sqrt{\rho_{L}\left(P_{G S}+\rho_{L} g L_{S}-P_{A}\right)}
$$

em que:

$Z_{L S}$ é a abertura da válvula de líquido do separador. [\%]

$K_{4}$ é a constante de vazão da válvula de líquido. $\left[\mathrm{m}^{-2}\right]$ (Constante)

$P_{G S}$ é a pressão do gás no vaso separador. [bar]

$g$ é a acelaração da gravidade. $\left[\mathrm{m} / \mathrm{s}^{2}\right]$

$P_{A}$ é a pressão a jusante da válvula, condição de contorno. [bar] (Constante) 
É interessante observar que o resultado obtido neste trabalho difere significativamente daquele obtido por Sausen [28], apresentado na Equação (2.24). A diferença advém da adoção de uma simplificação para a área da seção horizontal, $A_{S}$, no modelo de Sausen. Visando a explicitar o impacto desta simplificação, comparou-se as estimativas da área da superfície de líquido em função do nível para ambos os modelos, considerando-se $r_{S}$ e $H_{S}$ iguais a $1 \mathrm{~m}$. O resultado é apresentado na Figura 19.

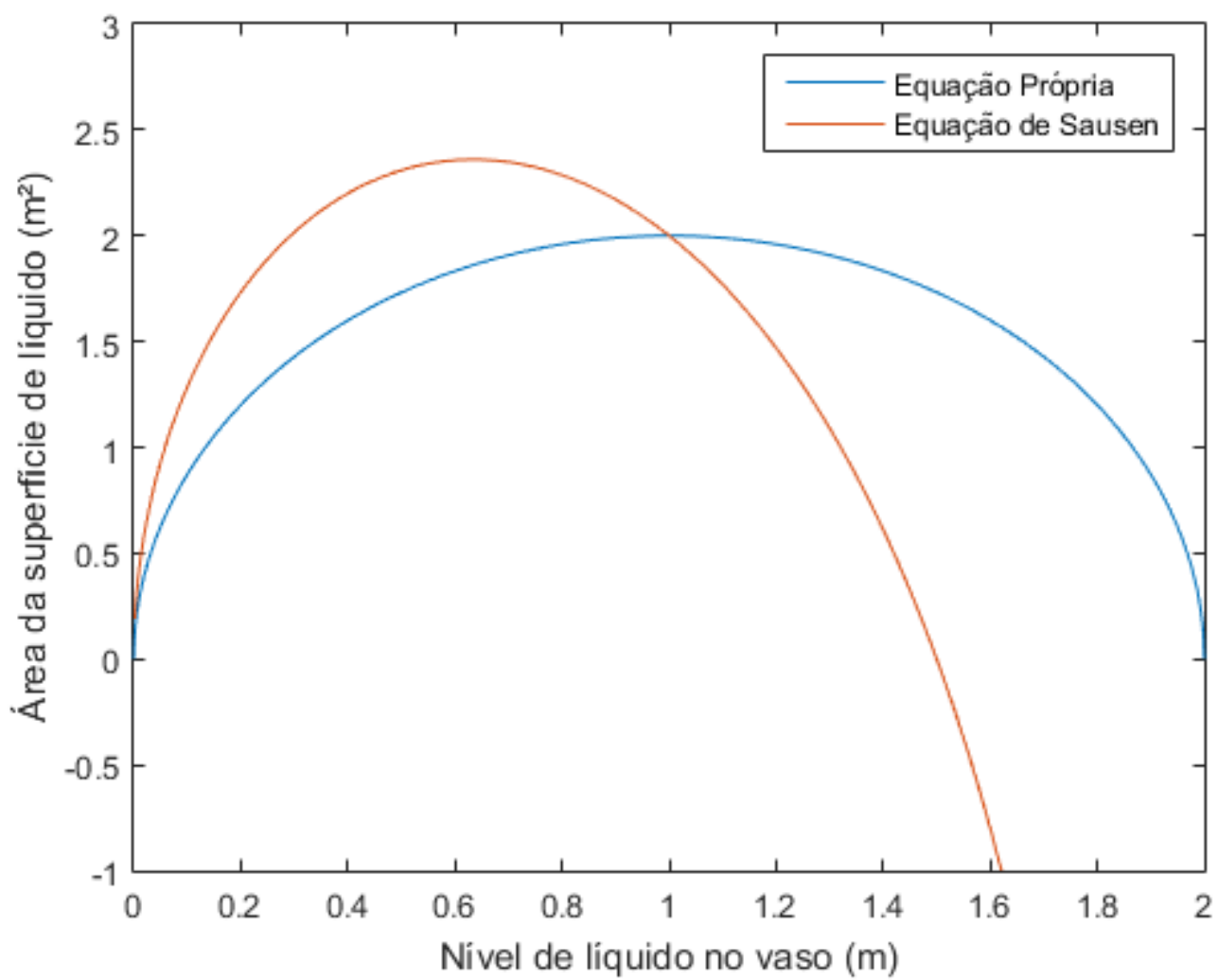

Figura 19 - Estimátivas das áreas das seções horizontais em vasos cilíndricos horizontais obtidas por meio de diferentes modelos.

Analisando o gráfico, é possível perceber que a modelagem adotada neste trabalho entrega uma solução exata para a área de superfície, com áreas nulas quando o vaso está totalmente cheio ou totalmente vazio, e área máxima quando o nível está na metade da altura do vazo, conforme esperado.

A aproximação de área adotada no modelo de Sausen tem como efeitos colaterais uma curva não simétrica em relação ao nível médio $(1 \mathrm{~m})$ e a existência de áreas negativas para níveis acima de 1,5m, impossibilitando o uso do modelo acima deste patamar em virtude de instabilidades numéricas. 


\subsection{2.}

\section{Modelagem da Pressão do Separador}

Assim como nas equações do SRM, considera-se ideal o gás contido no vaso separador, o que valida a seguinte relação:

$$
P_{G S} V_{G S}=\frac{m_{G S}}{M_{G}} R T
$$

em que:

$P_{G S}$ é a pressão do gás no vaso separador. [bar]

$V_{G S}$ é o volume do gás no separador. $\left[\mathrm{m}^{3}\right]$

$m_{G S}$ é a massa de gás no separador. [kg]

$R$ é a constante universal dos gases perfeitos. $[J / K . m o l]$ (Constante)

$M_{g}$ é massa molecular do gás. $[\mathrm{kg} / \mathrm{mol}]$. (Constante)

$T$ é a temperatura do sistema. $[K]$ (Constante)

Aplicando-se a derivada em relação ao tempo à Equação (3.12), obtém-se a seguinte equação:

$$
\dot{P}_{G S} V_{G S}+P_{G S} \dot{V}_{G S}=\dot{m}_{G S} \frac{R T}{M_{G}}
$$

Naturalmente, o volume de gás no vaso, $V_{G S}$, é igual ao volume total do vaso, $V_{T}$, subtraído do volume ocupado pelo líquido, $V_{L S}$. Por sua vez, enquanto $V_{T}$ é uma constante, $V_{L S}$ varia com o tempo, justificando o seguinte desenvolvimento:

$$
\begin{gathered}
V_{G S}=\left(V_{T}-V_{L S}\right) \\
\dot{V}_{G S}=\dot{V}_{T}-\dot{V}_{L S} \\
\dot{V}_{G S}=-\dot{V}_{L S} \\
\dot{V}_{G S}=-\frac{\dot{m}_{L S}}{\rho_{L}}
\end{gathered}
$$

Substituindo-se a Equação (3.17) na Equação (3.13) e isolando-se a pressão do gás no vaso separador, $\dot{P}_{G S}$, obtém-se a seguinte equação de estado:

$$
\dot{P}_{G S}=\frac{1}{V_{G S}}\left(\frac{R T}{M_{G}} \dot{m}_{G S}+\frac{P_{G S}}{\rho_{L}} \dot{m}_{L S}\right)
$$


Assim como realizado para $\dot{m}_{L S}$ na modelagem do nível, também foi suposta uma válvula linear na saída de gás, implicando no seguinte modelo para $\dot{m}_{G S}$ :

$$
\begin{gathered}
\dot{m}_{G S}=w_{G S i n}-w_{G S o u t} \\
w_{G S o u t}=z_{G S} K_{5} \sqrt{\rho_{G S}\left(P_{G S}-P_{A}\right)}
\end{gathered}
$$

em que:

$w_{G S i n}$ é a vazão de entrada de gás no separador. $[\mathrm{kg} / \mathrm{s}]$

$w_{G S o u t}$ é a vazão de saída de gás no separador. $[\mathrm{kg} / \mathrm{s}$ ]

$Z_{G S}$ é a abertura da válvula de gás do separador. [\%]

$K_{5}$ é a constante de vazão da válvula de gás. $\left[\mathrm{m}^{-2}\right]$ (Constante)

$\rho_{G S}$ é a densidade do gás no separador. $\left[\mathrm{kg} / \mathrm{m}^{3}\right]$

$P_{A}$ é a pressão a jusante da válvula. [bar] (Constante)

A última variável da Equação (3.18) a ser definida é o volume ocupado pelo gás, $V_{G S}$, que pode ser obtido através da integração da área da seção horizontal, $A_{S}$, do nível de líquido do separador, $L_{S}$, até o seu nível máximo, $2 r_{S}$ :

$$
V_{G S}=\int_{L_{S}}^{2 r_{S}} H_{S} \sqrt{8 L_{S} r_{S}-4 L_{S}^{2}} d L_{S}
$$

O resultado desta integral, solucionável através de substituições trigonométricas, é:

$$
V_{G S}=\left(r_{S}^{2}\left(\frac{\pi}{2}-\sin ^{-1}\left(\frac{L_{S}-r_{S}}{r_{S}}\right)\right)-\left(L_{S}-r_{S}\right) \sqrt{2 r_{S} L_{S}-L_{S}^{2}}\right) H_{S}
$$

Uma análise mais detalhada da Equação (3.22) revela que, para um vaso sem líquido $\left(L_{S}=0\right)$, o volume ocupado pelo gás é máximo e igual a $\pi r_{S}^{2} H_{S}$, o que corresponde ao volume total do cilindro. Por sua vez, quando o nível está na metade do vaso $\left(L_{S}=r_{S}\right)$, o volume ocupado pelo gás corresponde à metade do volume do vaso, $\pi r_{S}^{2} H_{S} / 2$. Por fim, para um vaso completamente preenchido $\left(L_{S}=2 r_{S}\right)$, o volume ocupado pelo gás é nulo. Desta forma, percebe-se que este é exatamente o comportamento esperado do volume de gás em função do nível de líquido. 


\subsection{3.}

\section{Acoplamento do Modelo do Separador}

As equações de estado obtidas com a adição do modelo do separador bifásico horizontal ao SRM são apresentadas a seguir:

$$
\begin{gathered}
\dot{L}_{S}=\frac{w_{L S i n}-w_{L S o u t}}{\rho_{L} H_{S} \sqrt{8 L_{S} r_{S}-4 L_{S}^{2}}} \\
\dot{P}_{G S}=\frac{1}{V_{G S}}\left(\frac{R T}{M_{G}}\left(w_{G S i n}-w_{G S o u t}\right)+\frac{P_{G S}}{\rho_{L}}\left(w_{L S i n}-w_{L S o u t}\right)\right)
\end{gathered}
$$

O acoplamento destas equações ao SRM é direto, com a utilização das seguintes relações: $w_{L \operatorname{Sin}}=w_{\text {Lout }}, w_{G S i n}=w_{\text {Gout }}$ e $P_{0}=P_{G S}$. Além disso, passam a integrar o modelo a Equação (3.11) da válvula de líquido, a Equação (3.20) da válvula de gás e a Equação (3.22), que determina o volume ocupado pelo gás no vaso separador.

\section{3. \\ Melhorias na Estabilidade Numérica do Modelo}

Até mesmo antes do acoplamento dos modelos do poço e do separador, a ocorrência de problemas numéricos durante algumas execuções impossibilitava a continuação do algoritmo de solução numérica das EDOs, implicando em um encerramento prematuro da simulação.

Um dos problemas se apresentava sempre que a válvula choke estava com pequenos graus de abertura, como 5\%. O diagnóstico foi obtido ao se analisarem as variáveis do sistema nos instantes imediatamente anteriores a sua ocorrência, pois foi possível perceber que, em virtude da alta restrição na choke, a vazão de líquido que deixava o sistema, $w_{\text {Lout }}$, era consistentemente inferior à vazão de entrada, $w_{\text {Lin }}$, constante no SRM original. Em um determinado ponto, o volume de líquido no riser se tornava igual ao seu volume total, gerando uma divisão por zero na Equação (2.9), interrompendo a simulação. Esta instabilidade foi solucionada ao se acoplar o modelo de poço, pois, com a válvula choke muito restrita, há um aumento na pressão na cabeça do poço, $P_{1}$, repercutindo na diminuição da vazão de entrada até que, após um transitório, esta se iguala à vazão média de saída. Com o modelo 
de poço, até mesmo uma choke totalmente fechada $(z=0 \%)$ deixa de causar problemas numéricos, pois nesta situação a pressão $P_{1}$ eleva-se até se igualar à pressão estática aparente, $P_{r a}$, fazendo com que o poço pare de produzir.

Também foi detectada uma outra instabilidade numérica, que ocorria de forma aparentemente aleatória durante a simulação do SRM e que passou a ocorrer com maior frequência após a adição do modelo de vaso separador. A origem desta instabilidade estava na avaliação das equações de válvula do sistema, especialmente na Equação (2.21) da válvula choke, ocorrendo sempre que o operando da radiciação destas equações se tornava negativo, impossibilitando uma solução real para equação.

No caso específico da válvula choke, a situação descrita acima ocorria sempre que a pressão do gás no riser, $P_{2}$, tornava-se menor do que a pressão a jusante da válvula. No SRM puro, esta situação só se configura em virtude de imprecisões do método de integração numérica, o que explica a raridade das ocorrências. Após a adição do modelo do vaso separador, a pressão a jusante da válvula tornou-se uma variável dinâmica, aumentando a frequência das ocorrências.

A solução adotada para a segunda instabilidade numérica detectada foi inspirada no fato de que, nas plantas reais, as três válvulas modeladas possuem válvulas de retenção instaladas em série, que impedem o fluxo reverso. Portanto, caso haja pressão reversa, a vazão pode ser considerada zero. Esta premissa foi inserida no modelo por meio de um novo equacionamento para as válvulas:

$$
\begin{gathered}
w_{\text {out }}=z K_{1} \sqrt{\rho_{T} \max \left(0, P_{2}-P_{0}\right)} \\
w_{G 1}=\left\{\begin{array}{r}
K_{2} \hat{\mathrm{A}} \frac{H_{1}-h_{1}}{H_{1}} \sqrt{\rho_{G 1} \max \left(0, P_{1}-P_{2}-\rho_{L} g \alpha_{L} H_{2}\right)}, h_{1}<H_{1} \\
0, h_{1} \geq H_{1}
\end{array}\right. \\
w_{L S o u t}=z_{L S} K_{4} \sqrt{\rho_{L} \max \left(0, P_{G S}+\rho_{L} g L_{S}-P_{A}\right)} \\
w_{G S o u t}=z_{G S} K_{5} \sqrt{\rho_{G S} \max \left(0, P_{G S}-P_{A}\right)}
\end{gathered}
$$

A premissa também foi adotada na equação de $w_{G 1}$, embora se trate de uma válvula fictícia, visto que este valor só pode ser negativo em virtude de imprecisões no método numérico que gerem operandos negativos muito próximos de 0 , tornando esta alteração inócua para a qualidade da modelagem. 


\section{4. Ensaios do Modelo}

Com a adição dos modelos do poço e do separador de produção, três condições de contorno do SRM $\left(w_{\text {Lin }}, w_{\text {Gin }}\right.$ e $\left.P_{0}\right)$ deixaram de ser estáticas e se tornaram variáveis, com possíveis implicações na dinâmica do sistema pipelineriser. Com objetivo de investigar estas implicações e também de adquirir informações necessárias para o projeto de controladores mitigadores de golfada, o modelo foi submetido a três ensaios, cujas configurações e resultados são apresentados ao longo desta seção.

Nos ensaios, os parâmetros utilizados no modelo do vaso separador foram os apresentados na Tabela 8. Os parâmetros geométricos, $r_{S}$ e $H_{S}$, foram baseados em separadores industriais reais, as constantes $K_{4}$ e $K_{5}$ foram escolhidas para que as vazões máximas de saída fossem $30 \mathrm{~kg} / \mathrm{s}$, para o líquido, e $2 \mathrm{~kg} / \mathrm{s}$, para o gás. Por sua vez, a pressão a jusante das válvulas, $P_{a}$, foi baseado na pressão de trabalho dos vasos atmosféricos, que compõem o último estágio de separação nas unidades de produção offshore.

Tabela 8 - Parâmetros do modelo de separador de produção.

\begin{tabular}{c|c|c} 
Parâmetro & Valor & Descrição \\
\hline$r_{S}$ & $1,0 \mathrm{~m}$ & Raio da seção transversal do separador \\
$H_{S}$ & $4,5 \mathrm{~m}$ & Comprimento do separador \\
$K_{4}$ & $0,0005 \mathrm{~m}^{-2}$ & Constante de vazão da válvula de líquido \\
$K_{5}$ & $0,0001 \mathrm{~m}^{-2}$ & Constante de vazão da válvula de gás \\
$P_{a}$ & $1,2 \mathrm{bar}$ & Pressão a jusante das válvulas
\end{tabular}

Outro aspecto importante dos ensaios realizados é que foram adicionados controladores PID para o nível pressão do vaso separador, reproduzindo as condições reais de operação deste equipamento. O setpoint utilizado no controlador de nível foi de $1 \mathrm{~m}$ (50\% do máximo) e no de pressão foi de 50 bar, que é o valor de contorno, $P_{0}$, utilizado no estudo de caso tomado como referência. 


\subsection{1. \\ Ensaio 1: Controle Estrito do Separador}

Neste primeiro ensaio, os controladores de pressão e de nível do vaso separador são sintonizados a fim de garantir que estas variáveis apresentem o mínimo desvio possível em relação aos seus setpoints, o que torna a dinâmica do vaso separador desprezível. Isto permite isolar a influência da dinâmica do poço ao processo de formação das golfadas severas.

O ensaio consiste na definição de diferentes valores constantes para a abertura da válvula choke (entrada do sistema) e observação do comportamento das principais variáveis do sistema para cada uma das aberturas.

Como primeira análise, foram extraídos os valores máximos e mínimos das pressões da flowline e do riser para construção de diagramas de bifurcação para estas variáveis, mostrados na Figura 20.

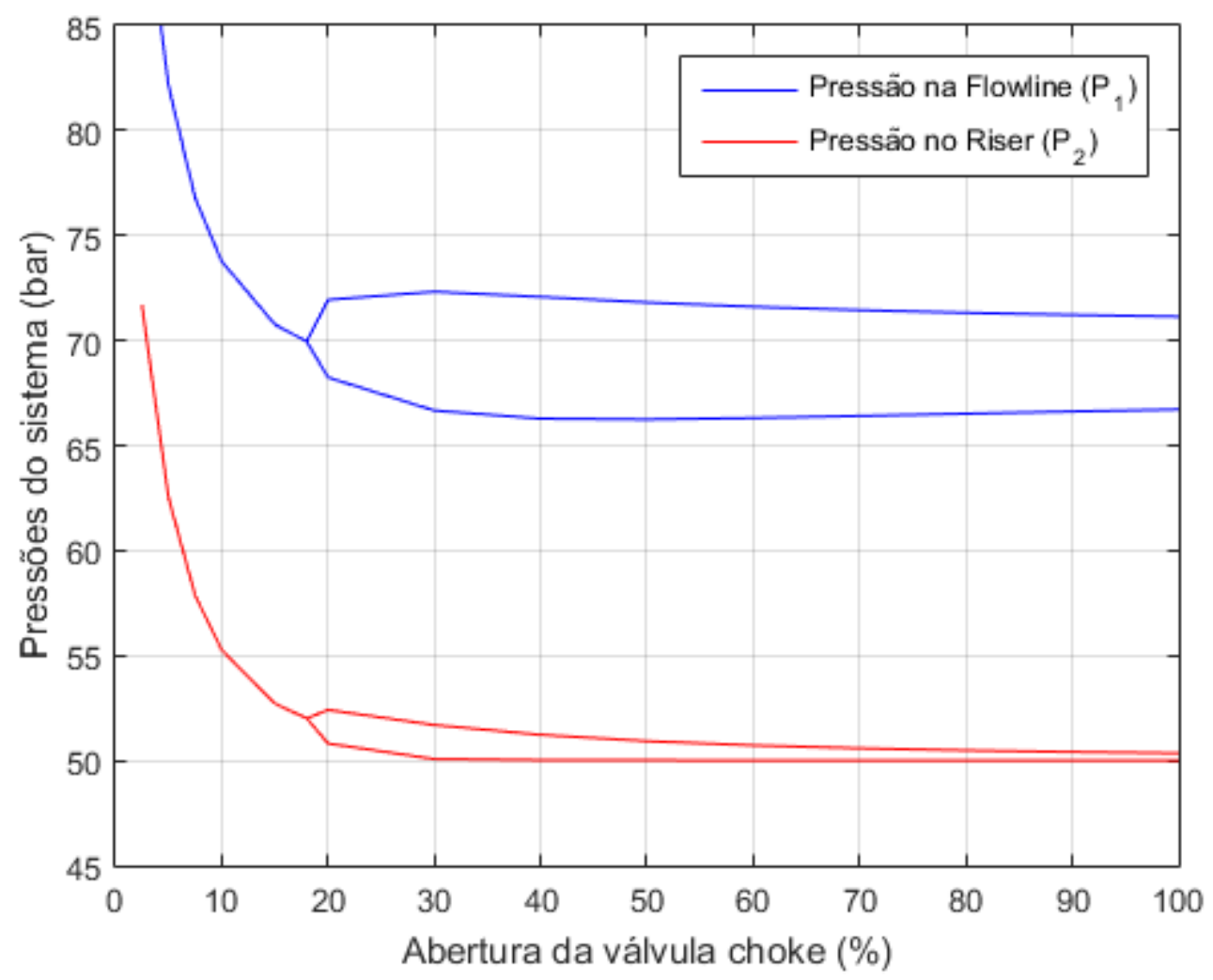

Figura 20 - Diagramas de bifurcação das pressões da flowline e do riser (Ensaio 1).

A análise deste primeiro gráfico revela que o sistema opera de forma estável até aberturas de $18 \%$ da válvula choke, tornando-se instável para aberturas maiores. Isto significa que houve um aumento da região de estabilidade em relação ao estudo 
de caso utilizado como referência no desenvolvimento do modelo, no qual o ponto crítico era $13 \%$.

Como a pressão do vaso separador esteve praticamente fixa na antiga condição de contorno, pode-se concluir que esta diferença é consequência direta da adição do modelo de poço. A explicação advém do fato de que a dinâmica do poço se assemelha à de um controlador em malha aberta, pois, quando a pressão da flowline aumenta, a vazão de entrada diminui, tendendo a reduzir a pressão; já quando a pressão da flowline diminui, a vazão de entrada cresce, tendendo a aumentar a pressão. Esta influência relevante na dinâmica do sistema revela a importância da inclusão de um modelo de poço ao SRM.

Outro resultado que pode ser inferido da Figura 20 é que a amplitude de oscilação é muito maior na pressão da flowline do que na pressão do riser, ou seja, a primeira é muito mais sensível às golfadas. Para analisar melhor esta situação, as pressões $P_{1}$ e $P_{2}$ nos ensaios de $z=30 \%$ e $z=80 \%$ são mostradas na Figura 21 .
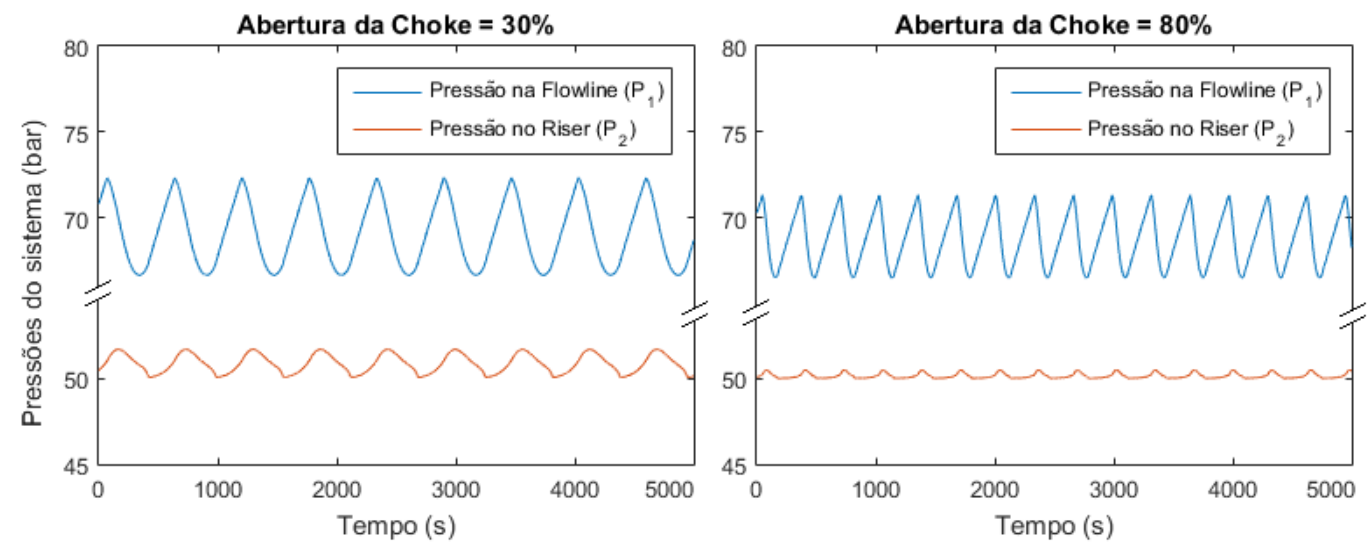

Figura 21 - Pressões da flowline e do riser para abertura de $30 \%$ e $80 \%$ (Ensaio 1).

A análise dos gráficos revela uma significativa diferença entre o nível de sensibilidade das duas variáveis às golfadas, especialmente em grandes aberturas da válvula choke. Esta diferença é uma das razões da maioria das aplicações bemsucedidas de controladores anti-golfada utilizarem a pressão da flowline como variável controlada.

Também é possível notar uma defasagem entre as duas pressões, sugerindo que alguma delas possa apresentar informação de perturbação antes da outra, sendo, portanto, melhor indicada como variável controlada. 
Para verificar esta hipótese, realizou-se um ensaio em que um degrau na vazão de entrada de líquido e gás é aplicado ao sistema durante uma operação estável, com a abertura da choke fixada em $13 \%$. As respostas das pressões da flowline e do riser a esta perturbação são mostradas na Figura 22. Visando a facilitar a comparação das respostas, o valor destas variáveis no instante imediatamente anterior à aplicação do degrau foi subtraído das formas de onda.

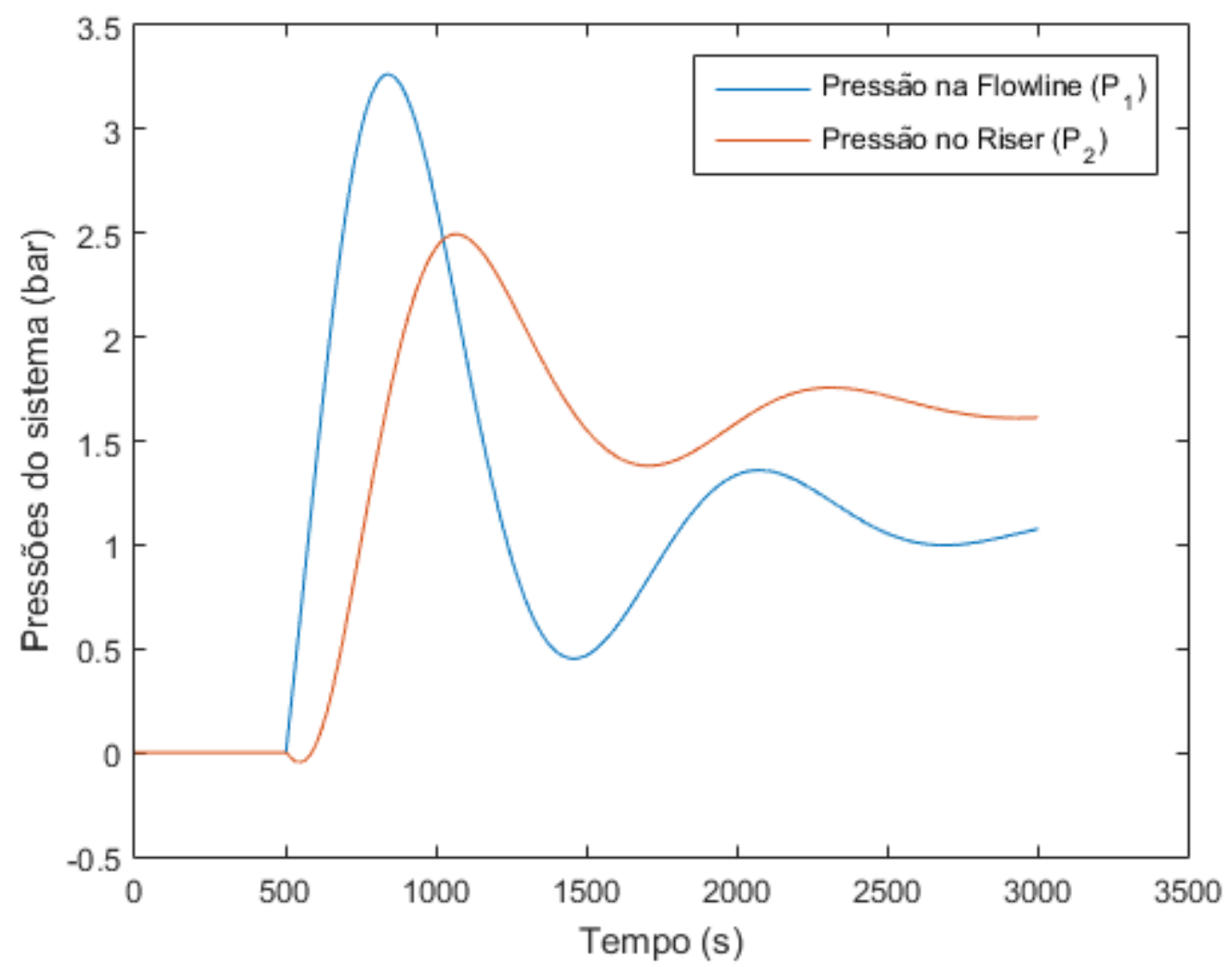

Figura 22 - Resposta das pressões da flowline e do riser a um degrau de produção (Ensaio 1).

Observando as respostas, percebe-se que, até mesmo para pequenas aberturas da válvula choke, a pressão do riser apresenta menor sensibilidade às perturbações do que a pressão da flowline. Além disso, percebe-se a existência de uma resposta inversa na pressão do riser, típica de sistemas de fase não-mínima, dificultando sua utilização como variável controlada.

Esta análise corrobora as observações feitas por diversos pesquisadores [4, $33,34]$ de que as pressões submarinas são as melhores variáveis para utilização em sistemas de controle anti-golfada. No entanto, elas são de difícil aquisição e na grande maioria das vezes não estão disponíveis, ao contrário das pressões de superfície, como a pressão do gás no topo riser. 
O comportamento da produção de líquido em função da abertura da choke para este ensaio está sintetizado no diagrama de bifurcação mostrado na Figura 23.

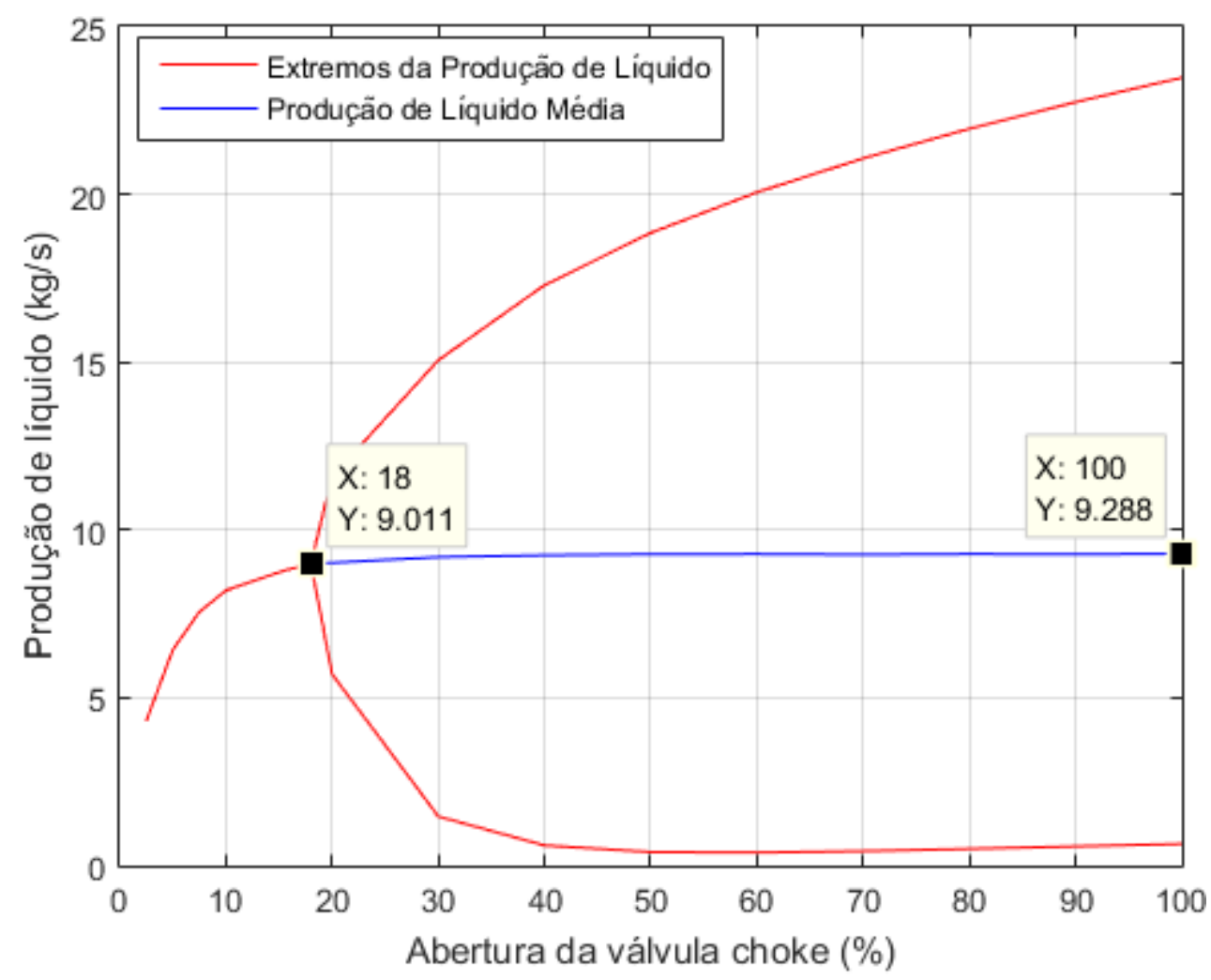

Figura 23 - Diagrama de bifurcação e média da produção de líquido. (Ensaio 1).

Analisado este diagrama de bifurcação, nota-se um dilema: quanto maior é a abertura da choke, maior é a amplitude das oscilações na produção, mas, ao mesmo tempo, maior é a produção média. Ao se comparar a operação no ponto crítico com a operação sem restrição (choke $=100 \%)$, percebe-se um aumento na ordem de $3 \%$ na produção. Este aumento de produção, que pode significar milhões de dólares ao ano na indústria do petróleo, é um grande estímulo para a "convivência" com as golfadas, seja através da instalação de capturadores de golfada ou da utilização de algoritmos de controle por banda nos vasos separadores, discutidos no Capítulo 2 deste trabalho.

Além de alterar a amplitude, a abertura da válvula choke também influencia diretamente a frequência das oscilações do sistema, como pode ser observado na Figura 24, em que são mostradas as vazões de produção de líquido e gás para aberturas da choke de $20 \%$ e $100 \%$. 

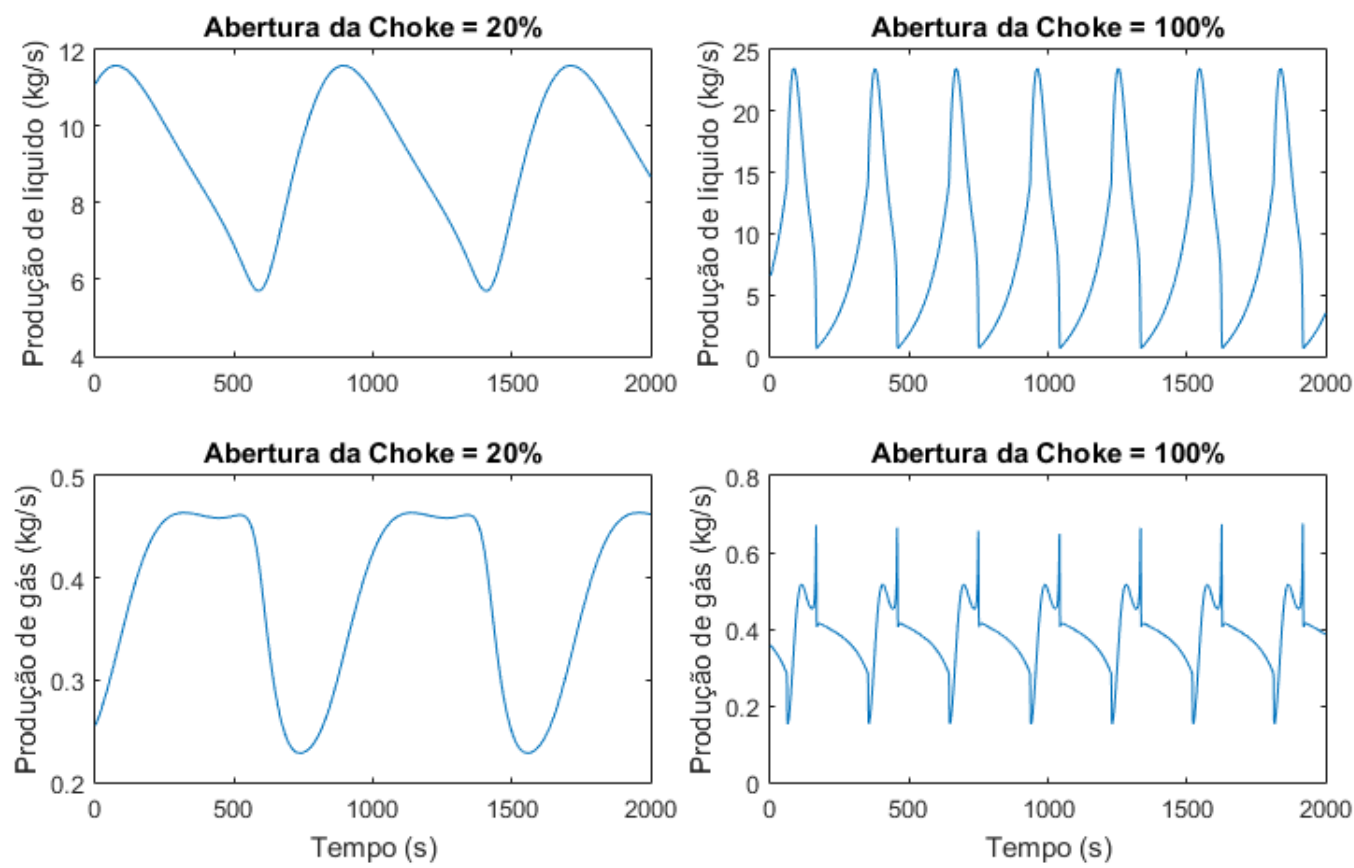

Figura 24 - Vazões de líquido e gás para aberturas da choke de 20\% e 100\%.(Ensaio 1).

Ao se analisarem as Figura 21 e Figura 24 é possível notar que, para uma determinada abertura, todas as variáveis do sistema oscilam com a mesma frequência, independentemente de sua sensibilidade às golfadas. Além disso, notase que quanto maior a abertura da válvula choke, maior a frequência de oscilação, conforme explicitado na Tabela 9.

Tabela 9 - Frequências de oscilação do sistema para diferentes aberturas de válvula. (Ensaio 1)

\begin{tabular}{c|c|c}
$\begin{array}{c}\text { Abertura da } \\
\text { choke (\%) }\end{array}$ & $\begin{array}{c}\text { Período de } \\
\text { Oscilação (s) }\end{array}$ & $\begin{array}{c}\text { Frequência de } \\
\text { Oscilação }(\mathbf{m H z})\end{array}$ \\
\hline 0 a 18 & - & 0 \\
20 & 819 & 1,22 \\
30 & 566 & 1,77 \\
40 & 479 & 2,09 \\
50 & 421 & 2,37 \\
60 & 381 & 2,63 \\
70 & 350 & 2,85 \\
80 & 327 & 3,06 \\
90 & 308 & 3,25 \\
100 & 291 & 3,43
\end{tabular}


Em uma primeira análise, este resultado pode parecer pouco relevante, mas ele esconde uma grande utilidade: a possibilidade de se utilizar qualquer variável do sistema na determinação da severidade das golfadas a que o sistema está exposto por meio de um algoritmo de estimação de frequência.

\subsection{2.}

\section{Ensaio 2: Controle Permissivo do Separador}

No ensaio anterior, os controladores de nível e pressão do vaso separador foram sintonizados de tal forma que as variações nestas grandezas ficaram abaixo de $0,5 \%$, eliminando a influência do vaso separador na dinâmica de formação das golfadas severas. Objetivando avaliar esta influência, novas sintonias foram realizadas, com redução dos ganhos dos controladores de forma a permitir maiores oscilações no valor da pressão e nível do vaso separador. As amplitudes destas oscilações para diferentes aberturas de choke podem ser observadas nos diagramas de bifurcação apresentados na Figura 25.
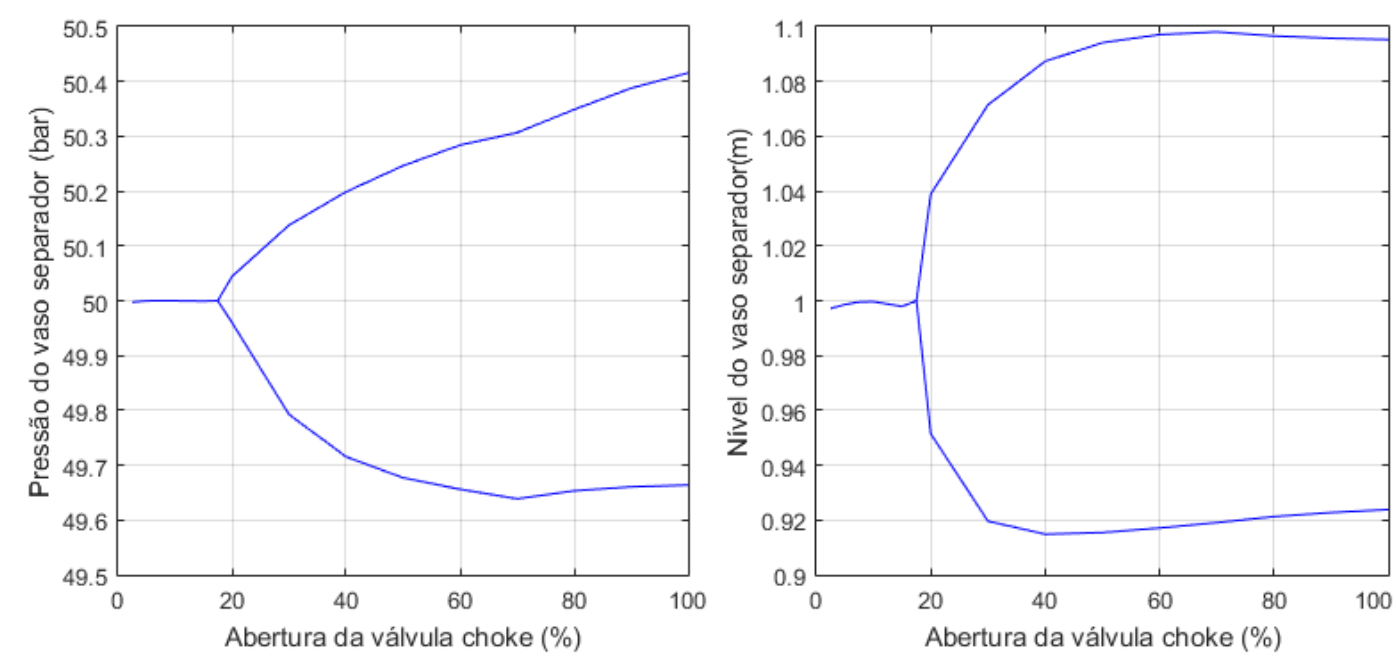

Figura 25 - Diagramas de bifurcação das variáveis de estado do vaso separador (Ensaio 2).

No ensaio anterior, não houve amortecimento das golfadas no vaso separador, uma vez que o nível do vaso manteve-se praticamente constante, implicando em vazões idênticas de entrada e saída de líquido do vaso. Já neste ensaio, um controlador mais lento permitiu oscilações da ordem de $10 \%$ no nível, permitindo que o separador amorteça as golfadas, conforme pode ser observado na Figura 26, onde é mostrado o diagrama de bifurcação das vazões de entrada e saída do vaso. 


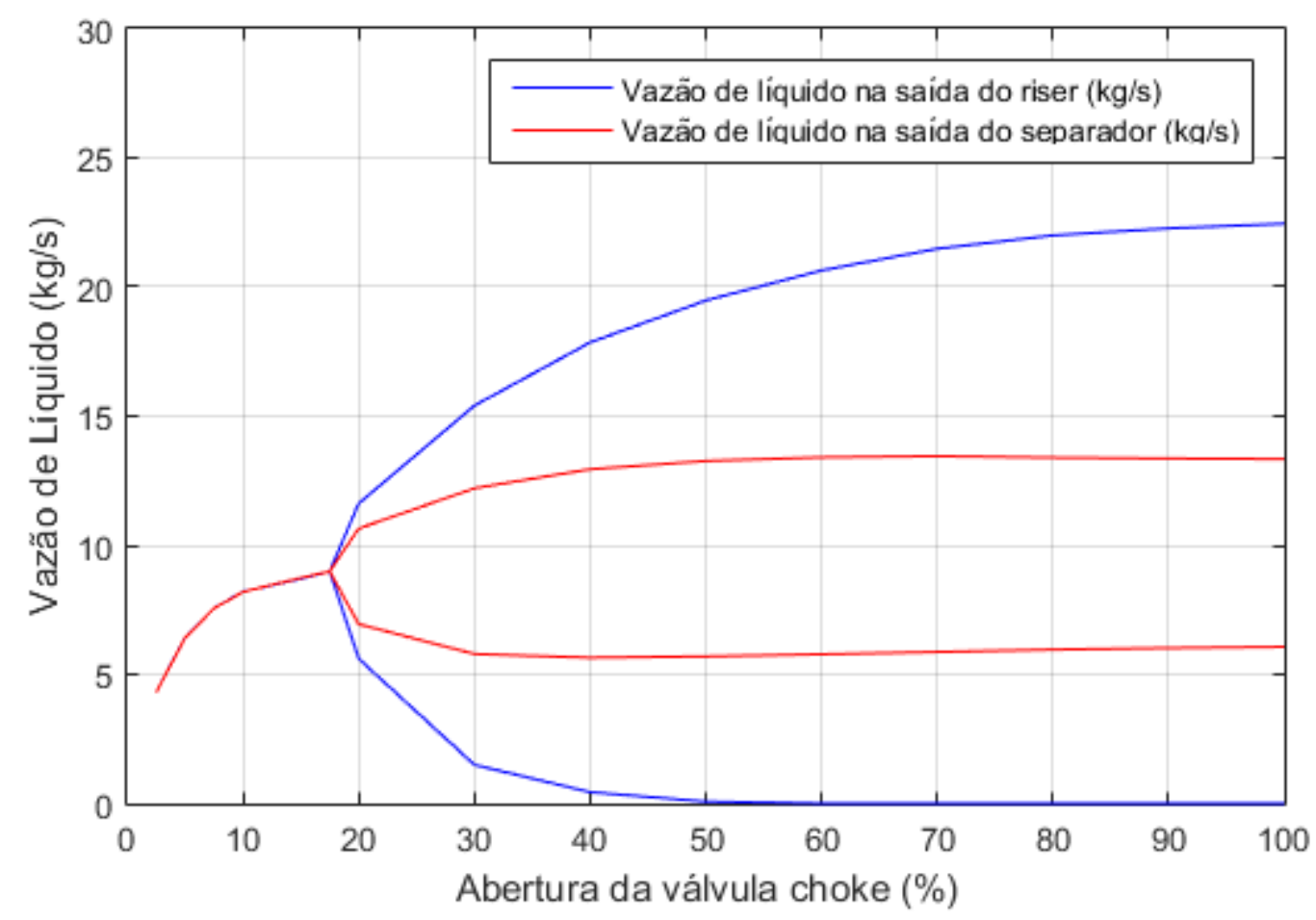

Figura 26 - Diagramas de bifurcação das vazões na entrada e na saída do separador. (Ensaio 2).

Analisando a Figura 26, percebe-se que as oscilações foram atenuadas significativamente no vaso. No caso extremo, com $100 \%$ de abertura da choke, a amplitude das oscilações caiu de $22,45 \mathrm{~kg} / \mathrm{s}$ para $7,27 \mathrm{~kg} / \mathrm{s}$, o que representa uma redução de $68 \%$. Este é o fenômeno que motiva o desenvolvimento dos controladores por banda, cujo objetivo é uma melhor exploração desta capacidade inerente aos vasos de acúmulo.

Outro aspecto relevante observado no ensaio é que a dinâmica mais lenta da pressão do separador repercutiu no próprio processo de formação de golfadas do sistema poço-flowline-riser, com aumento nas amplitudes de oscilação das pressões da flowline, $P_{1}$, e do riser, $P_{2}$, e diminuição nas frequências. A dimensão da variação destas variáveis é apresentada na Figura 27 por meio de diagramas de bifurcação destas duas variáveis. 


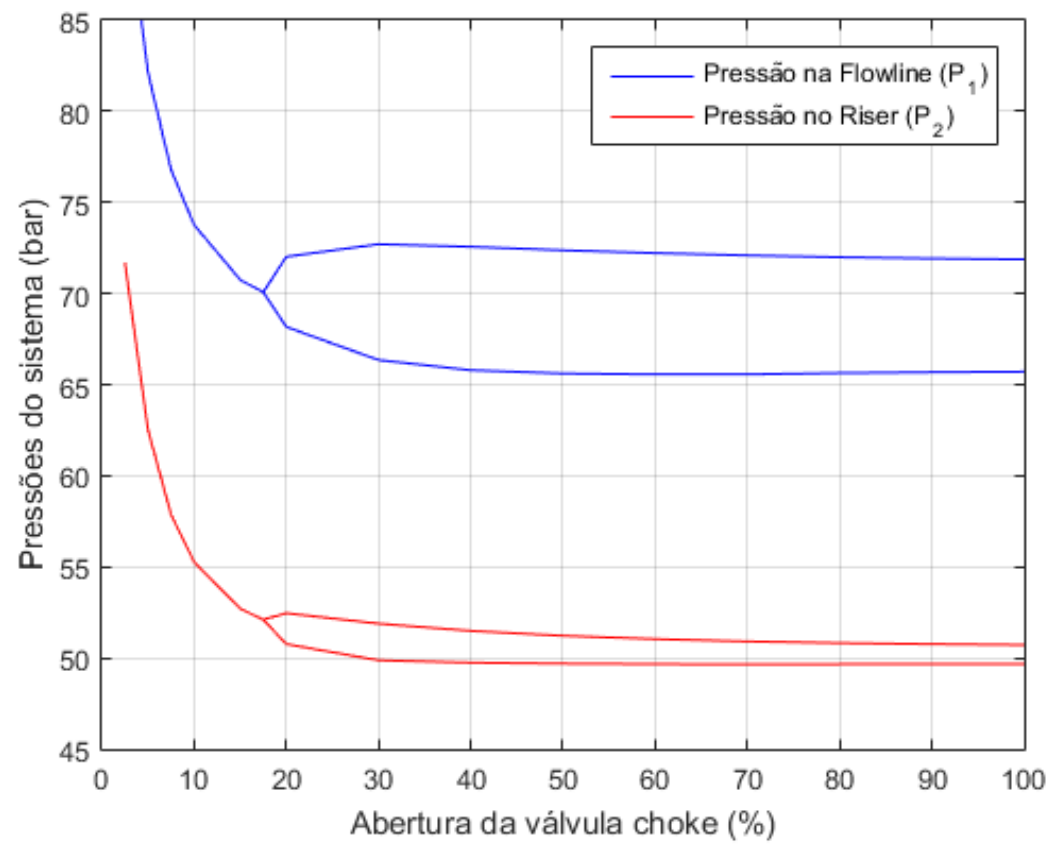

Figura 27 - Diagramas de bifurcação das pressões da flowline e do riser (Ensaio 2).

Quando comparado ao ensaio anterior, nota-se um aumento significativo da amplitude das oscilações de pressão no sistema, especialmente no riser. No caso de 100\% de abertura da choke, a amplitude de oscilação no riser passou de 0,35 bar para 1,04 bar, um aumento de 297\%. Esta maior variação deve-se ao fato da pressão no riser acompanhar a pressão do vaso separador, uma vez que a diferença entre elas é somente a queda de pressão na válvula choke. Na Figura 28, observa-se melhor esta relação.

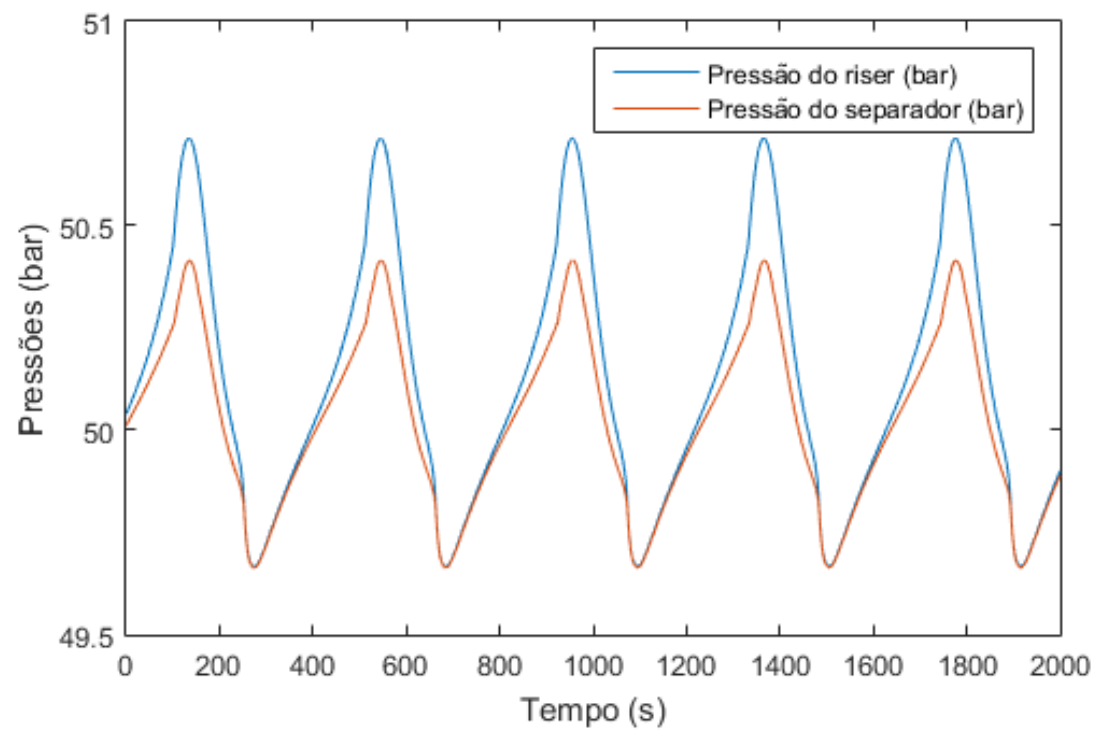

Figura 28 - Pressões do riser e do vaso separador durante ocorrência de golfadas no sistema com a choke totalmente aberta (Ensaio 2). 
Naturalmente, a maior sensibilidade da pressão do riser às golfadas facilita a aplicação de um controlador que utilize esta grandeza como variável controlada, uma vez que ela passa a informar melhor o estado da planta.

Por fim, as frequências de oscilação do sistema para diferentes aberturas da válvula choke são mostradas na Tabela 10 , onde são apresentadas também as frequências medidas no primeiro ensaio. Uma análise mais minuciosa destes dados revela uma redução de até $29 \%$ nas frequências de oscilação.

Tabela 10 - Frequências de oscilação do sistema para diferentes aberturas de válvula.

\begin{tabular}{c|c|c}
$\begin{array}{c}\text { Abertura da } \\
\text { choke (\%) }\end{array}$ & $\begin{array}{c}\text { Frequência de } \\
\text { Oscilação }(\boldsymbol{m H z}) \\
\text { (Ensaio 1) }\end{array}$ & $\begin{array}{c}\text { Frequência de } \\
\text { Oscilação }(\mathbf{m H z}) \\
\text { (Ensaio 2) }\end{array}$ \\
\hline 0 a 18 & 0 & 0 \\
20 & 1,22 & 1,20 \\
30 & 1,77 & 1,65 \\
40 & 2,09 & 1,86 \\
50 & 2,37 & 2,02 \\
60 & 2,63 & 2,15 \\
70 & 2,85 & 2,25 \\
80 & 3,06 & 2,33 \\
90 & 3,25 & 2,39 \\
100 & 3,43 & 2,44
\end{tabular}

\subsection{3.}

\section{Ensaio 3: Malha Fechada}

Com objetivo de verificar possíveis ganhos de produção decorrentes da operação em malha fechada, foi realizado um ensaio final em que a abertura da válvula choke foi ajustada dinamicamente por um controlador PI, cuja variável controlada era a pressão da flowline, $P_{1}$. A sintonia do controlador foi a mesma proposta por Storkaas para o estudo de caso utilizado na parametrização do modelo utilizado neste trabalho.

O ensaio consistiu em ajustar o setpoint inicial do controlador para um valor alto, correspondente à uma abertura da válvula choke de 10\%, e aguardar o estabelecimento de um regime permanente. Em seguida, o setpoint do controlador 
foi decrementado em 0,2 bar e novamente aguardou-se o estabelecimento de um regime permanente. Este processo foi repetido até que um setpoint muito baixo fizesse com que o sistema entrasse em operação instável, com a formação de golfadas severas.

Para cada ponto de operação estável obtido, determinou-se a vazão de líquido na saída do riser e a abertura média da válvula choke. Os resultados são apresentados na Figura 29, em conjunto com os valores de vazão média de líquido em malha aberta obtidos no Ensaio 2.

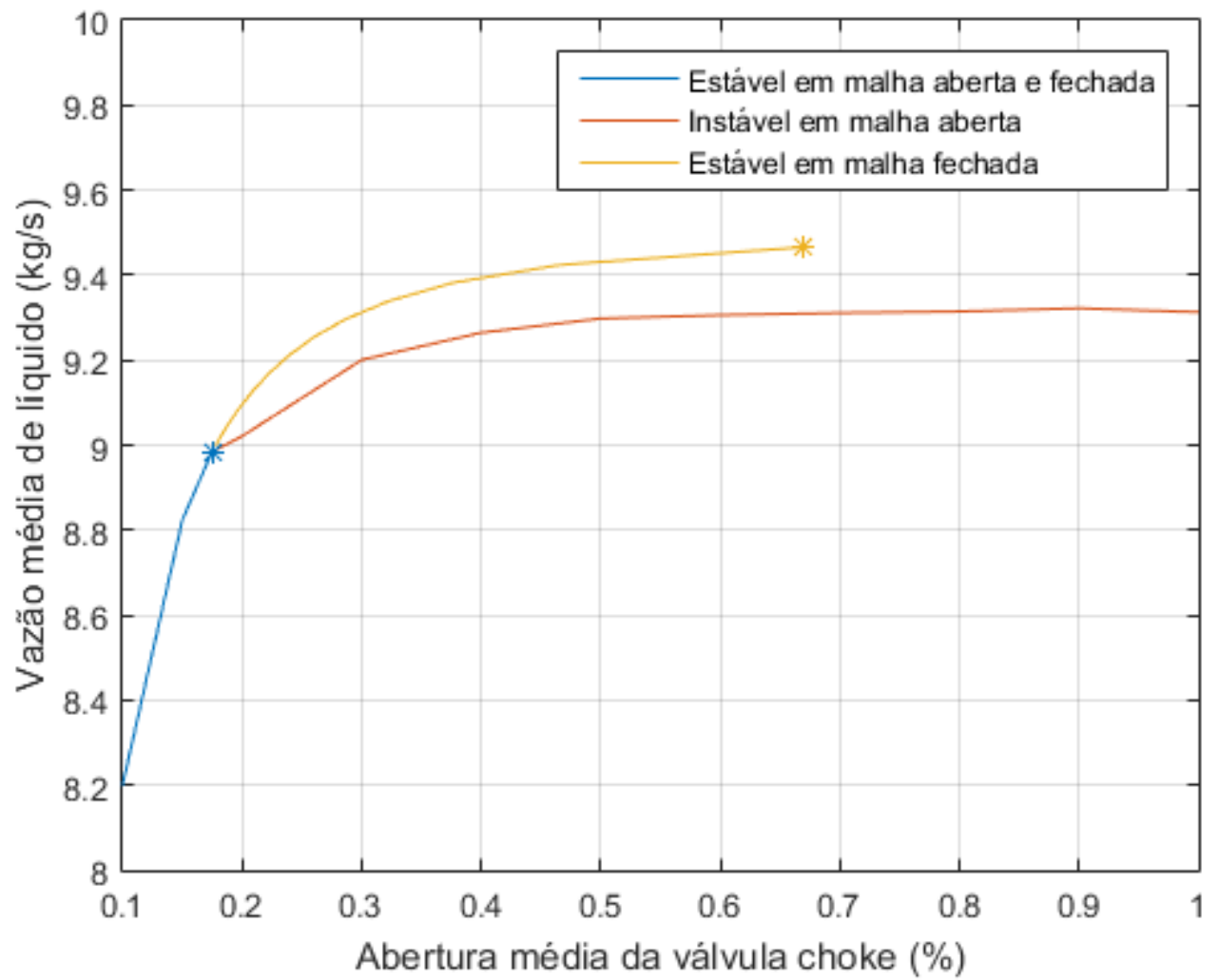

Figura 29 - Comparação entre as produções médias obtidas nos ensaios 2 e 3.

A observação do gráfico revela que o controlador PI foi capaz de estabilizar o sistema em aberturas médias da válvula choke de até $67 \%$, com uma produção correspondente de $9,46 \mathrm{~kg} / \mathrm{s}$. Qualquer tentativa de reduzir o setpoint de pressão além deste ponto resultou no ressurgimento de golfadas no sistema.

O aumento da produção obtido por este controlador é bastante significativo, tanto em relação à produção máxima na região estável (ponto crítico), quanto em relação à produção média máxima na região instável. Este comportamento consiste em um dos maiores incentivos para a utilização de controladores anti-golfada. 


\subsection{4.}

\section{Considerações Gerais}

De maneira geral, a análise dos resultados provenientes dos três ensaios possibilitou um melhor entendimento da dinâmica do modelo desenvolvido, especialmente em relação ao comportamento das principais variáveis do sistema em diferentes condições operacionais.

No primeiro ensaio, foi possível observar a influência da adição de um modelo para o poço produtor, o que alterou significativamente a dinâmica do sistema, aumentando sua faixa de estabilidade e permitindo a aferição de variações na produção em decorrência da mudança de parâmetros operacionais.

No segundo ensaio, os efeitos da adição de um modelo para o separador foram analisados com maior profundidade, permitindo a verificação de uma significativa influência na dinâmica de formação de golfadas quando há um controle de pressão permissivo no vaso separador. Além disso, foi possível verificar uma boa capacidade de amortecimento das golfadas pela dinâmica do vaso quando há um controlador de nível lento, que permite variações na variável controlada. Por outro lado, um controlador PID lento pode apresentar problemas ao rejeitar grandes perturbações, como a entrada ou saída de um novo poço, permitindo que o nível viole limites aceitáveis.

No último ensaio, foi possível verificar que um controlador PID que utiliza a pressão da flowline como variável controlada possui a capacidade de aumentar a produção média de um poço. Embora o resultado seja excelente, muitas vezes esta variável não está disponível em sistemas de produção reais, limitando a aplicação destes controladores, que não possuem bom desempenho com as variáveis de topo, mais comumente disponíveis em sistemas industriais.

Apesar de ambos os controladores utilizados nos ensaios possuírem vantagens, seus pontos fracos muitas vezes impossibilitam sua aplicação prática. No próximo capítulo, será apresentado o desenvolvimento de dois controladores fuzzy que tem como objetivo entregar estes mesmos resultados positivos, sem, entretanto, apresentar as mesmas limitações. 


\section{4. \\ Desenvolvimento dos Controladores}

Neste trabalho, foram desenvolvidos dois controladores mitigadores de golfadas, ambos baseados em técnicas de inteligência computacional, mas de baixa complexidade, visando a facilitar sua utilização em ambiente industrial. $\mathrm{O}$ primeiro deles é um controlador supressor de golfadas, que utiliza a pressão no topo do riser como variável controlada e modula a abertura da válvula choke com o objetivo de suprimir ou evitar o estabelecimento de golfadas no sistema de produção. O segundo é um controlador de nível amortecedor de golfadas, que atua na válvula de saída de óleo do vaso separador com o duplo objetivo de regular o nível do vaso e, ao mesmo tempo, tirar proveito de sua capacitância na atenuação das golfadas provenientes do poço.

Os controladores são independentes e podem ser aplicados isoladamente ou em conjunto, embora o controlador amortecedor tenha sua maior aplicação em sistemas onde as golfadas não foram totalmente suprimidas.

Ao longo deste capítulo, o processo de desenvolvimento dos controladores é apresentado. Por sua vez, os resultados obtidos são apresentados e discutidos no capítulo seguinte.

\section{1.}

\section{Controlador Supressor de Golfadas}

Conforme discutido no Capítulo 2 e observado nos resultados dos experimentos realizados no Capítulo 3 , a pressão do gás no topo riser, $P_{2}$, não é a melhor variável para o desenvolvimento de controladores anti-golfada, pois possui características indesejáveis como baixo ganho e fase não mínima.

No entanto, esta é a grandeza de mais fácil obtenção em uma planta industrial, pois exige tão somente a instalação de um transmissor de pressão na tubulação a montante da válvula choke do poço a ser controlado, localizada na plataforma e, portanto, de fácil acesso para instalação e manutenção. Assim, decidiu-se utilizar 
esta variável no desenvolvimento de um controlador anti-golfada SISO, mesmo sabendo-se das limitações anteriormente discutidas.

Ressalta-se que as limitações da utilização da pressão do riser como variável controlada foram analisadas através da óptica da teoria de controle linear e, portanto, se aplicam diretamente a controladores lineares, como o PID. Isto explica o relativo insucesso dos controladores anti-golfada lineares baseados nesta variável. No entanto, é possível que estas limitações possam ser parcialmente compensadas pela utilização de algoritmos não-lineares, como o aqui proposto.

O controlador desenvolvido neste trabalho é formado pela hibridização de um sistema de inferência fuzzy (SIF) com um algoritmo de controle PID clássico, em que o SIF é responsável por ajustar o ganho integral do controlador PID e por gerar uma ação adicional de fechamento da válvula choke durante a ocorrência de golfadas. Um diagrama ilustrativo da arquitetura deste controlador é apresentado na Figura 30.

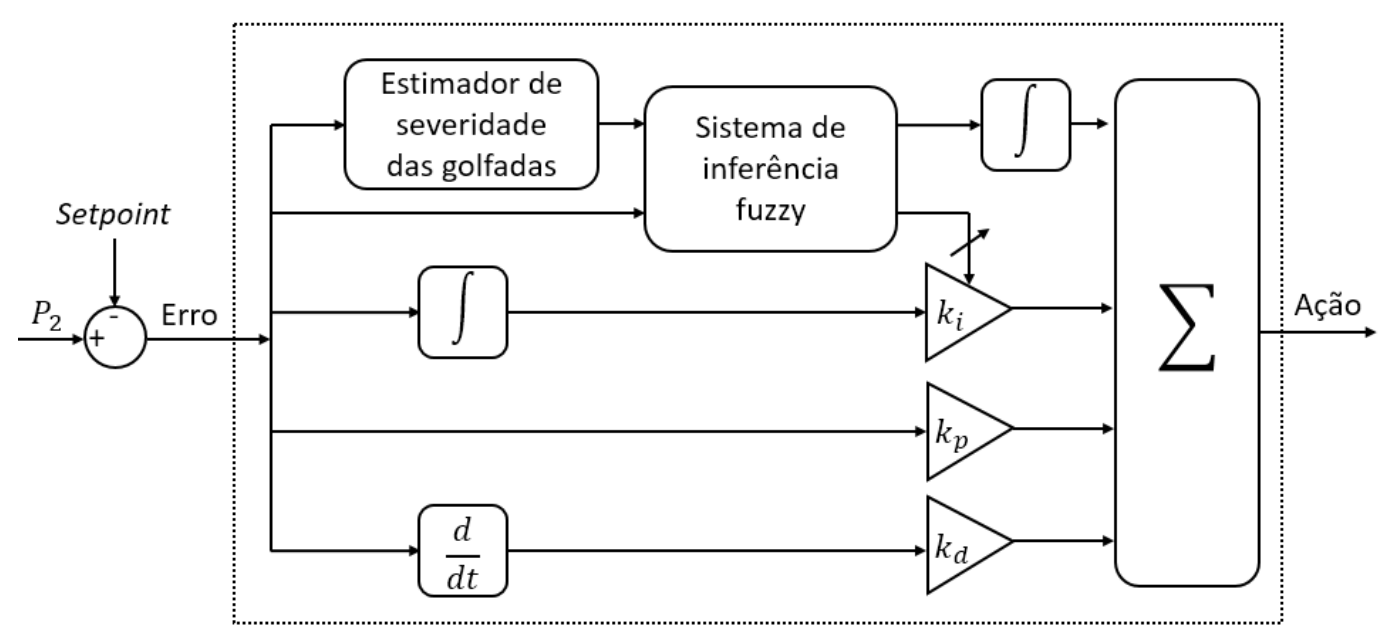

Figura 30 - Arquitetura do controlador supressor de golfadas.

É possível reconhecer a representação de um controlador PID clássico na parte inferior do diagrama, com a peculiaridade de seu ganho integral, $k_{i}$, ser variável. Além disso, compõem o controlador um bloco cuja função é estimar a severidade das golfadas na planta de produção e um sistema de inferência fuzzy com duas variáveis de entrada: erro e grau de severidade das golfadas; e duas variáveis de saída: o ganho integral do PID e a ação de controle que é integrada e somada à saída do PID. 


\subsection{1.}

\section{Estimador de Severidade das Golfadas}

Uma das variáveis de entrada do sistema de inferência fuzzy é um valor que mede o grau de severidade das golfadas no sistema de produção. Assim, torna-se necessário definir um algoritmo que determine esta grandeza.

Em uma primeira análise, pode-se imaginar que a variância do sinal de entrada possa ser uma boa medida da severidade das golfadas, mas existem limitações nesta abordagem, em virtude de uma relação não monotônica entre a variância da pressão no riser e a severidade das golfadas.

Embora a variância seja muito baixa com o sistema estável e alta para aberturas da válvula choke entre $20 \%$ e $30 \%$, ela tende a cair conforme a golfada se torna mais severa. Esta característica pode ser inferida por meio dos diagramas de bifurcação apresentados nas Figura 20 e Figura 27, em que se observa diminuição das amplitudes de oscilação das pressões conforme se intensificam as golfadas, especialmente quando a pressão do vaso separador é controlada estritamente. Este comportamento ambíguo é indesejável, pois uma baixa variância pode ser interpretada tanto como um sistema de produção estável, quanto como um sistema com presença de golfadas de alta severidade, prejudicando o desempenho do controlador.

Nos ensaios realizados no Capítulo 3, notou-se uma clara relação entre a frequência de oscilação das variáveis do sistema de produção e a severidade das golfadas a que este sistema estava submetido, com um aumento monotônico das frequências conforme as golfadas se intensificam. Além disso, a frequência de oscilação é observável em todas as variáveis do sistema, inclusive na pressão no topo do riser, tornando a frequência de oscilação um bom parâmetro para estimação do grau de severidade das golfadas.

Para determinação da frequência do sinal de entrada em tempo real, faz-se necessária a utilização de um algoritmo de estimação de frequência - um problema bastante comum nas áreas de telecomunicações e processamento de sinais e, portanto, com soluções bastante estabelecidas.

Neste trabalho, foram testados algoritmos baseados em autocorrelação, análise espectral, análise cepstral [40] e transformadas wavelet [41]. Para medições sem ruído, as melhores estimativas foram obtidas pelos métodos baseados em 
autocorrelação e em wavelets, com uma maior precisão do segundo. Entrentanto, na presença de ruído, o único método que apresentou resultados satisfatórios foi o baseado em autocorrelação, uma vez que ruídos de medição são bastante descorrelacionados. Este resultado é positivo, uma vez que o algoritmo de autocorrelação é o mais simples entre os estudados.

Portanto, o bloco de estimação de frequência, baseado em autocorrelação, é implementado através da execução periódica (a cada $T_{a}$ segundos) do seguinte algoritmo:

1. Amostra-se o valor atual de $P_{2}$, adicionando-o a um buffer de tamanho $L$.

2. Calcula-se a média do buffer $P_{2}(1: L)$, armazenando-a em $\overline{P_{2}}$.

3. Determina-se a sequência de média zero, $P_{2}^{0}$, através da equação $P_{2}^{0}(1: L)=P_{2}(1: L)-\overline{P_{2}}$.

4. Calcula-se a variância de $P_{2}^{0}(1: L)$; caso seja menor do que um limiar $\sigma_{\text {min }}^{2}$, considera-se o sistema estável e o algoritmo retorna frequência 0 .

5. Calcula-se a autocorrelação de $P_{2}^{0}(1: L)$, armazenando-a em $X_{P_{2}}(1: L)$.

6. Determina-se o índice $i$ do elemento pertencente à $X_{P_{2}}(1: L)$ que possui o maior valor após o primeiro cruzamento por zero.

7. Calcula-se o período de oscilação a partir da equação $T_{g}=T_{a}(i-1)$.

8. Retorna-se o valor da frequência, em $\mathrm{mHz}$, calculada como $1000 / T_{g}$.

$\mathrm{Na}$ implementação realizada para controlar o sistema apresentado nos ensaios do Capítulo 3, utilizou-se $T_{a}=10$ segundos, $L=200$ amostras e $\sigma_{\min }^{2}=0,05$. Estes parâmetros implicam em uma janela de amostragem de 2000 segundos que, a depender da severidade da golfada, poderá conter de 2 a 6 ciclos completos.

A eficácia do algoritmo pode ser verificada na Figura 31, em que são mostradas a pressão do topo do riser e a frequência estimada para um ensaio em que a válvula choke é aberta continuamente de 0 a 100\% ao longo de 12 horas de simulação. O ensaio foi realizado tanto com a utilização de controle estrito na pressão do vaso separador, quanto com a utilização de controle permissivo. 

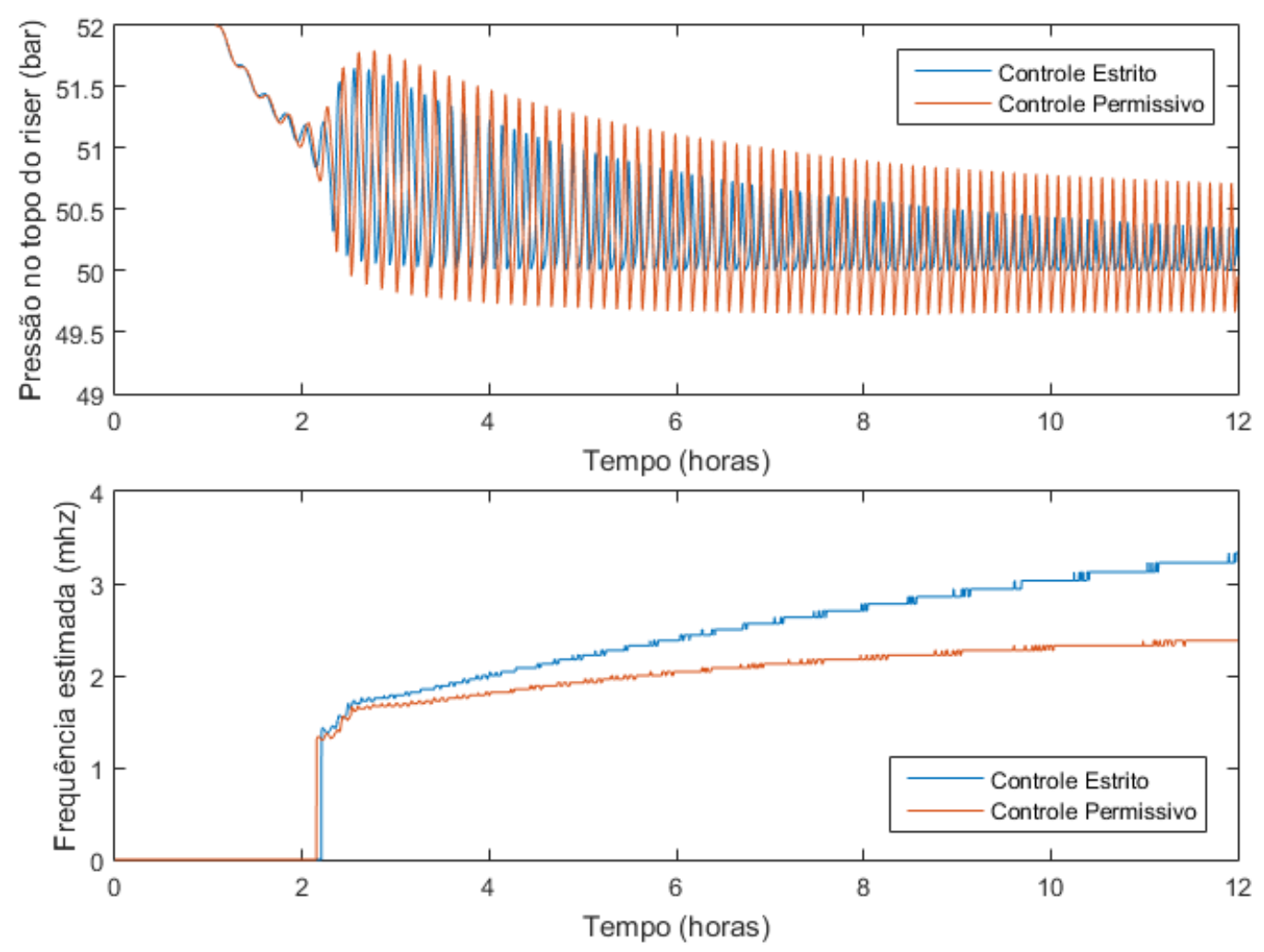

Figura 31 - Resultado do ensaio de verificação do algoritmo de autocorrelação para estimação de frequência.

Nota-se que o algoritmo foi capaz de estimar as frequências com alto grau de concordância em relação as frequências apresentadas nas Tabela 9 e Tabela 10, extraídas através de inspeção das formas de onda geradas nos Ensaios 1 e 2 apresentados no Capítulo 3.

Este ensaio reafirma a relação comentada anteriormente entre frequência, amplitude e severidade das golfadas, com aumento da frequência e diminuição da amplitude conforme cresce o grau de severidade das golfadas.

\subsection{2.}

\section{Sistema de Inferência Fuzzy}

A essência do controlador supressor de golfadas proposto baseia-se na execução de duas ações heurísticas: a primeira consiste no fechamento da válvula choke de uma forma específica enquanto o poço estiver golfando, e a segunda em manipular o ganho integral do PID em função do erro da variável controlada e da intensidade das golfadas a que o sistema de produção está submetido. 
Considerando a capacidade dos Sistemas de Inferência Fuzzy (SIF) de converterem regras heurísticas expressas de forma linguística em um algoritmo matemático executável de maneira relativamente simples, decidiu-se pela utilização de um SIF na implementação destas duas tarefas.

Para execução da função proposta, o SIF empregado no controlador utiliza duas entradas e duas saídas. As entradas são o erro da variável controlada e uma estimativa da severidade das golfadas no sistema, que nesta implementação foi aproximada pela frequência de oscilação. Por sua vez, as saídas do sistema são a constante integral do controlador PID, $k_{i}$, e uma ação de controle que é integrada e somada à saída do PID no sentido de fechar a válvula choke, chamada ação restritiva. Um diagrama do SIF descrito é apresentado na Figura 32.

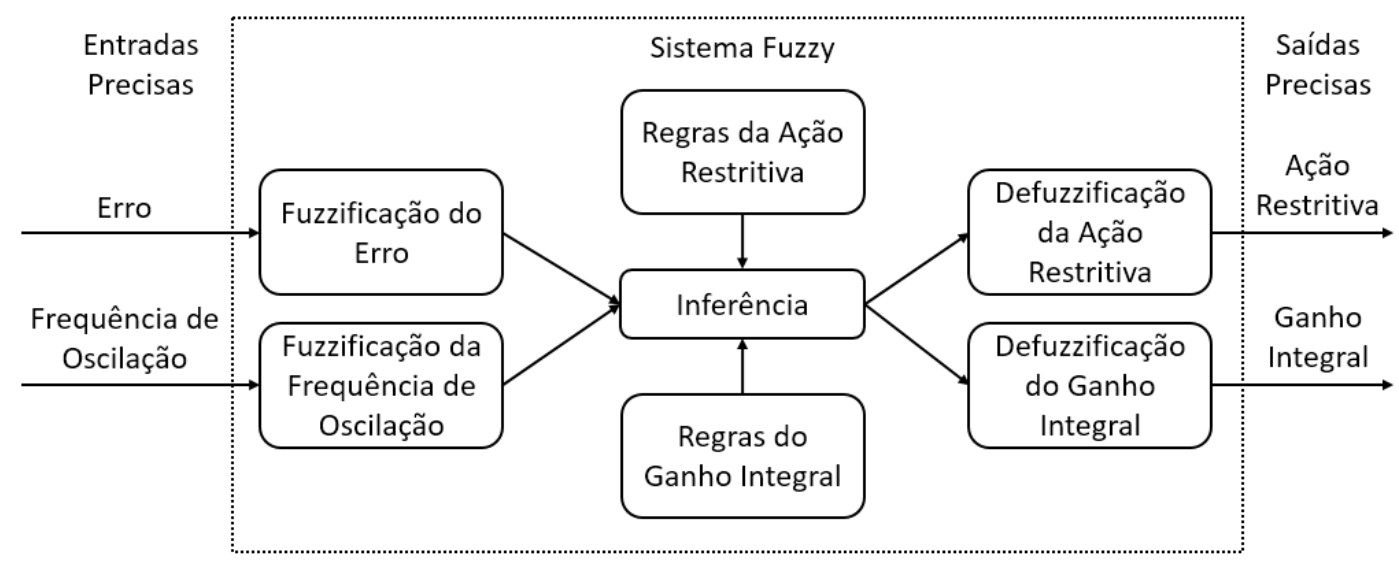

Figura 32 - Diagrama do sistema de inferência fuzzy utilizado no controlador supressor de golfadas.

É interessante notar que o sistema fuzzy mostrado na Figura 32 também pode ser entendido como dois sistemas fuzzy que compartilham os conjuntos fuzzy de entrada, operadores e método de defuzzificação, mas possuem base de regras e consequentes distintos.

\subsubsection{1.}

\section{Conjuntos de Entrada e Saída}

Com o objetivo de tornar a implementação do SIF a mais simples possível, utilizaram-se funções de pertinência triangulares e trapezoidais na definição dos termos das variáveis linguísticas de entrada e funções singleton nos termos das variáveis linguísticas de saída. 
Para a variável de entrada "Erro", considerou-se um universo de discurso de -3bar a 3bar e os cinco termos linguísticos mostrados na Figura 33.

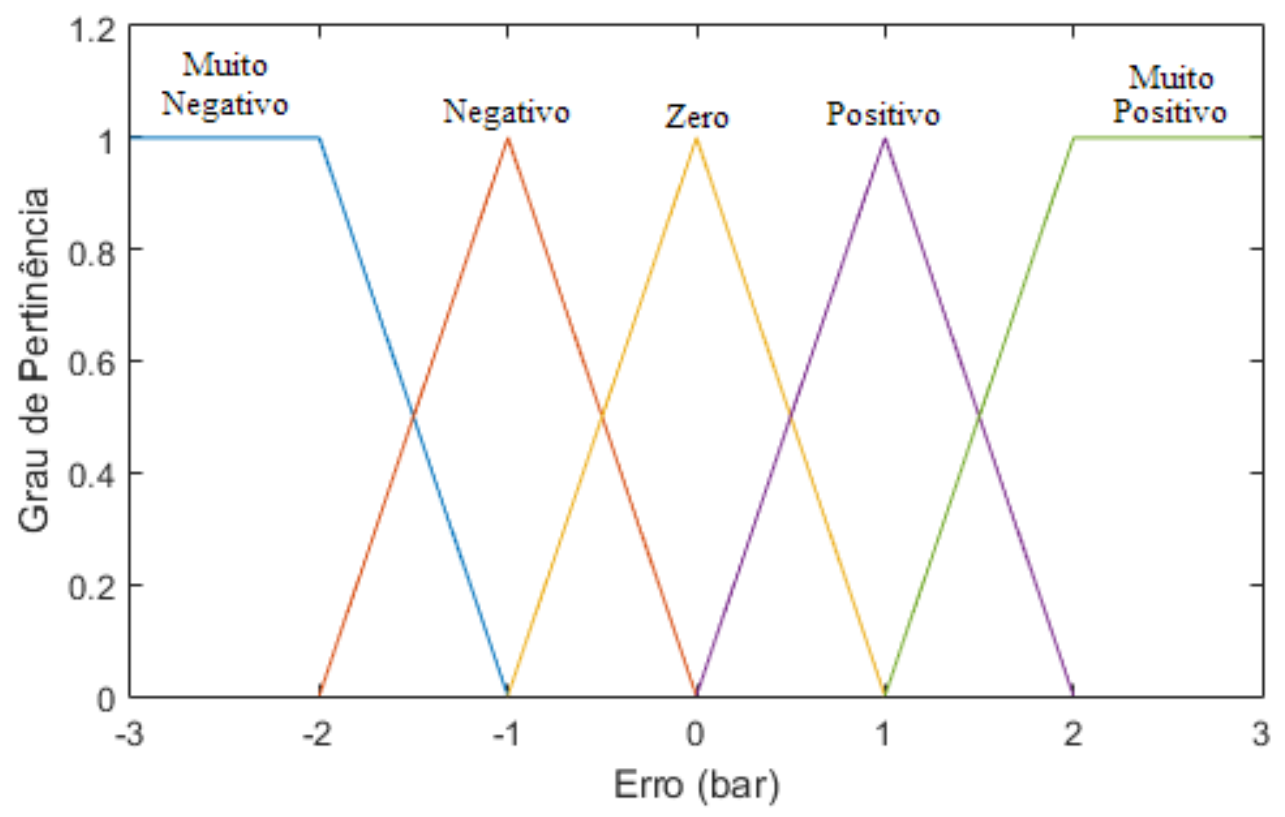

造

Figura 33 - Funções de pertinência da variável linguística "Erro".

Para variável de entrada "Frequência de Oscilação", considerou-se um universo de discurso de 0 a $4 \mathrm{mHz}$ (milihertz) e apenas dois termos linguísticos conforme mostrado na Figura 34.

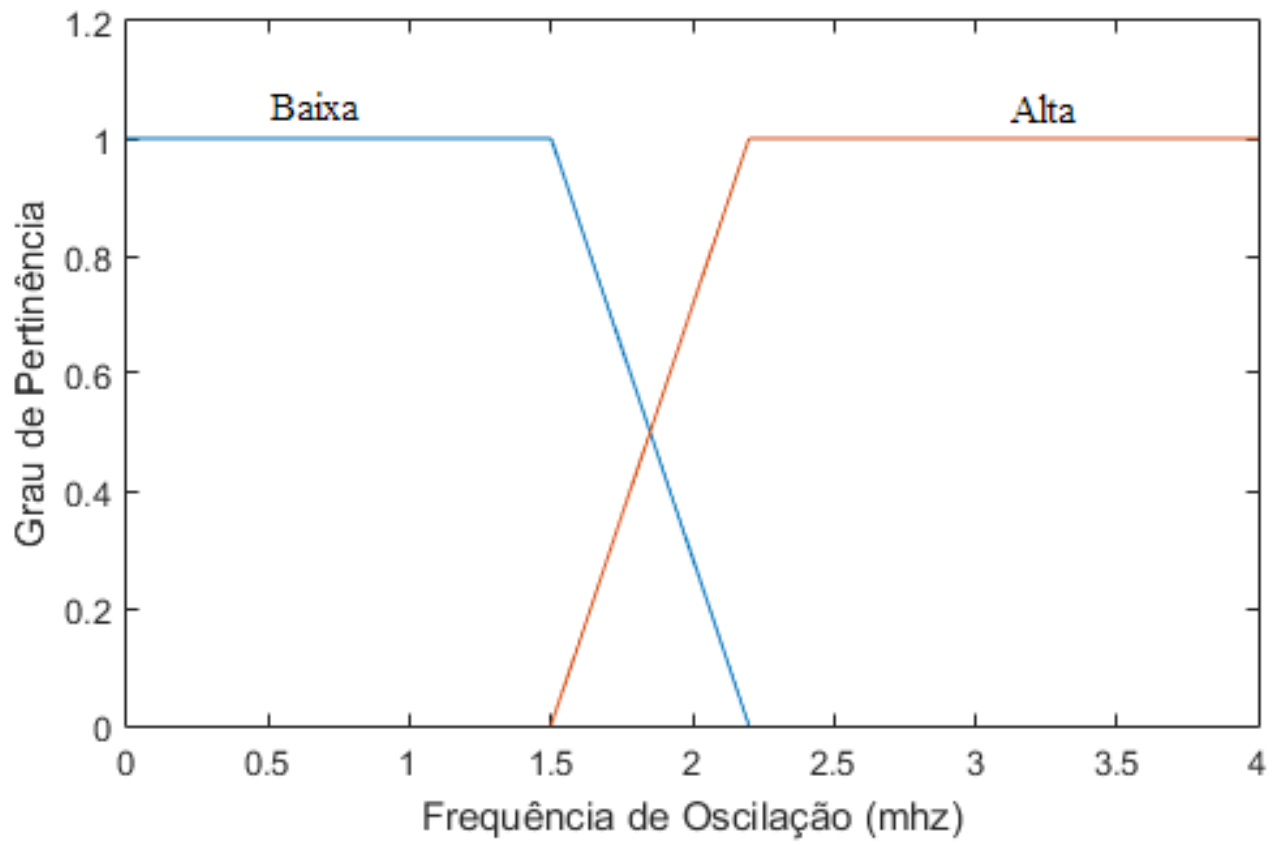

Figura 34 - Funções de pertinência da variável linguística "Frequência de Oscilação". 
É possível observar nos resultados dos ensaios do Capítulo 3, especificamente na Tabela 10, que as oscilações se iniciam com frequência em torno de 1,5 mHz e, portanto, o termo linguístico "frequência é baixa" tem significado similar ao termo "sistema não está golfando", enquanto o termo "frequência é alta" é similar ao termo "sistema está golfando".

A variável linguística de saída "Ação Restritiva” foi definida a partir de dois termos linguísticos, conforme pode ser observado na Figura 35.

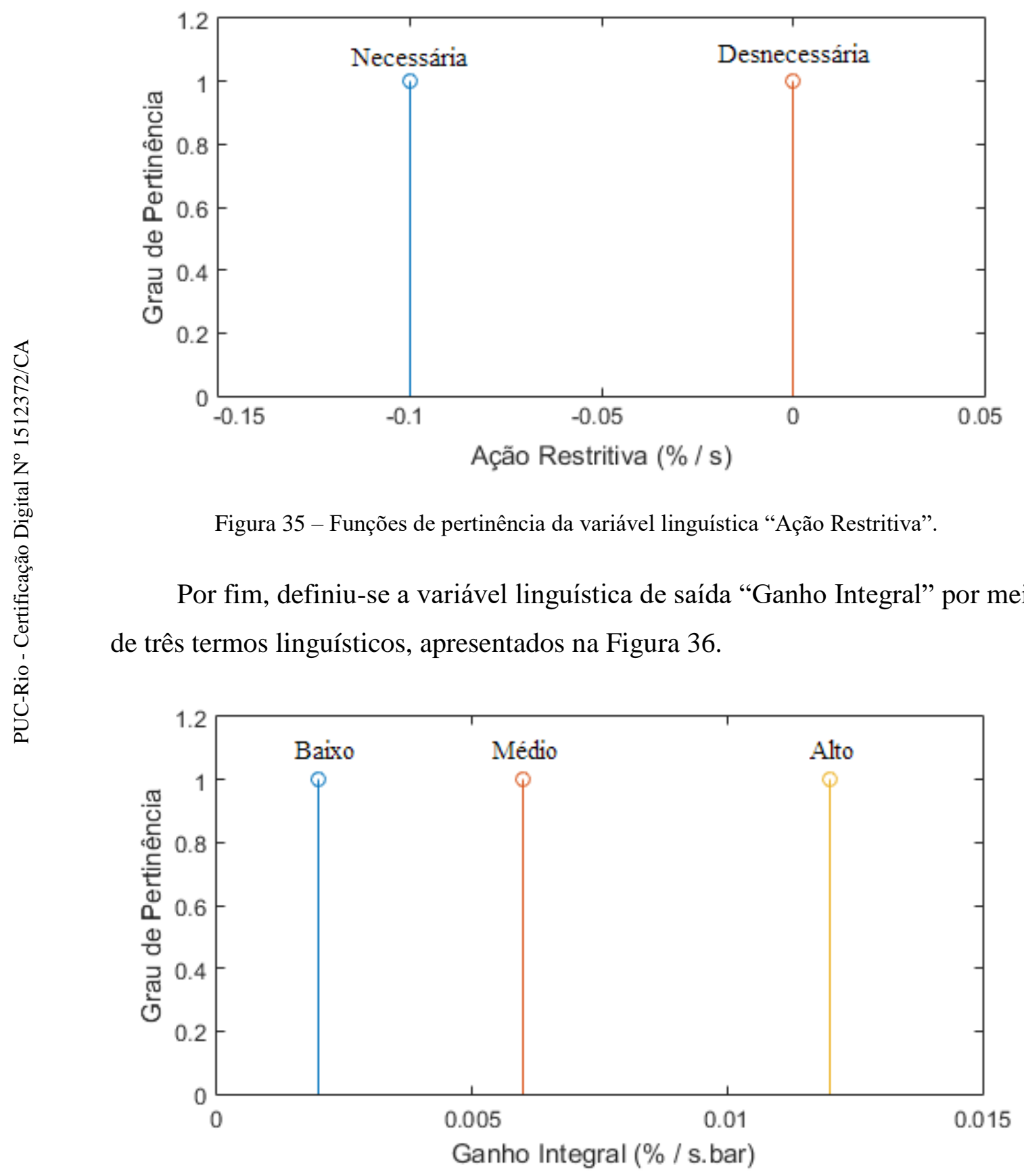

Figura 36 - Funções de pertinência da variável linguística "Ganho Integral". 


\subsubsection{2. Inferência Fuzzy}

Para realização da inferência do sistema fuzzy foram utilizados o operador produto para o conectivo "E" (interseção dos antecedentes), o mínimo para implicação e o máximo para agregação.

As regras de inferência utilizadas neste SIF foram definidas com base no conhecimento adquirido ao longo dos ensaios realizados no Capítulo 3, com o ajuste fino sendo realizado através de diversas simulações.

As regras linguísticas para definição da saída “Ação Restritiva” são:

1. Se o sistema não está golfando, então a ação restritiva é desnecessária.

2. Se o sistema está golfando e o erro é muito negativo, então a ação restritiva é necessária.

3. Se o sistema está golfando e o erro é negativo, então a ação restritiva é necessária.

4. Se o sistema está golfando e o erro é zero, então a ação restritiva é necessária.

5. Se o sistema está golfando e o erro é positivo, então a ação restritiva é desnecessária.

6. Se o sistema está golfando e o erro é muito positivo, então a ação restritiva é desnecessária.

É interessante realizar uma análise da motivação destas regras. A primeira regra decorre do fato de que o sistema fuzzy auxilia a estabilização do sistema com o fechamento gradual da choke somente durante a ocorrência de golfadas, não sendo necessária esta ação quando o escoamento está estabilizado.

As outras regras definem o seguinte comportamento: durante a ocorrência do ciclo da golfada, o sistema fuzzy tenderá a fechar a válvula choke somente quando a pressão estiver abaixo do setpoint e não tomará ação quando a pressão estiver acima, já que neste estágio do ciclo da golfada existe uma tendência à autoregulação.

Quanto à regra 4, notou-se um desempenho levemente superior com a atuação da ação restritiva na condição de "erro zero", mas um consequente "desnecessário" também poderia ter sido utilizado sem grande perda de desempenho. 
O algoritmo PID também tenderá a fechar a válvula choke durante a parcela negativa do ciclo, mas tenderá a abri-la durante a parcela positiva, o que, a depender da característica da golfada, poderá até mesmo agravar a instabilidade do escoamento. Por esta razão, é preciso reduzir a capacidade de atuação do controlador PID durante a ocorrência das golfadas. Isto é realizado pela manipulação do ganho integral do PID pelo SIF. As regras linguísticas que definem esta variável são:

1. Se o sistema está golfando, então o ganho integral é baixo.

2. Se o sistema não está golfando e o erro é muito negativo, então o ganho integral é alto.

3. Se o sistema não está golfando e o erro é negativo, então o ganho integral é alto.

4. Se o sistema não está golfando e o erro é zero, então o ganho integral é baixo.

5. Se o sistema não está golfando e o erro é positivo, então o ganho integral é médio.

6. Se o sistema não está golfando e o erro é muito positivo, então o ganho integral é alto.

Observando as regras, percebe-se que além de reduzirem o ganho integral durante a ocorrência de golfadas, melhoram a capacidade do algoritmo PID na rejeição de perturbações devido ao ganho integral não linear, que aumenta com o erro. A assimetria entre as regras 3 e 5 é decorrente do fato de que o controlador pode ser mais agressivo ao fechar a válvula choke, uma vez que esta é uma ação estabilizante.

\subsubsection{3.}

\section{Defuzzificação}

Em virtude da utilização de funções singleton na definição dos termos das variáveis de saída, o processo de defuzzificação degenera-se em uma simples média ponderada dos valores de suporte dos conjuntos singleton, onde o peso de cada consequente é dado pelo maior grau de ativação entre as regras que o ativaram.

Nas Figura 37 e Figura 38 são mostradas as superfícies de respostas das variáveis de saída do sistema de inferência fuzzy descrito nesta seção. Nelas é 
possível verificar graficamente que o sistema de inferência fuzzy desenvolvido apresenta o comportamento desejado, que foi descrito linguisticamente pelas regras de inferência fuzzy.

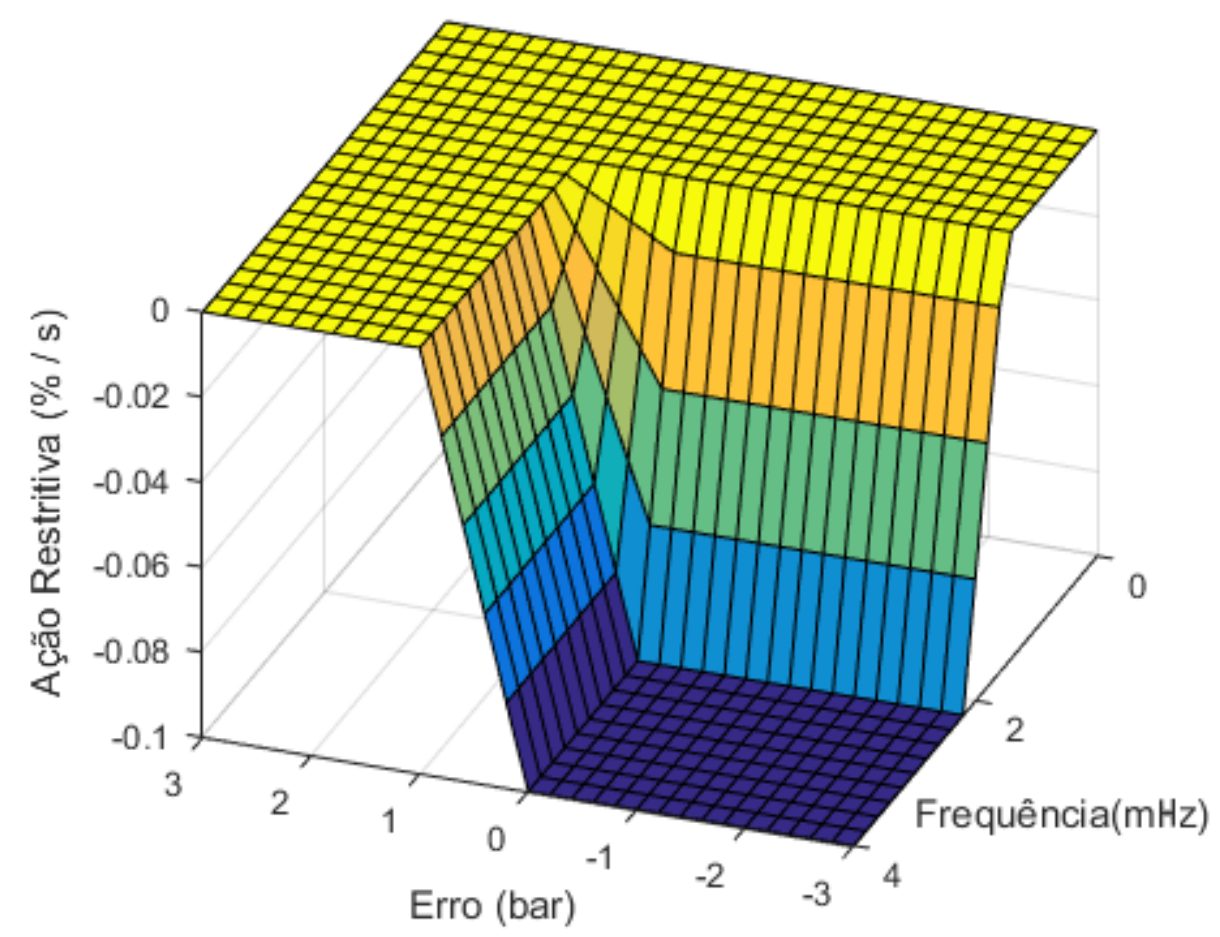

Figura 37 - Superfície de resposta do SIF para a variável de saída "Açao Restritiva".

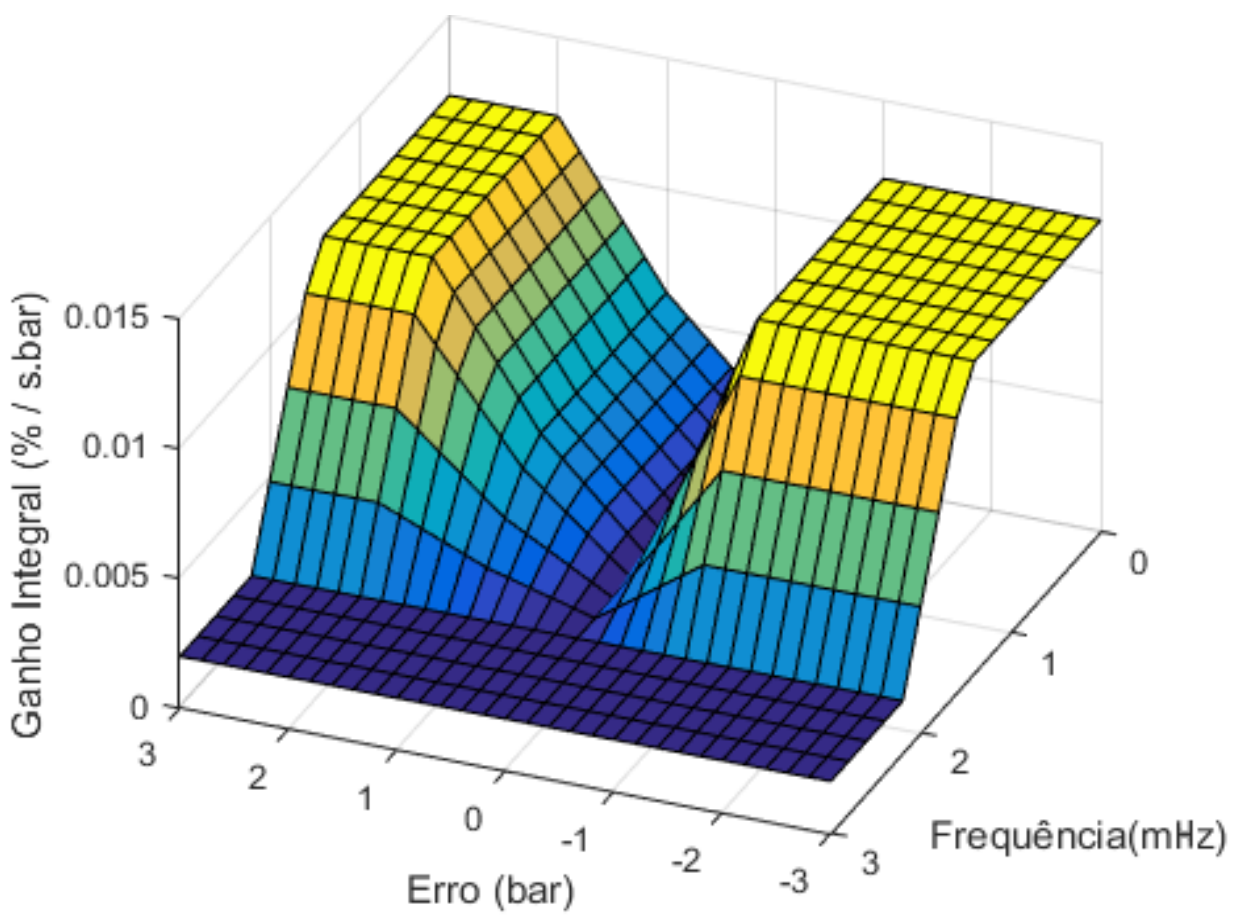

Figura 38 - Superfície de resposta do SIF para a variável de saída "Ganho Integral”. 


\subsection{3.}

\section{Algoritmo PID}

Além do estimador de frequência e do sistema de inferência fuzzy, o controlador supressor de golfadas também utiliza um algoritmo PID em sua estrutura, com o objetivo de melhorar a capacidade regulatória do controlador e possibilitar o rastreamento de um setpoint.

O algoritmo PID utilizado foi levemente modificado com objetivo de melhor integrá-lo ao restante do controlador e ao sistema controlado. A primeira modificação, já discutida, foi a utilização de um ganho integral variável, diminuindo a sua interferência com a ação do controlador fuzzy durante as golfadas e melhorando sua capacidade de regulação durante a operação estável.

Outra modificação introduzida, bastante comum em aplicações industrias, foi a utilização de um algoritmo anti-clamping na ação integral, que impossibilita que esta aumente quando a saída está em 100\% ou decresça quando a saída está em 0\%. Este algoritmo também foi utilizado na ação restritiva, gerada pelo SIF, já que a mesma também passa por uma integração antes de ser somada às ações do PID.

Por fim, também foi utilizado um termo derivativo em série com um filtro passa baixa de primeira ordem, evitando que ruídos de medição influenciem demasiadamente na ação derivativa. Esta modificação também é muito comum em aplicações industriais.

O ganho proporcional, $K_{p}$, e o ganho derivativo, $K_{d}$, são considerados constantes e foram sintonizados através da execução de diversas simulações, resultando em $0,5 \% /$ bar para $K_{p}$ e 1200 s.\%/bar para $K_{d}$. 


\section{2.}

\section{Controlador Amortecedor de Golfadas}

Conforme discutido no Capítulo 2 e posteriormente observado nos resultados dos ensaios do Capítulo 3, as grandes oscilações nas vazões de produção de óleo e gás, características de um sistema de produção sujeito a golfadas, podem ser atenuadas por meio do aproveitamento da capacitância dos vasos separadores com a utilização de controladores de nível que reduzam a intensidade de sua ação sempre que o nível se situe dentro de uma faixa aceitável, denominada banda.

Controladores que se utilizam desta estratégia representam uma boa alternativa para diminuição do efeito nocivo das golfadas nos sistemas de produção sempre que as causas fundamentais destas não puderem ser suprimidas em sua origem. Estes algoritmos de controle possuem características não-lineares em relação ao erro, uma vez que a intensidade da ação de controle depende da localização do nível em relação à banda, com uma ação lenta dentro da banda e rápida fora desta. Os três algoritmos apresentados na fundamentação teórica, propostos por Nunes [11], Campos [27] e Sausen [28], implementam esta não linearidade através de mudanças na estrutura de controladores PID, ao invés da utilização de controladores inerentemente não lineares.

Neste trabalho, é proposta a utilização de um controlador fuzzy na implementação desta estratégia de controle não-linear, uma vez que sistemas fuzzy possibilitam a incorporação de não-linearidades de forma natural e com maior versatilidade, além de permitirem uma melhor interpretação do algoritmo desenvolvido. Por outro lado, controladores fuzzy costumam possuir um número bastante elevado de parâmetros de ajustes, dificultando significativamente sua sintonia, até mesmo quando um modelo computacional da planta se encontra disponível para realização de ensaios. Para facilitar esta sintonia, também foi desenvolvido um algoritmo genético que tem como objetivo otimizar os conjuntos e regras do controlador fuzzy, com base em simulações computacionais realizadas a partir do modelo desenvolvido no Capítulo 3. 


\subsection{1.}

\section{Estrutura do Controlador}

O controlador fuzzy utilizado neste trabalho possui as mesmas entradas e a mesma saída de um controlador PI implementado por um algoritmo de velocidade [42], descrito pelas seguintes equações:

$$
\begin{gathered}
z_{L S}(n)=z_{L S}(n-1)+\Delta z_{L S}(n) \\
\Delta z_{L S}(n)=k_{P}(e(n)-e(n-1))+k_{i} T_{S} e(n)
\end{gathered}
$$

em que:

$n$ é o indexador da amostragem. [-]

$Z_{L S}$ é a abertura da válvula de saída de líquido. [\%]

$\Delta z_{L S}$ é a variação da abertura da válvula de saída de líquido. [\%]

$e$ é o erro da variável controlada. [\%]

$k_{p}$ é o ganho proporcional do controlador PI. [\%/m] (Constante)

$k_{i}$ é o ganho integral do controlador PI. [\%/s.m] (Constante)

$T_{s}$ é o tempo de amostragem. [s] (Constante).

Uma rápida análise da Equação (4.2) revela que o algoritmo de velocidade do controlador PI tem como entradas o erro e a diferença do erro e como saída a variação da variável controlada, que é somada cumulativamente para determinação da saída do controlador. O controlador fuzzy amortecedor de golfadas desenvolvido neste trabalho possui esta mesma estrutura, diferenciando-se pela utilização de um sistema de inferência fuzzy em substituição à relação linear apresentada na Equação (4.2), como pode ser observado no diagrama do controlador, apresentado na Figura 39.

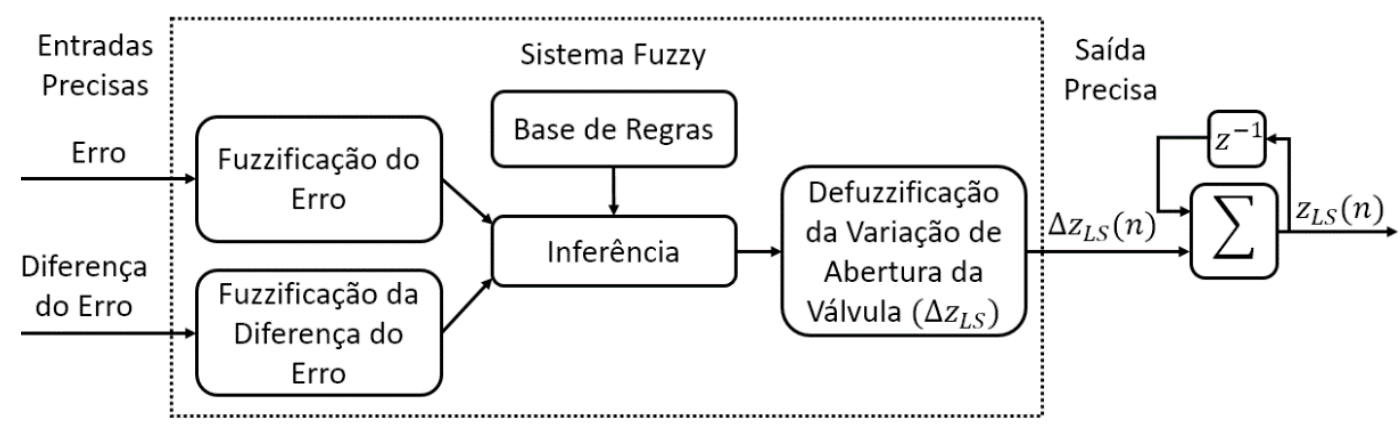

Figura 39 - Diagrama do controlador amortecedor de golfadas, com ênfase no sistema de inferência fuzzy. 


\subsection{2.}

\section{Sistema de Inferência Fuzzy}

Assim como no controlador supressor de golfadas, o sistema de inferência fuzzy do controlador amortecedor de golfadas foi especificado com o objetivo de tornar a implementação tão simples quanto possível.

Além de facilitar a aplicação do controlador, um SIF simples permitiu uma redução do número de parâmetros de sintonia a serem otimizados e também uma diminuição significativa no custo computacional do algoritmo. Estas características permitiram a diminuição do espaço de busca e do tempo de execução do algoritmo genético utilizado para sintonia do controlador.

Em essência, a simplicidade do controlador consistiu na utilização de funções de pertinência trapezoidais e triangulares para as variáveis de entrada, funções de pertinência singleton para a saída, defuzzificação simplificada e, principalmente, utilização de simetria nas funções de pertinência e na base de regras.

\subsubsection{1. Fuzzificação das Entradas}

Para a variável "Erro", utilizaram-se cinco funções de pertinência, que são sintetizadas a partir de três números reais positivos, $E_{P 1}, E_{P 2}$ e $E_{P 3}$, sujeitos a seguinte restrição: $E_{P 1}<E_{P 2}<E_{P 3}$. Na Figura 40, é possível observar como estes parâmetros são utilizados na definição das funções de pertinência.

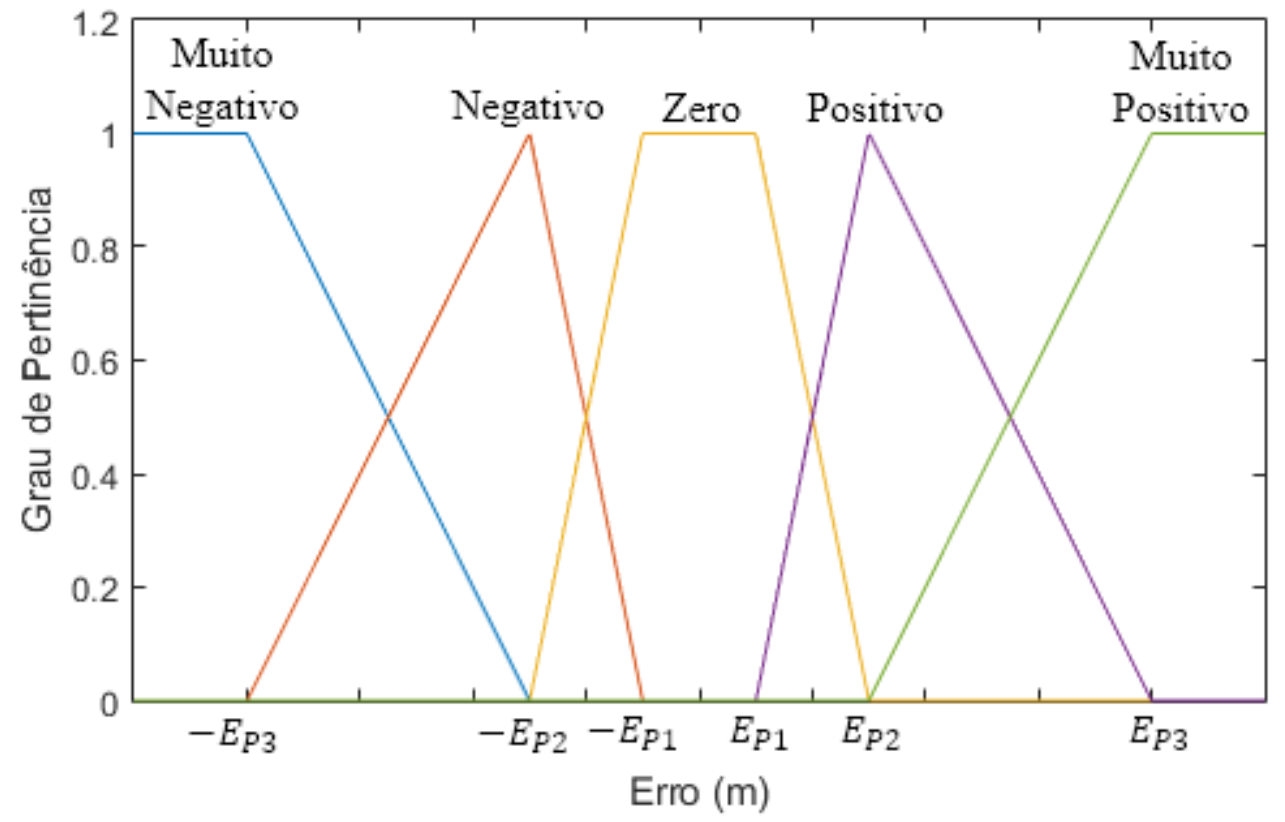

Figura 40 - Funções de pertinência da variável linguística "Erro". 
Analisando as funções apresentadas, é possível perceber que as mesmas foram definidas a partir de interpolações lineares entre seis números reais, que consistem nos três parâmetros e seus opostos. A utilização dos opostos reduz a quantidade de parâmetros de sintonia pela metade e tem como consequência direta a simetria das funções de pertinência em torno de zero. Além disto, a topologia adotada garante que, para qualquer valor da variável "Erro", no máximo dois graus de pertinência serão maiores do que 0 , limitando o número de regras ativadas a cada avaliação do SIF.

O mesmo processo de síntese das funções de pertinência foi utilizado para a variável "Diferença do Erro", com o diferencial de que apenas três termos linguísticos foram necessários para a obtenção de bons resultados. As funções de pertinência relativas a estes termos são sintetizadas a partir de dois números reais positivos, $D_{P 1}$ e $D_{P 2}$, sujeitos à seguinte restrição: $D_{P 1}<D_{P 2}$.

Na Figura 41, mostra-se como estes parâmetros são utilizados na definição das funções de pertinência, observando-se a adoção da mesma heurística utilizada para a variável "Erro".

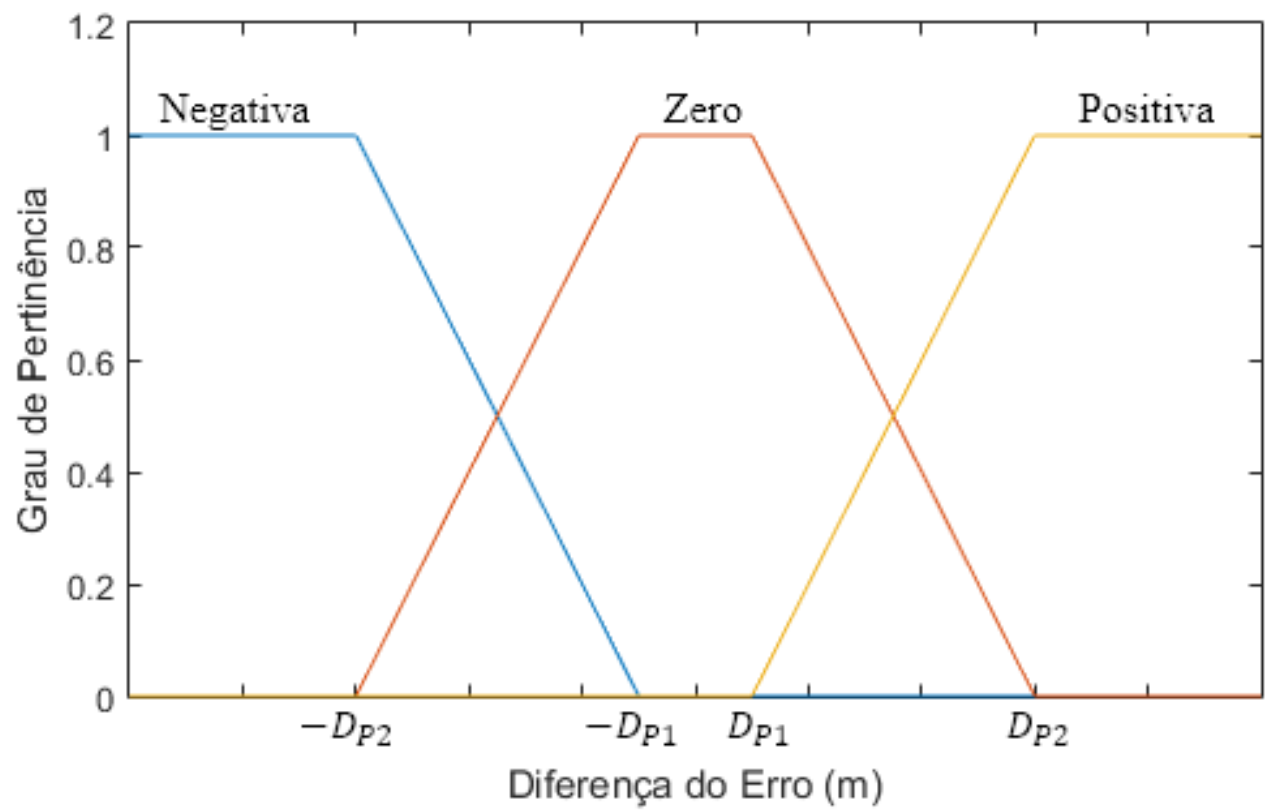

Figura 41 - Funções de pertinência da variável linguística "Diferença do Erro". 


\subsubsection{2.}

\section{Defuzzificação da Saída}

Para a variável linguística de saída, "Variação de Abertura da Válvula", utilizaram-se cinco funções de pertinência singleton, sintetizadas a partir de dois números reais positivos, $V_{P 1}$ e $V_{P 2}$, sujeitos à seguinte restrição: $V_{P 1}<V_{P 2}$. Na Figura 42, é possível observar como estes parâmetros são utilizados na definição das funções de pertinência.

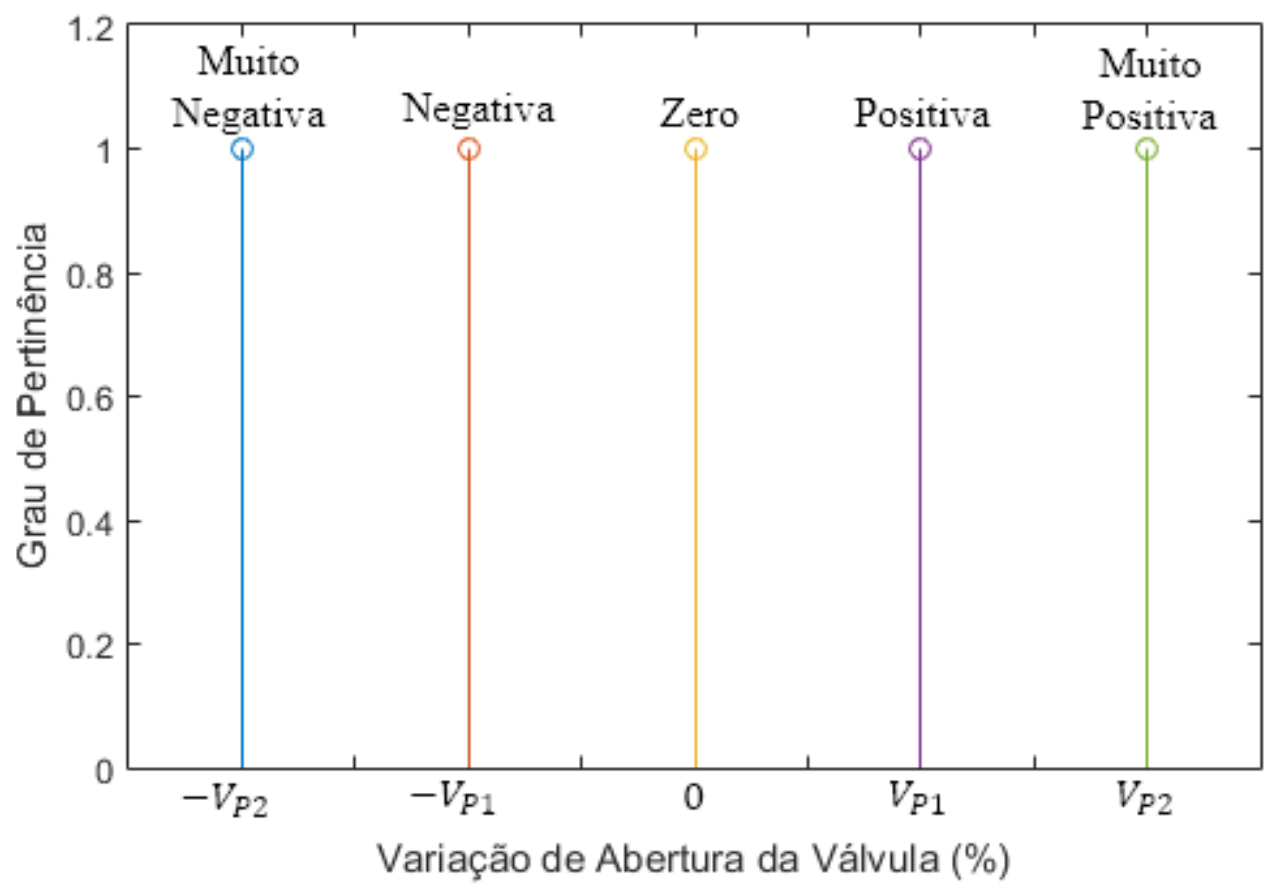

Figura 42 - Funções de pertinência da variável linguística "Variação de Abertura da Válvula".

Além da utilização dos parâmetros $V_{P 1}$ e $V_{P 2}$ e seus opostos como suporte das funções de pertinência singleton, também foi adicionado o termo linguístico singleton "Zero", com suporte fixo no valor real 0.

Com objetivo de simplificar o processo de defuzzificação, foram adotados o operador mínimo para implicação e o operador máximo para agregação, que em conjunto com funções de pertinência singleton na variável de saída, degeneram o processo de defuzzificação em uma simples média ponderada dos valores de suporte das funções singletons, onde o peso de cada consequente é dado pelo maior grau de ativação das regras. 


\subsubsection{3. Regras de Inferência Fuzzy}

Assim como na definição das funções de pertinência, as regras de inferência do SIF também são definidas através de parâmetros, sujeitos a otimização. Estes parâmetros podem assumir valores inteiros entre -2 e 2, com cada valor associado a um termo do consequente de acordo a seguinte regra:

- -2: A regra equivalente aciona o termo linguístico "Muito Negativa".

- -1: A regra equivalente aciona o termo linguístico "Negativa".

- 0: A regra equivalente aciona o termo linguístico "Zero".

- 1: A regra equivalente aciona o termo linguístico "Positiva".

- 2: A regra equivalente aciona o termo linguístico "Muito Positiva".

Como a variável "Erro" possui cinco termos linguísticos e a variável "Diferença do Erro" possui três, seriam necessários quinze parâmetros para determinação do consequente de todas as regras. No entanto, este número foi reduzido ao se forçar uma simetria na base de regras, imposta pela restrição de que regras com consequentes simétricos devem implicar em um consequente oposto. Dessa forma, por exemplo, se a premissa "O erro é muito positivo e a diferença do erro é negativa" ativa o consequente "A variação da abertura da válvula é positiva", força-se a regra "O erro é muito negativo e a diferença do erro é positiva" a ativar o consequente oposto "A variação da abertura da válvula é negativa".

Ademais, decidiu-se por adotar o consequente fixo "A variação da abertura da válvula é zero" para a premissa "O erro é zero e a diferença de erro é zero", que não possui simétrico distinto. Em tese, esta regra também poderia ser aprendida a partir de um parâmetro exclusivo para ela, mas optou-se por retirá-la do algoritmo de otimização em virtude de sua obviedade.

Desta forma, o número de parâmetros necessários para a definiç̧ão das regras do SIF proposto é reduzido de quinze para sete, denominados $R_{1}, R_{2}, R_{3}, R_{4}, R_{5}, R_{6}$ e $R_{7}$, sujeitos à restrição $-2 \leq R_{n} \leq 2, R_{n} \in \mathbb{Z}$. A forma como cada um destes parâmetros define a regra do SIF é apresentada na Tabela 11. 
Tabela 11 - Heurística utilizada na síntese das quinze regras a partir dos parâmetros $R_{n}$.

\begin{tabular}{c|c|c|c}
$\begin{array}{c}\text { Parâmetro } \\
\boldsymbol{R}_{\boldsymbol{n}}\end{array}$ & Erro & $\begin{array}{c}\text { Diferença do } \\
\text { Erro }\end{array}$ & $\begin{array}{c}\text { Variação de Abertura } \\
\text { da Válvula }\end{array}$ \\
\hline$R_{1}$ & Zero & Positiva & Termo associado a $R_{1}$ \\
& Zero & Negativa & Termo associado a $-R_{1}$ \\
$R_{2}$ & Positivo & Zero & Termo associado a $R_{2}$ \\
& Negativo & Zero & Termo associado a $-R_{2}$ \\
$R_{3}$ & Positivo & Positiva & Termo associado a $R_{3}$ \\
$R_{4}$ & Negativo & Negativa & Termo associado a $-R_{3}$ \\
& Positivo & Negativa & Termo associado a $R_{4}$ \\
$R_{5}$ & Muito positivo & Positiva & Termo associado a $-R_{4}$ \\
& Muito negativo & Zero & Termo associado a $R_{5}$ \\
$R_{6}$ & Muito positivo & Positiva & Termo associado a $-R_{5}$ \\
& Muito negativo & Negativa & Termo associado a $R_{6}$ \\
$R_{7}$ & Muito positivo & Negativa & Termo associado a $R_{7}$ \\
- & Muito negativo & Positiva & Termo associado a $-R_{7}$ \\
& Zero & Zero & Zero \\
& & &
\end{tabular}

Escolheu-se o operador mínimo para implementação do conectivo linguístico "E", mas outros operadores t-norma podem ser utilizados sem maiores impactos na funcionalidade do sistema.

\subsubsection{4. \\ Considerações sobre o Sistema de Inferência Fuzzy}

Embora vários graus de liberdade do sistema de inferência fuzzy tenham sido eliminados pelas definições realizadas nesta seção, ainda se faz necessária a determinação dos valores de cada um dos parâmetros apresentados para que o controlador esteja perfeitamente definido e possa ser aplicado.

Ao todo, o sistema possui quatorze parâmetros de sintonia, cinco para definir os antecedentes, dois para o consequente e sete para definição das regras. A tarefa de sintonizar todos estes parâmetros não é simples, mesmo com auxílio de um modelo matemático, e, portanto, optou-se por utilizar uma metodologia automática de sintonia, baseada em algoritmo genético e detalhada a seguir. 


\subsection{3.}

\section{Sintonia por Algoritmo Genético}

Ao longo desta seção, explica-se em detalhes como um algoritmo genético foi aplicado ao problema de sintonia do controlador amortecedor de golfadas.

\subsubsection{1.}

\section{Indivíduo e Cromossomo}

O indivíduo do problema em questão é caracterizado por um cromossomo composto por quatorze genes, onde cada gene representa um dos parâmetros de sintonia do controlador amortecedor de golfadas. A Tabela 12 apresenta o cromossomo de um indivíduo, em conjunto com suas características, como domínio, limite inferior, limite superior e restrição.

Tabela 12 - Caracterização do cromossomo de um indivíduo.

\begin{tabular}{|c|c|c|c|c|c|}
\hline Genes & Pertinência & Domínio & $\begin{array}{c}\text { Limite } \\
\text { Inferior }\end{array}$ & $\begin{array}{c}\text { Limite } \\
\text { Superior }\end{array}$ & $\begin{array}{l}\text { Restrição } \\
\text { Adicional }\end{array}$ \\
\hline$E_{P 1}$ & Precedente & Real & 0 & $1 \mathrm{~m}$ & $<E_{P 2}$ \\
\hline$E_{P 2}$ & Precedente & Real & 0 & $1 \mathrm{~m}$ & $<E_{P 3}$ \\
\hline$E_{P 3}$ & Precedente & Real & 0 & $1 \mathrm{~m}$ & - \\
\hline$D_{P 1}$ & Precedente & Real & 0 & $0,01 \mathrm{~m}$ & $<D_{P 2}$ \\
\hline$D_{P 2}$ & Precedente & Real & 0 & $0,01 \mathrm{~m}$ & - \\
\hline$V_{P 1}$ & Consequente & Real & 0 & $10 \%$ & $<V_{P 2}$ \\
\hline$V_{P 2}$ & Consequente & Real & 0 & $10 \%$ & - \\
\hline$R_{1}$ & Regra & Inteiro & -2 & 2 & - \\
\hline$R_{2}$ & Regra & Inteiro & -2 & 2 & - \\
\hline$R_{3}$ & Regra & Inteiro & -2 & 2 & - \\
\hline$R_{4}$ & Regra & Inteiro & -2 & 2 & - \\
\hline$R_{5}$ & Regra & Inteiro & -2 & 2 & - \\
\hline$R_{6}$ & Regra & Inteiro & -2 & 2 & - \\
\hline$R_{7}$ & Regra & Inteiro & -2 & 2 & - \\
\hline
\end{tabular}




\subsubsection{2.}

\section{População e Reprodução}

Na otimização do problema proposto, foi utilizada uma população de 50 indivíduos, com a primeira geração criada aleatoriamente. As gerações subsequentes foram formadas pelos 3 melhores indivíduos da geração anterior, 37 novos indivíduos gerados a partir de cruzamento cromossômico e 10 novos indivíduos gerados a partir de mutação.

A seleção dos indivíduos para formação de gerações subsequentes foi realizada por meio da técnica da roleta, favorecendo assim indivíduos com maior aptidão. Naturalmente, para cada indivíduo gerado por cruzamento são selecionados dois pais, enquanto um indivíduo gerado por mutação exige a seleção de apenas um pai.

A técnica de cruzamento utilizada consiste na geração de um descendente através da média ponderada dos cromossomos dos pais, onde o primeiro tem o peso $p$ e o segundo tem o peso $(1-p)$, onde $p$ é uma variável aleatória uniforme no intervalo $[0,1]$. Como os últimos sete genes precisam ser inteiros, o valor obtido pelo cruzamento desses genes é aproximado para o inteiro mais próximo após a computação da média ponderada.

Já a técnica de mutação utilizada consistiu em somar aos genes do cromossomo pai valores aleatórios uniformemente distribuídos no intervalo $[-a R, a R]$, em que $a$ é um valor que se inicia em 1 e decai ao longo das gerações e $R$ é a faixa de valores do gene em questão. Essa soma é limitada pelas restrições estabelecidas aos genes, evitando a criação de descentes inválidos. No caso dos genes inteiros, o valor obtido é aproximado para o inteiro mais próximo.

O critério de parada adotado foi o atingimento da $200^{\text {a }}$ geração, ou melhoria na aptidão do melhor indivíduo inferior a $0,1 \%$ durante 15 gerações.

\subsubsection{3.}

\section{Função de Avaliação}

Uma das definições mais importantes de um algoritmo genético é a da função que avalia a aptidão de um indivíduo, especialmente em casos em que a aptidão não é uma quantidade matemática explícita. Exemplos de quantidades explícitas são: volume de ferro em uma estrutura e área de um circuito integrado. 
No caso em questão, a aptidão do indivíduo é medida pela capacidade do controlador correspondente em manter o nível dentro de uma faixa considerada aceitável, ao mesmo tempo em que minimiza variações na vazão de saída. Essa definição é qualitativa e, portanto, faz-se necessário convertê-la em uma grandeza matemática para utilização no algoritmo genético.

A solução adotada foi a realização de uma simulação numérica para cada controlador gerado pelo algoritmo genético, de forma a possibilitar a medição quantitativa das capacidades de regulação e de amortecimento das variações.

O modelo de processo utilizado nesta simulação foi o desenvolvido no Capítulo 3, desprezando-se a dinâmica de pressão do vaso, uma vez que esta simplificação aumenta significativamente a velocidade de simulação sem impacto significativo no resultado final. Sendo assim, a equação que rege as variações do nível do vaso separador em função do tempo é dada por:

$$
\dot{L}_{S}=\frac{w_{L S i n}-z_{L S} K_{4} \sqrt{\rho_{L}\left(P_{G S}+\rho_{L} g L_{S}-P_{A}\right)}}{\rho_{L} H_{S} \sqrt{8 L_{S} r_{S}-4 L_{S}^{2}}}
$$

em que:

$L_{S}$ é o nível de líquido no separador. $[\mathrm{m}]$

$w_{L S i n}$ é a vazão de entrada de líquido no separador. $[\mathrm{kg} / \mathrm{s}]$

$Z_{L S}$ é a abertura da válvula de líquido do separador (Saída do Controlador). [\%]

$K_{4}$ é a constante de vazão da válvula de líquido. $\left[\mathrm{m}^{-2}\right]$ (Constante)

$\rho_{L}$ é a densidade do líquido. $\left[\mathrm{kg} / \mathrm{m}^{3}\right]$ (Constante)

$P_{G S}$ é a pressão do gás no vaso separador. [bar] (Constante)

$P_{A}$ é a pressão a jusante da válvula. [bar] (Constante)

$H_{S}$ é o comprimento do separador. $[m]$ (Constante)

$r_{S}$ é o raio da seção transversal do separador. [m] (Constante)

Os valores das constantes foram os mesmos utilizados nas simulações do Capítulo 3, conforme apresentado na Tabela 8. Utilizou-se uma curva de vazão de líquido de entrada, $w_{L S i n}(t)$, padrão, sintetizada a partir das formas de onda de golfadas obtidas nos ensaios do Capítulo 3 para aberturas de válvulas de 30\% e $80 \%$, somadas à perturbações em formato de degraus e ruído, como pode ser observado na Figura 43. 


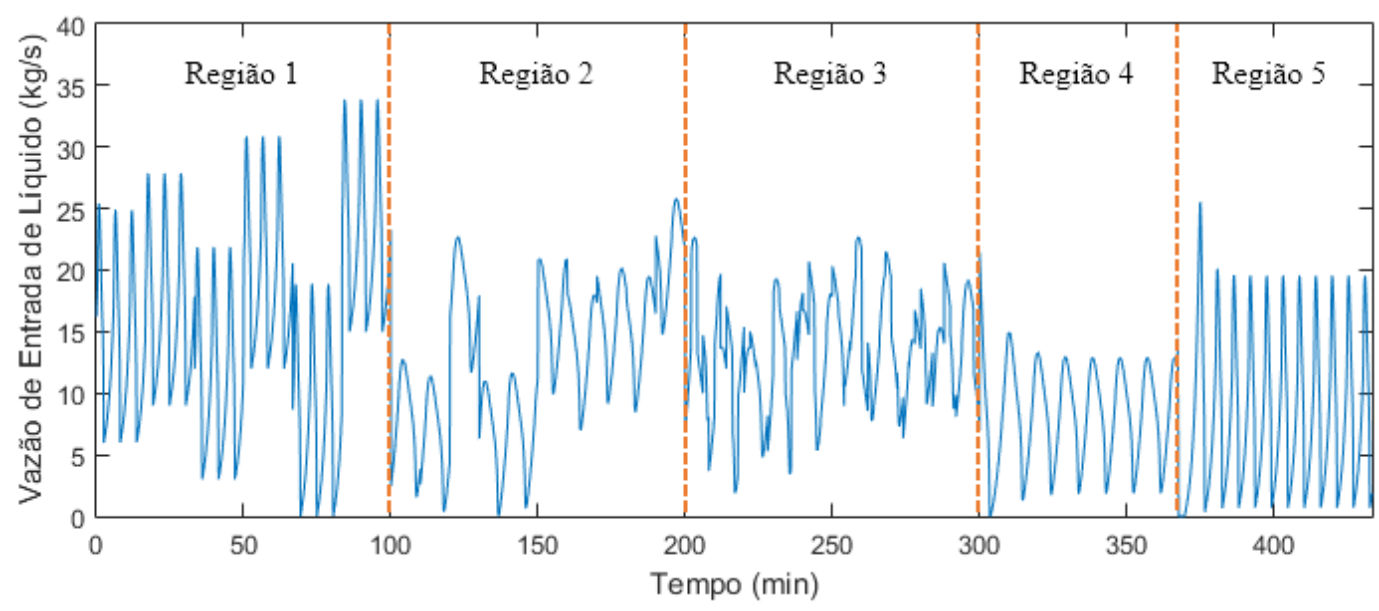

Figura 43 - Vazão de entrada de líquido utilizada na simulação para obtenção de aptidão.

A forma de onda apresentada na Figura 43 foi obtida após intensa experimentação e tem como objetivo estimular o sistema com diferentes tipos de perturbação além das golfadas, especialmente com degraus que tendem a demandar mais da capacidade regulatória do controlador.

As regiões marcadas na imagem foram sintetizadas da seguinte forma:

- Região 1: Golfadas a 80\% mais degraus alternados e crescentes.

- Região 2: Golfadas a 30\% mais degraus de valor aleatório.

- Região 3: Golfadas a 30\% mais ruído gaussiano de média positiva.

- Região 4: Golfadas a $30 \%$.

- Região 5: Golfadas a $80 \%$.

Definidos o controlador, o modelo de processo e a vazão de entrada, é possível realizar a simulação através da solução numérica da Equação (4.3), obtendo-se as formas de onda do nível do vaso, $L_{S}(t)$, e da vazão de saída de líquido, $w_{L S}(t)$, associadas ao indivíduo que está tendo sua aptidão medida.

Para avaliar a capacidade de regulação do controlador, utilizou-se uma função, representada na Figura 44, que associa um custo à cada amostra da função $L_{S}(t)$. Este custo é nulo para um erro absoluto menor do que $0,15 \mathrm{~m}$, cresce lentamente entre $0,15 \mathrm{~m}$ e $0,30 \mathrm{~m}$ e rapidamente acima de $0,30 \mathrm{~m}$. Desta forma, a banda não é definida por limites precisos, mas sim de forma contínua, embora seja possível afirmar que a banda preferencial situa-se entre os limites $-0,15 \mathrm{~m}$ e $0,15 \mathrm{~m}$. 


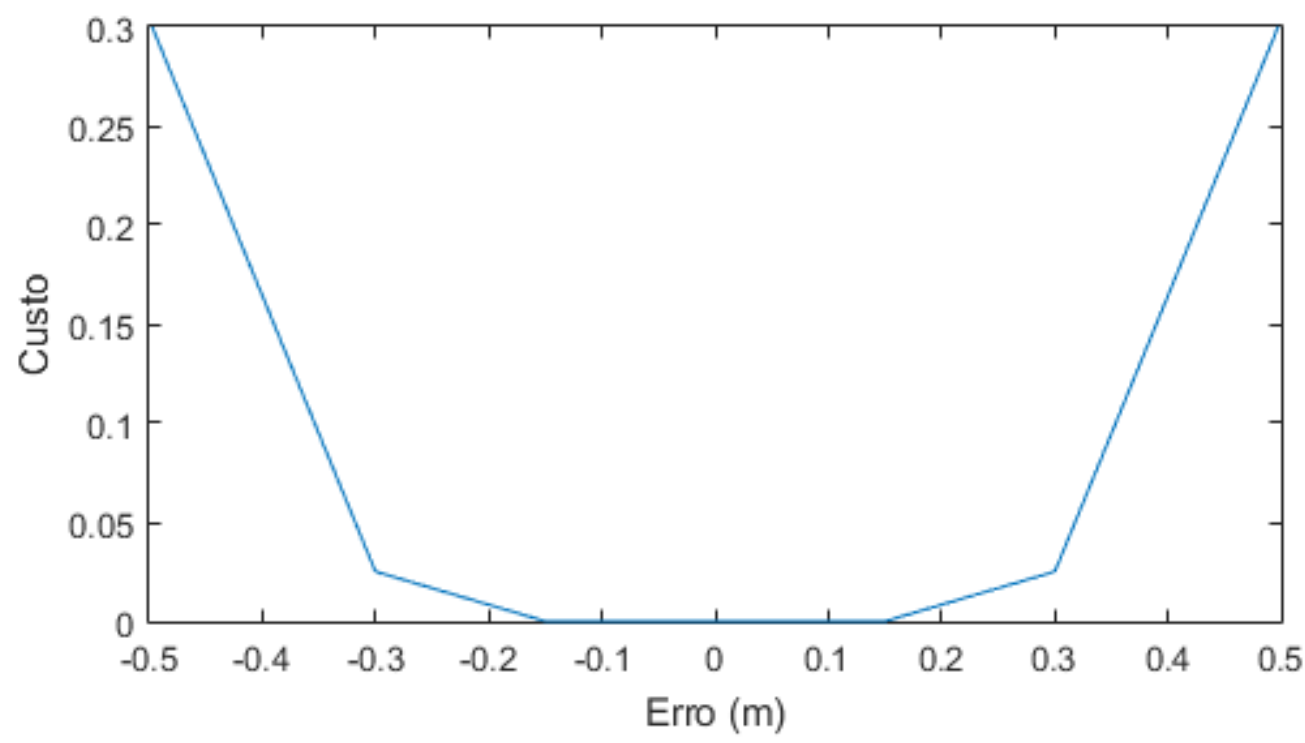

Figura 44 - Função custo utilizada na determinação da capacidade de regulação.

O custo associado à regulação é definido matematicamente pela Equação (4.4):

$$
C_{R}=\frac{1}{L} \sum_{n=1}^{L} f_{c}\left(L_{S}\left(n T_{S}\right)-S P\right)
$$

em que:

$C_{R}$ é o custo associado à capacidade de regulação. [-]

$L$ é o número de amostras utilizado na simulação numérica. [-] (Constante)

$f_{c}($.$) é a função custo utilizada.$

$n$ é o indexador da amostra. [-]

$T_{S}$ é o passo de tempo utilizado na simulação. [s] (Constante)

$S P$ é o setpoint utilizado no controlador. $[m]$ (Constante).

É interessante observar que um controlador capaz de manter o erro do nível compreendido entre $-0,15 \mathrm{~m}$ e $0,15 \mathrm{~m}$ terá custo de regulação nulo. Caso este patamar seja violado por pouco tempo ou com pouca intensidade, o custo será baixo. No entanto, caso o controlador mantenha o erro absoluto da variável controlada acima de $0,15 \mathrm{~m}$ durante muito tempo ou até mesmo acima de $0,30 \mathrm{~m}$ por pouco tempo, a tendência é que o mesmo possua custo de regulação bastante alto.

Além de regular, o controlador amortecedor de golfadas tem como objetivo a diminuição da variabilidade das vazões de saída e, portanto, esta característica também precisa ser medida quantitativamente. Em uma primeira análise, pode-se 
pensar na utilização da variância para esta medida; entretanto, quando avaliada ao longo de toda a simulação, a variância não gera bons resultados, pois compara os desvios em torno da média global, a qual não captura as grandes variações nos patamares de produção, inseridos na simulação em virtude da adição de degraus à vazão de entrada.

Com o objetivo de contornar este problema, decidiu-se pela utilização de uma medida de dispersão inspirada na variância, mas que considera os desvios na média local inseridos tanto pelos degraus quanto pelo ruído de média não nula. Para isto, basta que os desvios não sejam comparados à média global, mas à uma vazão de referência, que modela a média local, obtida através da soma da produção média das golfadas aos valores médios das perturbações. Este sinal de referência é mostrado na Figura 45, em conjunto com a vazão de entrada do sistema para fins de comparação.

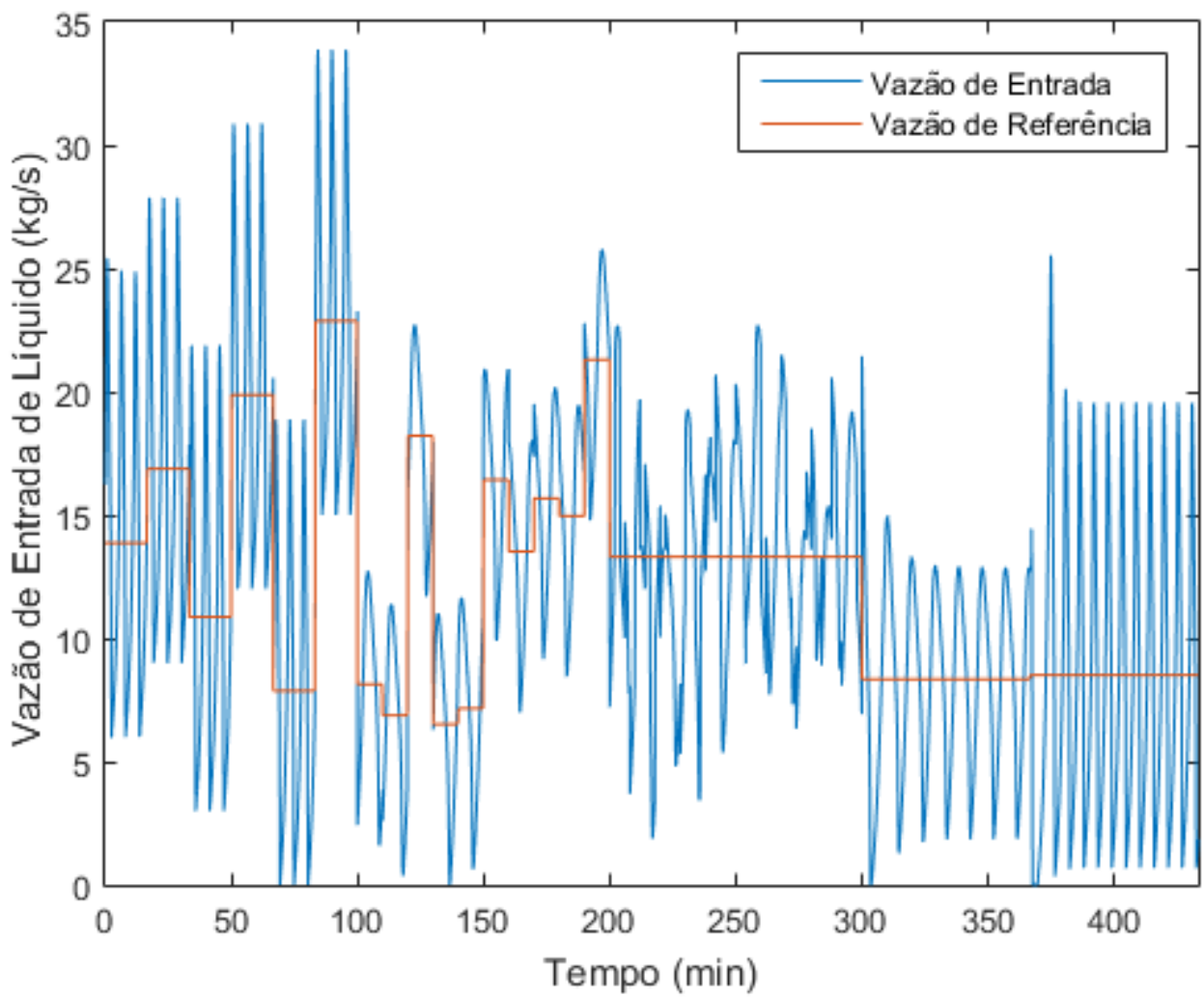

Figura 45 - Vazão de entrada e de referência utilizados na determinação da capacidade de amortecimento.

De posse da vazão de referência e da vazão de saída, a capacidade de amortecimento do controlador é determinada através do Custo de Amortecimento, $C_{A}$, definido pela Equação (4.5). 


$$
C_{A}=\frac{1}{L} \sum_{n=1}^{L}\left(w_{L S}\left(n T_{s}\right)-w_{r e f}\left(n T_{s}\right)\right)^{2}
$$

em que:

$C_{A}$ é o custo associado à capacidade de amortecimento. $\left[\mathrm{kg}^{2} / \mathrm{s}^{2}\right]$

$w_{L S}$ é a vazão de saída do vaso separador. $[\mathrm{kg} / \mathrm{s}]$

$w_{\text {ref }}$ é a vazão de referência. $[\mathrm{kg} / \mathrm{s}]$

As Equações (4.4) e (4.5) definem dois custos que precisam ser minimizados pelo algoritmo genético, caracterizando um problema de otimização multiobjetivo, com o agravante de os objetivos serem conflitantes.

$\mathrm{Na}$ literatura de algoritmos genéticos, existem diversas formas de se abordar este tipo de problema, mas neste trabalho optou-se por uma das formas mais simples, que se mostrou suficiente para solução do problema em questão: definição de um Custo Total formado pela soma ponderada dos dois outros custos. Matematicamente, essa definição é dada pela Equação (4.6).

$$
C_{T}=\alpha C_{A}+\beta C_{R}
$$

em que:

$C_{T}$ é o custo total do controlador. [-]

$\alpha$ é o peso do custo $C_{A}$ no custo total. $\left[\mathrm{s}^{2} / \mathrm{kg}^{2}\right]$ (Constante)

$\beta$ é o peso do custo $C_{R}$ no custo total. [-] (Constante)

Finalmente, a aptidão do indivíduo pode ser definida como o inverso do custo total obtido pelo controlador correspondente, conforme a Equação (4.7).

$$
A=\frac{1}{C_{T}}=\frac{1}{\alpha C_{A}+\beta C_{R}}
$$

Desta forma, o processo de simulação, em conjunto com a computação das métricas, pode ser entendido como a função de avaliação, pois mapeia um indivíduo em sua aptidão. 


\subsection{4.}

\section{Resultado da Otimização}

Foram realizados testes com o algoritmo genético afim de se ajustar os parâmetros de ponderação dos custos. Estes ensaios indicaram uma otimização do desempenho geral do controlador para pesos $\alpha$ e $\beta$ iguais a $1 \mathrm{~s}^{2} / \mathrm{kg}^{2}$ e 1000, respectivamente. Esta grande disparidade numérica entre os pesos foi necessária para equalização da importância dos custos, uma vez que na maioria dos ensaios o custo de regulação era da ordem de um milésimo do custo de amortecimento. Além disso, utilizou-se um tempo de amostragem de 1 segundo e setpoint de nível em 1 metro, que corresponde a 50\% do nível máximo. As evoluções da aptidão média e da aptidão do melhor indivíduo são mostradas na Figura 46.

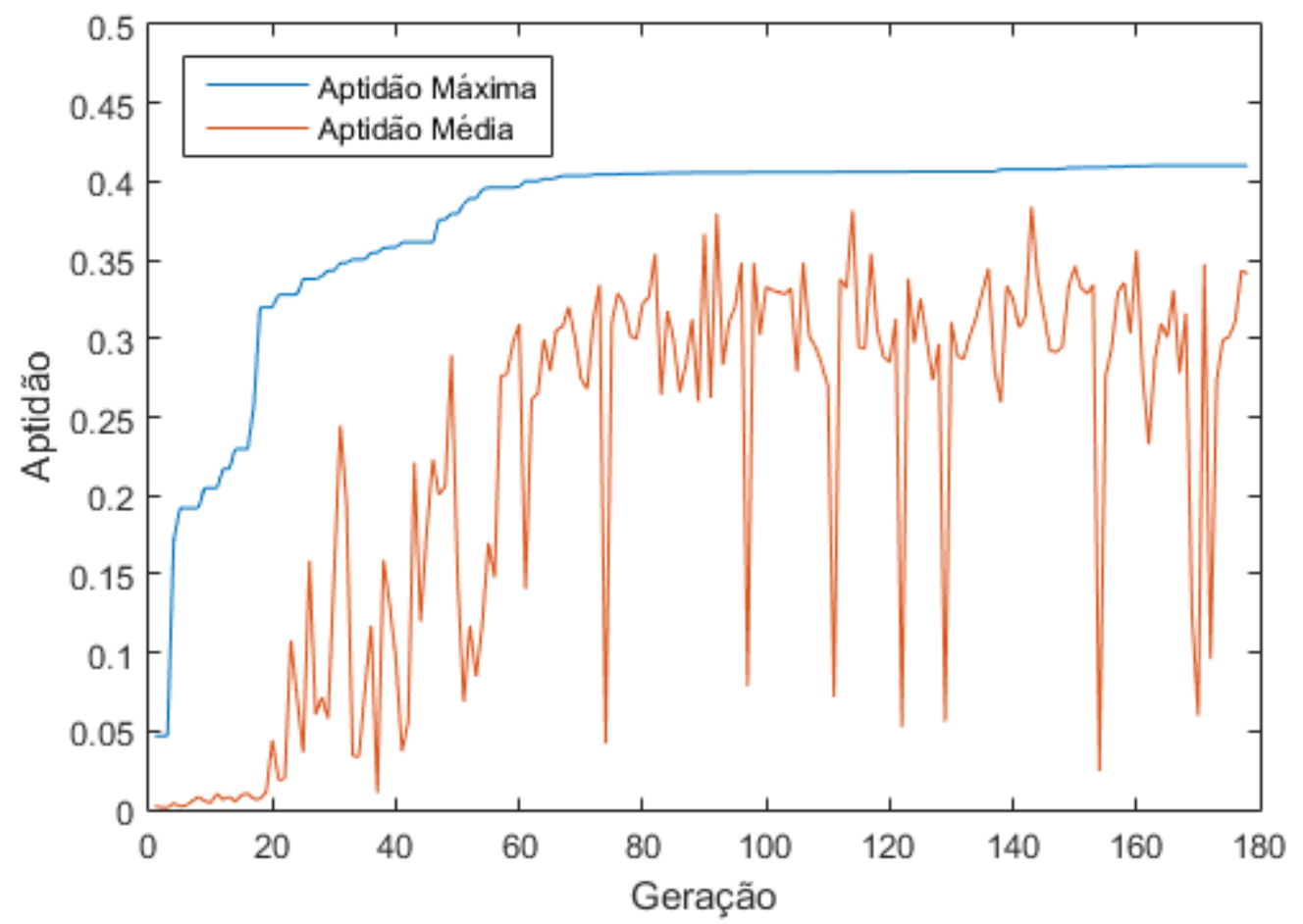

Figura 46 - Evolução das aptidões média e máxima durante o processo de otimização.

O algoritmo genético encerrou a otimização na geração 178 devido à ocorrência de 15 gerações sem alterações significativas na aptidão do melhor indivíduo, que foi de 0,4104 .

O cromossomo deste indivíduo é apresentado na Tabela 13 e suas funções de pertinência, na Figura 47. 
Tabela 13 - Cromossomo do melhor indíviduo.

\begin{tabular}{c|cc|c} 
Gene & Valor & Gene & Valor \\
\cline { 3 - 4 }$E_{P 1}$ & 0,099 & $R_{1}$ & 1 \\
$E_{P 2}$ & 0,316 & $R_{2}$ & 0 \\
$E_{P 3}$ & 0,827 & $R_{3}$ & 2 \\
$D_{P 1}$ & 0,000111 & $R_{4}$ & 0 \\
$D_{P 2}$ & 0,004364 & $R_{5}$ & 2 \\
$V_{P 1}$ & $0,23 \%$ & $R_{6}$ & 2 \\
$V_{P 2}$ & $9,14 \%$ & $R_{7}$ & 1
\end{tabular}
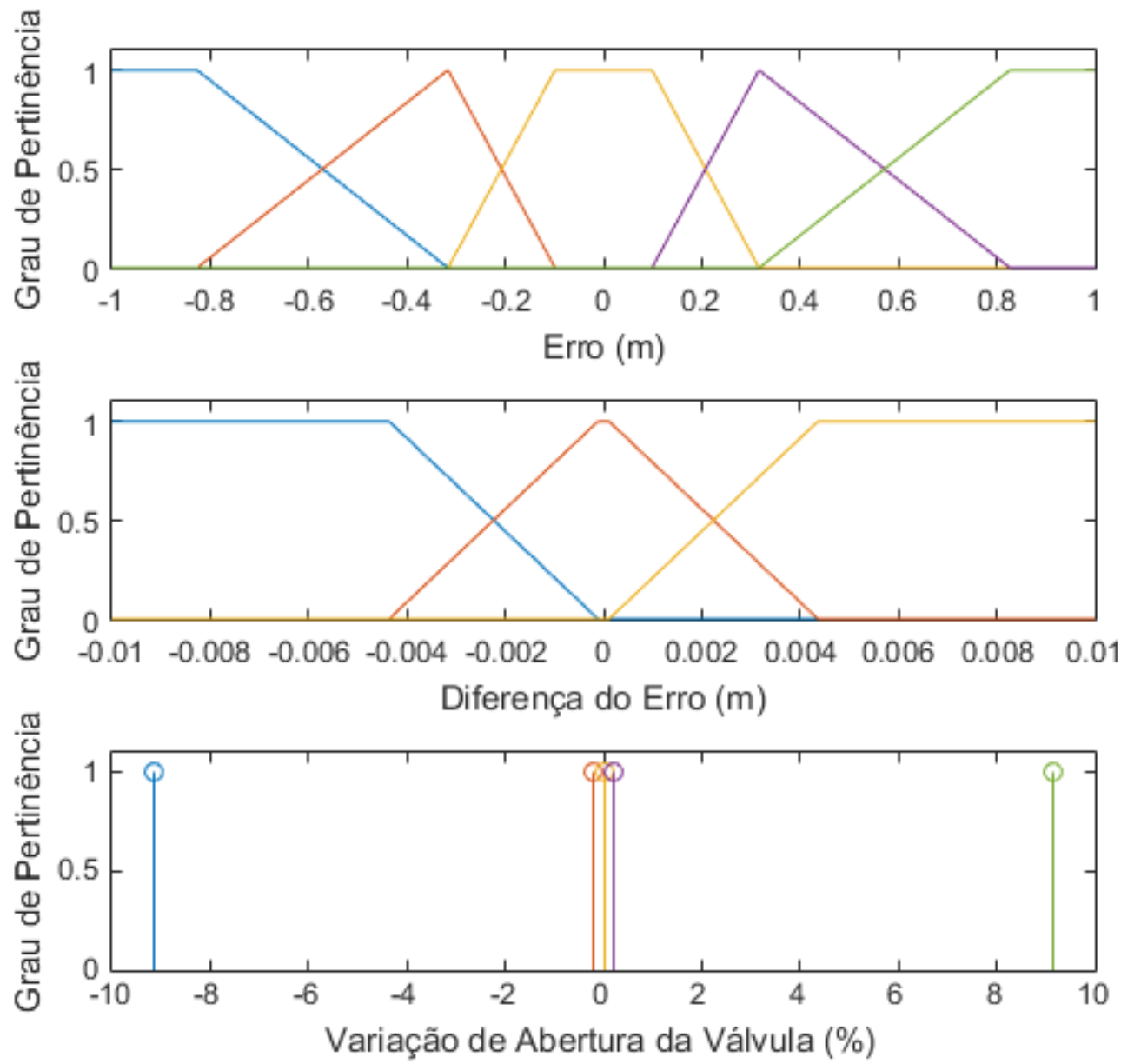

Figura 47 - Funções de pertinência das variáveis lingúisticas do controlador fuzzy otimizado. 
As regras aprendidas pelo controlador fuzzy através da otimização genética foram as seguintes:

1. Se o Erro é Zero e a Diferença do Erro é Positiva, então a Variação da Abertura da Válvula é Positiva.

2. Se o Erro é Zero e a Diferença do Erro é Negativa, então a Variação da Abertura da Válvula é Negativa.

3. Se o Erro é Positivo e a Diferença do Erro é Zero, então a Variação da Abertura da Válvula é Zero.

4. Se o Erro é Negativo e a Diferença do Erro é Zero, então a Variação da Abertura da Válvula é Zero.

5. Se o Erro é Positivo e a Diferença do Erro é Positiva, então a Variação da Abertura da Válvula é Muito Positiva.

6. Se o Erro é Negativo e a Diferença do Erro é Negativa, então a Variação da Abertura da Válvula é Muito Negativa.

7. Se o Erro é Positivo e a Diferença do Erro é Negativa, então a Variação da Abertura da Válvula é Zero.

8. Se o Erro é Negativo e a Diferença do Erro é Positiva, então a Variação da Abertura da Válvula é Zero.

9. Se o Erro é Muito positivo e a Diferença do Erro é Zero, então a Variação da Abertura da Válvula é Muito Positiva.

10. Se o Erro é Muito negativo e a Diferença do Erro é Zero, então a Variação da Abertura da Válvula é Muito Negativa.

11. Se o Erro é Muito positivo e a Diferença do Erro é Positiva, então a Variação da Abertura da Válvula é Muito Positiva.

12. Se o Erro é Muito negativo e a Diferença do Erro é Negativa, então a Variação da Abertura da Válvula é Muito Negativa.

13. Se o Erro é Muito positivo e a Diferença do Erro é Negativa, então a Variação da Abertura da Válvula é Positiva.

14. Se o Erro é Muito negativo e a Diferença do Erro é Positiva, então a Variação da Abertura da Válvula é Negativa.

15. Se o Erro é Zero e a Diferença do Erro é Zero, então a Variação da Abertura da Válvula é Zero. 
Por fim, a superfície de resposta da variável de saída é exibida na Figura 48.

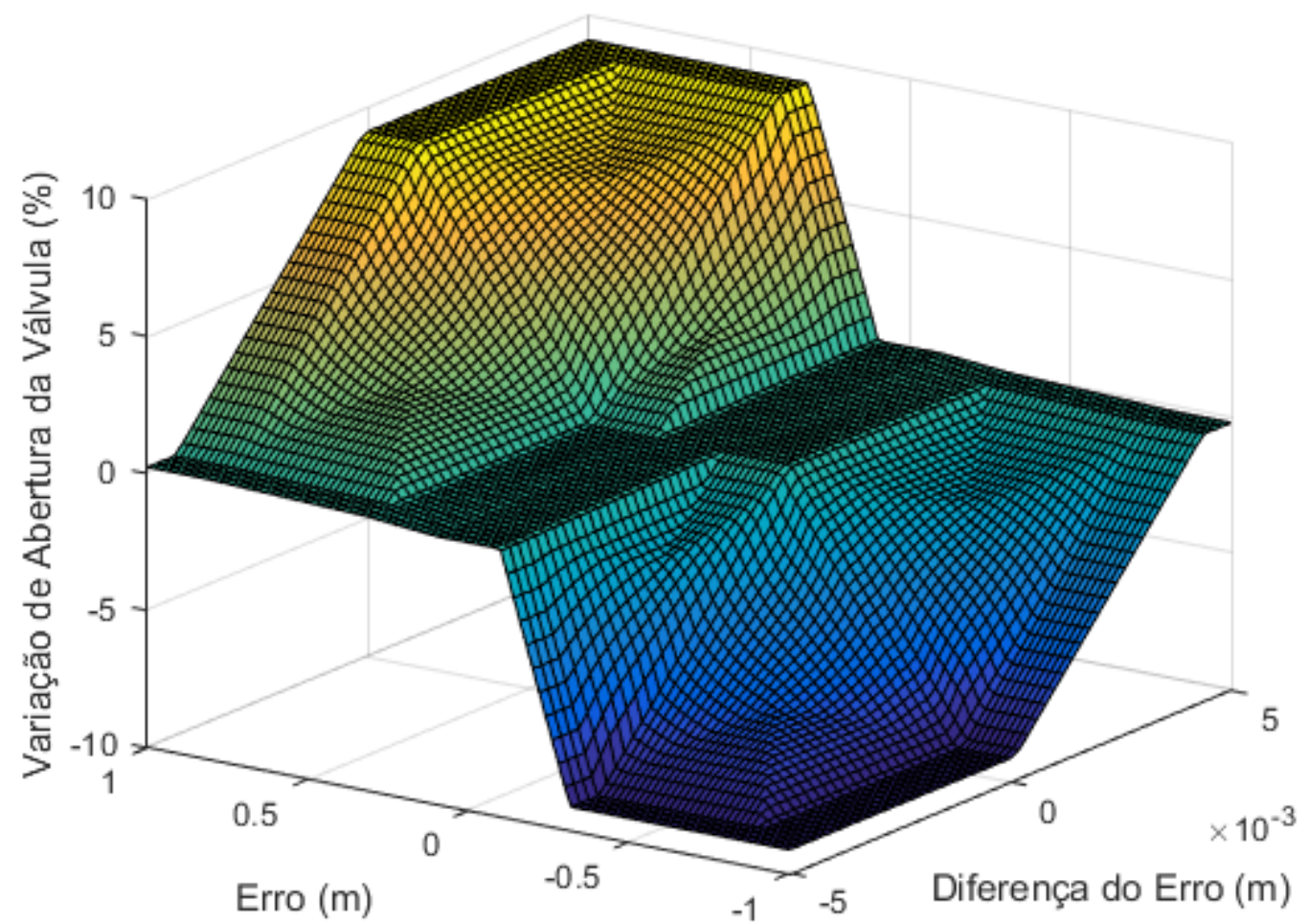

Figura 48 - Superfície de resposta do SIF para a variável de saída "Variação de Abertura da Válvula".

A análise desta superfície de resposta revela algumas das características que possibilitam a obtenção do duplo objetivo, como, por exemplo, a grande região de ação nula nas regiões em que a própria variação do nível tende a estabilizar o sistema e uma ação mais enérgica quando o nível sai de controle, principalmente se a variação do nível age no sentido de agravar a situação.

\subsection{5.}

\section{Otimização de Controlador PI de Referência}

Com objetivo de ter um controlador de referência para comparação dos resultados, o algoritmo genético descrito neste capítulo foi adaptado para otimização dos ganhos de um controlador PI, definido pelas Equações (4.1) e (4.2), costumeiramente utilizado no controle de nível de vasos acumuladores e que possui as mesmas entradas do controlador supressor de golfadas.

Após 84 gerações, a otimização genética foi encerrada devido à ocorrência de 15 gerações sem alterações significativas na aptidão do melhor indivíduo, que foi de 0,1035 . Os ganhos do controlador associado foram $k_{p}$ de 0,7366 e $k_{i}$ de 0,0062 . 


\section{5. \\ Análise dos Resultados}

Com o objetivo de avaliar o desempenho dos controladores desenvolvidos quanto aos seus objetivos de projeto, realizaram-se diversos ensaios cujos resultados foram analisados tanto de forma qualitativa quanto quantitativa.

Para realização dos ensaios, empregou-se o modelo computacional desenvolvido no Capítulo 3, com a mesma parametrização dos ensaios apresentados naquele capítulo.

Visando a possibilitar a realização de comparações com as soluções classicamente empregadas nos problemas de controle tratados, controladores lineares foram utilizados como referência na maioria dos ensaios.

\section{1. \\ Controlador Supressor de Golfadas}

O objetivo principal do controlador supressor de golfadas desenvolvido neste trabalho é, observando apenas a pressão de topo do riser, $P_{2}$, suprimir as golfadas que porventura se estabeleçam em sistemas de produção e também evitar que elas se formem. Já o objetivo secundário deste tipo de controlador é possibilitar um acréscimo da produção de óleo e gás em relação à técnica de choking estático. Neste capítulo, esse controlador é referenciado como "FPID-P2", em referência a sua arquitetura híbrida fuzzy e PID e a sua variável observada.

Como referência para os ensaios realizados nesta seção, será utilizado um controlador PI que controla a pressão da flowline, $P_{1}$, em virtude de esta ser a estratégia mais utilizada em controladores anti-golfada. A sintonia utilizada no controlador é a mesma empregada no terceiro ensaio do Capítulo 3, proposta por Storkaas [4]. Este controlador é referenciado neste capítulo como "PI-P1". 


\subsection{1.}

\section{Supressão de Golfada}

Neste ensaio, um sistema de produção é inicializado com abertura da válvula choke fixada em $40 \%$, região em que a operação é instável, com escoamento caracterizado pela ocorrência de golfadas. Após 2000 segundos de simulação, a malha é fechada através do controlador em avaliação, que age sobre o sistema até o encerramento do ensaio, aos 5000 segundos.

Os resultados do ensaio para ambos os controladores são mostrados na Figura 49, em que pode ser observada a resposta da vazão de saída do riser, $w_{\text {Lout }}$, da pressão a montante de choke, $P_{2}$, e da abertura da válvula choke, $z$.
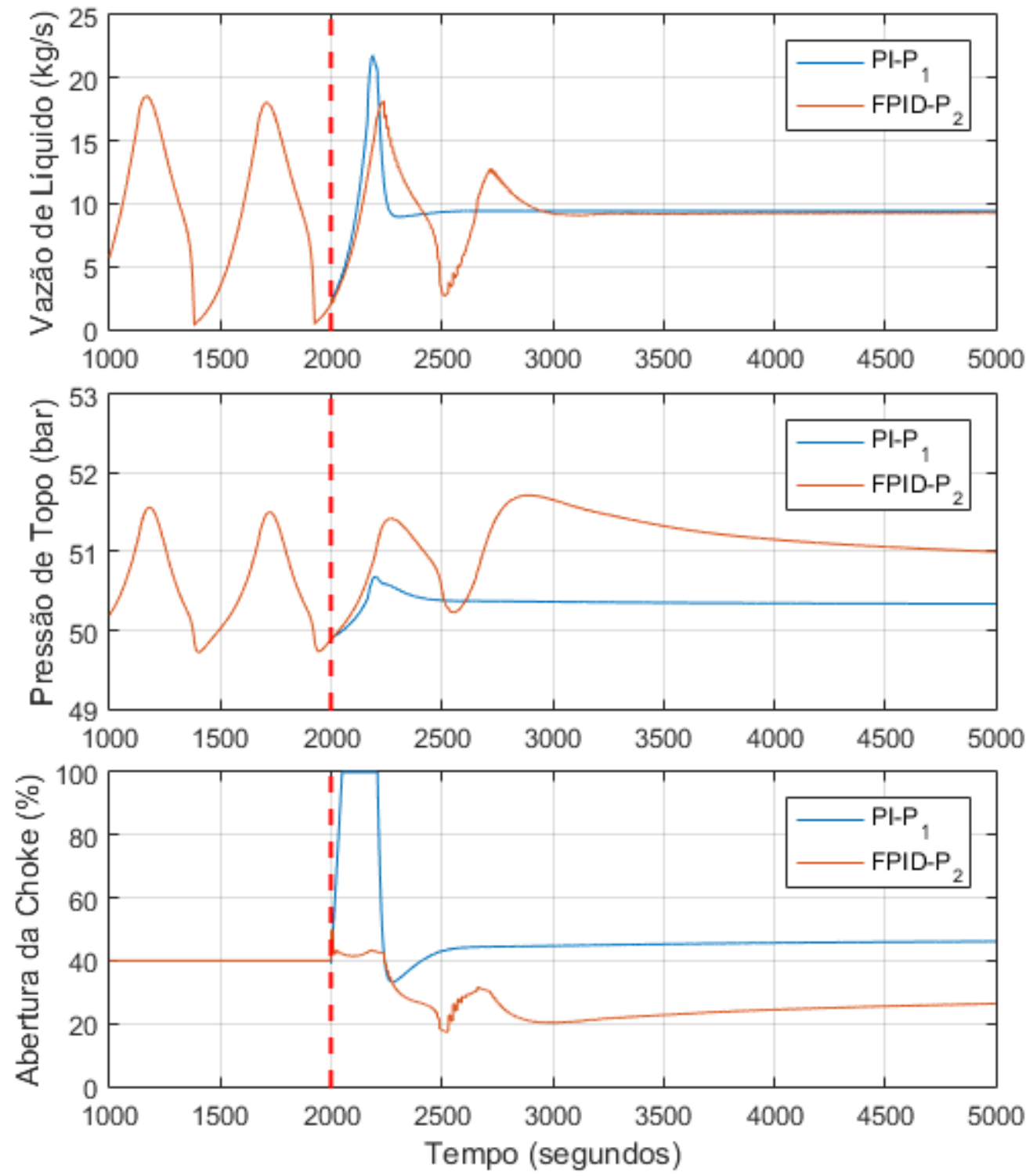

Figura 49 - Respostas das variáveis mais relevantes do ensaio de capacidade de supressão com abertura inicial da choke de $40 \%$. 
Observa-se que o controlador FPID- $\mathrm{P}_{2}$ foi bem-sucedido na tarefa de estabilizar o escoamento do sistema. No entanto, quando comparado ao controlador de referência, nota-se uma resposta significativamente mais lenta, demandando mais tempo para efetiva supressão. Além disso, é possível notar que a vazão se estabiliza em um valor levemente inferior.

Com objetivo de verificar se esses resultados se repetem em outras condições, o ensaio foi repetido para uma situação mais severa, com uma abertura inicial da válvula choke de 100\%. O resultado deste ensaio é apresentado na Figura 50.
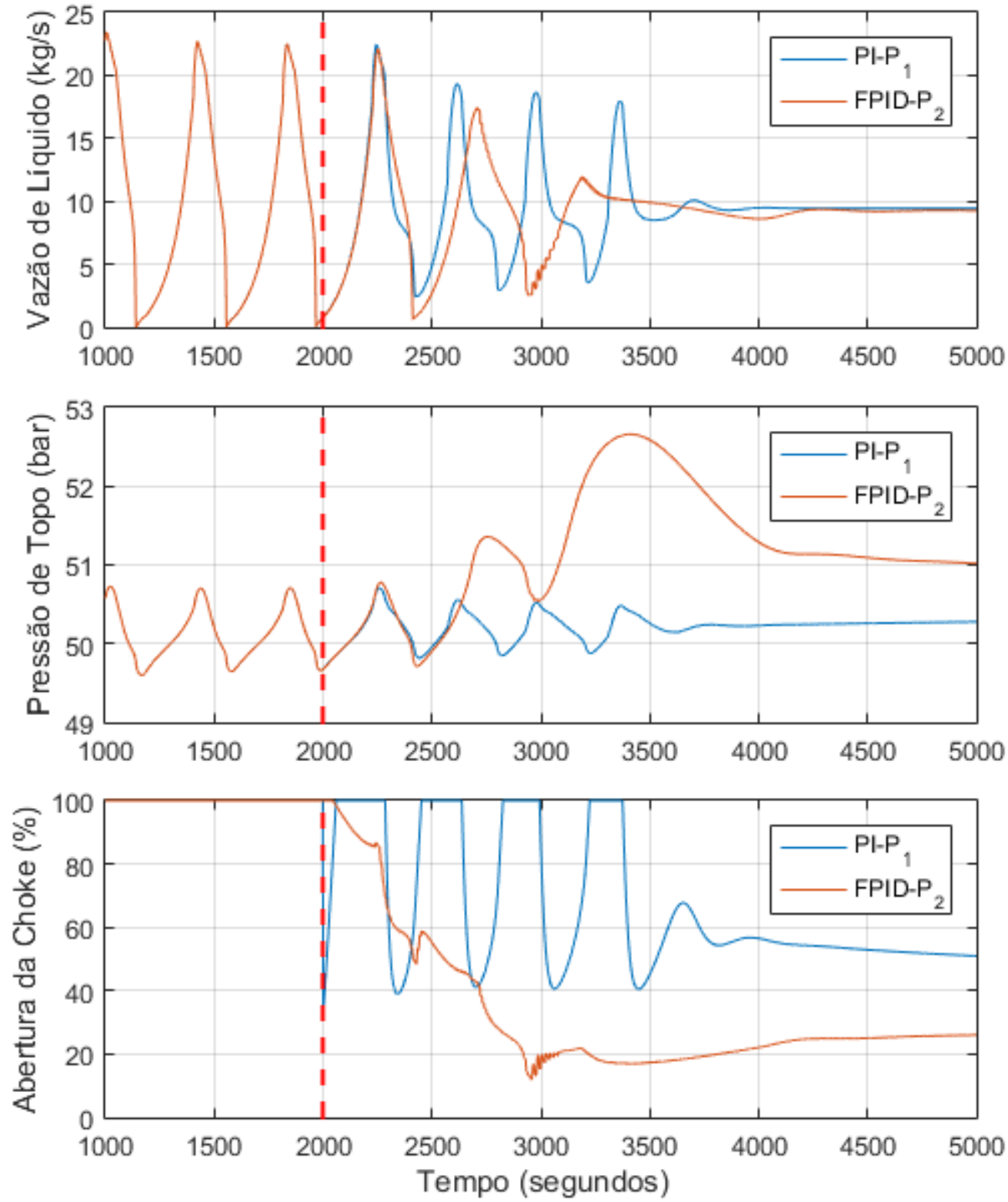

Figura 50 - Respostas das variáveis mais relevantes do ensaio de capacidade supressão com abertura inicial da choke de $100 \%$. 
Neste segundo ensaio, o controlador FPID-P $\mathrm{P}_{2}$ foi capaz de suprimir as golfadas mais rapidamente do que o controlador de referência, mesmo com uma ação de controle significativamente mais lenta. Novamente, notou-se uma estabilização da vazão em valores levemente inferiores aos obtidos pelo controlador de referência.

Como houve uma diferença significativa em relação à velocidade de estabilização dos controladores, o mesmo ensaio foi repetido para aberturas de $20 \%$, $60 \%$ e $80 \%$. Os tempos necessários para supressão das golfadas nos ensaios realizados são apresentados na Tabela 14. Considera-se a golfada suprimida a partir do instante em a vazão não desvia mais do que $10 \%$ do valor de regime permanente.

Tabela 14 - Tempo necessário para supressão das golfadas (FPID-P $\mathrm{P}_{2}$ e PI-P P $_{1}$.

\begin{tabular}{c|c|c}
$\begin{array}{c}\text { Abertura da } \\
\text { Choke }\end{array}$ & FPID-P2 & PI-P1 \\
\hline $20 \%$ & $280 \mathrm{~s}$ & $20 \mathrm{~s}$ \\
$40 \%$ & $830 \mathrm{~s}$ & $245 \mathrm{~s}$ \\
$60 \%$ & $910 \mathrm{~s}$ & $318 \mathrm{~s}$ \\
$80 \%$ & $930 \mathrm{~s}$ & $746 \mathrm{~s}$ \\
$100 \%$ & $1270 \mathrm{~s}$ & $1414 \mathrm{~s}$
\end{tabular}

É possível notar que, de uma forma geral, o controlador FPID- $\mathrm{P}_{2}$ leva mais tempo do que o controlador de referência para estabilizar o escoamento do sistema, a não ser em ensaios em que a válvula choke é inicializada em grandes aberturas, nos quais o controlador proposto neste trabalho mostrou-se mais rápido.

É importante ressaltar que o controlador de referência (PI-P $\left.{ }_{1}\right)$ utiliza a pressão da flowline como variável controlada e, por isto, é capaz de atuar mais rapidamente do que um controlador que emprega a pressão no topo do riser como variável controlada, que é exatamente o caso do controlador desenvolvido neste trabalho.

Objetivando investigar a importância da ação heurística implementada pelo SIF do controlador FPID- $\mathrm{P}_{2}$, os mesmos ensaios foram repetidos com um controlador PID "puro", que também utiliza a pressão no topo do riser como variável controlada, chamado PID- $\mathrm{P}_{2}$. Os ganhos utilizados neste controlador foram os mesmos utilizados na parcela PID do controlador FPID-P ${ }_{2}$, com $k_{i}$ fixo em 0,01 $\% /$ s.bar. Os resultados são apresentados na Tabela 15, onde o símbolo '-' representa ensaios em que o controlador PID-P 2 não foi capaz de estabilizar o escoamento. 
Tabela 15 - Tempo necessário para supressão das golfadas (Fuzzy e PID-P P $_{\text {). }}$

\begin{tabular}{c|c|c}
$\begin{array}{c}\text { Abertura da } \\
\text { Choke }\end{array}$ & FPID-P2 & PID-P2 \\
\hline $20 \%$ & $280 \mathrm{~s}$ & $285 \mathrm{~s}$ \\
$40 \%$ & $830 \mathrm{~s}$ & - \\
$60 \%$ & $910 \mathrm{~s}$ & - \\
$80 \%$ & $930 \mathrm{~s}$ & - \\
$100 \%$ & $1270 \mathrm{~s}$ & -
\end{tabular}

A análise da Tabela 15 revela a importância crucial da ação heurística do controlador FPID-P 2 , já que um controlador PID "puro", que também observa apenas a pressão no topo do riser, só foi capaz de suprimir golfadas de baixa severidade, que ocorrem muito próximas à abertura de estabilidade estática (18\%).

Com o objetivo de exemplificar o comportamento do controlador PID-P 2 , são apresentados na Figura 51 a vazão na saída do riser e a ação de controle durante o ensaio em que a abertura da choke foi inicializada em 40\%. A análise da resposta revela total incapacidade do controlador em estabilizar o escoamento.
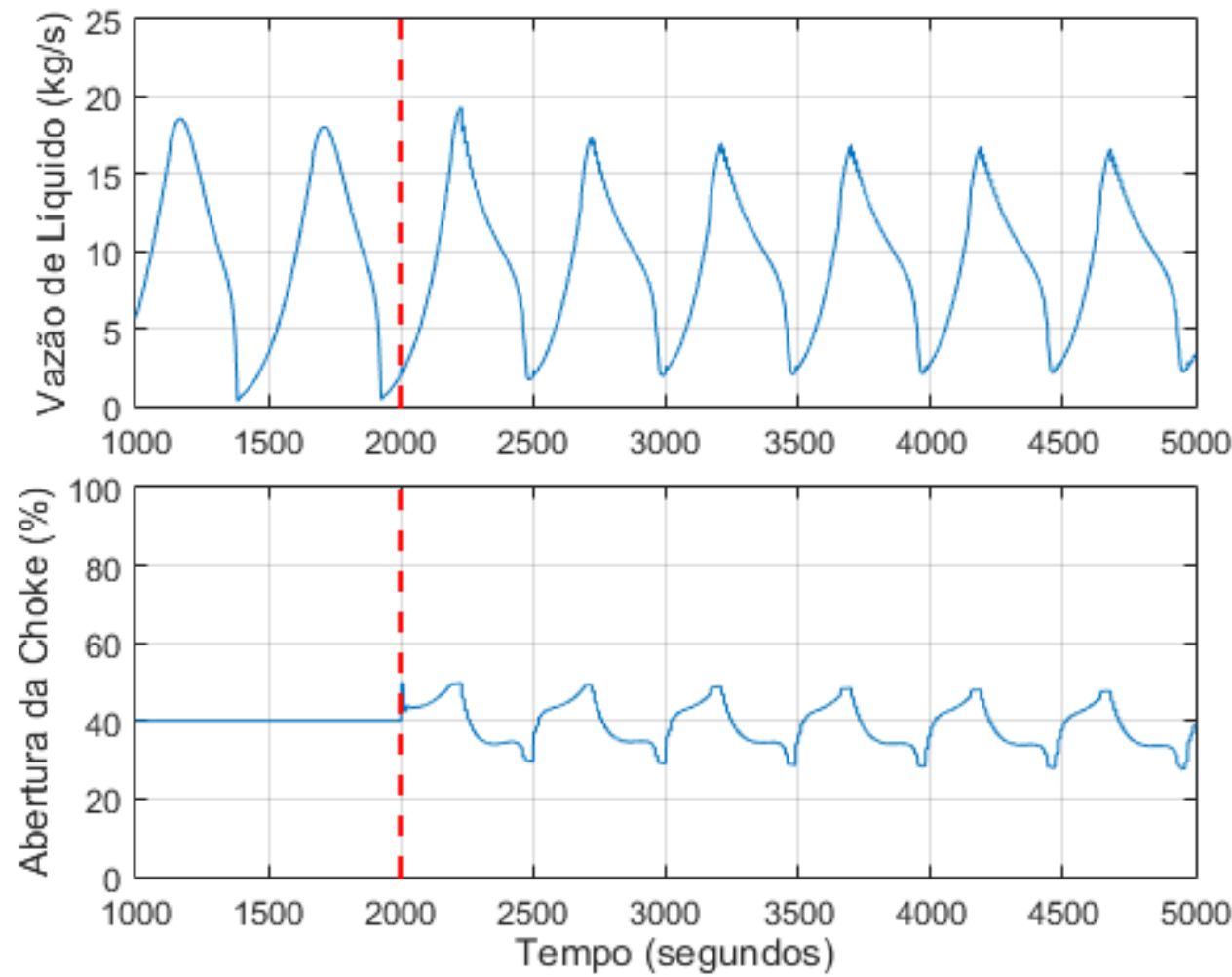

Figura 51 - Respostas da vazão e abertura de válvula no ensaio com o controlador PID baseado na pressão no topo do riser e abertura prévia de $40 \%$. 


\subsection{2.}

\section{Limite da Velocidade de Atuação da Choke}

Nos ensaios apresentados na seção anterior, notou-se que o controlador PI-P $\mathrm{P}_{1}$ baseado na pressão da flowline, possui uma resposta de controle significativamente mais rápida do que a do controlador FPID-P2. Por exemplo, no ensaio apresentado na Figura 50, o controlador PI-P ${ }_{1}$ fecha a válvula de choke de $100 \%$ para $40 \%$ em apenas 40 segundos. Esta ação, que possui uma velocidade média de 1,5\%/s, atinge velocidades instantâneas de até 3,26 \%/s no início do fechamento.

Em virtude de suas grandes dimensões, válvulas choke costumam ter atuação bastante lenta, não raramente levando até três minutos para abertura ou fechamento completo. Este aspecto constitui uma limitação fundamental na aplicação de controladores anti-golfada baseados em algoritmos lineares [4].

A consequência da lentidão de atuação das válvulas choke no sinal de controle efetivamente entregue à planta pode ser vista na Figura 52, na qual são mostradas as aberturas reais da válvula quando um sinal de controle senoidal com velocidade máxima de 3\%/s é aplicado às mesmas. São consideradas três válvulas, uma com atuação instantânea, uma que necessita de 60 segundos para realizar uma transição completa e uma que necessita de 120 segundos para o mesmo feito.

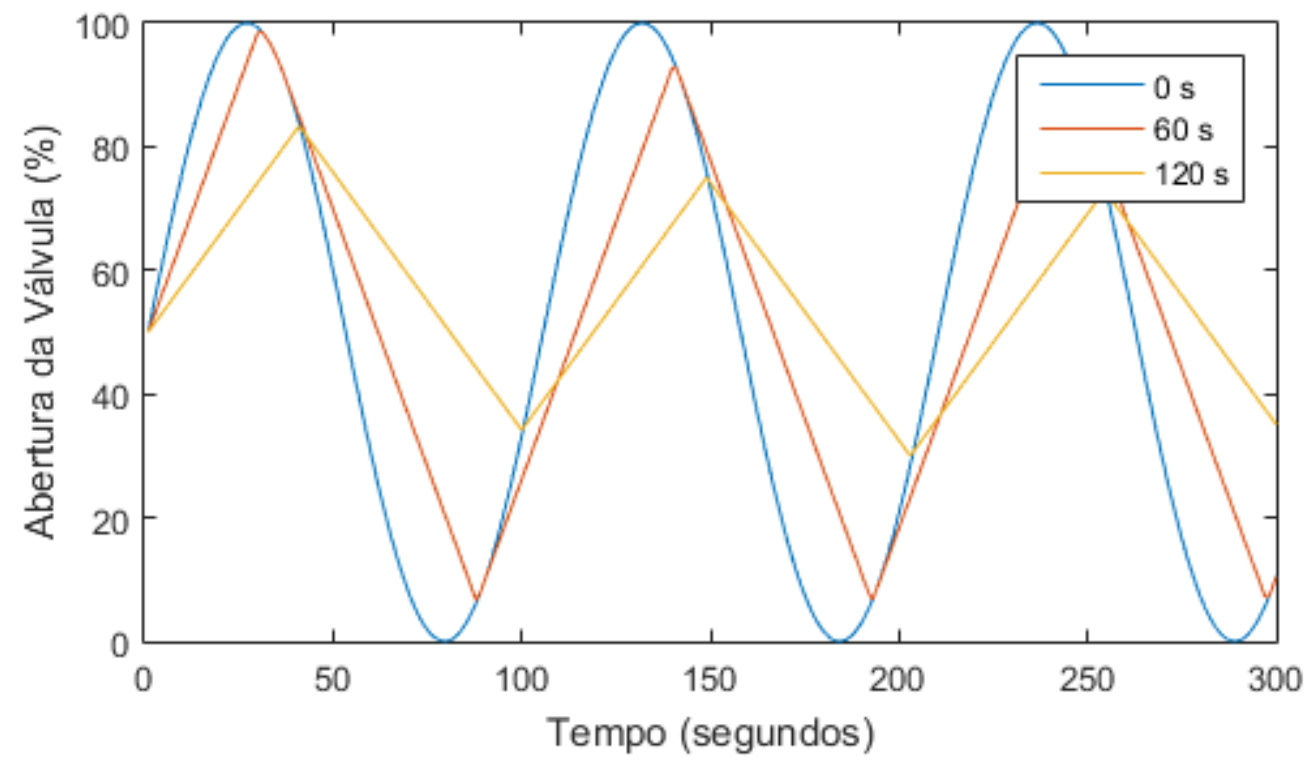

Figura 52 - Influência da limitação da taxa de entrada à sinais de controladores rápidos.

Observa-se no gráfico o efeito drástico que limitações na taxa de entrada impõem à controladores, evidenciando a razão de chokes lentas constituírem um grande desafio no projeto de controladores anti-golfada. 
A priori, é razoável supor que o controlador desenvolvido neste trabalho é menos sensível à limitações na velocidade de atuação por ser um controlador mais lento. Com objetivo de verificar esta hipótese, os ensaios realizados anteriormente foram repetidos considerando-se válvulas chokes que fazem transição completa em 60, 90, 120 e 180 segundos. Os tempos necessários para supressão das golfadas em cada um dos ensaios são apresentados na Tabela 16.

Tabela 16 - Tempo necessário para supressão das golfadas para diferentes velocidades de atuação da válvula choke (Fuzzy e PI-P 1 )

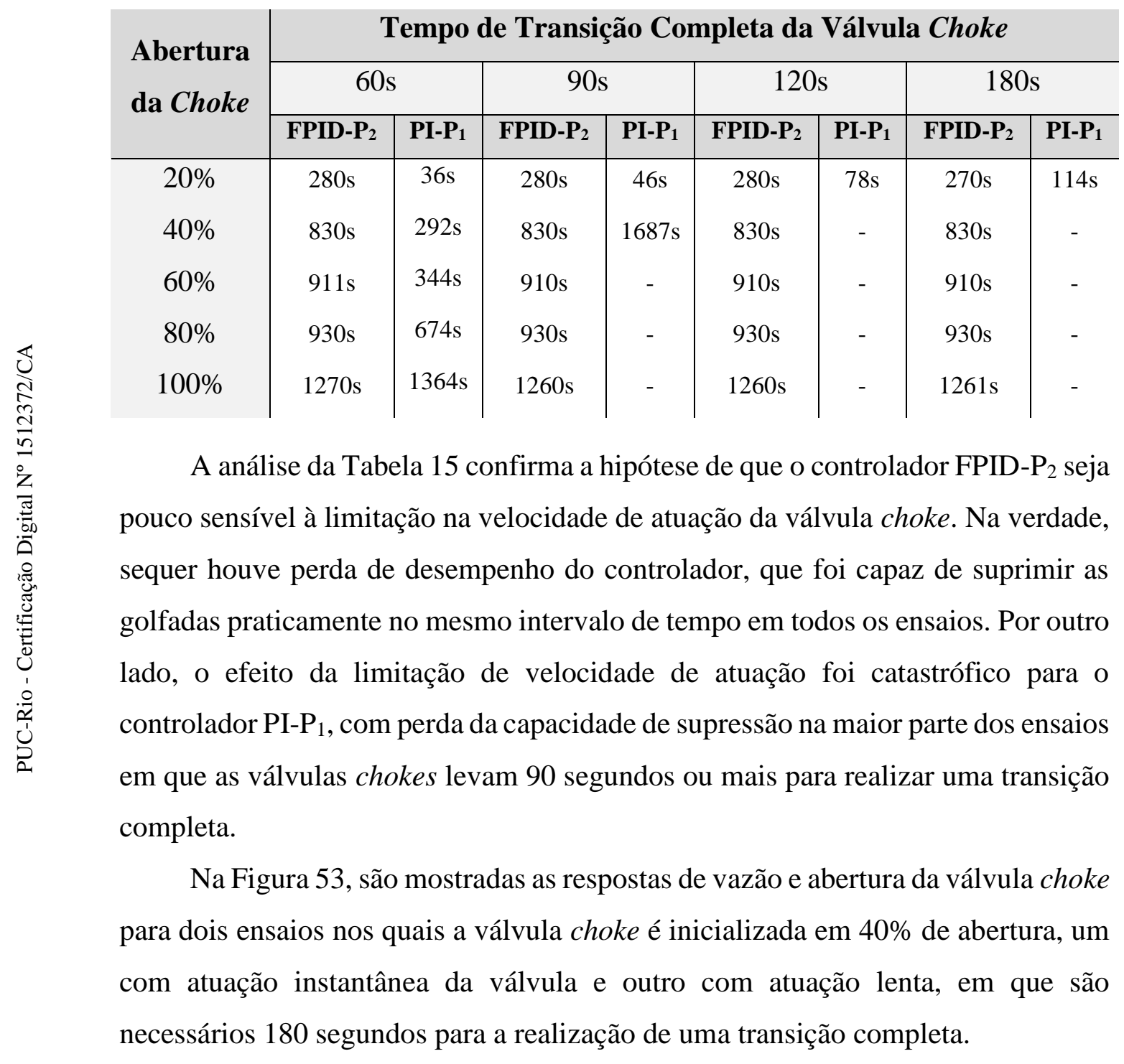



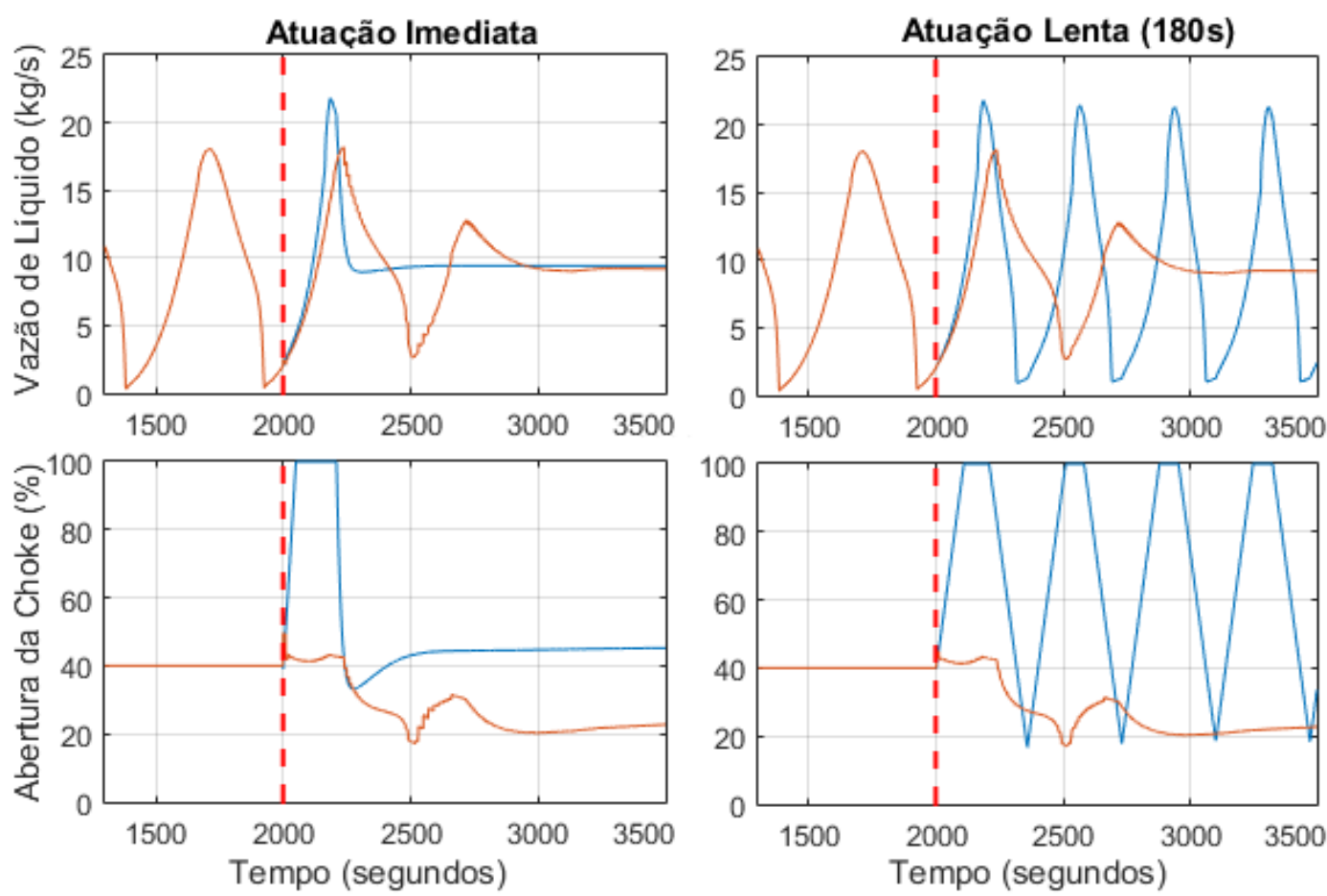

Figura 53 - Vazão e abertura de válvula para os ensaios em que a atuação é instantânea (à esquerda) e lenta (à direita). Curvas laranjas são do FPID-P 2 e azuis do PI-P ${ }_{1}$.

Observando os gráficos, é possível constatar que o controlador FPID-P $\mathrm{P}_{2}$ foi praticamente imune à lentidão da válvula choke. A única diferença observável ocorre logo após 2500 segundos, em que nota-se uma pequena suavização da ação de controle no ensaio em que a válvula choke é lenta. Por outro lado, a ação do controlador PI-P 1 foi completamente desfigurada, resultando em um funcionamento contrário ao esperado, com intensificação da severidade da golfada após a ativação do controlador.

Também é interessante notar que sintonias mais lentas do controlador PI não solucionaram esta limitação, pois embora ações de controle mais lentas não sofram deformação pela dinâmica da válvula, elas deixam de ser suficientes para impedir a formação das golfadas. Este resultado é alinhado com o desenvolvimento teórico de Storkaas [4], no qual é verificado que a velocidade de abertura da choke é um limitante fundamental para o desempenho de controladores lineares.

Este ensaio revela que, embora o controlador FPID-P $\mathrm{P}_{2}$ observe uma variável de baixa sensibilidade e fase não-mínima, a pressão no topo do riser, sua capacidade de detectar as golfadas e agir heuristicamente não só compensa esta deficiência como em alguns casos assegura um desempenho superior ao de controladores lineares que observam variáveis mais adequadas ao controle anti-golfada. 


\subsection{3.}

\section{Estabilização de um Ponto de Operação Instável}

$\mathrm{Na}$ fundamentação teórica deste trabalho, foram discutidas algumas implementações de controladores anti-golfada, como a de Courbot [5], que embora suprimam as golfadas dos sistemas de produção, o fazem através da automatização do processo de choking estático e não pela estabilização de um ponto instável de operação [7].

A verificação da capacidade de um controlador anti-golfada de estabilizar um ponto estável é bastante simples e consiste em aguardar a estabilização do escoamento e então desligar o controlador, mantendo a válvula choke fixada na última posição definida pelo algoritmo. Caso o escoamento se mantenha estável após o desligamento, o controlador meramente automatiza o choking estático; por outro lado, caso o sistema comece a oscilar novamente, o controlador estava de fato estabilizando um ponto de operação instável.

Com objetivo de verificar a capacidade de estabilização do controlador FPID-P ${ }_{2}$, realizou-se um ensaio em que a válvula choke foi inicializada em $50 \%$ de abertura, com o controlador sendo ligado aos 2000 e desligado aos 10000 segundos. Os resultados deste ensaio são mostrados na Figura 54.

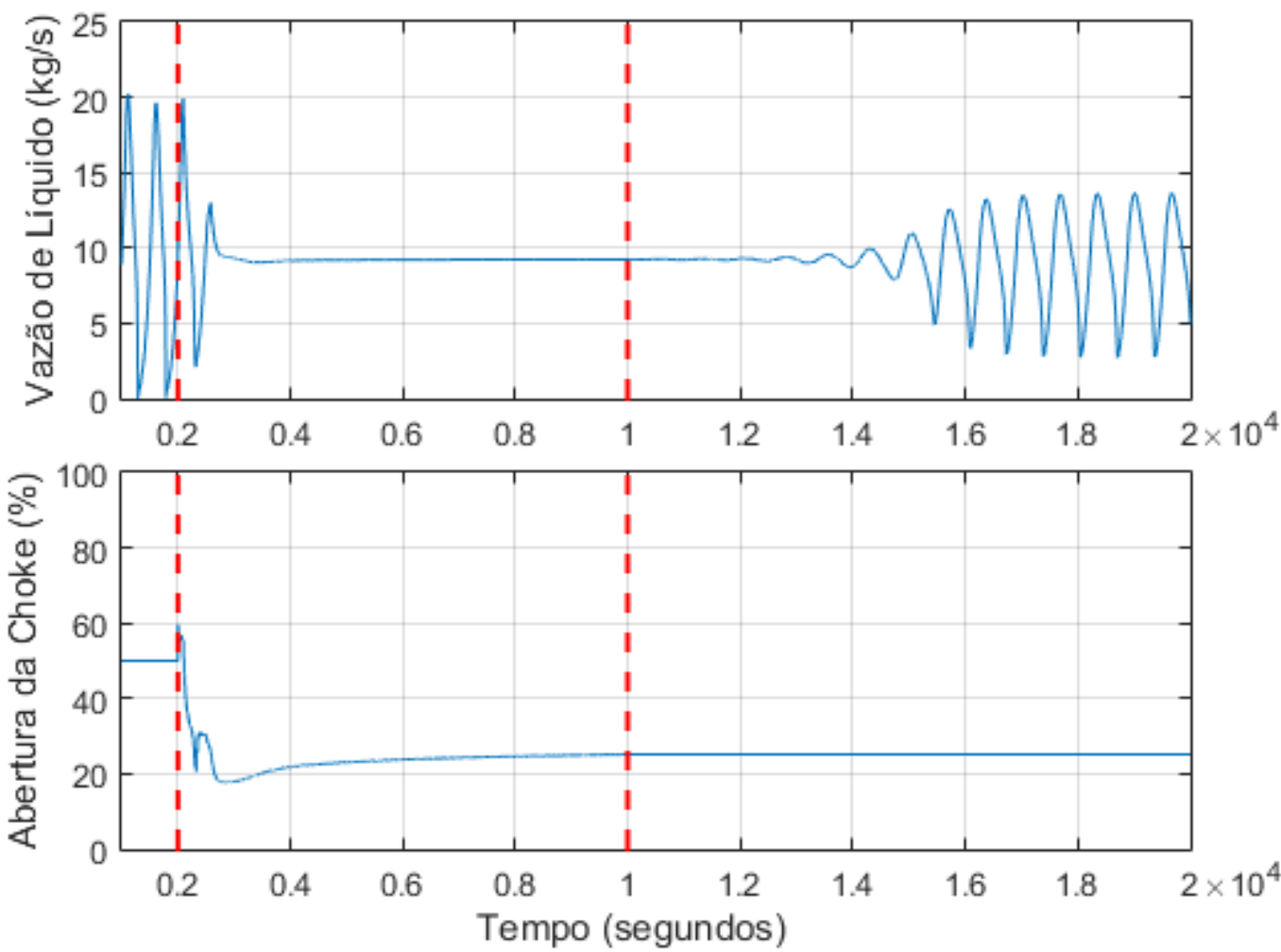

Figura 54 - Respostas da vazão e abertura de válvula no ensaio de estabilização de ponto estável. 
A análise dos resultados revela que após o desligamento do controlador, aos 10000 segundos, o sistema voltou a apresentar comportamento oscilatório, mesmo sem a introdução de qualquer perturbação. Logo, pode-se concluir que o controlador desenvolvido neste trabalho está na classe dos controladores que de fato estabilizam pontos de operação instáveis e, portanto, possibilitam ganhos na produção de petróleo.

\subsection{4.}

\section{Ganhos de Produção}

Conforme discutido anteriormente, a estabilização de pontos de operação instáveis permite uma redução geral das pressões do sistema de produção, resultando em maiores vazões dos poços produtores e, portanto, maior rentabilidade do negócio.

No Capítulo 3, o controlador PI-P P $_{1}$ foi utilizado em um ensaio cujo objetivo era estabelecer os limites do ganho de produção proporcionados pelo mesmo. O resultado foi uma produção máxima de $9,46 \mathrm{~kg} / \mathrm{s}$ de líquido com uma abertura média de válvula de $67 \%$. Naquele ensaio, não foram consideradas limitações na velocidade de atuação da válvula choke. Visando a estabelecer os limites de ganho de produção proporcionados pelo controlador FPID-P 2 , repetiu-se o mesmo ensaio para este controlador.

O ensaio consiste em ajustar o setpoint inicial do controlador para um valor alto, correspondente à uma abertura da válvula choke de 10\%, e decrementar o setpoint em 0,2 bar sempre que o sistema entrar em regime permanente. Este processo continua até que um setpoint muito baixo faça com que o sistema entre em operação instável, marcando o encerramento do ensaio. Para cada ponto de operação estável obtido no ensaio, determina-se a vazão de líquido na saída do riser e a abertura média da válvula choke.

Os resultados obtidos no ensaio do controlador FPID-P 2 são apresentados na Figura 55, onde são comparados com os resultados obtidos pelo controlador PI-P 1 e com a vazão média em malha aberta, com ocorrência de golfadas para aberturas maiores do que a crítica. 


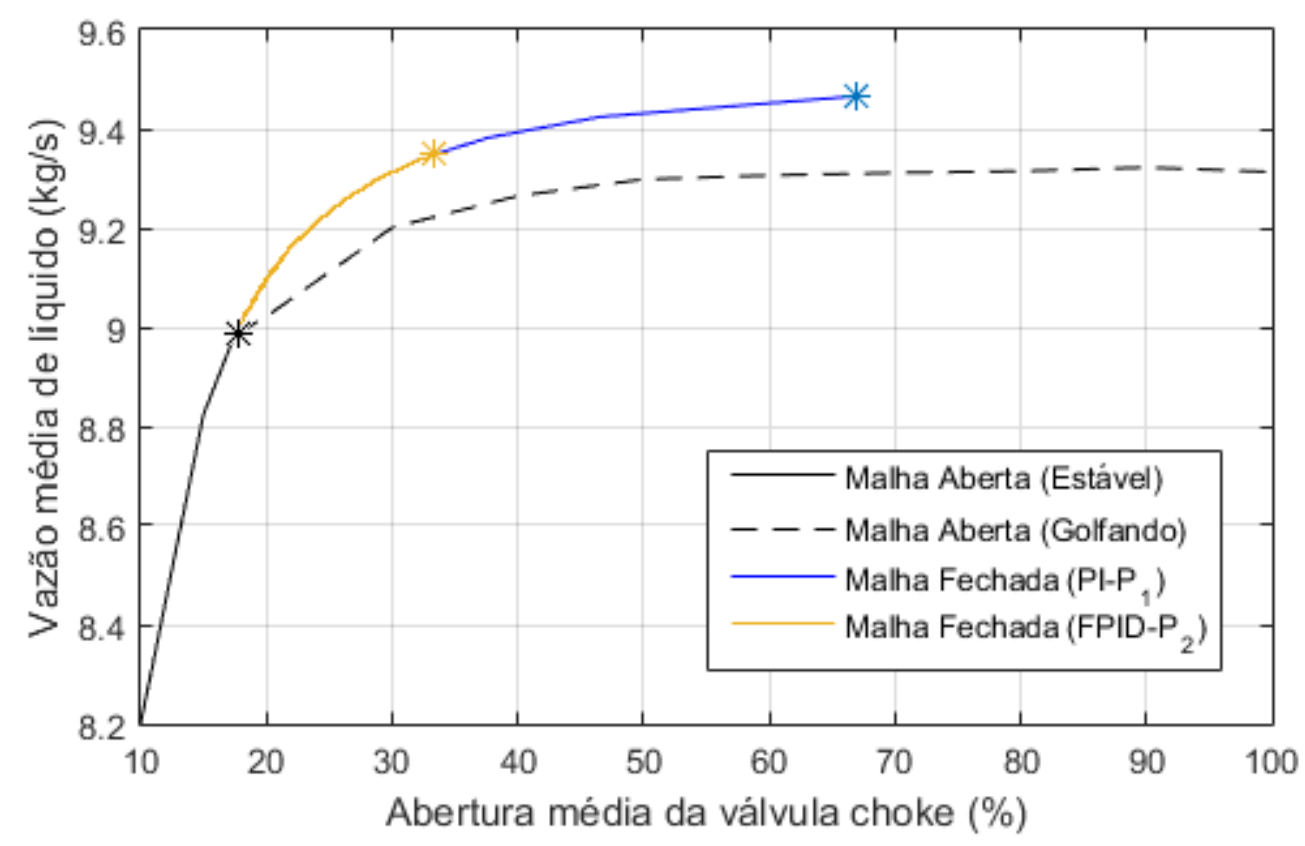

Figura 55 - Comparação da produção média obtida pelo controlador fuzzy, controlador de referência e planta em malha aberta.

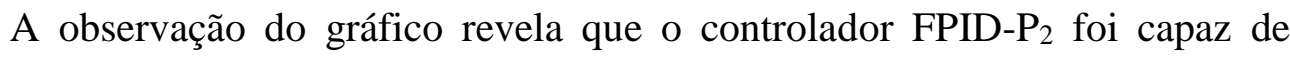
estabilizar o sistema em aberturas médias de até $34 \%$, com uma produção correspondente de $9,35 \mathrm{~kg} / \mathrm{s}$. Qualquer tentativa de reduzir o setpoint de pressão além deste ponto resultou no ressurgimento de golfadas no sistema.

A produção obtida pelo controlador FPID-P ${ }_{2}$ representa um ganho de 4,1\% em relação ao melhor caso de choking estático. Já o controlador PI-P 1 , que é capaz de estabilizar o sistema em aberturas maiores da choke, atinge uma produção limite de $9,46 \mathrm{~kg} / \mathrm{s}$, um ganho de 5,3\% em relação ao melhor caso de choking estático.

Pode-se concluir que o controlador desenvolvido neste trabalho proporciona um menor ganho de produção quando comparado ao controlador de referência, que tem acesso à pressão da flowline. Esta desvantagem é uma consequência direta da utilização de uma variável controlada com menor sensibilidade e fase não-mínima no controlador FPID-P2, uma vez que, na ausência de golfadas, o controlador se comporta como um controlador PID baseado nesta variável e, portanto, fica sujeito às mesmas limitações dos controladores lineares. 


\subsection{5. \\ Rejeição à Perturbações}

Em todos os ensaios realizados anteriormente, não foram consideradas perturbações no sistema de produção e, portanto, a capacidade do controlador FPID-P $\mathrm{P}_{2}$ de rejeitá-las não foi testada. Com esta finalidade, foram feitos dois ensaios com perturbações típicas de sistemas de produção de petróleo.

No primeiro ensaio, considerou-se o efeito de uma produção com variações de alta frequência (ruído) na capacidade do controlador de manter o sistema estável. Estas variações foram modeladas por meio de uma alteração na Equação (3.2), que modela a vazão de saída do poço. Esta alteração consistiu na adição de ruído gaussiano à pressão aparente do reservatório, $P_{r a}$, resultando em:

$$
w_{T}=k_{p}\left(P_{r a}+P_{\sigma}-P_{1}\right)
$$

em que:

$w_{T}$ é a vazão total do poço. $[\mathrm{kg} / \mathrm{s}]$

$k_{p}$ é a constante de produtividade do poço. $[\mathrm{kg} /(\mathrm{s}$. bar $)]$ (Constante)

$P_{r a}$ é a pressão estática aparente do reservatório. [bar] (Constante)

$P_{\sigma}$ é um processo estocástico gaussiano independente e de média nula. [bar]

$P_{1}$ é a pressão na cabeça do poço. [bar]

Utilizou-se como variância do ruído gaussiano um valor equivalente a $20 \%$ da pressão aparente do reservatório, $P_{r a}$, utilizada no modelo do poço produtor. Esta modelagem equivale a um reservatório com flutuações em sua pressão estática, o que causa flutuações nas vazões de gás e líquido mesmo com uma pressão constante na cabeça do poço.

A alteração no modelo reduziu ligeiramente o limite de estabilidade do sistema em malha fechada, com ambos os controladores atingindo seus setpoints limite em valores 0,2 bar acima dos encontrados no ensaio anterior, resultando em decréscimos nas aberturas médias das válvulas. Os resultados do ensaio para ambos os controladores operando no setpoint limite são apresentados na Figura 56. 

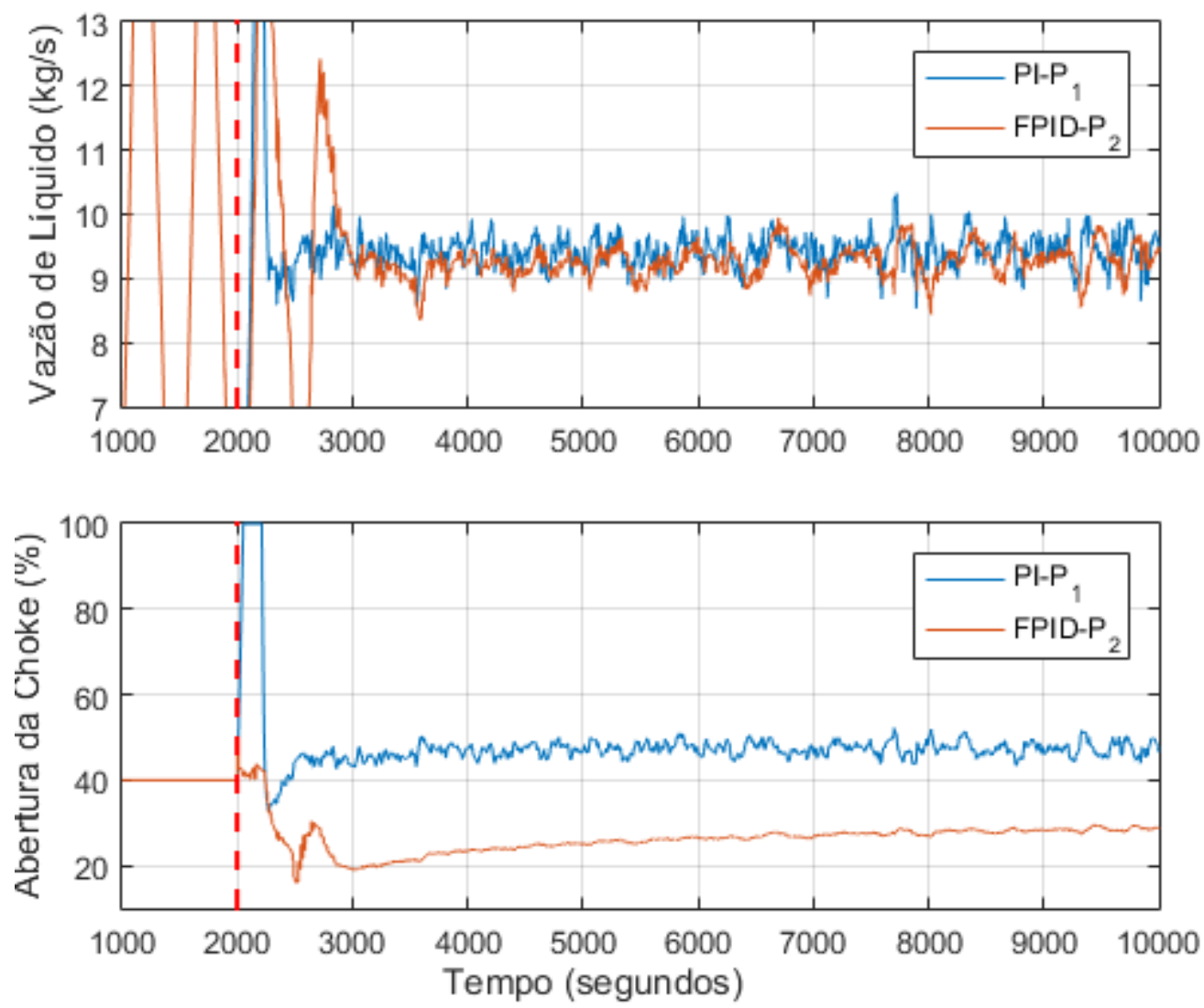

Figura 56 - Respostas da vazão e abertura de válvula no ensaio de produção ruidosa.

A análise dos gráficos acima revela que ambos os controladores são capazes de suprimir as golfadas e manter a estabilidade do sistema, mesmo quando flutuações de vazão estão presentes. No entanto, a manutenção da estabilidade só pôde ser assegurada com operação em aberturas médias de válvula levemente inferiores às alcançadas no cenário de produção sem flutuações.

A menor abertura das válvulas fez com que a produção máxima atingida pelo controlador FPID-P 2 caísse de 9,35 kg/s para 9,33 kg/s e pelo controlador PI-P 1 de 9,46kg/s para 9,44 kg/s. No entanto, estas reduções não implicam em menores ganhos de produção, uma vez que a estabilidade do sistema em malha aberta também foi afetada pelas flutuações, passando a ser estável somente para aberturas iguais ou inferiores a $16 \%$, cuja produção correspondente é de $8,73 \mathrm{~kg} / \mathrm{s}$. Desta forma, os ganhos de produção passam a ser de 6,9\% para o controlador FPID- $\mathrm{P}_{2} \mathrm{e}$ $8,1 \%$ para o controlador PI-P 1 .

Outro resultado interessante deste ensaio é que as flutuações, também presentes na pressão de topo do riser, não foram interpretadas como golfadas pelo 
controlador FPID-P2, não desencadeando assim o uso desnecessário da ação restritiva, que fecharia gradualmente a válvula choke.

O segundo tipo de perturbação considerada foram degraus, que modelam algumas perturbações típicas de sistemas de produção de petróleo, como, por exemplo início de produção de outro poço em sistemas em que o riser é compartilhado ou até mesmo mudanças repentinas nas características do reservatório ou sistema de produção.

A abordagem para inserção da perturbação do sistema foi a mesma adotada no ensaio anterior, apresentada na Equação (5.1), com o processo estocástico $P_{\sigma}$ sendo substituído por um sinal determinístico dado por um degrau de subida aos 5000 segundos e um degrau de descida aos 10000 segundos. Ambos os degraus têm amplitude equivalente a $20 \%$ da pressão aparente do reservatório, $P_{r a}$, utilizada no modelo do poço produtor.

Os resultados deste ensaio são apresentados na Figura 57.
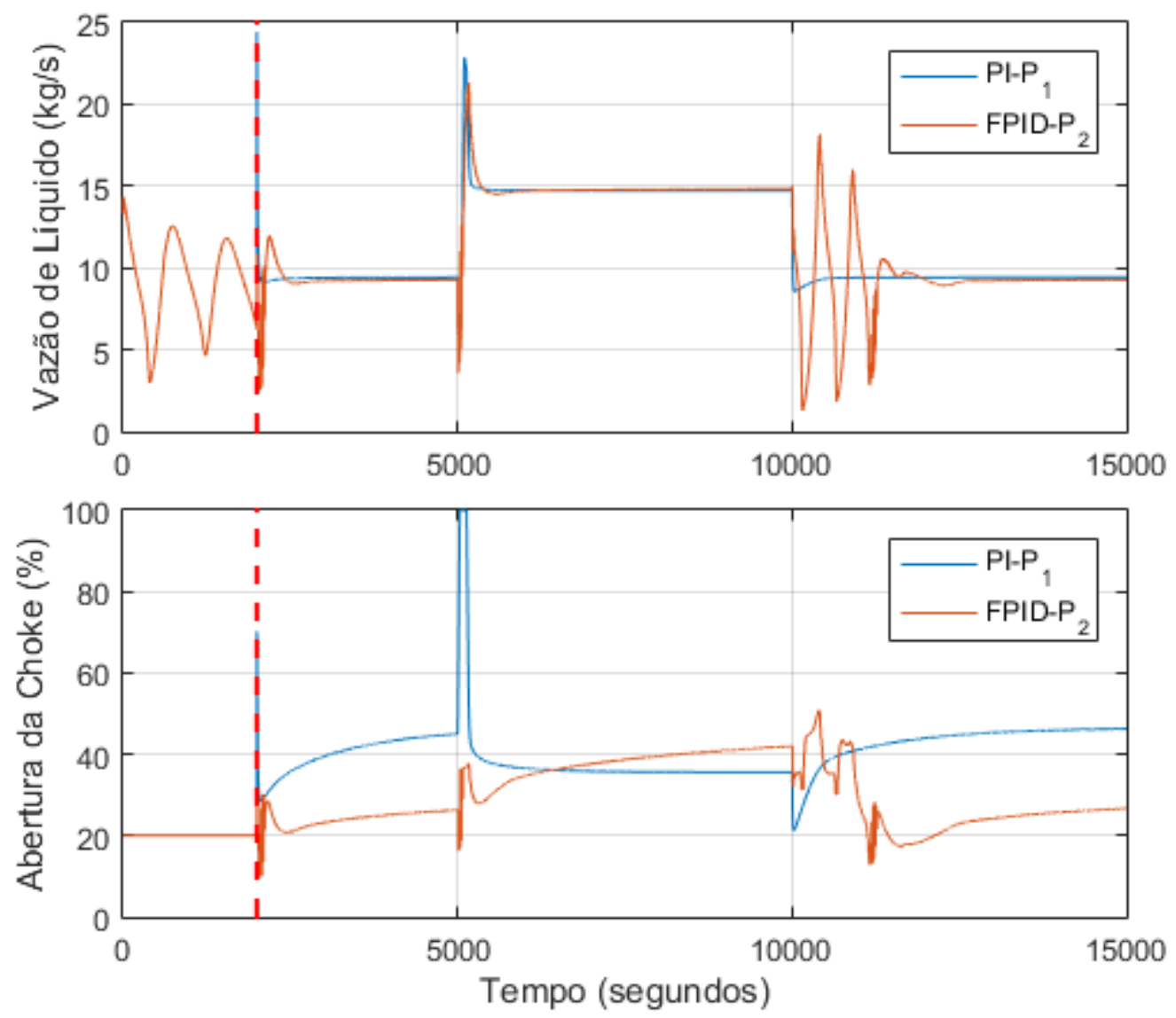

Figura 57 - Respostas da vazão e abertura de válvula no ensaio de resposta à degraus de produção. 
A primeira observação que pode ser feita é que o controlador PI-P1 demonstrou maior capacidade de regulação, como já era esperado, uma vez que tem acesso a uma variável com melhores características para controle.

Já o controlador FPID-P $\mathrm{P}_{2}$ embora tenha tido bom desempenho regulatório no degrau de subida, que é estabilizante, não foi capaz de manter a estabilidade do sistema no degrau de descida, tornando necessária a atuação da ação restritiva para reestabelecimento da estabilidade após a ocorrência de duas golfadas. Caso não houvesse esta ação heurística proporcionada pelo controlador fuzzy, o sistema se instabilizaria indefinidamente, uma vez que, no momento do degrau negativo, a abertura da choke era de aproximadamente $40 \%$, situação que um controlador PID baseado na pressão de topo não é capaz de estabilizar, conforme pode ser observado no ensaio da Figura 51.

Outra observação interessante é que, após a aplicação do degrau de subida, a abertura da choke e a produção foram maiores no ensaio com o controlador FPID-P $\mathrm{P}_{2}$, ao contrário de todos os resultados obtidos até então. Inclusive, no ensaio com o controlador PI- $\mathrm{P}_{1}$, houve ação de fechamento da válvula choke após a aplicação do degrau, ocasionando uma perda desnecessária de produção, visto que aumentos na pressão do reservatório possibilitam a estabilização do sistema em maiores aberturas de válvula. Este comportamento pode ser explicado por uma maior robustez do setpoint dos controladores baseados na pressão do topo, uma vez que esta grandeza é menos sensível às perturbações impostas ao sistema de produção.

O último ponto a se observar deste ensaio é que, novamente, o controlador PI apresentou uma resposta exageradamente rápida, com uma abertura quase instantânea da válvula choke no momento da aplicação do degrau de subida. Como discutido anteriormente, a atuação destas válvulas costuma ser lenta, impossibilitando este tipo de atuação. Para verificar o efeito da limitação da velocidade de atuação à capacidade regulatória do sistema, os ensaios foram repetidos com uma válvula choke mais realista, que faz uma transição completa em 180 segundos. Os resultados deste ensaio são apresentados na Figura 58. 

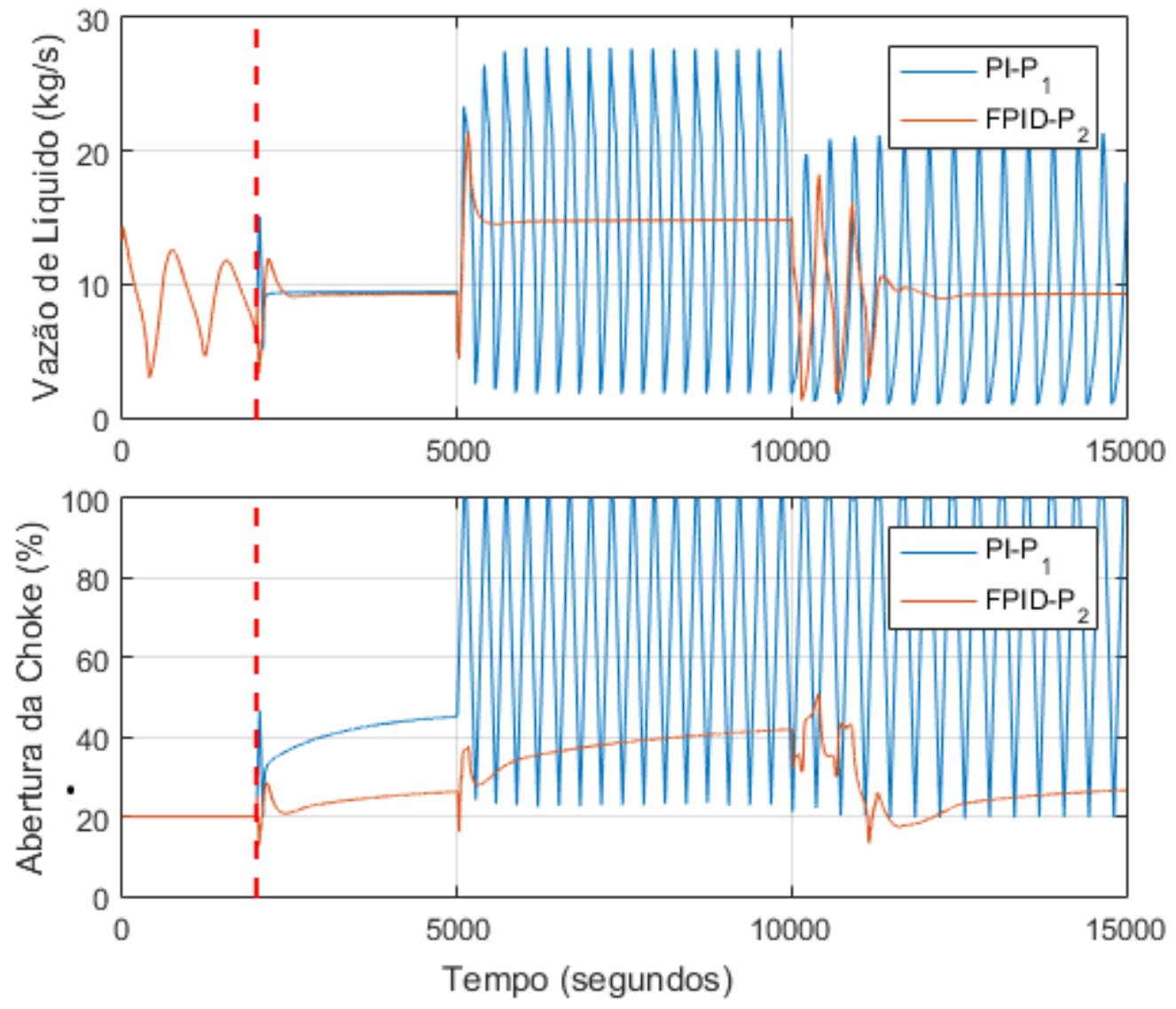

Figura 58 - Respostas da vazão e abertura de válvula no ensaio de resposta à degraus de produção com válvula choke realista.

Novamente, a consideração realista de lentidão na atuação da choke afetou drasticamente a capacidade do controlador PI-P $\mathrm{P}_{1}$ de regular o sistema, pois, embora tenha sido capaz de estabilizar o sistema na situação inicial, em que a válvula choke estava apenas $20 \%$ aberta, a estabilidade foi perdida indefinidamente após a aplicação do primeiro degrau, em um instante em que a choke estava 45\% aberta. Este resultado exemplifica a importância de um controlador anti-golfada ser capaz de estabilizar um sistema para quaisquer condições iniciais e afasta a ideia de que uma simples restrição manual da válvula antes da ativação do controlador automático possa eliminar a desvantagem de uma baixa capacidade de estabilização.

Por sua vez, o controlador FPID-P 2 , que não apresenta perda da capacidade de estabilização em função de uma atuação lenta da válvula choke, praticamente manteve a resposta do ensaio anterior, apresentando novamente apenas duas golfadas após o degrau de descida. 


\subsection{6.}

\section{Operação com Setpoint Instável}

A aplicação de controladores lineares estabilizantes exige muito cuidado na escolha dos setpoints, uma vez que valores que extrapolem um determinado limite colocam o sistema em regime instável.

No caso do sistema de produção modelado neste trabalho, os setpoints tem limites inferiores, abaixo dos quais os controladores lineares tendem a induzir a ocorrência de golfadas. Inclusive, é recomendável sempre operar com um setpoint um pouco maior que seu limite, evitando assim que pequenas perturbações ou mudanças nas características do processo instabilizem o sistema, mesmo que isto implique em uma pequena redução na produção.

No caso do controlador PI-P $\mathrm{P}_{1}$, os setpoints limite foram determinados nos ensaios anteriores como 67,8 bar na modelagem sem flutuações e 68,0 bar na modelagem em que foram consideradas flutuações na vazão do poço. Embora a redução dos setpoints abaixo desses valores leve o sistema à instabilidade contínua, esta não é maneira com que um sistema de produção em malha fechada pode se instabilizar, uma vez que mudanças nas características da planta podem fazer com que um setpoint estável torne-se instável. No contexto da produção de petróleo, a mudança que mais facilmente pode causar este fenômeno é a redução da vazão de saída do poço, causada pela depleção natural do reservatório e também por problemas no próprio poço, como obstrução da região canhoneada.

Para verificar o comportamento de ambos os controladores avaliados durante a ocorrência de mudanças nas características do processo, montou-se um ensaio em que a pressão aparente do reservatório, $P_{r a}$, é levemente reduzida de 112,5 bar para 110 bar após a estabilização do escoamento. As respostas da vazão e do sinal de controle para o controlador PI-P 1 são apresentadas na Figura 59. 

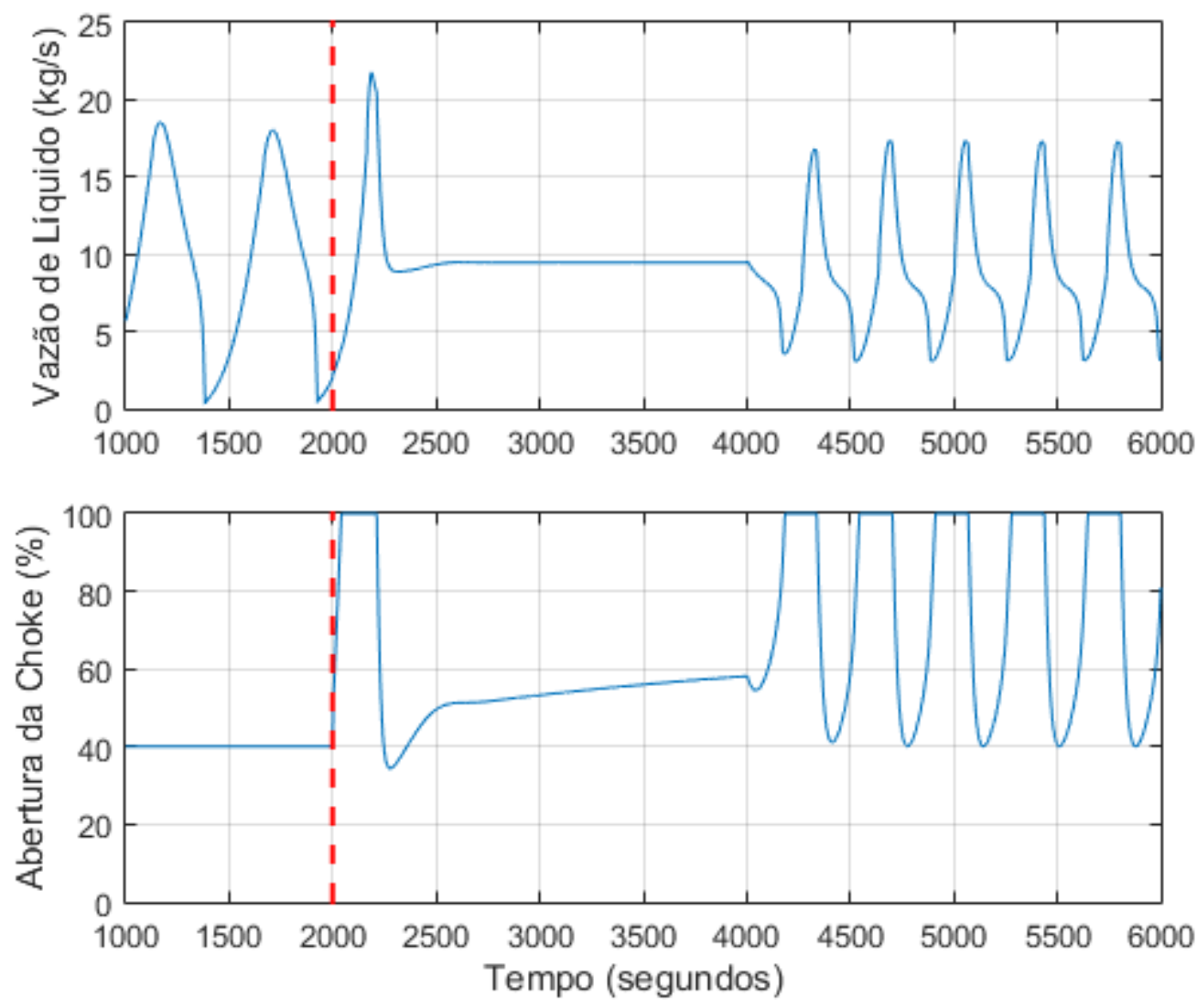

Figura 59 - Respostas da vazão e abertura de válvula no ensaio de resposta de mudanças de condições operacionais realizado com o controlador PI-P ${ }_{1}$

Como esperado, o controlador PI-P 1 não foi capaz de estabilizar o sistema após a pequena redução da pressão aparente do reservatório, pois seu setpoint deixou de ser estável. Em uma situação real, a solução deste problema requer que um operador perceba o descontrole de processo, identifique o poço que está golfando e ajuste o setpoint do controlador.

Uma forma de evitar que estas situações ocorram com frequência é ajustar um setpoint mais distante do limite de estabilidade, evitando assim que pequenas variações nas condições de processo levem-no à instabilidade. O problema desta solução é que ela implica na diminuição da produção.

O mesmo ensaio foi realizado com o controlador FPID- $\mathrm{P}_{2}$, tendo sido obtidos os resultados apresentados na Figura 60, em que podem ser observadas a vazão de saída, a pressão no topo do riser, o sinal de controle e a saída do bloco estimador da severidade da golfada. 

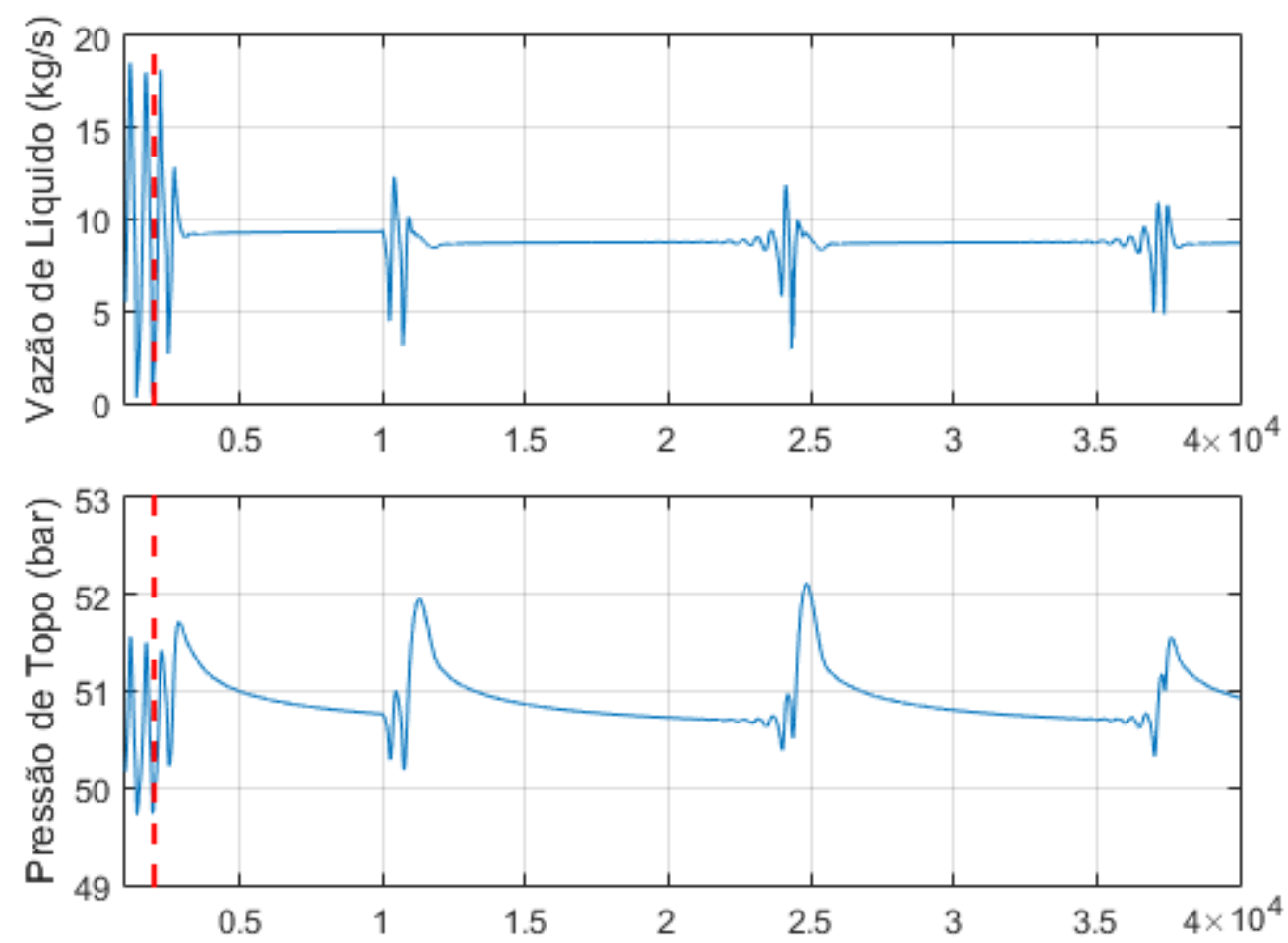

造
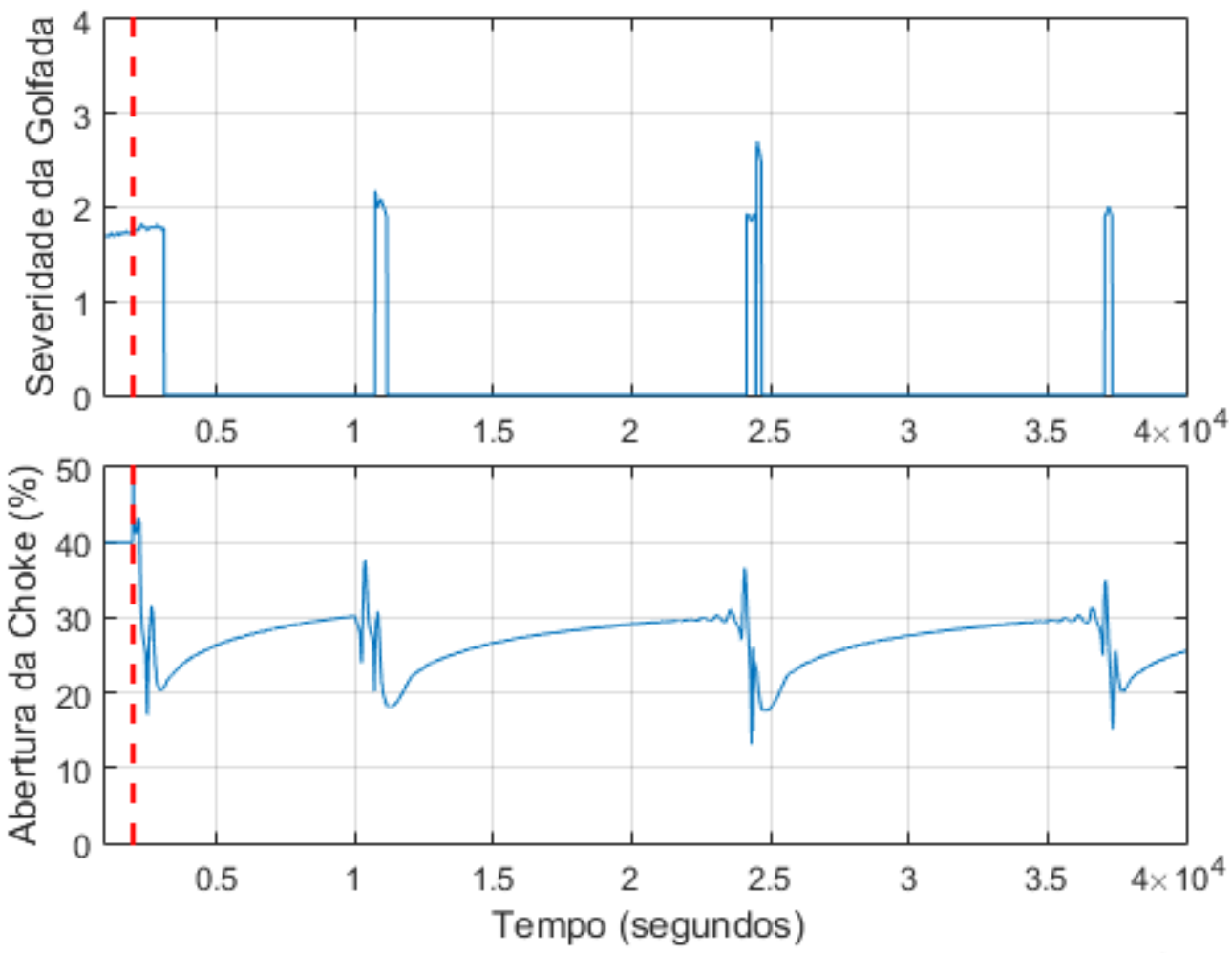

Figura 60 - Respostas da vazão e abertura de válvula no ensaio de resposta de mudanças de condições operacionais realizado com o controlador FPID-P ${ }_{2}$ 
Além das conclusões pertinentes ao ensaio, a análise da Figura 60 possibilita um melhor entendimento do controlador FPID- $\mathrm{P}_{2}$, pois também mostra a resposta de um sinal essencial para o funcionamento do controlador: a estimativa de severidade das golfadas.

Antes da ativação do controlador, marcada pela linha tracejada em vermelho, o estimador indicava continuamente a ocorrência de golfada de intensidade 1,8. Após a ativação, este sinal comanda o fechamento heurístico da válvula choke, conforme pode ser visto no quarto quadro, estabilizando o sistema.

Após a estabilização, a parcela PID do controlador busca o setpoint de pressão normalmente, até que aos 10000 segundos ocorre a diminuição da pressão aparente do reservatório, levando à ocorrência de golfadas, que são refletidas na pressão do topo do riser e prontamente detectadas pelo estimador de frequência do controlador, que novamente atua heuristicamente no fechamento da válvula até a estabilização.

Após a nova estabilização, a parcela PID do controlador volta a perseguir o setpoint, agora inatingível pois tornou-se instável após a mudança de pressão, levando novamente à formação de golfadas, que são prontamente detectadas e suprimidas.

Como o setpoint do controlador é constante, o processo continua indefinidamente, com a geração de pequenas golfadas em formato de wavelets na vazão de saída. Já na pressão de topo do riser, única variável que o controlador de fato observa, a deformação é bem mais significativa, com desvios de até 2 bar em relação ao setpoint. Isto exemplifica como uma ação de controle não-linear, que aparentemente prejudica o sistema ao contrariar o objetivo clássico de minimizar o erro, está na verdade favorecendo o objetivo de controle. Este tipo de ação, não implementável por controlador linear, permite que este controlador tenha um bom desempenho mesmo sendo dependente de uma variável de baixa qualidade para fins de controle.

Neste ensaio, a vazão média obtida foi de $8,71 \mathrm{~kg} / \mathrm{s}$, levemente inferior à vazão máxima alcançável com um setpoint estável, que passou a ser de $8,74 \mathrm{~kg} / \mathrm{s}$, mas significativamente superior à máxima vazão obtida através da técnica de choking estático, $8,35 \mathrm{~kg} / \mathrm{s}$ para as novas condições do reservatório. Isto demonstra que, do ponto de vista de produção, a operação com setpoint instável não é um grande problema, e pode ser preferível em relação à operação com grande folga de setpoint. 
Naturalmente, operar com um setpoint instável não é a situação ideal, mas, caso isso venha a acontecer, a perda de desempenho do controlador FPID-P é significativamente inferior à observada no PI-P ${ }_{1}$. Além disso, como o controlador fuzzy possui um detector de golfadas, é possível utilizá-lo na criação de um alarme na tela de operação, indicando operação instável e necessidade de reajuste de setpoint.

Quanto às golfadas em formato de wavelets, é possível que elas sejam facilmente absorvidas pela capacitância dos vasos separadores, especialmente caso estejam sejam empregadas estratégias de controle por banda no vaso, minimizando o efeito negativo da operação com setpoint instável.

\section{2.}

\section{Controlador Amortecedor de Golfadas}

O objetivo do controlador amortecedor de golfadas é entregar na saída do vaso separador uma vazão mais constante possível, atenuando oscilações que porventura estejam presentes na vazão de entrada e, ao mesmo tempo, garantir que o nível do vaso se mantenha dentro de uma faixa desejável.

A capacidade do controlador desenvolvido em atender estes objetivos conflitantes é verificada nesta seção por meio de diversos ensaios em que diferentes entradas são aplicadas ao vaso. Os resultados destes ensaios foram comparados aos obtidos por um controlador PI sintonizado por algoritmo genético semelhante ao utilizado na otimização dos parâmetros do controlador fuzzy.

\subsection{1.}

\section{Amortecimento de Golfadas}

O primeiro ensaio a que os controladores são submetidos tem como objetivo avaliar a capacidade destes em amortecer golfadas de diferentes severidades, formadas no sistema de produção em estudo. Com esta finalidade, foram realizados ensaios em que a abertura da válvula choke é mantida constante e o controle de nível do vaso separador é realizado pelos controladores em avaliação.

Para cada abertura da válvula choke e controlador utilizados nos ensaios, registram-se os valores máximos e mínimos do nível do vaso e da vazão de saída de líquido obtidos. Esses valores são apresentados de forma sintética por meio dos diagramas de bifurcação da Figura 61. 

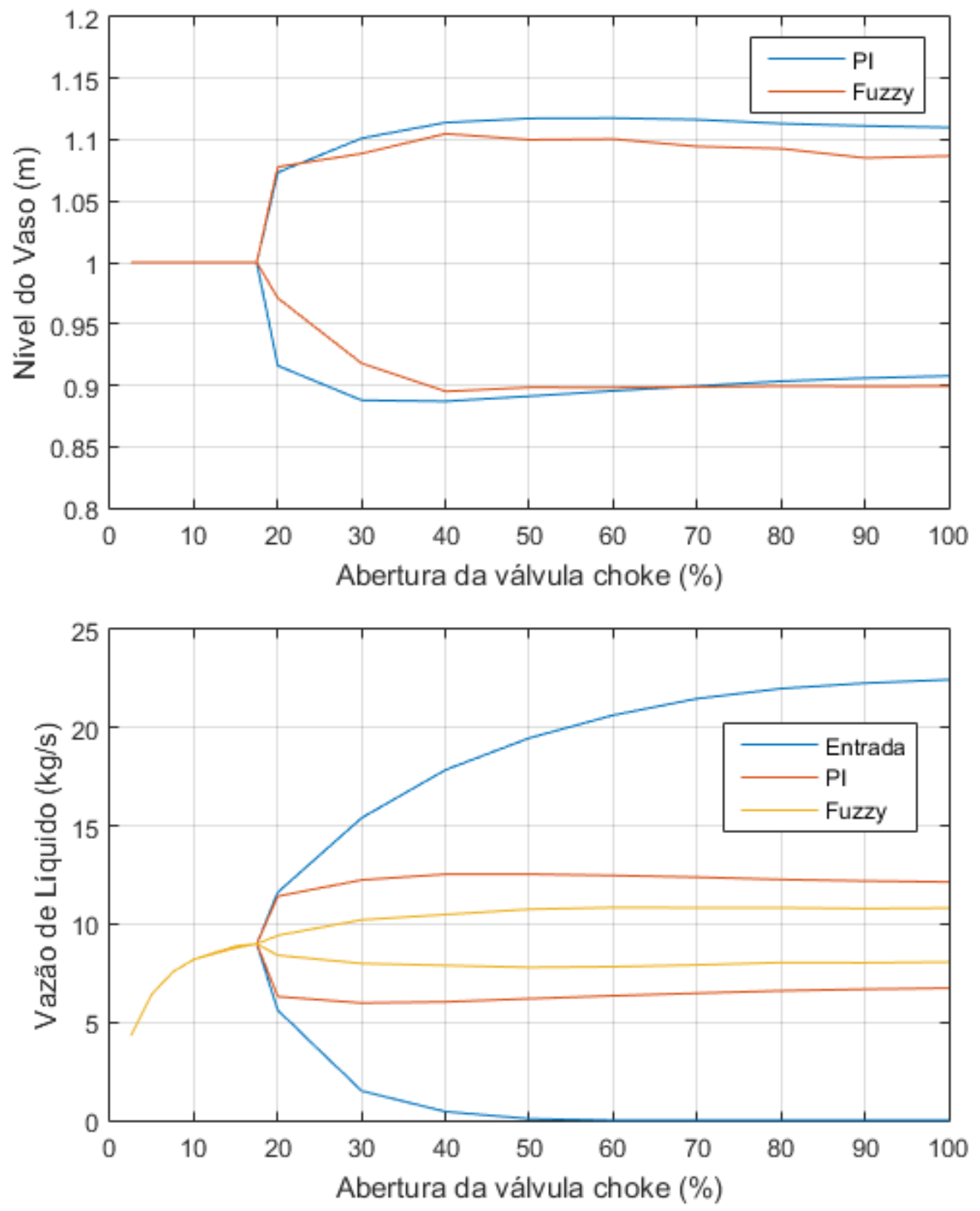

Figura 61 - Diagramas de bifurcação dos níveis (acima) e das vazões de líquido (abaixo).

A análise do diagrama de bifurcação das vazões de saída revela que o controlador fuzzy possui uma capacidade de amortecimento das golfadas significativamente maior que a do controlador PI, especialmente nas golfadas de menor severidade. Esta observação pode ser melhor verificada na Figura 62, em que a capacidade de amortecimento dos controladores é avaliada quantitativamente por meio da razão entre as amplitudes das golfadas na entrada e saída do vaso.

Ademais, é possível observar que o melhor desempenho em amortecimento não se deu às custas de um mau desempenho regulatório, uma vez que o controlador fuzzy também apresentou desempenho superior ao controlador PI neste aspecto. 


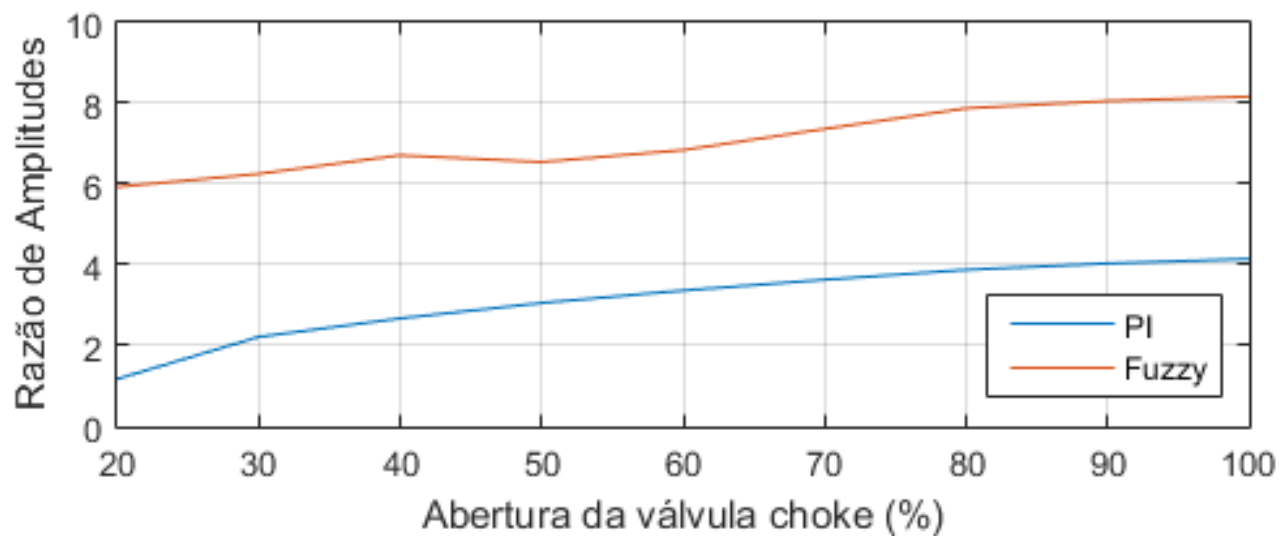

Figura 62 - Razão entre as amplitudes das golfadas na vazão de entrada e na vazão de saída.

Para fins de exemplificação, são apresentados na Figura 63 o nível do vaso e a vazão de líquido na saída do vaso obtidos nos ensaios em que a choke foi inicializada com $30 \%$ de abertura.
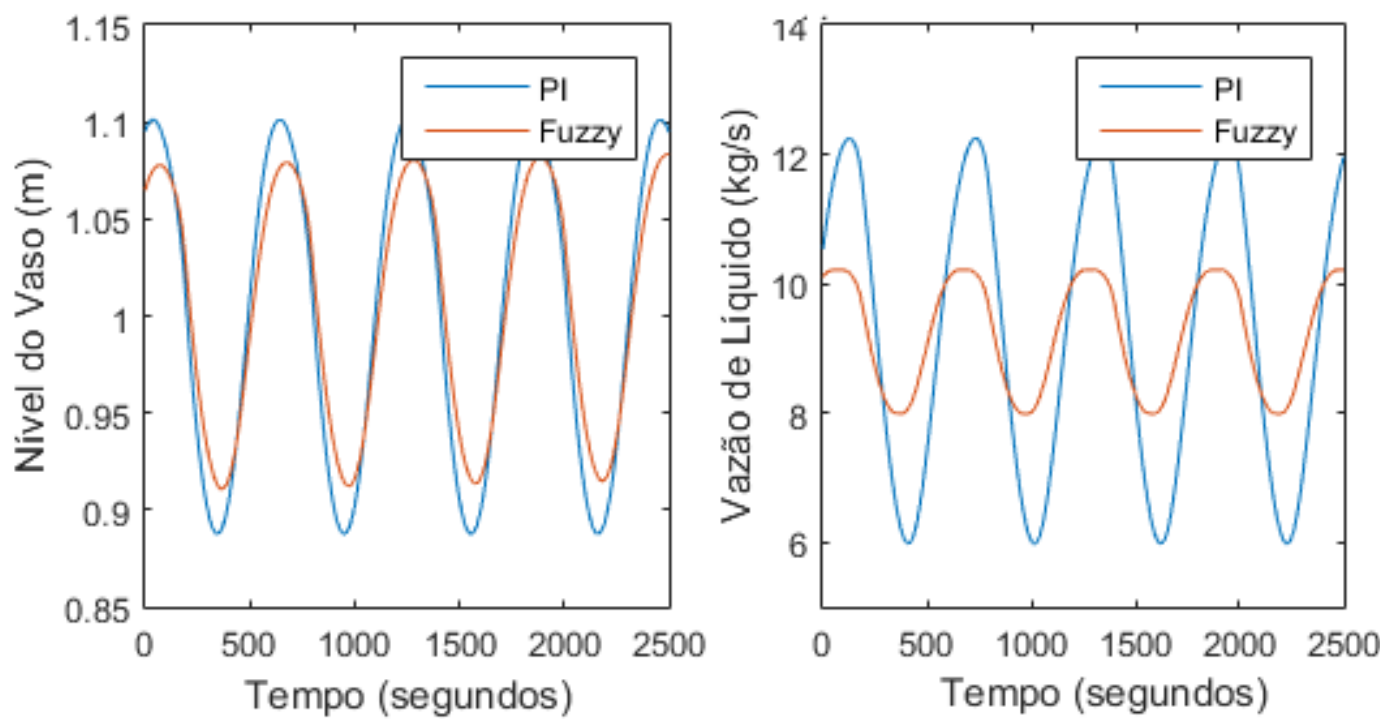

Figura 63 - Nível do vaso (esquerda) e vazão de líquido na saída do vaso (direita) nos ensaios em que válvula choke encontrava-se $30 \%$ aberta.

A análise da Figura 63 reafirma as observações feitas por meio dos diagramas de bifurcação, em que foi constatado um desempenho superior do controlador fuzzy quanto a ambos os critérios, especialmente na capacidade de amortecimento. Esta melhoria dupla só é possível em virtude da característica não-linear do controlador fuzzy, que age mais lentamente quando a derivada do erro atua no sentido de reduzir a magnitude do erro. 


\subsection{2.}

\section{Múltiplos Estágios de Amortecimento}

No Capítulo 2 foi discutida a possibilidade de se utilizarem controladores por banda nos diferentes estágios de uma planta de separação de petróleo, amplificando a capacidade de amortecimento das golfadas. Com o objetivo de verificar os ganhos desta arquitetura, repetiu-se o ensaio anterior com a inclusão de um novo vaso separador no sistema. Este novo vaso, que recebe como entrada a saída de líquido do primeiro vaso, possui as mesmas características geométricas e tem seu nível controlado por um controlador fuzzy idêntico ao do primeiro.

A capacidade de amortecimento combinada pode ser observada através do diagrama de bifurcação das vazões de saída, apresentado na Figura 64.

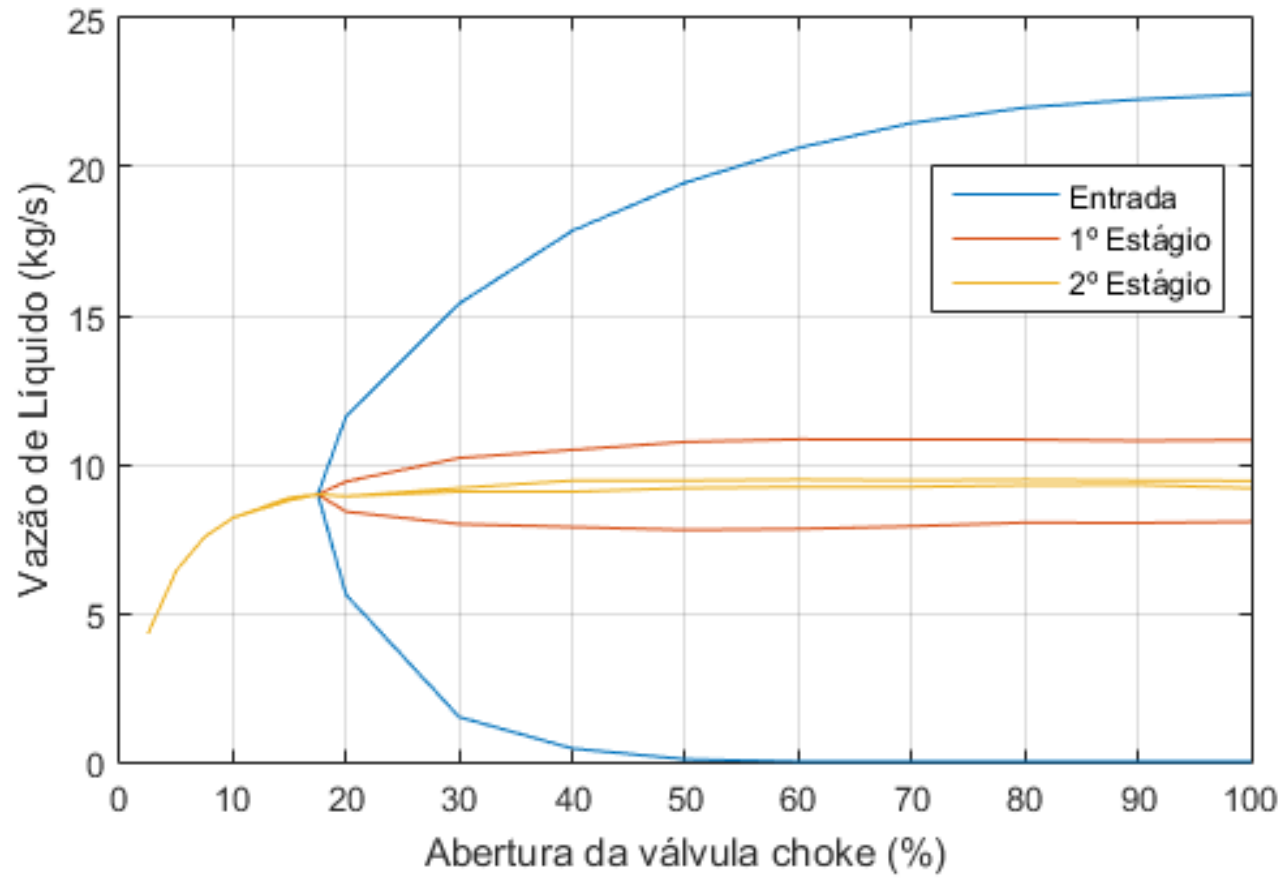

Figura 64 - Diagramas de bifurcação das vazões de líquido no ensaio de amortecimento multi-estágio.

É possível observar no diagrama de bifurcação que as golfadas presentes na vazão de entrada são quase que completamente amortecidas na vazão de saída do segundo estágio, confirmando o benefício da utilização do controlador em mais de um estágio da planta de separação.

Os níveis e as vazões de saídas de ambos os vasos, obtidos no ensaio em que a choke encontrava-se 30\% aberta, são apresentados na Figura 65. 

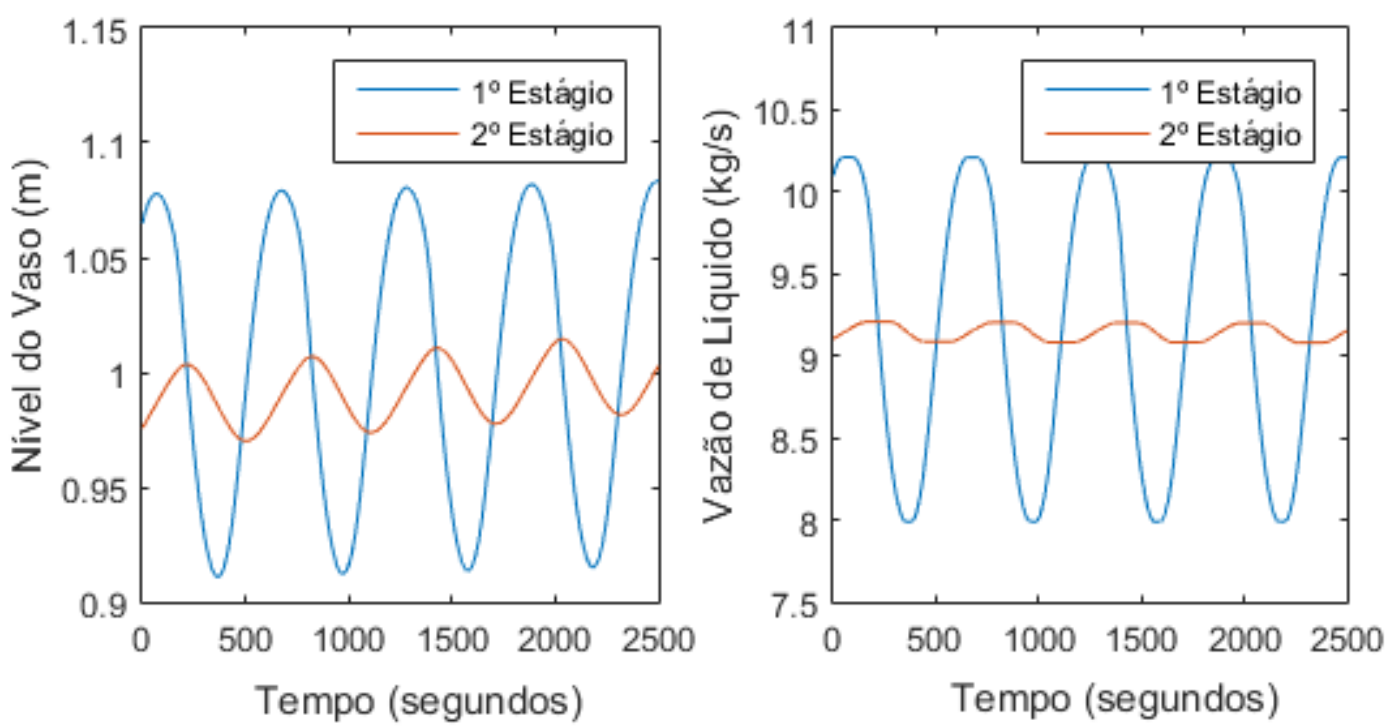

Figura 65 - Níveis dos vasos (esquerda) e vazões de líquido nas saídas dos vasos (direita) no ensaio de amortecimento multi-estágio em que válvula choke encontrava-se $30 \%$ aberta.

Analisando as variáveis do segundo vaso, é possível constatar uma significativa redução da amplitude das oscilações e também uma lenta tendência de correção do nível, que oscila com valores médios inferiores ao setpoint de $1 \mathrm{~m}$. A correção não é mais rápida em virtude de o nível se encontrar dentro da faixa de oscilação aceitável, não sendo necessária uma correção mais enérgica que resultaria em uma maior variação da saída.

\subsection{3. \\ Entradas Compostas}

Uma vez comprovado o desempenho superior do controlador fuzzy em amortecer as golfadas provenientes de um único poço, realizaram-se ensaios com entradas formadas pela combinação de diversos sinais. No primeiro ensaio, considerou-se uma vazão de entrada formada pela superposição de golfadas de quatro severidades diferentes, geradas pelo modelo para aberturas de choke de $25 \%$, $50 \%, 75 \%$ e $100 \%$. A forma de onda desta vazão de entrada é representada na Figura 66. 


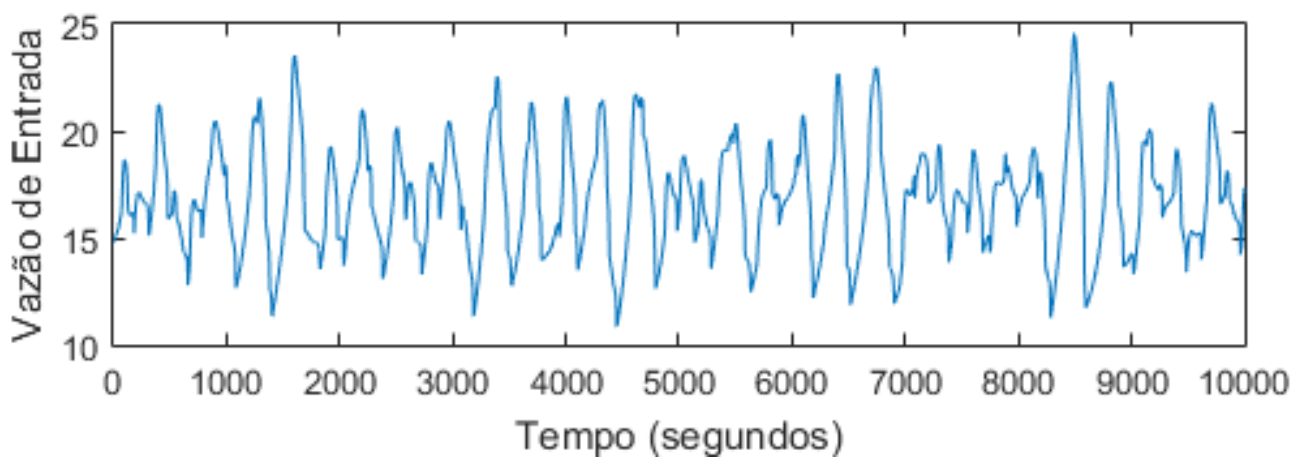

Figura 66 - Vazão de entrada no primeiro ensaio de entradas compostas.

Os resultados dos ensaios para ambos os controladores em avaliação são apresentados na Figura 67.
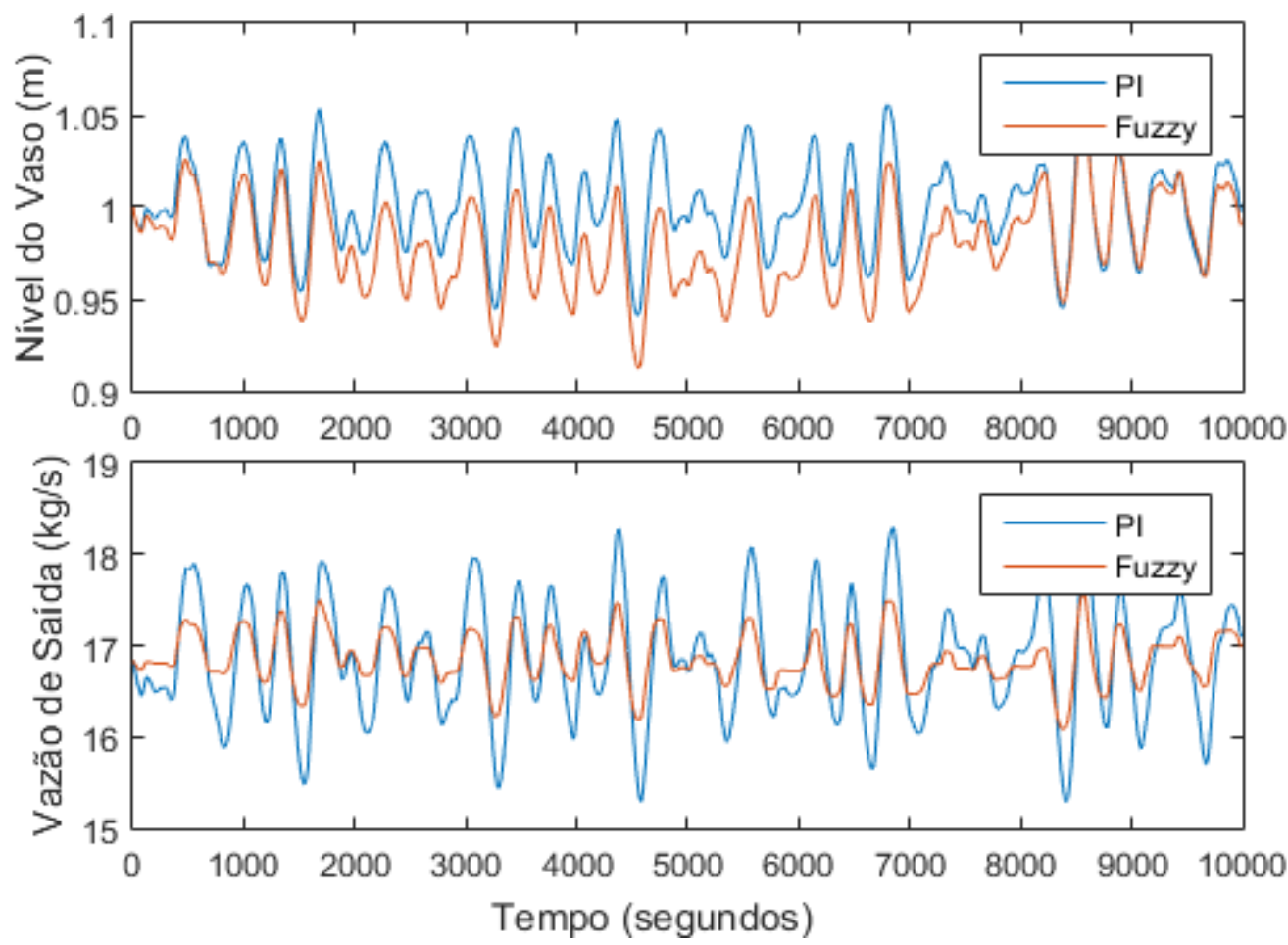

Figura 67 - Nível e vazão de saída do vaso separador no ensaio em que a entrada é composta por uma combinação de golfadas de difeerntes severidades.

Os resultados do ensaio demonstram que ambos os controladores foram capazes de manter o nível do vaso dentro da faixa preferencial de $\pm 0.15 \mathrm{~m}$. No entanto, em termos de amortecimento das oscilações, o desempenho do controlador fuzzy foi consideravelmente superior ao do controlador PI. Quantitativamente, enquanto a variância da vazão de saída foi de $0,40 \mathrm{~kg}^{2} / \mathrm{s}^{2}$ no ensaio com o controlador PI, esta foi de apenas $0,08 \mathrm{~kg}^{2} / \mathrm{s}^{2}$ no ensaio com o controlador fuzzy, o que representa uma capacidade de amortecimento cinco vezes maior do controlador não-linear. 
Como segundo ensaio, considerou-se uma vazão de entrada ruidosa com valor médio inicial de $10 \mathrm{~kg} / \mathrm{s}$, mas que a partir dos 5000 segundos, passa a ter valor médio de $12 \mathrm{~kg} / \mathrm{s}$, o que corresponde a um degrau de $20 \%$. O resultado deste ensaio é apresentado na Figura 68.
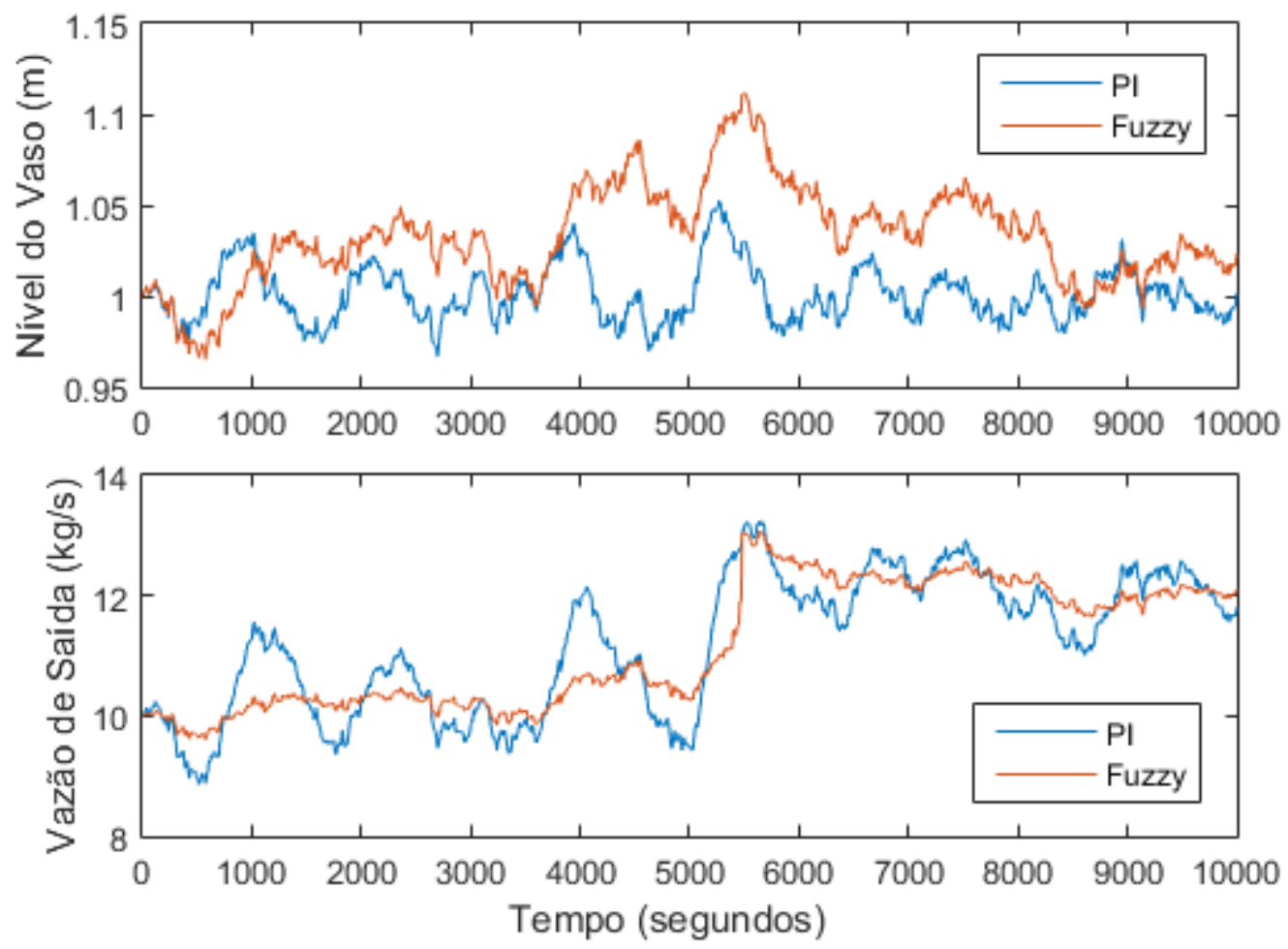

Figura 68 - Nível e vazão de saída do vaso separador no ensaio em que a entrada, ruidosa, é sujeita um pequeno degrau de produção.

Assim como nos outros ensaios, pode-se observar um desempenho claramente superior do controlador fuzzy na atenuação das variações presentes na vazão de entrada do vaso, pois, enquanto a vazão de saída no ensaio com o controlador PI chega a oscilar $3 \mathrm{~kg} / \mathrm{s}$, antes mesmo da aplicação do degrau, verificase que a mesma oscila menos de $1 \mathrm{~kg} / \mathrm{s}$ no ensaio com o controlador fuzzy, mudando de patamar somente após a aplicação do degrau na entrada aos 5000 segundos.

Quanto à regulação, ambos os controladores foram capazes de manter o nível dentro da banda, com o controlador PI mantendo a variável controlada mais próxima do setpoint. Embora a ocorrência do degrau tenha impactado de forma mais acentuada o nível do vaso no ensaio com o controlador fuzzy, esta perturbação o elevou somente a $1,11 \mathrm{~m}$, mantendo-o dentro da banda preferencial.

Com objetivo de avaliar a capacidade de regulação do controlador fuzzy a grandes degraus de entrada, realizou-se um novo ensaio em que a intensidade do 
degrau aos 5000 segundos foi aumentada de $2 \mathrm{~kg} / \mathrm{s}$ para $10 \mathrm{~kg} / \mathrm{s}$, o que representa um aumento repentino de $100 \%$ na vazão de entrada média. O resultado deste ensaio é apresentado na Figura 69.
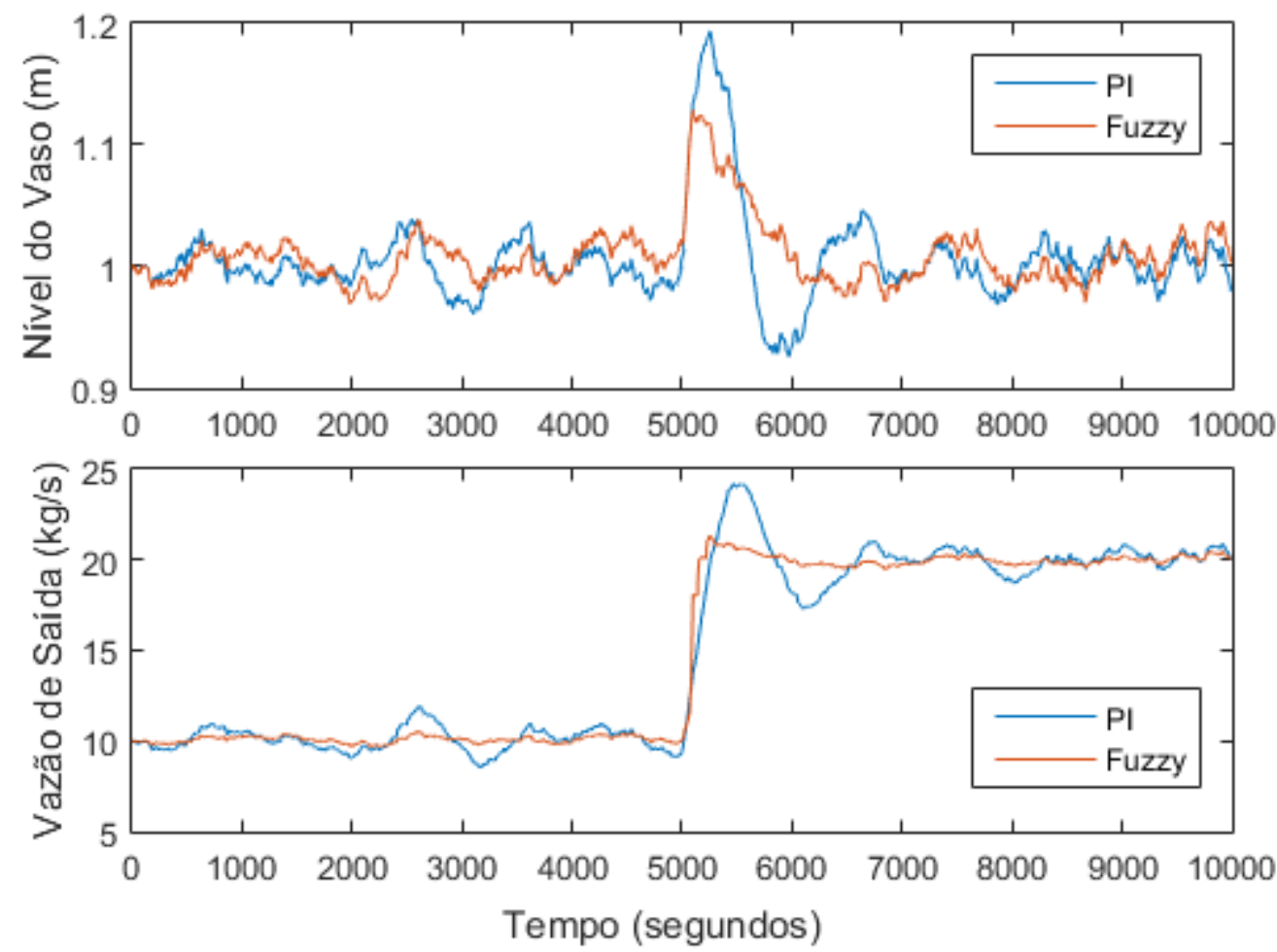

Figura 69 - Nível e vazão de saída do vaso separador no ensaio em que uma entrada ruidosa é sujeita a um grande degrau de produção.

É possível observar no gráfico acima que, embora o nível do vaso com o controlador fuzzy estivesse levemente superior ao nível do vaso com o controlador PI no momento do degrau, a rejeição à perturbação foi melhor no controlador fuzzy, que só permitiu que o de nível se elevasse até $1,12 \mathrm{~m}$, enquanto o controlador PI permitiu níveis de até $1,19 \mathrm{~m}$, fora da banda preferencial de $\pm 0,15 \mathrm{~m}$ utilizada no projeto do controlador. Este resultado pode parecer contraditório com o do ensaio anterior, em que o degrau impactou mais o vaso com o controlador fuzzy, mas na verdade este é exatamente o comportamento que se espera deste controlador, pois devido sua característica não-linear, o mesmo pode apresentar comportamentos distintos em função do estado em que o sistema se encontra, comportando-se lentamente dentro da banda e rapidamente fora da mesma. Desta forma, verifica-se que o controlador fuzzy consegue alinhar ambos os objetivos de controle: amortecimento das cargas processadas e respeito aos limites impostos para o nível do vaso separador. 


\section{6. \\ Conclusões e Trabalhos Futuros}

\section{1. Conclusões}

Neste trabalho, estratégias de controle mitigadoras de golfadas foram revisitadas sob a óptica do controle inteligente por meio da utilização de lógica fuzzy e da computação evolucionária. Este tratamento possibilitou o desenvolvimento de dois controladores com desempenho significativamente superior ao propiciado por abordagens puramente lineares.

Preliminarmente, realizou-se uma extensão do Modelo Simplificado de Riser (SRM) por meio do acoplamento de modelos de um poço produtor e de um vaso separador bifásico. Esta extensão possibilitou a verificação da significativa influência da dinâmica destes componentes no processo de formação das golfadas em sistemas de produção, com impacto direto nos limites de estabilidade e nas frequências e amplitudes das golfadas a que estes sistemas estão sujeitos. Além disso, a adição do modelo de poço concedeu ao SRM a capacidade de verificar ganhos ou perdas de produção decorrentes de mudanças de parâmetros operacionais ou da adoção de diferentes estratégias de controle.

O modelo estendido foi uma ferramenta essencial no desenvolvimento das estratégias de controle propostas neste trabalho, uma vez que, além de proporcionar a compreensão necessária para o projeto dos controladores, possibilitou que seus desempenhos fossem avaliados por meio de ensaios que simularam as mais diversas situações operacionais.

O primeiro controlador desenvolvido com o auxílio do modelo foi um controlador anti-golfada de estrutura híbrida Fuzzy-PID que age heuristicamente na válvula choke no intuito de suprimir quaisquer golfadas que venham a se estabelecer no sistema de produção. Para isto, observa-se unicamente a pressão no topo do riser, variável raramente utilizada em controladores anti-golfada clássicos em virtude de sua baixa sensibilidade e fase não-mínima. 
Embora sujeito às limitações da variável observada, o controlador anti-golfada mostrou-se capaz de suprimir qualquer regime de golfadas, independentemente da severidade, e também de estabilizar um ponto de operação instável em malha aberta, propiciando ganhos de produção em relação à técnica amplamente difundida de choking estático. Este resultado é bastante positivo, uma vez que não foi encontrado relato na bibliografia de um controlador anti-golfada SISO baseado em uma grandeza de topo que tenha sido capaz de obter resultados semelhantes.

Quando comparado a um algoritmo linear para controle da pressão da flowline, estratégia classicamente utilizada em sistemas anti-golfada, o controlador desenvolvido neste trabalho apresentou um ganho de produção ligeiramente inferior e necessitou de mais tempo para supressão das golfadas. No entanto, mostrou-se mais robusto em diversas situações, sendo menos afetado por mudanças nas condições operacionais e mantendo o desempenho quando aplicado em sistemas em que a atuação da válvula choke é lenta, característica que inviabiliza a utilização de controladores anti-golfada clássicos.

Os resultados apresentados demonstram como as ações heurísticas e não-lineares, proporcionadas pelo sistema de inferência fuzzy, não só foram capazes de compensar as limitações fundamentais da variável observada, como também possibilitaram a obtenção de resultados inalcançáveis por controladores anti-golfada clássicos, que necessitam observar variáveis mais adequadas a este tipo de controle.

É interessante notar que a estratégia de controle anti-golfada desenvolvida neste trabalho tem o potencial de expandir substancialmente o número de sistemas de produção aptos à utilização de controladores anti-golfada, uma vez que os dois maiores impeditivos para instalação dos controladores clássicos, ausência de medição submarina e lentidão das válvulas choke, não representam um problema para aplicação do controlador proposto.

O modelo do sistema de produção também foi utilizado no desenvolvimento de um controlador amortecedor de golfadas, implementado por um sistema de inferência fuzzy cujos parâmetros foram otimizados por um algoritmo genético. $\mathrm{O}$ controlador observa o nível de líquido do vaso separador e atua na válvula de saída de líquido do vaso com o objetivo de entregar uma vazão de saída o mais constante 
possível e, ao mesmo tempo, garantir que o nível do vaso se mantenha dentro de uma faixa aceitável, denominada banda.

Embora as estratégias de amortecimento mais sofisticadas sejam não-lineares, esta característica costuma ser implementada por meio do escalonamento de ganhos de um controlador PI em função da posição do nível em relação à banda, procedimento que pode ser entendido como uma troca, em tempo de execução, da capacidade de amortecer pela capacidade de regular. Por outro lado, o controlador fuzzy proposto neste trabalho incorpora não-linearidades de forma natural e com maior versatilidade, possibilitando alguns comportamentos não alcançáveis por algoritmos PI, como a manutenção da abertura da válvula constante sempre que o sistema apresentar tendência autorregulatória, melhorando a capacidade de amortecimento sem prejuízo da capacidade de regulação.

A expectativa de bom desempenho do controlador fuzzy foi confirmada por meio da execução de diversos ensaios, realizados no intuito de avaliar suas capacidades de amortecimento e regulação. Quando comparado a um controlador PI de referência, também sintonizado por um algoritmo genético, o controlador fuzzy demonstrou uma capacidade de amortecimento muito superior, com um fator de redução das amplitudes das golfadas até cinco vezes maior. Esta maior capacidade de amortecimento não se deu às custas de redução da capacidade de regulação, uma vez que o controlador fuzzy também apresentou melhor desempenho neste critério, especialmente em ensaios em que grandes perturbações em formato de degrau na vazão de entrada foram aplicadas ao sistema, gerando violação da banda apenas no ensaio com o controlador PI.

O controlador amortecedor é uma alternativa interessante para situações em que as golfadas não podem ser suprimidas em sua origem, mas se deseja operar com grandes aberturas da válvula choke em virtude do acréscimo de produção caraterístico dessa condição operacional. Além disso, a aplicação do controlador pode ser vantajosa até mesmo em plantas não sujeitas a golfadas em razão da sua boa capacidade de rejeição às flutuações da vazão produzida e aos degraus de produção, que ocorrem durante entrada e saída de novos poços.

A maior desvantagem do controlador amortecedor proposto está na sua dificuldade de sintonia, decorrente do grande número de parâmetros necessários para sua definição: sete para a base de regras e sete para os conjuntos fuzzy. Mesmo supondo uma base de regras fixa, o número de parâmetros remanescentes ainda é 
muito superior aos de um controlador PI, que possui apenas dois. Por esta razão, não é recomendável realizar a sintonia inicial do controlador fuzzy diretamente na planta real; sendo recomendável a obtenção de modelos matemáticos do vaso separador e da válvula de saída com o objetivo de possibilitar a realização de sintonia prévia em ambiente computacional, que pode ser significativamente facilitada pela utilização do algoritmo genético proposto neste trabalho.

Embora contenham um sistema de inferência fuzzy em sua estrutura, ambos os controladores desenvolvidos neste trabalho possuem baixa complexidade de implementação, possibilitando sua programação em controladores lógicos programáveis (CLPs), hardware normalmente utilizado para controle de plataformas de petróleo. Esta característica facilita a instalação dos controladores, pois dispensa a aquisição e integração de outro componente ao sistema de automação da plataforma.

Por fim, é interessante ressaltar que a abordagem heurística e não-linear utilizada no desenvolvimento de ambos os controladores possibilitou a obtenção de ótimos resultados, caracterizados por melhoras significativas de desempenho ou até mesmo pela aquisição de capacidades fora do alcance dos controladores lineares. Estes resultados demonstram a validade da proposta original deste trabalho: explorar estratégias de controle inteligente para mitigação de golfadas. Além disso, os resultados obtidos vão ao encontro de uma tendência de aumento na demanda industrial por controladores mitigadores de golfada eficazes, em face do novo contexto da produção de petróleo mundial, em que se espera um incremento na produção proveniente de campos maduros, mais vulneráveis à ocorrência de golfadas.

\section{2 . \\ Trabalhos Futuros}

Para trabalhos futuros, as seguintes ideias parecem promissoras:

\section{- Ensaio de campo dos controladores}

O próximo passo deste trabalho será o ensaio dos controladores propostos em um sistema de produção real na província petrolífera de Campos, no estado do Rio de Janeiro. Isto possibilitará a observação do desempenho destes controladores em 
um ambiente real, com realização dos ajustes que se façam necessários, e posterior validação dos algoritmos para utilização em ambientes de produção.

\section{- Extensão do modelo do sistema de produção}

A extensão do SRM realizada no Capítulo 3 pode ser ampliada, com a inclusão de um modelo mais detalhado da planta de separação. Para isto, a corrente de saída do riser pode ser estratificada em correntes de óleo, água e gás por meio da definição de uma fração mássica de água no líquido. Com isto, será possível modelar uma planta de separação trifásica em toda a sua complexidade, com vasos separadores trifásicos, hidrociclones, separadores eletrostáticos, etc.

Estas alterações permitirão que modelo preveja a influência das golfadas na capacidade de separação da planta, possibilitando uma análise mais detalhada dos efeitos deste fenômeno na rentabilidade do negócio. Além disso, estratégias de controle inteligente para outros componentes do sistema de separação, como os hidrociclones, também poderão ser desenvolvidas com auxílio do modelo.

\section{- Utilização de variáveis de fundo no controlador supressor de golfadas}

As variáveis de fundo, como pressão na flowline ou pressão na base do riser, são as que possuem as melhores características para utilização em controladores anti-golfada. No entanto, controladores lineares baseados nestas variáveis não apresentam desempenhos satisfatórios em sistemas com válvulas choke lentas, característica que, por sua vez, não afeta o desempenho do controlador anti-golfada proposto neste trabalho.

Considerando que alguns sistemas de produção disponibilizam medição de variáveis de fundo, mas possuem válvulas choke de atuação lenta, sugere-se o desenvolvimento de uma versão do controlador supressor de golfadas que observe uma variável de fundo, como a pressão da flowline. Possivelmente, esta versão do controlador combinará as vantagens de ambas as estratégias de controle anti-golfada ensaiadas no Capítulo 5.

\section{- Ajuste automático de setpoint no controlador supressor de golfadas}

O ensaio de operação com setpoint instável, realizado no Capítulo 5, demonstrou a capacidade do controlador supressor de golfadas se recuperar de uma situação de instabilidade causada por um setpoint inadequado. Esta capacidade pode ser mais bem explorada por meio de um algoritmo de ajuste automático do 
setpoint, que tenha o objetivo de fazer com que o controlador opere com o menor setpoint estável possível, maximizando a produção em diferentes condições operacionais.

O algoritmo pode, inclusive, ser baseado em aprendizado por reforço, em que a diminuição do setpoint sem ocorrência de golfadas é recompensada e a diminuição com ocorrência de golfadas é punida.

- Utilização de algoritmo genético multiobjetivo na otimização do controlador amortecedor de golfadas

Embora o desempenho do controlador amortecedor tenha sido medido por duas métricas distintas, que quantificam a capacidade de amortecimento e a capacidade de regulação, optou-se pela combinação das mesmas em um único número real, com o objetivo de viabilizar a utilização de um algoritmo genético mono-objetivo.

É possível que uma abordagem multiobjetivo possa proporcionar sintonias de melhor qualidade e, portanto, sugere-se uma investigação dos benefícios trazidos pela utilização desta classe de algoritmos na solução do problema de sintonia do controlador.

\section{- Utilização de outras funções de avaliação na otimização do controlador amortecedor de golfadas}

Embora a função de avaliação utilizada na determinação da aptidão dos controladores fuzzy tenha gerado boas sintonias, não existe qualquer garantia de optimalidade desta função, sendo perfeitamente possível que outras funções de avaliação proporcionem sintonias ainda melhores. Sendo assim, a busca por melhores funções de avaliação é um tema válido para trabalhos futuros.

Entre as características da função de avaliação passíveis de alteração estão a forma de onda da vazão de entrada, que deve ser representativa e diversa, e as métricas utilizadas na quantificação do resultado obtido. Em particular, a métrica utilizada na quantificação da variabilidade da vazão de saída possui um grande efeito na sintonia final do controlador fuzzy e, portanto, um bom ponto de partida seria investigar o efeito na sintonia final da utilização de diferentes medidas de dispersão como métricas de variabilidade. 
Referências bibliográficas

[1] AIE. World Energy Outlook, Paris, 2016.

[2] OPEP. World Oil Outlook, Viena, 2016.

[3] OGAZI, A. I. Multiphase Severe Slug Flow Control, Cranfield: PhD Thesis, 2011.

[4] STORKAAS, E. Stabilizing Control and Controllability: Control Solutions to Avoid Slug Flow in Pipeline-Riser Systems, Trondheim: PhD Thesis, 2005.

[5] HAVRE, K.; STORNES, K.; STRAY, H. Taming slug flow in pipelines, Relatório Técnico da ABB, 2000.

[6] HENRIOT, V.; COURBOT, A.; MOYEUX, L. Simulation of process to control severe slugging: Application to the Dunbar pipeline, SPE Annual Conference and Exhibition, Houston, 1999.

[7] STASIAK, M.; PAGANO, D.; PLUCENIO, A. A New Discrete Slug-Flow Controller for Production Pipeline Risers, IFAC Workshop - Automatic Control in Offshore Oil and Gas Production, Trondheim, 2012.

[8] DAlSMO, M.; HAlVORSEN, E.; SluPphaug, O. Active Feedback Control of Unstable Wells at the Brage Field, SPE Annual Technical Conference and Exibition, San Antonio, 2002.

[9] CAMPOS, M. C. M. M.; TEIXEIRA, H. C. G. Controles Típicos de Equipamentos e Processos Industriais, São Paulo: Blucher, 2010.

[10] NUNES, G. C. Controle por Bandas: Conceitos Básicos e Aplicação no Amortecimento de Oscilações de Carga em Unidades de Produção de Petróleo, Relatório Petrobras, Rio de Janeiro, 2004. 
[11] PETROBRAS. Exploração e Produção de Petróleo e Gás, Divulgação, [Online]. Disponível em: http://www.petrobras.com.br/pt/nossasatividades/areas-de-atuacao/exploracao-e-producao-de-petroleo-e-gas/. [Acesso em 0502 2017].

[12] BRENNEN, C. Fundamentals of Multiphase Flows, 1st edition, Cambridge: Cambridge University Press, 2005.

[13] CHISHOLM, D. Two-phase flow in pipelines and heat exchangers, Londres: Longman Group Limited, 1983.

[14] WEISMAN, J. Handbook of Two-phase Flow Patterns, Michigan: Ann Arbor Science Publisher, 1983.

[15] BRATLAND, O. Pipe Flow: Multi-Phase Flow Assurance, Chonburi, 2010.

[16] HILL, T.; WOOD D. Slug flow: Occurrence, consequences, and prediction, Procedings SPE Annual Technical Conference and Exhibition, 1994.

[17] GODHAVN J.; FARD, M. F. P. New slug control strategies, tuning rules and experimental results, Journal of Process Control, vol. 15, pp. 547-557, 2005.

[18] FARGHARLY, M. A. Study of severe slugging in real offshore pipeline riser-pipe system, Procedings SPE Middle East Oil Show, 7-10 Março 1997.

[19] MAKOGAN, T. Y.; BROOK, G. J. Device for controlling slugging, Inglaterra, Patente 2007/034142, 2007.

[20] JANSEN, F. E. Method of eliminating pipeline-riser flow instability, Procedings SPE Western Regional Meeting, 23-25 Março 1994.

[21] ALVAREZ, C. J.; AL-MALKI, S. S. Using gas injection for reducing pressure losses in multiphase pipelines, Procedings SPE Annual Technical Conference and Exhibition, 5-8 Outubro 2003.

[22] AL-KANDARI, A. H.; KOLESHWAR, V. S. Overcoming slugging problems in a long-distance multiphase crude pipeline, Procedings SPE Annual Technical Conference and Exhibition, 3-6 Outubro 1999. 
[23] POTS, B. F. M.; BROMILOW, I. G.; KONJIN, M. J. W. F. Severe slug flow in offshore flow-line/riser systems, SPE Production Engineering, pp. 319324, 1987.

[24] SCHMIDT, Z.; BRILL, J. P.; BEGGS, H. D. Experimental study of severe slugging in a two-phase-flow pipeline riser pipe system, SPE Journal, pp. 407-414, 1980.

[25] HASSANEIN, T.; FAIRHURST, P. Challenges in the mechanical and hydraulic aspects of riser design for deep water developments, Procedings IBC UK Conf. Ltd. Offshore Pipeline Technology Conference, 29 Setembro 1998.

[26] CAMPOS, M. C. M.; LAUREIRO, P.; BORGES, A. M. Novas estratégias de controle para a plataforma de petróleo P-55, Rio Oil e Gas Expo and Conference, Rio de Janeiro, 2006.

[27] SAUSEN, A. T. Z. R. Modelagem Matemática de um Sistema TubulaçãoSeparador sob Regime de Fluxo com Golfadas e Controle de Nível Considerando um Algoritmo de Erro-Quadrático, Campina Grande: Tese de Doutorado, 2009.

[28] BORGES, A. M.; MEIRA, M. A. A.; VAZ, C. E. M. Sistema de controle de golfadas, Rio Oil \& Gas Expo and Conference, Rio de Janeiro, 2004.

[29] SCHMIDT, Z.; BRILL, J. P.; BEGGS, H. D. Choking can eliminate severe pipeline slugging, Oil and Gas Journal, pp. 230-238, 1979.

[30] HEDNE, P. A. L. H. Suppression of terrain slugging with automatic and manual riser choking, Advances in Gas-Liquid Flows, pp. 453-469, 1990.

[31] COURBOT, A. Prevention of severe slugging in the Dunbar 16" multiphase pipeline, Offshore Technology Conference, Houston, 1996.

[32] DASlmO, M.; HALVORSEN, E.; SLUPPHAUG, O. Active Feedback Control of Unstable Wells at the Brage Field, SPE Annual Technical Conference and Exhibition, San Antonio, 2002.

[33] DRENGSTIG, T.; MAGNDAL, S. Slug control of production pipeline, Relatório Técnico N-4091 da Stavanger University College, School of Science and Technology, Ullandhaug, 2001. 
[34] CAO, Y.; LAO, L.; YEUNG, H. Method, Controller and System for Controlling Slug Flow of a Multiphase Fluid. Estados Unidos da América Patente 2010/0307598 A1, 9 Dezembro 2010.

[35] CAO, Y. Inferential Slug Control System Field Trial Summary, Relatório N. 09/YC/581, Cranfield, 2011.

[36] DI MEGLIO, F. Dynamics and control of slugging in oil production, Paris: $\mathrm{PhD}$ Thesis, 2011.

[37] SCHHLUMBERGER, OLGA Dynamic Multiphase Flow Simulator, [Online]. Disponível em: https://www.software.slb.com/products/olga. [Acesso em 0515 2017].

[38] ALMEIDA, B. R.; JOTA, F. G. Mitigação dos Efeitos da Golfada Severa por Sistemas Supervsionados de Controle Adaptativo, Simpósio Brasileiro de Automação Inteligente, São João del Rei, 2011.

[39] JAMAL, H. A.; ALI, S. M. F.; ISLAM, M. R. P. Petroleum Reservior Simulation, A Basic Approach, Texas: Gulf Publishing Company, 2006.

[40] NOLL, A. M.; SCHROEDER, M. R. Short-Time 'Cepstrum' Pitch Detection, Journal of the Acoustical Society of America, p. 1030, 1964.

[41] LARSON, E.; MADDOX, R. Real-Time Time-Domain Pitch Tracking Using Wavelets, Proceedings of the University of Illinois at Urbana Champaign Research Experience for Undergraduates Program, Champaign, 2005.

[42] ASTRÖM, K. J. Control System Design, Santa Barbara, 2002.

[43] GOLDBERG, D. Genetic Algorithms in Search, Optimization and Machine Learning, Addison-Wesley, 1989. 